University of Louisville

ThinkIR: The University of Louisville's Institutional Repository

$12-2008$

\title{
A comparison of faculty and administrator perceptions of the merger of Kentucky's community colleges and vocational/ technical institutes.
}

Jason Douglas Warren

University of Louisville

Follow this and additional works at: https://ir.library.louisville.edu/etd

\section{Recommended Citation}

Warren, Jason Douglas, "A comparison of faculty and administrator perceptions of the merger of Kentucky's community colleges and vocational/technical institutes." (2008). Electronic Theses and Dissertations. Paper 1534.

https://doi.org/10.18297/etd/1534

This Doctoral Dissertation is brought to you for free and open access by ThinkIR: The University of Louisville's Institutional Repository. It has been accepted for inclusion in Electronic Theses and Dissertations by an authorized administrator of ThinkIR: The University of Louisville's Institutional Repository. This title appears here courtesy of the author, who has retained all other copyrights. For more information, please contact thinkir@louisville.edu. 


\title{
A COMPARISON OF FACULTY AND ADMINISTRATOR PERCEPTIONS OF THE MERGER OF KENTUCKY'S COMMUNITY COLLEGES AND VOCATIONAL/TECHNICAL INSTITUTES
}

\author{
By \\ Jason Douglas Warren \\ B.S., University of Louisville, 1993 \\ M.A., University of Louisville 1995

\begin{abstract}
A Dissertation
Submitted to the Faculty of the

Graduate School of the University of Louisville and the

Graduate School of Western Kentucky University in Partial Fulfillment of the Requirements

for the Degree of
\end{abstract}

Doctor of Philosophy

Department of Educational Leadership, Foundations, and Human Resource Education University of Louisville, Louisville, Kentucky and

Department of Educational Administration, Leadership, and Research Western Kentucky University, Bowling Green, Kentucky

December 2008 


\title{
A COMPARISON OF FACULTY AND ADMINISTRATOR PERCEPTIONS OF THE MERGER OF KENTUCKY'S COMMUNITY COLLEGES AND \\ VOCATIONAL/TECHNICAL INSTITUTES
}

\author{
By \\ Jason Douglas Warren \\ B.S., University of Louisville, 1993 \\ M.A., University of Louisville 1995 \\ A Dissertation Approved on
}

October 28,2008

by the following Dissertation Committee:

Dr. Joseph M. Petrosko, Dissertation Director

Dr. Gayle Ecton

Dr. Aaron Hughey

Dr. John Keedy

Dr. Thomas G. Reio, Jr. 
Copyright 2008 by Jason D. Warren

All rights reserved 


\section{DEDICATION}

This dissertation is dedicated to my parents

Mr. Wendell Ray Warren

and

Mrs. Patricia Rice Warren

who taught me a love of education, instilled in me a passion for life-long learning, and gave me roots and wings.

This dissertation is also dedicated to the memories of my late grandmothers Mrs. Virginia "Gee Gee" Pritchett

who inspired the curiosities of a little boy with her love of teaching and learning and

Mrs. Thelma "Mamaw" Warren

who showed a grown man how to love life, to enjoy people, and to laugh. 


\section{ACKNOWLEDGEMENTS}

I would like to thank my dissertation director, Dr. Joseph Petrosko, for stepping in and helping me to complete the dissertation process after my original dissertation director left the university. I am indebted to him for his graciousness, accommodating spirit, and expert guidance through the final steps of study completion. I am grateful to my original dissertation director, Dr. John Welsh, for his valuable guidance and counsel in helping me to conceptualize and frame this study. In particular, I appreciate his extraordinary patience as I balanced dissertation writing with the personal challenges of my wife's two miscarriages, a tragic stillbirth, an international adoption from China, unanticipated acquisition of a small business, my responsibilities leading a community college's major gifts campaign, and the opportunity and challenge of an appointment as dean of student affairs at Hopkinsville Community College. I would also like to thank the other dissertation proposal and defense committee members who have assisted me immensely throughout this process: Dr. Gayle Ecton, Dr. John Keedy, Dr. Aaron Hughey, Dr. Ray Haynes, and Dr. Thomas G. Reio, Jr. I am also appreciative of Dr. Ric Keaster at Western Kentucky University for his guidance throughout this process.

I would like to thank my best friend, soul-mate, and wife, Paige, for her support and understanding during this project. And I wish to acknowledge my daughter, Kendall, who helps me to daily put life into perspective. Yang Guo Nuan - now Kendall Wen Nuan Warren - has added immeasurable joy to our lives. Also, I am indebted to my parents, Ray and Patty, who provided a home filled with love and to my younger brother, 
Lance, who continues to be an inspiration. In addition, I would like to recognize Phyllis and Jim Phillips, my wonderful in-laws who have supported me in numerous ways. I am also grateful to my extended family for their love and support. I would like to acknowledge my appreciation of the late Hobart Stone and other individuals in my life who did not have the opportunity to gain a "formal" education yet taught me the value of practical, matter-of-fact, common sense. Also, I would like to thank my friend, classmate, and colleague, Dr. Anthony Sanders, whose continuous encouragement during our carpool rides to class, study sessions, and frequent emails helped make the doctoral pursuit enjoyable. I admire his amazing talents and personal example. Most of all, I value our friendship.

I owe a great deal to my past supervisors and mentors from whom I have learned much and received encouragement: Sharon Edge (who gave me my first supervisory opportunity, who believed in my abilities, and who taught me a love for academic libraries), Dr. Robert Hoye (who introduced me to systems thinking and strategic planning), Dr. Denise Dickerson-Gifford (who first piqued my interest in student affairs administration), Dr. Jim Kerley (who selected me for my first administrative posts at Hopkinsville Community College as Upward Bound Director and later in the areas of public relations and resource development, who motivated me with his contagious enthusiasm, and who exemplified how a genuine interest in people compliments leadership), Dr. Janet Smith (who has always been encouraging and supportive of my college administration pursuits), Carl Barnett (who taught me the importance of humor in the workplace and reminded me of the importance of a student-centered perspective on campus), Dr. Bonnie Rogers (who reminded me often of the importance of money and 
people decisions in college administration and who gave me the opportunity to serve as Interim Dean of Student Affairs at HCC), Tim Burcham (who impressed upon me the benefits of being articulate, organized, and prepared), John Whitfield and Scott Weigel (for their long-standing friendship and encouragement during and since our college days), Jim Howard (for his friendship and influence during our college days), Dr. Aaron Hughey (who fostered my interest in student affairs and continues to serve as an excellent mentor), the amazing administrative assistants who have supported and guided me in my various administrative positions at $\mathrm{HCC}$ over the years (C.J Newcomb, Sandy Giltner, and Debbie Birdsong), Yvonne Glasman (the best HR Director I've ever known), Dr. Paige Tompkins (for helping to make statistics classes relevant and enjoyable), Dr. Stephen Schnacke (for his support and encouragement when I was first exploring the cooperative doctoral program), the panel of experts who reviewed my survey instruments (Dr. Jeff Hockaday, Dr. Aimes C. McGuinness, Jr., Dr. Donald E. Puyear, and Dr. John E. Roueche), my wonderful Student Services Team members (who maintained their patience with me as I attempted to balance work, family, and dissertation), the HCC faculty and staff (who continuously help me to grow and mature), the HCC leadership team and president's cabinet (who daily teach me the value of teamwork), Terry Duncan (who provided a model example of a campus information technology department and whose wise counsel helped me grow in my administrative capabilities), Beverly Atwood (who encouraged me to pursue my present dean position and provided an example of impeccable fiscal leadership and integrity in community college business affairs), Dr. Randy Wilson (who encouraged me all along the way), Dr. Kris Williams (whose constant sense of calm and wise counsel I treasure), and Dr. Jim Selbe (who named me 
Dean of Student Affairs at HCC, encouraged/tactfully prodded me to finish my dissertation, and allowed me the time to focus on my research project...I appreciate his constant inspiration and guidance and the opportunity to witness his amazing people skills and public speaking abilities in action), and the members of the HCC Foundation, Inc. (from whom I learned much about volunteerism and giving). I also appreciate the support and encouragement from Jackie Bondurant, Vince Shykes, and others in the KCTCS Central Office. I would like to thank our community college students (who remind me daily of our mission) and the campuses of Hopkinsville Community College, Western Kentucky University, and the University of Louisville for providing me an environment in which to grow, to learn, and to develop as a student, an adjunct instructor, a college administrator, and a person.

I would like to thank the interlibrary loan departments of Hopkinsville Community College (HCC) and Western Kentucky University (WKU) for their responsiveness and high quality service throughout this project. Specifically, I would like to acknowledge interlibrary loan librarians, Peggy Myers of $\mathrm{HCC}$ and Elisabeth Knight of WKU, and thank them for their attention to detail and sheer diligence. The background research for this cooperative doctoral program study could not have been accomplished without the assistance of the exceptional library staff of the two institutions. Additionally, off-campus access to the various databases provided by the HCC, WKU, and UofL was paramount to my completing the research for this study. Academic libraries represent the heart and soul of colleges and universities. 
And lastly, I would like to thank Bart Brady Ciampa for so freely sharing his mastery of the flugelhorn. His recordings allowed me to create an atmosphere suitable for writing and inspired me to reconnect with a talent that I had once set aside. 


\section{ABSTRACT \\ A COMPARISON OF FACULTY AND ADMINISTRATOR PERCEPTIONS OF THE MERGER OF KENTUCKY'S COMMUNITY COLLEGES AND VOCATIONAL/TECHNICAL INSTITUTES \\ Jason D. Warren}

December 17, 2008

One of the most nationally-recognized, two-year legislative reform initiatives in the U.S. began in Kentucky with the passage of the Kentucky Postsecondary Education Improvement Act of 1997 (HB1). This exploratory, cross-sectional, correlational study was administered at the 10-year anniversary of the HB1-legislated formation of the Kentucky Community and Technical College System (KCTCS), which originally combined 13 community colleges formerly governed by the University of Kentucky and 25 vocational/technical institutes previously governed by the Kentucky Cabinet for Workforce Development. This dissertation examined faculty and administrator perceptions of the merger of Kentucky's community colleges and vocational/technical institutes that resulted from $\mathrm{HB} 1$.

Two research questions guided the study. The first sought to determine whether significant differences in perceptions of merger were found between Kentucky Community and Technical College System (KCTCS) administrators and faculty. The second research question explored that, if there was a difference between the perceptions of the two groups concerning merger, could that difference be explained through five control variables which were gleaned from the research literature: (a) type of institutional 
decision-making, (b) depth of merger implementation, (c) level of involvement in merger initiatives, (d) internal versus external motivation for reform initiatives that led to merger, and (e) level of support for state postsecondary education reform initiatives that led to merger.

A survey instrument was designed using information gathered from a thorough literature review. A panel of experts validated the instrument. The survey instruments were mailed to a stratified random sample of faculty $(n=1,497)$ and all administrators $(N$ $=195$ ) of the 16 public two-year colleges that form KCTCS. A total of 569 faculty and administrators returned completed, usable surveys and became the sample for the study. The 33.7 percent total return rate for this study was consistent within the acceptable range described in the research literature. The results of the study suggested that administrators maintained a more positive view of the merger than faculty.

A one-way analysis of variance (ANOVA) was used to test the null hypothesis for the first question that there was no difference in the perception of merger, with Perception of Merger as the dependent variable and respondent status, faculty or administrator, as the independent variables. Administrators had a significantly higher mean score than faculty; therefore, the null hypothesis was rejected. Administrators maintained significantly more positive perceptions of the merger compared to faculty.

For the second research question, a multivariate analysis of variance (MANOVA) was performed with the six indices of perception, type, depth, support, involvement, and motivation as dependent variables. The MANOVA confirmed that the administrators had significantly higher scale mean scores than faculty. A regression analysis was conducted to determine the degree of the relationship between the dependent variable, Perception of 
Merger, and the five control variables. The control variable with the strongest correlation for the dependent variable, Perception of Merger, was Level of Support for State Postsecondary Education Reform Initiatives That Led to Merger. All five control variables were significantly and positively associated with the dependent variable, Perception of Merger. Approximately $74 \%$ of the variance was predicted by the control variables.

Two thematic constructs or clusters emerged from the data collected from administrators offering open-ended comments: (a) increased educational access and attainment - viewed as a positive result of merger, and (b) growth of the KCTCS Central Office and bureaucracy - viewed as a negative result of merger. Overall, administrators offered 31 positive comments regarding the merger and 42 negative comments.

Two positive thematic constructs or clusters emerged from the data collected from faculty offering open-ended comments: (a) increased educational access and attainment and (b) improved technical training - both viewed as positive results of merger. Additionally, 15 negative themes emerged: (a) growth of the KCTCS Central Office and bureaucracy, (b) too many administrators, (c) negative impact on technical colleges, (d) the KCTCS President's salary and benefits package, (e) lowered academic standards and declining quality of instruction, (f) negative impact on community colleges, (g) top-down management style, (h) differences of cultures/missions, (i) too much emphasis on enrollment numbers, (j) decline of general education transfer program, (k) rising tuition, (l) lack of local college autonomy, (m) loss of faculty authority and influence in college governance, (n) politically-motivated reforms, and (o) the move from a higher education 
model to a business model. Overall, faculty made 52 positive comments on the merger and 308 negative comments.

The findings will potentially benefit community and technical college leaders, stakeholders, strategic planners, and state higher education boards (particularly those considering a similar merger process or implementing institutional changes that impact organizational culture). Understanding faculty and administrator perceptual differences as well as identifying the conditions under which successful postsecondary education reforms may thrive - is an important element in guiding successful mergers and organizational change. 


\section{TABLE OF CONTENTS}

DEDICATION $\ldots \ldots \ldots \ldots \ldots \ldots$

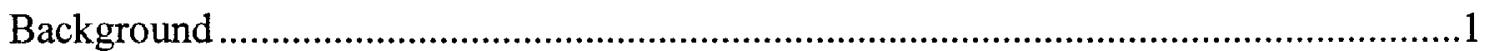

Two-Year College Organizational Reforms ..........................................................5

Kentucky: Emerging as a National Model of Two-Year College Governance ...............8

Progress of Kentucky's Public Two-Year College Merger .......................................10

Two-Year College Reform and Accountability ....................................................13

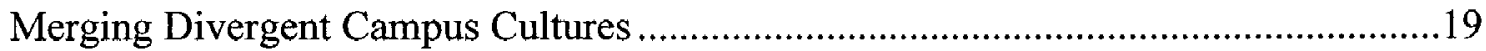

Disparate Faculty and Administrator World Views.............................................21

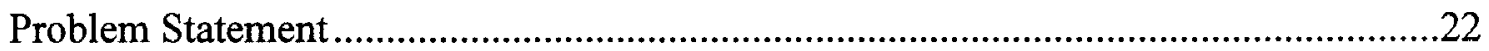

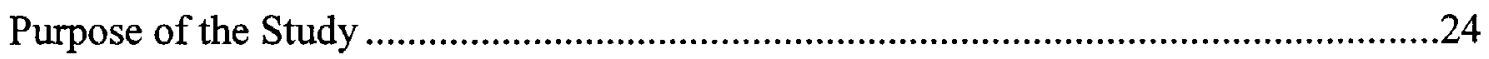

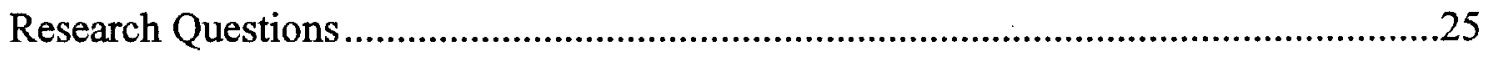

Identification of Variables in Research Questions..................................................26

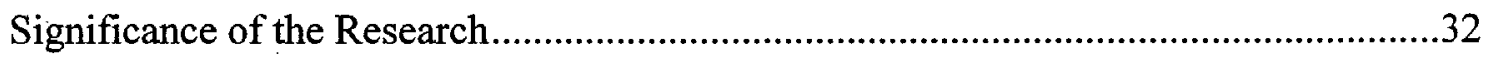

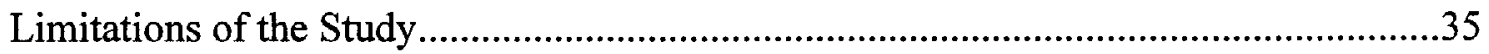

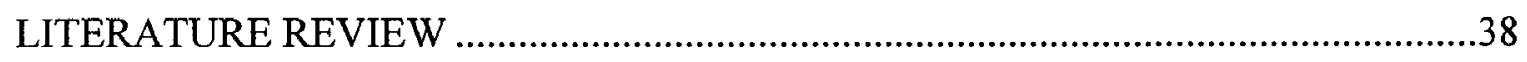

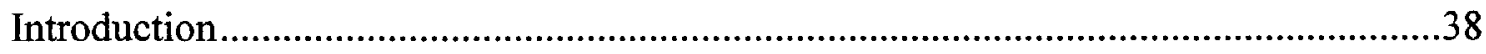


Higher Educational Change Nationwide

The Entrepreneurial College

Mergers as a Response to Growth and Change ..............................................................45

Two-Year College Reform in Kentucky ...............................................................51

A History of Two-Year Postsecondary Education in Kentucky ......................................52

Personality Characteristics and Curricular Values of Faculty and Administrators ........69

Institutional Climate and Organizational Functioning...............................................93

Faculty and Administrator World Views ................................................................120

Theoretical Framework - The Faculty/Administrator Chasm ......................................124

Type of Institutional Decision-Making .....................................................................125

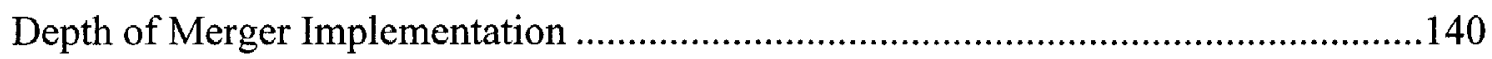

Level of Involvement in Merger Initiatives .............................................................140

Internal versus External Motivation for Reform Initiatives That Led to Merger ..........143

Level of Support for Postsecondary Ed. Reform Initiatives That Led to Merger.........144

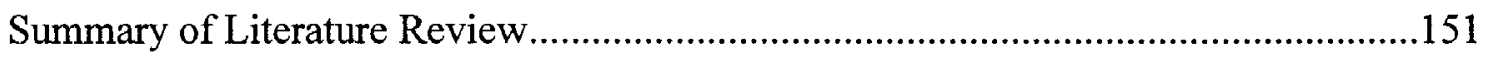

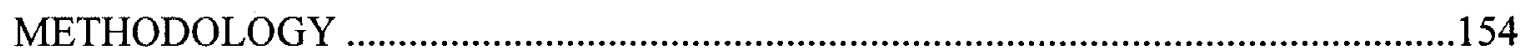

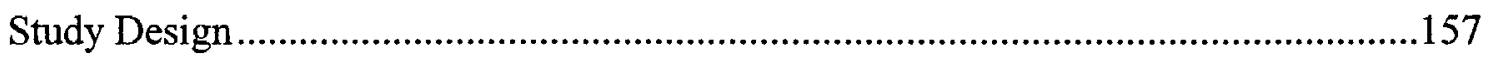

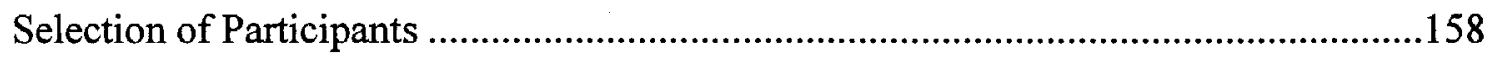

Instrumentation

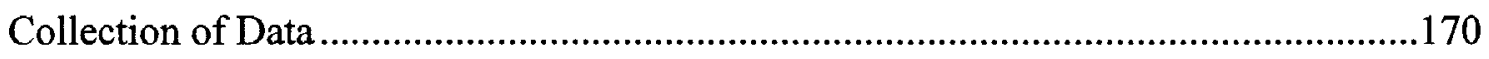

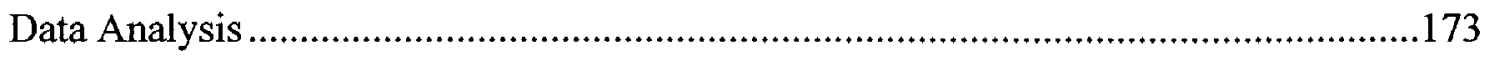

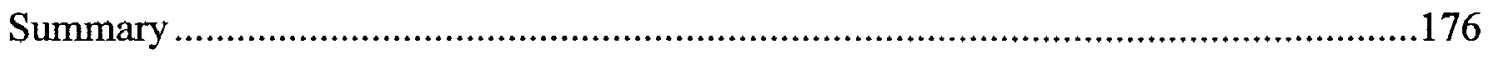

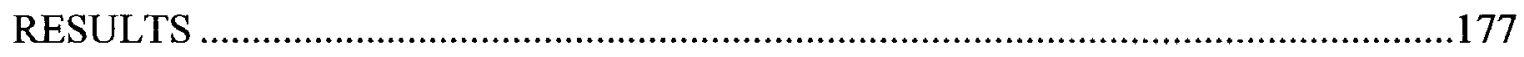


Participants.

Reliability of the Scales Used in the Study...

Research Question 1

Research Question 2

Regression Analysis

Open-Ended Responses

Summary

DISCUSSION AND SUMMARY.

Problem Statement

Methodology Review.

Summary of the Results .202

Discussion of the Results. .203

Recommendation for Postsecondary Education Professionals .208

Study Limitations. .209

Suggestions for Additional Research .211

Conclusion .212

REFERENCES

APPENDIX A: Campus Map of KCTCS at the Beginning of 1997. .232

APPENDIX B: Campus Map of KCTCS in 2008 .233

APPENDIX C: Survey Instrument .234

APPENDIX D; Response Rates by Administrators.

APPENDIX E: Response Rates by Faculty .238

APPENDIX F: Survey Instrument Insert. .239 
APPENDIX G: Expert Panelist Evaluation Form

APPENDIX H: Pilot Study Cover Letter. .254

APPENDIX I: Pilot Study Questionnaire Evaluation Form .255

APPENDIX J: Pre-Letter: First Contact / Sample Email on Behalf of Researcher .256

APPENDIX K: Informed Consent Document / Cover Letter, Second Contact .257

APPENDIX L: Follow-Up Email: Third Contact. .258

APPENDIX M: Frequency Table of Faculty Respondents' Academic Discipline .259

APPENDIX N: Frequency Table by Respondents' Institution .261

APPENDIX O: Summary of Open-Ended Responses .262

APPENDIX P: Open-Ended Responses: Administrator Themes .264

APPENDIX Q: Open-Ended Responses: Faculty Themes .269

APPENDIX R: Permission Letter to Conduct Research (KCTCS President/CEO)........283

APPENDIX S: Human Subjects Review - KCTCS .284

APPENDIX T: Human Subjects Review - University of Louisville .285

APPENDIX U: Human Subjects Review - Western Kentucky University .287 CURRICULUM VITAE .288 


\section{LIST OF TABLES}

TABLE

PAGE

Table 1: Available Population $(N)$ by Kentucky Community and Technical College System (KCTCS) Institution and Status

Table 2: Stratified Random Sample (n) of Kentucky Community and Technical College System (KCTCS) Institution Faculty

Table 3: Questions Forming Research Indices

$\begin{array}{ll}\text { Table 4: Expert Panel Members } & 168\end{array}$

Table 5: Data Collection Correspondence

Table 6: Respondents' Gender, Average Years in Present Job, and Average Years in Higher Education

Table 7: Age and Position of Respondents

Table 8: Respondents' Academic Rank and Tenure Status

Table 9: Type of Institution Where Respondents Were Employed Prior to Merger

Table 10: Cronbach's Coefficient Alpha Scores for Study Indices

Table 11: Descriptive Statistics for Perception of Merger by Respondent Group

Table 12: Descriptive Statistics for Six Scales Comparing Faculty and Administrators

Table 13: Results of ANOVA Comparing Administrators and Faculty on Six Indices

Table 14: Means, Standard Deviations, and Inter-correlations for Perception of Merger and Six Predictor Variables: Five Scale Variables and Respondent Status 
Table 15: R-Squared Statistics and Standard Error of Estimate for Two Regression Models

Table 16: Summary of Statistics on Regression Predictors for Dependent Variable Perception of Merger

Table 17: Descriptive Statistics Summary of Qualitative Data Collection From Open-Ended Survey Responses 


\section{CHAPTER 1}

\section{INTRODUCTION}

\section{Background}

During the year 2001, the U.S. community college celebrated its Centennial anniversary. Over a century ago, the community college concept emerged in Joliet, Illinois with the founding of Joliet Junior College in 1901 (American Association of Community Colleges, 2001). The two-year college movement gained momentum in 1907 when a California state mandate established schools for the thirteenth and fourteenth years (Reitano, 1998). In the 1930s, there were more than 200 public and 300 private two-year colleges across the nation (Phillippe \& Sullivan, 2005).

By January 2008, some 1,195 public, independent, and tribal community colleges existed nationwide that annually served over 11.5 million students (6.5 million taking courses for credit and 5 million taking noncredit courses); $39 \%$ of community college students were the first generation of their families to attend college (AACC). The average age of community college students was 29 (AACC). Community colleges annually awarded over 555,000 associate degrees and 295,000 certificates (AACC). Enrollment in the 1,195 institutions accounted for 46 percent of all U.S. undergraduates and 41 percent of first-time freshmen. Included in those figures were 46 percent of all Black students, 55 percent of all Hispanic, 46 percent of Asian/Pacific Islander and 55 percent of all Native American students (AACC, 2008). 
As the statistics indicate, community colleges now serve a prominent, influential role in postsecondary education nationwide. The importance of today's two-year institutions extends far beyond that of their predecessors. The present form, however, is markedly different than the Joliet model of 1901. A general examination revealed a variety of names referring to public and private two-year institutions nationwide: community college, technical college, community-technical college, technicalcommunity college, and community and technical college. Although possessing diverse titles, two-year college missions generally included one or more of the following: twoyear transfer and technical associate degree programs, workforce training for existing and new businesses and industries, remedial and continuing education, and adult services.

The original two-year colleges typically focused on general liberal arts studies. During the Depression of the 1930s, however, community colleges began offering jobs programs as a way of easing widespread unemployment. When World War II ended, military industries were transformed into makers of consumer goods. Skilled jobs and economic expansion resulted. In addition, the GI Bill created a major incentive for millions of military servicemen and servicewomen to pursue higher educational opportunities (Phillippe \& Sullivan, 2005).

The President's Commission on Higher Education, appointed by U.S. President Harry S. Truman on July 13, 1946, issued its six-volume report on December 11, 1947, under the title Higher Education for American Democracy. The Truman Commission, as the group was known, provided a detailed framework for higher education in postwar America (Vaughan, 1983). The Commission viewed the two-year college as "an important means for the democratization of higher education" (Vaughan, 1983, p. 21). 
The report placed such significance on the role of two-year colleges in opening the doors of higher education to a broader segment of American society that noted community college author and historian, George B. Vaughan, referred to the report as the “Community College Manifesto" (Vaughan, 1983, p. 21).

The Truman Commission suggested the creation of a network of public, community-based educational institutions to serve local areas and labeled the institutions community colleges. The Commission's report articulated three needs to be addressed by community colleges: business and industry pleas for trained workers, a shortage of university housing, and a desire to cut commuter distance (President's Commission on Higher Education, 1947). Vaughan (1983, pp. 22-23) described five essential characteristics of the community college outlined by the Commission:

1. It should conduct community surveys to determine community needs;

2. It should design its programs to meet the needs of a cross-section of the population, including older adults who needed to alternate their time between work and college attendance;

3. It should integrate general and vocational-technical education;

4. It should offer the first 2 years of a four-year degree or of professional study;

5. It should serve as the center for a comprehensive program of adult education. During the 1960 s, community colleges in the U.S. were opening at the rate of one per week (Brint \& Karabel, 1989). All total for the decade over 450 public community colleges opened their doors, and the explosive growth fostered a national network of twoyear institutions (Phillippe \& Sullivan, 2005; Vaughan, 2000). More moderate growth continued in the 1970s and 1980s (Brint \& Karabel, 1989). Over the next 2 decades, the 
number of new colleges increased from more than 600 to over 1,100 while enrollments grew from just under 1 million to beyond 4 million (Phillippe \& Sullivan, 2005). In 2000. community colleges served some 10 million credit and non-credit students. Community colleges reached all segments of society through an open-access admissions process designed to offer equal and fair treatment to all students. Most notably, community colleges maintained a tradition of charging low tuition that complimented the openaccess goal (Vaughn, 2000).

By the 1980s, the "comprehensive community college" had emerged as a significant postsecondary provider. Breneman and Nelson (1981) defined "comprehensive" as giving equal priority to academic, vocational-technical, and community service programs. As community college missions expanded, however, debates ensued between advocates of a broad focus for the two-year institutions and supporters of a narrow focus for the colleges (Bailey \& Averianova, 1998).

Enrollment growth, widespread appeal, and newfound influence placed welcomed attention on two-year institutions. These positive factors, however, led to a higher level of public scrutiny, increased expectations, and greater accountability. At the same time, community colleges began to face challenging circumstances: declining state support, increased enrollments, advancing technologies, deteriorating buildings, and an impending mass retirement of faculty and administrators (Roueche \& Jones, 2005). "Environmental factors currently affecting today's community colleges either will cause irreparable damage to their fiscal health and organizational structure or contribute to their rebirth" (Roueche \& Jones, p. vii). In response to the numerous challenges of the twenty-first century, two-year college organizational reforms inevitably have resulted. 


\section{Two-Year College Organizational Reforms}

As the American community college entered its second century, radical reform efforts were redefining two-year college organization and governance, renewing the "education versus training" debate, and influencing major cultural shifts among campus faculty and administrators. The reform initiatives centered on a new "entrepreneurial college" movement quickly gaining momentum nationwide amidst a spotlight on accountability (Grubb, Badway, Bell, Bragg \& Russman, 1997). As the twenty-first century began, colleges were seeking "innovative methods to transform themselves into flexible, adaptive, responsive, and financially secure entrepreneurial organizations" (Roueche \& Jones, 2005, p. 2). Major reform initiatives and ever-expanding missions of the maturing community college were drastically changing campus environments and potentially affecting employees' opinions of the organizations for which they work.

Community colleges continued to develop into more versatile organizations which provided a growing list of programs and offerings to a multitude of constituencies (Bailey \& Morest, 2004). The colleges were now "complex institutions taking on a broad array of educational, social, and economic functions" (Bailey \& Averinova, 1998, p. 1). Despite a consistent drumbeat of criticism that community colleges, with their constantly expanding responsibilities, were "sacrificing quality and falling short of promoting equity" there appeared to be no reduction in the diversification of community college missions (Bailey \& Morest, 2004, p. 1). Organizational forms based on comprehensiveness were fostered by political and fiscal incentives in spite of significant criticism (Bailey \& Morest, 2004). 
During the evolution of the comprehensive community college model over 2 decades, significant numbers of academics and researchers condemned the expanding missions of community colleges (Bailey \& Morest, 2004). Critics suggested that the colleges should "narrow their focus for fiscal reasons" (Breneman \& Nelson, 1980, p. 73). Reitano (1998, p. 1) characterized the community college mission controversy as a "crisis of identity," suggested that the purposes of the two-year colleges "border on chaos," and outlined the need to make their missions cohesive. Other opponents argued that the incompatible goals of academic and vocational education support class distinctions and heighten inequality (Brint \& Karabel, 1989; Clark, 1960, 1980; Dougherty, 1994). Dougherty (1994) even suggested that vocational offerings undermined academic programs which encouraged transfer to four-year universities. Conversely, some authors articulated a view that the comprehensive model deprived vocational education of its role as the essential function of community colleges (Blocker, Plummer, \& Richardson, 1965; Grubb, 1996). Others observed that successful for-profit institutions like the University of Phoenix and DeVry Technical Institute pursued a much more focused strategy (Bailey \& Morest, 2004). The University of Phoenix focused on non-traditional, working students rather than traditional 18-year-old students. DeVry Technical Institute specialized in a limited number of technical degrees rather than academic transfer courses.

Community college advocates praised the institutions' ever-expanding missions as examples of institutions adapting to meet the needs of changing communities (Bailey \& Averianova, 1998). Critics suggested, however, that the colleges had "lost their way" and were "squandering effort and resources" in a futile attempt to "be all things to all 
people" (Bailey \& Averianova, p. 1). "Logically, multiple missions mean a fracturing of resources and energy that makes it harder to have clear goals and to prioritize" (Brewer, 1999, p. 2). Dougerty (1994) termed the "contradictory college" suggesting that in undertaking many tasks, community colleges become less effective without a clear purpose, experience campus tensions among different program groups, and spread resources too thin. The author implied that it is easier to pursue single rather than multiple goals.

Meanwhile, in an effort to obtain technically sophisticated workers, employers were increasingly looking to the community colleges as the primary-training providers (AACC, 2001). It appeared that continued mission expansion was inevitable due to external influences. In an effort to be responsive, radical organizational reforms were legislated for two-year colleges in states such as Connecticut, Indiana, Kentucky, Louisiana, Minnesota, and Washington (Bailey \& Morest, 2004; Puyear, 2001). Technical and academic two-year colleges were merged to form more comprehensive community colleges (Bailey \& Morest, 2004; Puyear, 2001).

Puyear (2001) studied the six states whose legislatures initiated major two-year college reforms within the last decade. Each of the states maintained separate, parallel systems of public community colleges and vocational/technical institutes. Over time, the institutional missions of the community colleges and vocational/technical institutes began to overlap and become duplicative. To improve responsiveness and to increase efficiencies, legislative mandates were passed merging the community colleges and vocational/technical institutes in all six states. Puyear (2001, p. v) identified five broad areas of common concern that precipitated legislative structural change in the six states' 
higher education systems: "(a) the separate systems were too expensive and cost savings could be attained by a change; (b) the separate systems were producing unnecessary or inappropriate barriers to student transfer; (c) workforce preparation was disjointed and ineffective; (d) adults were not finding it convenient to continue their education; and (e) the systems were engaging in turf battles or presenting competing or conflicting budget proposals and were expecting the executive branch or legislature to resolve the conflicts." By the late 1990s, the Commonwealth of Kentucky's governor and General Assembly had fully embraced the need for some form of legislative structural change to its postsecondary education system.

Kentucky: Emerging as a National Model of Two-Year College Governance One of the most nationally-recognized, two-year college legislative reform initiatives took place in Kentucky in May 1997 when Governor Paul E. Patton proposed and the state's General Assembly approved the creation of the comprehensive Kentucky Community and Technical College System (KCTCS) as part of the Kentucky Postsecondary Education Improvement Act of 1997, known as House Bill 1 (Kentucky Postsecondary Education Improvement Act, 1997). A significant emphasis of the broadbased postsecondary reform legislation that dramatically impacted all of Kentucky's public colleges and universities required that 13 of the state's 14 community colleges previously administered by the University of Kentucky - the state's flagship land-grant university - be joined by the 15 technical institutes operated by the Department for Adult and Technical Education, Cabinet for Workforce Development - an agency of the executive branch of state government. Lexington Community College, according to the 1997 legislation, remained under the governance of the university. Kentucky's Governor 
championed the new KCTCS as a much more responsive model that would better serve the needs of students and businesses/industries (McCall, 2008; Puyear, 2001).

As explained by Puyear (2001, p. 35), the pre-1997 organizational structure of Kentucky's community colleges and technical institutes presented numerous problems:

1. While both the community colleges and technical institutes, as they were called at that time, were well dispersed across the state and many were located close to one another, there was only sporadic communication or collaboration between them;

2. The community colleges, caught up in the slow-moving academic process of the University of Kentucky, struggled to respond quickly to meet needs in their communities. One major employer was quoted as saying that it had to go to Iowa to get its people trained. By the time one of the UK community colleges could respond with a proposal for a program, a year had passed and the need was no longer the same;

3. The technical colleges were part of the bureaucracy of state government.

Dr. James Ramsey, senior policy advisor and state budget director in 1997, said: If the bureaucracy of the UK system held back responsiveness, the only thing that could be worse was to have the postsecondary technical schools part of state government - which is where they were. For instance, their hiring system for teachers was the same as the highway department's system for hiring road workers. From the economic development perspective, the community colleges were not meeting the professional development needs of the businesses. ... Also, with the postsecondary technical schools you had the same things. Even more bureaucratic, not 
nimble, not quick and no real focus on economic development. (Cited in Puyear, 2001, p. 35)

Kentucky's unique, comprehensive community and technical college organizational governance model continues to shape nationwide policy and discussion. In 2004, Kentucky's two-year college system's founding president, Dr. Michael B. McCall, was named chair elect of the American Association of Community Colleges (AACC) Board of Directors, and he served the role of chair during the 2005-06 academic year where he presided over the AACC national conference April 21-25, 2006, in Long Beach, California (Kentucky Community and Technical College System, 2006). A sign of Kentucky's growing national influence on two-year college education, McCall was the first system-level president ever elected as chair of the AACC Board, (Kentucky Community and Technical College System, 2004). AACC has served as the national voice for community colleges for 4 decades (Kentucky Community and Technical College System). The results of the reforms that led to merger are not yet clear, but the early signs hold promise.

Progress of Kentucky's Public Two-Year College Merger

Today, an important question regarding the state's "merged" two-year college governance structure is whether or not the Kentucky Community and Technical College System is now more responsive to communities and stakeholders than the governance structure arrangement that existed prior to House Bill 1.

Kentucky continues to increase its residents' participation in higher education. While Kentucky's performance still lags many states, state policy reforms appear to be sustaining these improvements. However, the state's performance in 
educating its young population could limit the state's access to a competitive workforce and weaken its economy over time (National Center for Public Policy and Higher Education, 2006, p. 3).

In 2006, KCTCS maintained an annual budget of $\$ 673$ million and $\$ 228$ million in additional capital projects, 16 colleges with 65 campuses statewide, and reportedly impacted 300,000 citizens annually. The System enrolled 84,931 students (64.4 percent enrollment growth since 1998), offered 600 credit program options, and awarded 15,741 credentials (5,723 associate degrees, 2,310 diplomas, 7,708 certificates) - an increase of 6,231 since 2001. Additionally, KCTCS enrolled 32,379 in adult education programs, 29,589 in community education offerings, and 77,650 in fire and rescue training and served 2,721 businesses and had 36,921 in workforce development (Kentucky Community and Technical College System, 2006).

The KCTCS Strategic Plan 2006-10 stated as a goal to place more Kentuckians on the path to a postsecondary credential (certificate, diploma, or associate degree) and a successful career. The plan was designed around four goals with corresponding core indicators of success and one- and five-year targets, creating a "yardstick" that will allow measurement of success: (1) promote excellence in teaching and learning, (2) increase student access and success, (3) expand diversity and global awareness, and (4) enhance the economic development of communities and the Commonwealth. KCTCS states as its "Year 2020 Vision" to create a comprehensive community and technical college system recognized as the nation's best (Kentucky Community and Technical College System).

KCTCS needs to be successful and effective to achieve the public's elevated expectations and to live up to its growing national status. As a national model for two- 
year postsecondary reform and for the advocates of the comprehensive community college archetype, much depends on the end results. Much can be learned from the Kentucky two-year college governance experiment.

Were efficiencies created by the merger of Kentucky's community colleges and vocational/technical institutes (reduced duplication, cost containment), or did just a new and different bureaucracy emerge from the legislation? Were turf battles resolved? Were educational opportunities enhanced for the local citizenry? Were educational barriers lessened for the benefit of students? Did a new entrepreneurial college emerge? What were short-term impacts on the employee culture during the transition? What are the anticipated effects long-term?

Most importantly, does the comprehensive community college debate continue among the internal and external KCTCS stakeholders? If so, are there advocates of a more narrow focus for Kentucky's two-year, public community colleges who remain critical of mission-expansion outlined in House Bill 1? What is the relationship between the proponents of mission expansion for Kentucky's two-year colleges and those who oppose it? Can the division be characterized as a clash of incongruent faculty and administrator world views? Such differing world views will be further examined in the review of literature in Chapter II of this study. How will the two opposing philosophical perspectives within KCTCS ultimately affect the conditions required for successful twoyear college reform?

Answers to such questions will be crucial to the future of the comprehensive community college model nationally and specifically for postsecondary education in the Commonwealth of Kentucky. Considering the substantial resources which are dedicated 
to two-year colleges nationwide and the public's emphasis on accountability and quality education, the KCTCS experiment will likely remain in the spotlight for years and potentially decades to come. Community and technical colleges will face fierce competition for financial resources amidst limited state budgets. Elementary and secondary institutions, healthcare, transportation, and four-year public institutions will continue to lobby for additional resources and put a strain on tight state budgets. The success of the new two-year college governance structure - a system of merged community colleges and vocational/technical institutes (KCTCS) - will continue to be measured and evaluated by a skeptical public that demands accountability and results during lean economic periods.

\section{Two-Year College Reform and Accountability}

Kentucky's public agenda for postsecondary education has become a nationallyrecognized model for reform (Kentucky Council on Postsecondary Education, 2005). The Kentucky Council on Postsecondary Education (CPE), a thirteen-member board appointed by the Governor, is the state coordinating board for postsecondary and adult education in Kentucky. The Council coordinates change and improvement in postsecondary and adult education as directed by the Kentucky Postsecondary Education Improvement Act of 1997. The state's postsecondary education reform initiatives required more institutional accountability for resources provided, and performance indicators were designed to track progress toward successful reform and to create an overall culture of data-driven decision making. The accountability measurement included progress indicators built around five simple, yet important questions designed to guide the state's 
entire adult and postsecondary education system from 2005-2010 (Kentucky Council on Postsecondary Education, 2005):

1. Are more Kentuckians ready for postsecondary education?

2. Is Kentucky postsecondary education affordable for its citizens?

3. Do more Kentuckians have certificates and degrees?

4. Are college graduates prepared for life and work in Kentucky?

5. Are Kentucky's people, communities, and economy benefiting?

According to an analysis of U.S. Census projections, Kentucky will need nearly 800,000 working-age adults with a bachelor's degree or higher to match the projected national average in 2020. Described as the "2020 Imperative," Kentucky will need to nearly double the number of Kentuckians ages 25-64 with at least a four-year degree over the next 15 years. The leaders of the educational reform efforts in Kentucky cite eight primary benefits of achieving established goals: better-educated Kentuckians, higher incomes, more high-value jobs, increased tax revenue, involved citizens, knowledgebased economy, less poverty, and healthier people (Kentucky Council on Postsecondary Education).

KRS 164.020(3) required the CPE to review the state's public agenda every four years and prepare an annual accountability report for the Governor, the Legislative Research Commission (LRC), and the Strategic Committee on Postsecondary Education (SCOPE). The purpose of the report was to inform policy makers, legislators, and taxpayers of system-wide and institutional progress toward achieving the mandates of the Kentucky Postsecondary Education Improvement Act of 1997 (Kentucky Council on Postsecondary Education, 2006). The motto of the reform was One Mission: Better Lives. 
The long-term goal was to raise the standard of living and quality of life in the Commonwealth of Kentucky above the national average by the year 2020 .

KCTCS will be judged on its overall effectiveness and contribution to the achievement of the state's progress indicators of reform. Valuable clues to the success of Kentucky's community college/vocational-technical institute merger may be obtained by a better understanding of faculty-administrator perceptions of the new, more comprehensive governance model. The present study seeks to flesh out the perceived reality of the reform legislation's success according to those charged with carrying out the day-to-day responsibilities of the reform initiatives - administrators and faculty.

Are conditions present within KCTCS that will ultimately contribute to successful merger and achievement of the expectations the public has for it? Do Kentucky's twoyear college faculty and administrators believe that progress is being made toward postsecondary education reform? Do the two groups possess an equal knowledge of and appreciation for the reform initiatives? Will Kentucky achieve the stated CPE success indicator goals? Do faculty and administrators believe that reform was even necessary? Do individuals employed by the community colleges prior to merger perceive the changes differently than those employed by the vocational/technical colleges prior to the merger? Will the two-decade old debate between the proponents of a narrowly-focused mission (who tend to be faculty whose responsibility is to teach and be an expert in a specific discipline) and the advocates of a comprehensive mission for community colleges (who tend to be administrators whose responsibility is to ensure that the institution is responsive to a variety of internal and external stakeholders) prevail longterm? Does conflict over mission priorities impact colleges on a day-to-day basis or 
present a potential impediment to success? Will the differing paradigms create a major obstacle for KCTCS in achieving its mandated goals?

Brewer (1999) noted that a survey of faculty at one U.S. community college suggested a number of potential problems as two-year college missions were expanded. Most notably, internal divisions were created with respect to the appropriate academic and occupational emphasis. "The diverse objectives under the community college umbrella are all too frequently pursued in isolation from each other, if not in an atmosphere of competition and defensiveness" (Reitano, 1998, p. 125).

Lofty expectations by key external and internal stakeholders led to the drastic, legislative change in Kentucky. In order for the new, merged organizational structure to succeed in its effectiveness and for the state to realize the goals of the accountabilityconscious reform, faculty and administrator perceptions of and attitudes toward KCTCS need to be congruent. Alfred and Kreider (pp. 38-39) described a culture for community college institutional effectiveness: "In an effective organization there will be congruency between the expressed values of staff and the organization's behaviors and activities." Alfred and Kreider (1991, pp. 34-35) further observed:

As the public calls for accountability have escalated, new metaphors have been used to describe effectiveness. No longer are indicators of size (e.g., enrollment, number of programs, and budget) or reputation sufficient to demonstrate effectiveness. Community colleges are now expected to show value-addedness with students and customers in the form of documented outcomes of teaching and learning. 
Habeck, Kröger, and Träm (2000) posited rules of successful organizational mergers that are relevant for the present study: (a) a clearly stated vision of the future, (b) charismatic and decisive leadership to prevent a vacuum from emerging, (c) clear understanding of cultural differences and effectively handling them, and (d) clear communication at all levels. Alfred and Linder (1990) articulated the complex culture of community colleges and noted the unique marriage of programs, services, and delivery systems that sometimes appear contradictory. They suggested that it is a challenge to understand the basic culture of community colleges and even more difficult to measure effectiveness.

Conflicting faculty-administrator views about the basic mission and vision of the new organizational layout may undermine achievement of the reforms and cause the institutions to fall short of state-mandated goals. Stark differences of opinion among internal stakeholders in the organization regarding accomplishments and benefits, may be problematic for future growth of the new educational system. If the internal stakeholders (the system's employees) are significantly conflicted about the merger, it will be an enormously greater challenge to obtain backing from external stakeholders.

The challenge is to turn conflicts into cohesiveness. Internal tensions must be resolved by asserting the validity of the two-year college experience as a special blend of traditional and non-traditional education (Reitano, 1998, p. 125).

Puyear (2001, p. v) posited twelve lessons drawn from analyzing case studies of two-year college reform initiatives taking place in six different states. The researcher suggested that the lessons may provide insight to leaders of other states who might be considering statewide higher education system structural change: "(a) structural change 
can produce education reform; (b) structural change is traumatic; (c) structural change is expensive; (d) structural change interrupts progress on other initiatives; (e) efforts should be kept; (f) a clear vision is needed; (g) states should get on with it; (h) the teams and boards must be built; (i) the people affected must be involved; (j) systems must get "the whole job"; (k) booby traps must be avoided; and (l) there are alternatives."

Puyear $(2001$, p. 8) further described the traumatic nature of structural change and noted the challenges of merging divergent campus cultures:

Change always causes stress. When the change is imposed from outside the organization, stress increases. Structural change in higher education usually includes the perception of winners and losers and always involves a change in culture and methods of operation. All of these produce fear, anger, a sense of loss and even grief. These feelings, which are natural, can be intense. They need to be addressed honestly and compassionately, but they also must be left behind so that the process can proceed.

In 1998, a planning assessment, conducted by The Clements Group, L.C. of Salt Lake City, Utah one year after Kentucky's postsecondary educational reform bill was enacted, measured attitudes of a cross-section of KCTCS personnel. The assessment focused on a variety of issues. Echoing some of the findings later identified by Puyear (2001), the Clements Group Report cited two major challenges most frequently mentioned by KCTCS employees: (a) the difference in backgrounds of KCTCS institutions and personnel and (b) the need for stability throughout the transition into a system (The Clements Group, 1998). Both The Clements Group (1998) and Puyear (2001) suggested challenges presented by the merging of divergent campus cultures. How 
the challenges are addressed will be important to the success of KCTCS and the achievement of the goals outlined in House Bill 1.

\section{Merging Divergent Campus Cultures}

Existing research clearly documents the challenge of merging divergent campus cultures (Buono \& Bowditch, 1989; Hagberg Consulting Group, 2002; Harman 2002; Martin \& Samels, 1994; and Selingo, 1999). "Understanding different cultures and where and how to integrate them quickly is vital to the success of an acquisition or a merger" (Hagberg Consulting Group, 2002, p. 1).

Public postsecondary education mergers have represented a significant policy matter over the past 20 years (Harman, 2002). A limited body of research exists, however, on merger as a sociocultural issue (Harman). "This is surprising given that managing the cultural dimensions of mergers is such an important element in helping to ensure integration, creating a sense of loyalty to the new institution and in addressing likely high levels of conflict and stress" (p. 92).

Harman noted that although governments have frequently used mergers to effect systemic change, post-merger integration has often been painful, messy and protracted due to the methods of implementation and the manner affected institutions respond to the external pressures. "Attempts to merge uncomplimentary campus cultures into a coherent, workable system in a newly merged institution present sizeable challenges for higher education leaders" (p. 97). Significant research has been compiled describing the divide between faculty and administrators: collegial versus managerial cultures, disciplinary versus institutional perspectives, and micro versus macro foci (McMillin, 2002). Garmon (1984) suggested that faculty and administrator world view is strongly 
tied to organizational culture. Recognizing the influence of organizational culture on mergers, Buono and Bowditch (1989, p. 142) pointed out:

The full potency of organizational culture can be seen during a merger or acquisition when two disparate cultures are forced to become one.... organizations that may appear to be highly compatible on the surface and that seemingly should be able to achieve valuable merger synergies can have underlying cultural differences that seriously threaten their integration .... Organizational members are usually so embedded in their own culture prior to major organizational changes that they rarely fully realize its influence on their behavior.

Postsecondary education administrators are charged with the overall responsibilities for enforcing legislative mandates, implementing structural changes, and guiding institutional mergers. In the process, however, the potential for administrator and faculty conflict increases during the difficult transition. "Whether institutions merge or collaborate voluntarily or by edict, developing from different cultures a new integrated culture of shared values and loyalties, attitudes and conditions of work is a mammoth challenge for leaders that needs to be handled sensitively and with relative speed" (Harman, 2002, p. 110). Martin and Samels (1994) described three key characteristics integral to merging colleges for mutual growth that are relevant to the present study: (a) campus-wide commitment, (b) shared vision, and (c) collaborative decision making. As administrators begin to lead the change in response to external pressures, faculty often begin the process in direct opposition to the legislative mandates. The differing viewpoints can be problematic for creating harmony among the internal 
institutional stakeholders, thus preventing progress toward reform. In the case of community college and vocational/technical institute mergers for instance, some technical-college faculty feared the gutting of hands-on-training courses in favor of liberal arts classes and the potential alienation of students who were not interested in academic courses (Selingo, 1999). Some community college faculty members worried about the diluting of academic coursework and the loss of academic rigor due to the emphasis on technical training. Faculty and administrator differences may exacerbate already stressful circumstances of merger. During major educational change such as merger, the potential for campus tensions may be heightened by the pre-existing, disparate faculty and administrator world views.

Disparate Faculty and Administrator World Views

The existence of disparate world views held by faculty and administrators in the postsecondary educational institutions in the U.S. has been clearly documented in the literature (Campbell \& Slaughter, 1999; Cardot, 1990; Daniel, 2008; Del Favero, 2002; Del Favero, 2003; Dodd \& Garmon, 1987; Garmon, 1984; Holton \& Phillips, 1995; McMillin, 2002; Nunez, 2003; Peterson \& White, 1992; Petry, 1957; Richard, Blocker \& Bender, 1972; Welsh \& Metcalf, 2003; White, 1990; and Zemsky, 1996).

Richard, Blocker, and Bender (1972, p. 70) stated, "It is a well-known fact that administrative values do not always coincide with faculty values." Campbell and Slaughter (1999, p. 310) further noted, "Some tension between faculty and administrators has been accepted as an enduring part of academic life." Bender, Blocker and Martorana (1975) contended that the academic community generally believes that scholarship and administration are incompatible. McMillan (2002, p. 3) commented on the differential in 
compensation between faculty and administrators noting that administrator's work is perceived by faculty "to be intrinsically less valuable" and the perceptions "can be a source of discomfort and resentments." Furthermore, "harsh stereotypes make the boundary between faculty and administrators harder to cross" (p. 3).

Perceptual differences in faculty and administrators' perceptions of the merger of community colleges and vocational/technical institutes logically then may be influenced by their prevailing world views. Higher education literature reveals pertinent differences between administrators and faculty that may dramatically hinder the successful implementation of the goals of House Bill 1 related to improving Kentucky's two-year public colleges. Positive outcomes of the merger of Kentucky's community colleges and vocational/technical institutes depend significantly on congruent perceptions and effective working relationships among faculty and administrators. It is suspected, because of documented world view dissimilarity, that KCTCS faculty and administrators differ in their perceptions of the merger of the community colleges and vocational/technical institutes. Such attitudinal differences may be problematic for a successful merger and for realizing the ultimate postsecondary education goals outlined by Kentucky legislators in 1997 and for the KCTCS goal of becoming the best community and technical college system in the nation by the year 2020 .

\section{Problem Statement}

If Kentucky's postsecondary education reform initiatives do not successfully address the community responsiveness demands and high expectations of an accountability-conscious public, serious consequences may await public, two-year colleges statewide. The institutions' responsibility for new postsecondary enrollment 
growth and for workforce preparation was clearly outlined in the legislation. Increased educational access and attainment is critical. The enactment of the Postsecondary Education Improvement Act of 1997 resulted in the formation of the Kentucky Community and Technical College System (KCTCS) through the merger of the state's community colleges and vocational/technical institutes. If KCTCS is not deemed successful by an increasingly skeptical public, the two-year colleges face the potential for losing their relevance in the new century. The possible consequences of external stakeholders failing to buy into the new system are far reaching: reduction of basic public funding (state and federal), decreased private sector funding support, deterioration of instructional quality, loss of prestige, and lessened momentum gained from the recent attention paid to the state's historically overlooked two-year institutions. The significant resources invested in KCTCS over the past decade would be wasted if the merger is not ultimately successful.

Little is known, however, about KCTCS faculty and administrators' perceptions of the merger of Kentucky's community colleges and vocational/technical institutes. A paucity of research exists on KCTCS since House Bill 1 was enacted into law. It is suspected that KCTCS faculty and administrators differ in their perceptions of the merger. The potentially differing views held by KCTCS faculty and administrators may serve as an obstacle for the successful implementation of the goals of the statewide reform initiatives.

A review of the literature in Chapter 2 provides ample evidence of a pre-existing faculty/administrator chasm which may serve as a potential source for the differing perceptions of the merger. Differences among the two postsecondary education 
subcultures - faculty and administrator - may exacerbate conflicting perceptions of merger. The essential challenge in achieving community college success is "to increase synergy among these different forms of work-related preparation in ways that nurture them all while ultimately fostering academic education" (Carnevale \& Desrochers, 2001, p. 39). However, achieving synergy through higher educational mergers has proven to be difficult and traumatic due to the divergent campus cultures (Buono \& Bowditch, 1989; Harman, 2002; Martin \& Samuels, 1994)

Literature related to faculty and administrator differing perspectives on organizational change is extensive (Klein \& Dunlap, 1994; Levin, 1998; Solis, 1995). Research further suggests a degree of tension has always existed between faculty and administrators and offers that it is important to understand the cultural differences between the two groups (Campbell \& Slaughter, 1999; Zemsky, 1996). Petry (1957) speculated that the source of faculty and administrator tension derives from three sources: (a) background, training, and interests, (b) personal characteristics, and (c) responsibilities. The present study attempts to gain insight on the congruity of perception of institutional merger by KCTCS faculty and administrators who represent an essential element in its successful implementation.

\section{Purpose of the Study}

The purpose of this investigation is to determine whether faculty and administrators employed by KCTCS exhibit significantly different perceptions of the merger of Kentucky's community colleges and vocational/technical institutes. The examination looks at the conditions necessary for successful organizational mergers and attempts to gain insight, using responses from faculty and administrators, on whether or 
not such conditions presently exist for KCTCS. Skodvin (1999, pp. 77-78) observed that, "A successful merger is above all characterized by visible and strong management which is able to collect the different sub-cultures, as well as create a joint feeling of identity and organizational structure."

Has such a joint feeling of identity and organizational structured been realized for KCTCS? Has management successfully collected the different sub-cultures to create a sense of unity? Achievement of such conditions will be vital for Kentucky's community colleges to effectively meet the public's lofty expectations outlined in the state's postsecondary reform legislation. The study will also evaluate influencing factors, gleaned from the literature, which may play a role in faculty and administrator perceptions of the merger and ultimately gauge their feelings with regard to system-wide unity.

\section{Research Questions}

A review of the literature detailed in Chapter 2 revealed notable differences in world view between higher education faculty and administrators (Campbell \& Slaughter, 1999; Cardot, 1990; Del Favero, 2002, 2003; Dodd \& Garmon, 1987; Garmon, 1984; Holton \& Phillips, 1995; McMillin, 2002; Nunez, 2003; Peterson \& White, 1992; Petry, 1957; Richard, Blocker \& Bender, 1972; Welsh \& Metcalf, 2003; White, 1990; Zemsky, 1996). The degree of world view differences exhibited by faculty and administrators served as an overarching theme across the questions. Two research questions framed the study and provided the basis for analysis: 
(1) Are there significant differences between faculty and administrators in their perceptions of the merger of Kentucky's community colleges and vocational/technical institutes?

(2) What factors help us understand faculty and administrator perceptions of the merger of Kentucky's community colleges and vocational/technical institutes? The literature review suggested that faculty and administrator views of the merger of Kentucky's community colleges and vocational/technical institutes may be affected by five variables: (a) perceived type of institutional decision making - collegial, hierarchical, or political, (b) perceived depth of merger implementation, (c) level of involvement in the merger initiatives, (d) perception of reform initiatives as internally or externally motivated, and (e) level of support for state postsecondary education reform initiatives that led to the merger initiatives?

\section{Identification of Variables in Research Questions}

Seven variables appear in the research questions as independent, dependent, or control variables. The following is a brief outline identifying each variable contained in the research questions.

\section{Research Question 1}

In this question, Respondent Status, faculty or administrator, is an independent variable, and the Respondent Perception of Merger is a dependent variable.

\section{Research Question 2}

Respondent Status, faculty or administrator, is an independent variable. The Respondent Perception of Merger is a dependent variable. Existing research and policy analysis detailed in Chapter 2 suggested five control (predictor) variables that influence 
faculty and administrators' perceptions of merger. The effects of the following five control variables were examined against respondents' perceptions of merger: (a) type of institutional decision making, (b) perceived depth of merger implementation, (c) level of involvement in merger initiatives, (d) perception of reform initiatives as internally or externally motivated, and (e) level of support for state postsecondary education.

\section{Respondent Status}

Faculty were those full-time community and technical college employees whose primary role is classroom teaching and who were listed under "Faculty" in the official 2007-2008 Kentucky Community and Technical College System Catalog. Administrators were those full-time community and technical college employees who held the position of president, vice president, dean, or a mid-management/supervisory role who were listed under "Administration" in the official 2007-2008 Kentucky Community and Technical College System Catalog. Administrators holding faculty status were grouped in the "administrator" category for the purpose of this study. Faculty holding division chair and other administrative responsibilities such as council and senate representation were grouped in the "faculty" category for the purpose of this study. The study focused on faculty and administrators employed by one of the 16 individual KCTCS institutions. Administrators employed in the KCTCS central administration office in Versailles, Kentucky, were not included in the present study nor was the researcher who was a KCTCS employee.

Respondent Perceptions of Merger 
Respondent Opinions of Merger is defined as the degree to which respondents maintain a positive or negative view of the merger of Kentucky's community colleges and vocational/technical institutes.

Type of Institutional Decision Making

Martin and Samels (1994) noted collaborative decision making as a key characteristic integral to merging colleges for mutual growth. Type of Institutional Decision Making is defined as the perceptions of respondents regarding whether institutional decision making is perceived as collegial - where participative/shared decision-making takes place among a "community of scholars" (Bing \& Dye, 1992; Birnbaum, 1989), hierarchical - where constituent groups' views are voiced and "listened to" and then leadership ultimately makes bold decisions (Bing \& Dye, 1992), or political - where organizations compete for power and resources through conflict and coalition (Birnbaum, 1989). Understanding the type of institutional decision making present at the institution can offer valuable insight toward the support for postsecondary education reform efforts that led to merger. This variable helps to control for faculty and administrator perceptions of merger by the respondents' indication of the type of institutional decision making present at the institution: collegial, hierarchical or political. The type of institutional decision-making was found to be a significant predictor of faculty and administrator support for strategic planning (Nunez, 2003). Facultyadministrator relationships regarding institutional decision making were identified as an integral component of high-performing postsecondary education governance systems (Del Favero, 2002; Del Favero, 2003; and DuPont, 2000).

Depth of Merger Implementation 
Depth of Merger Implementation is defined as the attitudes of respondents regarding whether a high or low degree of merger implementation was perceived at their institutions. The measures on this scale range from comprehensive to limited. The depth of implementation of reform initiatives can influence faculty and administrator views of activities such as institutional effectiveness (Metcalf, 2001) and strategic planning (Nunez, 2003). Faculty and administrators who perceive that the reform efforts are limited in scope may maintain more negative perceptions of the merger. In contrast, faculty and administrators who perceive that the merger initiatives were comprehensive and will have significant, far reaching effects toward the institution may indicate more positive perceptions of the merger. This variable helps to control for faculty and administrator perceptions of the merger of Kentucky's community colleges and vocational/technical institutions by indicating the depth of implementation the respondents perceive related to the merger of Kentucky's community colleges and vocational/technical institutes.

Level of Involvement in Merger Initiatives

Level of Involvement in Merger Initiatives is defined as the amount of respondents' personal involvement in activities related to the merger of Kentucky's community colleges and vocational/technical institutes. Specifically, respondents were asked about their involvement in the consolidation of community college and vocational/technical institute programs, services, and functions at their respective institutions. Measures on this scale range from high to low. Research suggests that broad participation and involvement of faculty and administrators in educational change and innovation is critical to the success of major reform initiatives (Bennis, 1984; Metcalf, 
2001; Nunez 2003; Puyear, 2001). However, faculty and administrators who attribute low importance to reform efforts may do so due to insufficient involvement in the process.

Schilling and Schilling (1998, p. 64) noted that "Higher education contains little, if any, history of successful top-down initiatives, as faculty ownership is a key element of change in institutions of higher education." Skodvin (1999, p. 70) commented that "Topdown processes are most common (most of the state-initiated mergers) - but they are often connected to a lot of tensions and conflicts among both administrative and academic staff." This variable helps to control for faculty and administrator perceptions of merger by indicating the amount of participation the respondent has had in efforts related to the merger of Kentucky's community colleges and vocational/technical institutes.

Internal Versus External Motivation for Reforms That Led to Merger

Internal Versus External Motivation for Reforms That Led to Merger is defined as the perceptions of respondents regarding whether the merger of Kentucky's community colleges and vocational/technical institutes was precipitated by internally-driven efforts or externally-driven efforts. The spread of the quality movement from the business sector to public education has influenced significant change in higher education (Quehl, Bergquist, \& Subbiondo, 1999). External forces such as student demands, public agencies, and industry have a greater influence on higher education than internally motivated initiatives (Banta, 1995, p. 217). The research literature, however, documents an extensive history of resistance toward change by public colleges (Benjamin, 1994; Bok, 1986; and McConnell, 1992). 
The independent nature of the academy may affect the degree to which faculty and administrators view the importance of the merger of Kentucky's community colleges and vocational/technical institutes. Chambliss (1994) pointed out that faculty members selected their academic careers largely due to the premium they personally placed on autonomy. Faculty value "maximum freedom, and few distracting, mindless, menial required tasks ... faculty generally resent being told what to do" (pp. 2-3).

If campus faculty and administrators perceive merger as simply efforts to please outside stakeholders, they will likely perceive lower levels of importance for the merger and will probably remain less supportive of the endeavors. This variable helps to control for faculty and administrators perceptions of merger by indicating whether the merger is perceived as internally or externally motivated.

Level of Support for State Postsecondary Education Reform Initiatives That Led to Merger

Level of Support for State Postsecondary Education Reform Initiatives That Led to Merger is defined as the attitudes of respondents regarding whether a high or low degree of support for higher education reform initiatives was perceived. The level of support for state postsecondary education reform initiatives can influence the views of those activities (Nunez, 2003). If faculty and administrators maintain a high level of support for state postsecondary education reform initiatives in general, they will likely maintain more positive views of Kentucky's postsecondary education reforms, specifically the merger of Kentucky's community colleges and vocational/technical institutes. This variable helps to control for faculty and administrator perceptions of 
merger by indicating the level of faculty and administrator support for state postsecondary education reform initiatives that led to merger.

\section{Demographic Variables}

In addition to the variables measuring faculty and administrator perceptions of the merger of Kentucky's community colleges and technical/vocational institutes, demographic variables assessing various faculty and administrator identifying characteristics were also utilized to provide more depth and breadth about the survey respondents. The demographic variables were as follows:

1. Position at the college (faculty or administrator)

2. Primary academic discipline (if faculty)

3. Years employed in present job

4. Years employed in higher education

5. Gender

6. Age

7. Faculty rank

8. Tenure (yes or no)

9. Type of institution employed at the time of merger (vocational/technical college-KY, community college-UK, or N.A./other)

Respondents were also provided the opportunity to submit open-ended responses in an "additional comments" section.

\section{Significance of the Research}

The present study investigated faculty and administrator perceptions of the merger of Kentucky's community colleges and vocational/technical institutes. The study 
explored the relationship of existing faculty/administrator perceptual differences on twoyear college reform. Particular emphasis was placed on how the faculty/administrator chasm serves as a potential obstacle to addressing the public's desire for more responsive and efficient two-year colleges. The study examined the perceptions, attitudes, and opinions of faculty and administrators employed by KCTCS with regard to the merger of Kentucky's community colleges and vocational/technical institutes.

Understanding pertinent differences that exist between KCTCS administrators and faculty represents a vital element in the successful implementation of the merger. The positive outcomes of the merger depend on the congruent perceptions, attitudes, and perceptions of faculty and administrators regarding the merger. House Bill 1 and the resulting reforms are seen by many as vital to increasing the educational attainment of Kentucky's citizens, to developing a skilled workforce, and to improving Kentucky's economy. Incongruity of faculty and administrator perception and lack of understanding regarding the statewide reform initiatives that led to merger may serve as a potential roadblock for successful implementation of the legislation. There is a dearth of literature on the topic. In fact, a limited body of research exists on merger as a sociocultural issue (Harman, 2002). The present study is significant for Kentucky's postsecondary education stakeholders who maintain a responsibility for achieving the important goals outlined in House Bill 1.

The study will also provide insight on the beneficial or detrimental effects of the ever-expanding community college mission and its impact on outcomes. Perspectives of comprehensive community college mission advocates as well as critics who suggest that 
community colleges should maintain a more focused strategy will serve an educational purpose. The two differing paradigms represent an essential aspect of this research. The present study will add to the limited body of literature on two-year colleges. The majority of research on postsecondary education faculty and administrators relates to the university setting, while faculties and administrators in community and technical colleges are rarely studied. Furthermore, most research on education reform focuses on secondary education and universities. Cohen and Brawer (1996) observed that serious academic research on community colleges is sparse. Significant community college reorganization efforts are a relatively new phenomenon. Consequently, very little research exists with regard to community college reorganizations nationwide. Most studies on community college members simply focus on one group - faculty or administrators - without comparing positions across groups (Kelsey, Jr., Mezack, III, \& Cardot, III, 1992). Research on Kentucky's community and technical colleges since the merger is almost nonexistent.

This study is significant in that it adds to the limited body of research on two-year college reform efforts and, specifically, Kentucky's community and technical colleges an influential, national organizational model. The research improves understanding of the perceptions, attitudes, and opinions of faculty and administrators employed by KCTCS. It is anticipated that the study will enhance and enlighten the body of existing research concerning faculty and administrator relationships and the emerging community college reforms. Kentucky higher educational leaders, and specifically those charged with overseeing the development of KCTCS, may view the results as a useful tool for developing strategies for successfully implementing the goals of a significant portion of 
the Kentucky Postsecondary Education Improvement Act of 1997 (House Bill 1) - the impetus for the merger of the state's community colleges and vocational/technical institutes.

\section{Limitations of the Study}

The current study is limited in its generalizability due to a couple of factors. First, the population selected for the study included only faculty and administrators from Kentucky's public, two-year community and technical colleges. A convenience sample was selected for ease and accessibility. The location of the merger and reform efforts as well as the study participants was in Kentucky. Political climates, state policy goals, and resources vary among different states. Individuals from other states might have responded differently to a similar questionnaire on two-year college merger and reform initiatives. Nationwide, two-year college reforms were initiated in unique ways and evolved differently making direct comparison difficult. KCTCS represents a very distinctive statewide, "merged" governance structure for two-year institutions. Consequently, a study of this nature may not be generalizable to populations outside of the state of Kentucky.

Secondly, the study utilized self-reported information based on personal views, rather than actual behaviors. Respondents may indicate opinions on a confidential, written survey instrument that vary from what actual occurs in reality. Viewed behavior is the ideal method of gathering data, but that approach was not possible in the present study.

Thirdly, some limitations of content validity studies such as this one should be noted. Feedback obtained from the panel of experts who reviewed the survey instrument 
materials was subjective. Thus, the present study is subjected to bias that may exist among the experts consulted.

Fourth, higher education research suggests that institutional mergers are difficult, but the literature is not clear on the length of time a merger takes to complete. This study reflects only one snapshot in time - approximately 10 years after the merger legislation took place. If the study took place earlier or later than the 10-year window, different results might have been obtained.

Lastly, the researcher chose to study both faculty and administrator groups as defined in their most simple form. Some faculty, however, maintain more complex, administrative roles such as division chairs and work on committee assignments and representation on faculty councils and senates. For the sake of simplicity and for the general purposes of the present study, the researcher chose not to subdivide faculty into two groups - faculty-planners and faculty non-planners as demonstrated by Nunez (2003).

A significant strength of the study, however, lies in its narrow focus on KCTCS faculty and administrators. KCTCS is recognized as a unique and important example of two-year college reform nationwide which has not been heavily studied. The merger of the state's community colleges and vocational/technical institutes is significant. Another strength of the project is its timeliness. The research took place during the 2007-08 academic year which represented the tenth academic year since the hiring of KCTCS' Founding President, Dr. Michael B. McCall, in January 1999 and the eleventh academic year since the May 1997 reform legislation was passed by the Kentucky legislature which ultimately led to the merger of Kentucky's community colleges and technical/vocational 
institutes. Experiences from postsecondary mergers from the U.S., Australia, and The Netherlands demonstrate that it can take up to ten years before the situation is normalized after a merger (Millet, 1976; Mulvey, 1993; Skodvin, 1999). 


\section{CHAPTER II}

\section{LITERATURE REVIEW}

Introduction

The American public's desire for educational accountability has had a profound effect and has served as an impetus for noteworthy change. The resulting nationwide reforms are clearly documented in the literature. This chapter will explore the relationship between pre-existing faculty/administrator world view differences and perceptions of postsecondary educational reform initiatives. Specifically, the chapter will investigate how the faculty/administrator chasm serves as a potential obstacle to the successful achievement of postsecondary education reform goals established for Kentucky's public system of two-year colleges.

The present review of the literature has five objectives:

1. To examine higher educational change nationwide as a context for Commonwealth of Kentucky reform initiatives;

2. To examine postsecondary education mergers as a response to growth and higher educational change;

3. To examine the Kentucky Postsecondary Education Improvement Act of 1997 (House Bill 1) and the resulting merger of the state's community colleges and vocational/technical institutes;

4. To examine relevant empirical research addressing faculty and administrator world view differences; 
5. To examine the control variables impacting both the dependent and independent variables identified in Chapter 1 (Rosenberg, 1968, p. 39).

\section{Higher Educational Change Nationwide}

The publication of $A$ Nation at Risk (National Commission on Excellence in Education, 1983) first awakened the American public to the need for major educational reform. The report generated increased accountability of public schools and ultimately affected substantial change on primary, secondary, and postsecondary educational institutions. A decade later, the Wingspread Group on Higher Education noted that "Education is in trouble, and with it our nation's hopes for the future. America's ability to compete in a global economy is threatened" (1993, p.12). A new approach to higher education was inevitably needed.

Osborne and Gaebler (1992) described traditional public education as a classic example of the bureaucratic model that assured stability, not change. In the national bestseller, Reinventing Government: How the Entrepreneurial Spirit is Transforming the Public Sector (Osborne \& Gaebler, 1992), the authors advocated a new model emerging across the U.S. called "entrepreneurial government" whereby innovative organizations used resources in new ways to maximize productivity and effectiveness. The authors suggested the concept to combat a central failure of government and the bankruptcy of bureaucracy that led to a crisis of confidence in the government as a whole.

Bureaucracy developed in a slow-paced society and served a useful purpose. The authors argued, however, that bureaucracies are less effective in today's era of breathtaking change, the global marketplace, an informational society, a knowledgebased economy, and competitive economic institutions/industries. The authors contended 
that today's organizations must be responsive, flexible, and adaptable. They suggested that a spirit of entrepreneurial government serves as a better fit for today's environment whereby government eliminates duplicative services, reduces costs, and accommodates the public's needs.

Although on-going improvement reforms in American higher education institutions should be, according to many, a proactive, internally-driven endeavor, the current emphasis on quality and effectiveness is commonly a response to outside edicts. Seymour (1993) identified four driving forces behind the quality movement in postsecondary education: (a) competition, (b) costs, (c) accountability, and (d) service orientation. In general, the current motivation for higher educational reform can be defined as reactionary.

Seymour (1995, p. 10) described the external demands for postsecondary improvement as the following:

These stakeholders expect the same thing in a college education that they expect in a toaster oven or a new home-utility. Skip the rhetoric. Forget about the cute accessories or the quaint features. People want to be assured that what they purchase today will be useful tomorrow. They work hard for their money, and so when they spend it, on anything, they want good quality at a fair price.

Quehl, Berquist, and Subbionado (1999, p. 3) described the changing attitudes of the American public toward higher education by noting the following:

A perception swept the country that a serious mismatch existed between the purposes and outcomes of higher education and the needs of the American workplace and economy. In short order, the new challenge for higher education 
was to ensure the nation's competitiveness in the global economy. The "Age of Accountability" for higher education had arrived.

Today, such attitudes toward public educational institutions are considerably different than the opinions held when the first two-year colleges were established. As community colleges have evolved, so have the public's expectations. Tillery and Deegan (1985) described the evolution of two-year colleges within a framework of four generations: (a) Extention of High School, 1900-1930, (b) Junior College, 1930-1950, (c) Community College, 1950-1970, and (d) Comprehensive Community College (1970-mid 1980s). The authors suggested that a fifth generation framework for the contemporary community college is still emerging. The latest growth stage may be the "entrepreneurial college" (Grubb, Badway, Bell, Bragg \& Russman, 1997). As the twenty-first century began, colleges were seeking "innovative methods to transform themselves into flexible, adaptive, responsive, and financially secure entrepreneurial organizations" (Roueche \& Jones, 2005, p. 2).

\section{The Entrepreneurial College}

Bailey and Averianova (1998, p. 28) suggested that, as publicly funded institutions, community colleges are expected to offer a variety of community services, and "they need to develop entrepreneurial functions in search of new revenues to make up for increasingly scarce state resources." Grubb, et al. (1997) examined three nontraditional program areas which have emerged and now heavily influence community colleges: (a) workforce development, (b) economic development, and (c) community development. The authors used the term "entrepreneurial college" to describe the new market-oriented community college that is evolving to be more responsive to external 
organizations. But they cautioned, "When a college begins to pursue community, workforce, and economic development, it risks losing sight of its other missions given the enormous visibility associated with workforce and economic development" (p. 36). The researchers contended that oftentimes, "These new functions have created a college within the community college, operating with a new culture, new rules and regulations" (p. v).

Such mission expansion holds the potential for creating tension between the collegiate/academic function and the vocational function within the community colleges (Bailey \& Averianova, 1998). The possibility exists that conflict will arise between two of the community college subcultures - faculty (who tend to hold a narrow view of twoyear colleges missions) and administrators (who tend to advocate a broader view of twoyear colleges). Nevertheless, some researchers suggested that the expanded role of community colleges as practically inevitable (Bailey \& Averianova, 1998; Lewis, 1991). Lewis (1991, p. 27), in discussing the global economy and education for work in the U.S., articulated the new labor market realities and predicted the new entrepreneurial role of community colleges:

In postsecondary institutions (such as area vocational schools, technical institutes, and community colleges), vocational education should be playing at least two broad roles, one proactive and the other reactive.... Community colleges, and indeed all other postsecondary vocational institutions, may have to become decidedly more entrepreneurial in the evolving labor market, responding to customer needs on the one hand and pressing the frontiers of training (being proactive) on the other. 
The challenge ahead is to identify what parts, if any, of the community college missions have been affected by significant organizational changes in recent years that were made in response to calls for more entrepreneurial institutions. It must be determined if there is a proper balance among the ever-evolving missions of public, twoyear colleges. It is unclear from existing literature what effect the new "entrepreneurial college" has had or is having on community college faculty and administrator attitudes, opinions, perceptions, and behaviors.

What is clear, however, is an emerging trend toward the integration of academic and vocational education nationwide and ever-expanding missions for community colleges. Lewis (1991) described the challenge faced by institutions offering both types of curriculum:

The overwhelming majority of companies in the U.S. do not have, nor can they afford, training infrastructure. What companies need are highly skilled electronics technicians, welders, medical technicians, and so forth, who are also highly literate. (p. 26)

Nationwide, community colleges are experiencing an identity crisis as a result of significant organizational change in mission and governance. Some colleges emphasize traditional, academic transfer functions (general education core) while other colleges focus on the short-term training demands of returning students, businesses, and industries. It is anticipated that a majority will retain comprehensive missions by balancing education and training functions opportunities for both traditional and nontraditional students (Carnevale \& Desrochers, 2001). 
According to many policymakers, community colleges must expand their role in economic development to remain relevant in the twenty-first century. A tremendous need exists to increase the technical skills of the nation's workforce in support of economic growth. Former U.S. Federal Reserve Board Chairman, Alan Greenspan, articulated the critical role of community college education in the nation's economy and noted the importance of both general knowledge and practical skills:

Generic capabilities in mathematics, writing, and verbal skills are key to the ability to learn and to apply new skills and thus to earn higher real wages over time.... one effective tool that we have developed to facilitate the transition to a new job or profession has been our community colleges....The impressive expansion of these learning centers attests to their success in imparting both general and practical job-related learning. (Greenspan, 2004, p. 3)

Faced with enormous transition and competition, businesses and industries across the nation are emphasizing the necessity for performance-based, skills certifications. Community colleges that have accepted the "entrepreneurial" challenge are emerging as the primary providers of workforce and economic development. Greenspan (2004) further commented:

The United States economy has long been characterized by a strong tradition of entrepreneurial spirit among our business people, a high level of skill among our workers, and an openness by firms and workers alike to intense competition within and beyond our borders. Those attributes have given us a standard of living unparalleled for so large a population - and one that has risen steadily over the history of our nation. (p.1) 
The research clearly indicates that an entrepreneurial spirit will be a vital element to creating relevant two-year education in the coming decades. But significant changes will be necessary. For some states, merger of community colleges and vocational/technical institutes has served as a necessary response to growth and change. Mergers as a Response to Growth and Change

One response to higher education growth and change has been the mutual growth merger (Martin \& Samels, 1994). Approximately 500 mergers took place in the public higher education sector in developed nations from the 1960s to the mid-1990s (Eastman \& Lang, 2001). Little is known, however, about the outcomes of two-year college mergers which have been commonplace in recent years.

In order to truly understand the results of the legislatively-imposed restructuring, individual state reform initiatives must be studied in-depth. Success depends on both the external influences (political and social elements' satisfaction) as well as the internal environment (faculty, administrator, staff and student attitudes toward the change). Jansen (2003, p. 29) offered contingency theory as a conceptual platform for understanding mergers:

Contingency theory is derived from a principal proposition that can be summarized (and then unpacked) as follows: the origins, forms and outcomes of mergers are conditioned by, and are contingent on, the specific forms of interaction between institutional micro-politics, on the one hand, and governmental macro-politics, on the other, especially in turbulent or transitional contexts. 
Zekan (1994, p. 118) offered a thesis that coincides with the theory of contingency for explaining the course and outcomes of postsecondary mergers:

The most appropriate focus for public sector mergers is away from institutional organizational characteristics and toward the complex relations between institutional mission and public policy. In this context, a crucial factor for the success of public sector mergers becomes the interplay of public policy and institutional mission within local and regional political structures. Another commonly cited theory on higher education mergers is resourcedependency theory (Jansen, 2003). According to Jansen, The principal knowledge claims associated with resource dependency is that organizations engage in mergers as a result of the threat of diminishing resources. Organizations - like biological organisms - respond to change because of threats in the external environments. In other words, organizations conform to what is required when their survival is under threat because of the fear, real or perceived, that the resources that sustain them might be curtailed.

In 2001, the Center for Community College Policy of the Education Commission of the States (ECS) sponsored a study of community college/technical institute mission convergence. The results of the study revealed significant changes in the governance of community colleges and vocational/technical institutes in a number of states over the past 10-15 years:

In the evolution of higher education, some states created parallel systems of "junior colleges" and "technical institutes," usually with different governance and funding structures. In some states as these systems matured, individual institutions 
of both systems became more comprehensive to the point where the two systems may now be providing redundant and competing services. For these and other reasons, some states with dual systems are considering merging or consolidating the two systems. (Puyear, 2001, p. iii)

Since the early $1990 \mathrm{~s}$, a number of state legislatures have approached the need for major two-year college reform. Only a handful of states, however, have succeeded in effecting significant change. Obstacles include a multitude of political, social, and historical forces. Notable two-year college mergers may be observed in Connecticut, Indiana, Kentucky, Louisiana, Minnesota, and Washington State (Puyear, 2001).

Connecticut: The state implemented a strategic plan for technical education in 1990. In 1992 the Community-Technical Colleges of Connecticut revised its mission statement. The revision incorporated the 1990 goals to enhance and expand access to technical education through 12 comprehensive community-technical colleges (Cox, 1999).

Indiana: The Community College of Indiana was approved by the state legislature in 1999. The partnership combined Ivy Tech's technical programs with Vincennes University's liberal arts courses (Lords, 2000).

Louisiana: In July 1999 the state's 43 technical schools officially became a part of Louisiana's higher education system. Prior to state legislation, the technical institution was loosely administered by the state board of elementary and secondary education (Dyer, 1999).

Minnesota: State legislation mandated merger of the state university, community college, and technical college systems in an effort to help contain costs, increase 
efficiency, and improve student mobility and choice in public higher education (Moe, 1994; Minnesota Commission on Postsecondary Education, 1992). The bill (Chapter No. 212, H.F. No. 1856), which created a Higher Education Board governing the Community College System, the State University System, and the Technical College System, became law in 1991. The state passed a large-scale plan for restructuring public higher education in July 1995 that created a 45 -institution system. The legislation eventually led to the consolidation of 18 community colleges into 10 (Healy, 1996).

Washington: The state maintained a community college system of 29 colleges in 26 districts. In addition, the state had five vocational-technical institutes (VTIs) which operated as part of local public school districts. In 1991, legislation re-organized the VTIs under the State Board for Community and Technical Colleges. The move did not represent a merger, but all of the institutions were as a result governed under one system. The VTI districts overlap the community college districts under the new organizational governance structure (Puyear, 2001).

The six mutual growth mergers cited by Puyear (2001) represented only a small percentage of public, two-year colleges nationwide. The radical governance structure reforms, however, collectively represented a unique and significant response to higher education growth and change. Common goal elements were present in the various state legislative actions: better responsiveness, reduced duplication of services, cost containment, improved student choices with multiple entry and exit points, and increased overall efficiency. The Puyear (2001) study outlined the multiple influences that ultimately led to legislation, described the major governance structure realignments, and obtained anecdotal comments on the resulting mergers from selective legislators and 
system administrators. The study did not, however, provide ample evidence of the outcomes of such governance restructuring or whether the conditions for successful mergers were present.

The research literature on mergers offers consistent themes for success. Habeck, Kröger, and Träm (2000) suggested seven rules for successful post-merger integration: (a) vision; (b) leadership; (c) growth; (d) early wins without exaggeration; (e) accurately addressing cultural differences; (f) honest communication; and (g) proper risk management - embracing it as opposed to avoiding it. Appelbaum (2000) stated that "the most important way to execute a merger and change culture successfully is to be open and honest with employees" (p. 653) and "the role of top management is crucial in determining the eventual success of a merger" (p. 679). Swanepoel (2003) offered eight success factors for higher education mergers: (a) preparation, (b) support and stability, (c) complementary missions, (d) communication, (e) honesty, (f) leadership, (g) understanding cultural issues, and (h) visible and strong management. Although good preparation, support, good communication, etc. are vital for a merger, the mere existence of sufficient resources, good communication channels and so forth will not contribute to successful mergers, but rather to the way leaders use the available inputs and manage the process. (Swanepoel, 2003, p. 4) Jansen (2003, pp. 47-49) identified seven clear guidelines that emerged from five higher education case studies that suggested conditions under which mergers could be successful: “(a) a strong and reliable institutional leadership whose authority is respected across the various institutions concerned, including government and the two institutions targeted for a merger; (b) a strong and verifiable financial position on the part of the 
entity being merged - the stronger the entity (small or large) being merged in terms of financial resources, the greater its capacity to negotiate a favorable position for its staff, students and curriculum; (c) a strong and strategic leadership that, having accepted the broad macro-political arrangements for incorporation, then decides to deploy its energy and resources for optimal positioning of its staff, students and curriculum in the merged entity; (d) a strong and reliable student enrollment which, together with other factors, create a favorable basis for negotiations especially if the other entity has fewer students or, worse, declining numbers of students at the time of the merger discussions; (e) a strong and loyal staff complement whose commitment and participation is ensured and sustained by the institutional leadership throughout the merger process in a consistent and transparent manager; (f) a well-planned and well-timed merger implementation that proceeds at an appropriate period of time in the life-cycle of one or more of the partner institutions; (g) a strong and interventionist government that intervenes proactively, decisively, and appropriately to ensure that the merger process stays on track, especially in times where the proposed merger threatens to disintegrate."

The research on mergers unfortunately differs significantly on the time that it takes to conduct and complete the merger process. Harman and Meek. $(2002$, p. 4) stated the following:

In the literature on mergers, it is generally agreed that it can take up to ten years for the wounds to heal and for the new institution forged from previously autonomous identities to operate as a cohesive and well integrated whole. This may be one reason why it takes so long for many of the efficiencies expected of mergers to appear. The negotiations leading up to a merger can be long and 
protracted and those individuals and groups who feel that they have lost advantage because of the merger may continue their opposition long after agreements have been formalized.

Appelbaum (2000, p. 653) notes that "....five to seven years are typically needed for employees to feel truly assimilated in a merged identity." Fielden \& Markham (1997, p. 4) reported data from a higher education survey which revealed that

The typical merger took more than a year, but less than two to complete. Mergers completed in less than a year seemed to result in extremes of outcome: all those institutions who were disappointed with how the merger had turned out had taken less than a year, though there were also cases of mergers which exceeded all expectations taking less than a year.

Walker and Price $(2000$, p. 6$)$ suggested that "A period of six to nine months is ideal for implementing a merger." An analysis of higher education mergers in the U.S., Australia, and The Netherlands demonstrated that it can take up to 10 years before a situation is normalized (Goedegebuure, 1992; Millet, 1976; Mulvey, 1993).

Limited research exists on the consequences of the governance changes of twoyear colleges and vocational-technical institutions - in particular, such research is lacking with regard to the state of Kentucky which has been acknowledged as one of the most comprehensive two-year college reform efforts nationwide (Arnone, 2003).

\section{Two-Year College Reform in Kentucky}

Two-year postsecondary education in Kentucky followed a similar generational pattern to the one that evolved nationwide. Kentucky responded vigorously to the public calls for educational change. Significant reform policy changes were commonplace in 
Kentucky for the past two decades—both in primary/secondary education and most recently in postsecondary education. The radical reform efforts of concerned Kentuckians simply reflected the national sentiments held by numerous citizens across the United States.

In 1989, the Kentucky Supreme Court ordered the General Assembly to form a new, more efficient system of K-12 public schools. The existing educational system was declared unconstitutional due to uneven funding and resources available to school districts (Rose v. Council for Better Education, Inc., 1989). The landmark decision resulted in the passage of the Kentucky Education Reform Act of 1990 (KERA), considered the most comprehensive piece of state educational reform legislation in the United States. Seven years later, substantial educational reform legislation was again enacted, this time focused on Kentucky's postsecondary educational institutions. Most significantly affected were the state's public, two-year community colleges and vocational/technical institutes, both of which had a long history of serving the state's postsecondary educational needs.

A History of Two-Year Postsecondary Education in Kentucky

Two-year postsecondary education in Kentucky has a long history beginning in 1917. Historically, the state offered two-year education through two distinct types of institutions: area vocational education centers and community colleges.

\section{Vocational Education Centers}

The federal Smith-Hughes Act of 1917 provided the formal beginning of vocational education in Kentucky. The Act made available state grants that supported agriculture, home economics, and industrial educational offerings in local high schools. 
In 1938, the Kentucky General Assembly established two vocational schools: Mayo State Vocational School in Paintsville and the West Kentucky State Vocational School in Paducah. The Northern Kentucky State Vocational School was created by the Kentucky General Assembly in 1944. During the 1940s, other schools were started by local districts to take advantage of the Veteran's Training Act programs. The George-Barden Act of 1946 expanded federal support for vocational education. The National Defense Education Act of 1958 provided significant assistance to state and local school systems. The Act supported vocational education for technical occupations such as data processing and other instructional areas necessary to the national defense.

In 1962, seven local districts requested legislative action for their vocational schools to be operated by the State Board of Education: (a) Ashland Area Vocational School, Ashland, (b) Harlan Area Vocational School, Harlan, (c) Hazard Area Vocational School, Hazard, (d) Jeffersontown Area Vocational School, Jeffersontown, (e) Madisonville Area Vocational School, Madisonville, (f) Somerset Area Vocational School, Somerset, and (g) West Area Vocational School, Bowling Green.

The Manpower Development and Training Act of 1963 provided training in new and improved skills for the unemployed and underemployed. The same year, the Vocational Education Act increased federal support of vocational education, including support of residential vocational schools, vocational work study programs, and research, training, and demonstrations in vocational education. The Higher Education Facilities Act also authorized grants and loans for classrooms and laboratories in public community colleges and technical institutes. 
The Economic Opportunity Act of 1964, among numerous other areas of higher educational support, authorized federal support for work training programs to provide education and vocational training and work experience for unemployed youth. During the 1960s, additional area vocational education centers were constructed with local funds but began operations as extension centers of the state operated schools. The schools included (a) Morgan County AVEC, West Liberty, 1960, (b) Knox County AVEC, Barbourville, 1962, (c) Union County AVEC, Morganfield, 1964, (d) Garth AVEC, Floyd County, 1964, and (e) Millard AVEC, Pike County, 1965.

The area vocational education center concept in Kentucky inspired the Vocational Act of 1963. Congressman Carl D. Perkins and Kentucky vocational education leaders were instrumental in developing the Act which provided construction funds for vocational education for the first time (Kentucky Planning Association, 1979). Two key issues supported the area vocational education concept: a) vocational programs were too expensive to offer in each high school and b) only a limited number of students needed training in each occupation in each community. In 1968, the Vocational Education Amendment provided for a National Advisory Council on Vocational Education and expanded vocational education services.

During the late 1960s and early 1970s, efforts were made to provide a vocational program within 25 miles of every potential student in Kentucky. The Elizabethtown State Vocational Technical School was constructed in 1966, and a technical school was completed in Daviess County in 1971. The last area vocational education center Rowan State Vocational Technical School was constructed at Morehead in 1985. 
In 1965, the Lafayette Area Vocational School in Lexington became a state school. The following year, the Owensboro Area Vocational School transferred to state control. In 1976, the Education Amendment extended and revised the Vocational Education Act of 1963 and the Vocational Education Amendments of 1963.

During the 1970s, secondary enrollment in state-operated area vocational education centers declined, and local administrators were encouraged to enroll adults in slots previously reserved for secondary students in the area centers. The practice continued through the 1980s and 1990s and contributed to a blurring of the curriculum and the mission of the area centers.

The Carl D. Perkins Act of 1984 replaced the 1976 amendments on vocational education. In 1988, the Kentucky General Assembly created a State Board for Adult, Vocational Education and Vocational Rehabilitation. In 1990, the Kentucky General Assembly created a Cabinet for Workforce Development including a State Board for Adult and Technical Education and Department for Adult and Technical Education. The move effectively removed the state-operated vocational-technical system (Kentucky Tech) from the Kentucky Department of Education (KDE) and left responsibility for secondary vocational education curriculum responsibilities with $\mathrm{KDE}$. When the Kentucky Education Reform Act of 1990 passed, it said little about secondary vocational education. The Act created expectations for locally-operated schools but did not address the issue for state-operated secondary programs.

\section{Community Colleges}

By legislative act in 1960 (Senate Bill 102), the Kentucky General Assembly ordered the establishment of a University of Kentucky extension center in Elizabethtown. 
The Act authorized an advisory board for the extension center maintained by the University and created a study commission on the need and placement of higher learning centers in the state (Legislative Record, 1960). Through another legislative act in 1962 (House Bill 234), the Kentucky General Assembly mandated the formation of a system of two-year community colleges and placed governance responsibility with the University of Kentucky Board of Trustees. The Community College Act of 1962 authorized the establishment of two-year colleges at Prestonsburg, Hopkinsville, Somerset, and the Hazard-Blackey area as well as prioritized future community colleges as funds became available. The legislation also converted existing facilities at Ashland, Covington, Henderson, Cumberland, and Elizabethtown into the program and required local advisory boards of seven members appointed by the Governor (Legislative Record, 1962). On July 1,1964 , acting under the authorization of the 1962 legislation, the state's first community colleges opened under the umbrella of the state's flagship university (Dupont, 2000).

In 1964 the number of campuses under the new system totaled seven with an enrollment of 2,876 students. By 1986, the University of Kentucky Community College System (UKCCS) included fourteen campuses:

Ashland Community College

Elizabethtown Community College

Hazard Community College

Henderson Community College

Hopkinsville Community College

Jefferson Community College (Downtown and Southwest campuses)

Lexington Community College 


\author{
Madisonville Community College \\ Maysville Community College \\ Owensboro Community College \\ Paducah Community College \\ Prestonsburg Community College \\ Somerset Community College \\ Southeast Community College
}

Total enrollment in the University of Kentucky Community College System in 1993 reached 48,370 students (University of Kentucky Community College System Fact Book, 1998).

Two-year college reform began in Kentucky in May 1997 when Governor Paul E. Patton signed into law the Kentucky Postsecondary Education Improvement Act of 1997, also known as House Bill 1 (Kentucky Postsecondary Education Improvement Act, 1997). Kentucky's initiative was "widely recognized as one of the most far-reaching, significant state-level higher education reforms of the past quarter century in the United States" (McGuinness, 2002, p. 1). "Kentucky's revamping of its higher-education system ... has been much heralded-and copied-in other states" (Arnone, 2003, p. A43).

The "seeds for reform were planted in 1996" (Arnone, 2003, p. A43). Because of perceived duplication, apparent competition, lingering obstacles to course transfers between the two systems, and poor coordination, state policymakers began to discuss whether the Kentucky Tech System and the University of Kentucky Community College System should be merged (Smith-Mello, Blankenship, Hamm, Jr., \& Strohmaier, 1996; Commission on the Future of the UK Community College System, 1996). Kentucky 
policymakers sought a system that yielded better outcomes, provided greater legitimacy, fostered stronger external support, and offered the possibility of higher returns on public investment (Smith-Mello et al., 1996). That year the Governor's Task Force on Higher Education commissioned the National Center for Higher Education Management Systems (NCHEMS) to assess Kentucky's higher-education system and assist the panel in formulating recommendations (McGuinness, 2002). The following year, a report was issued from the nonprofit, Colorado-based, organization (National Center for Higher Education Management Systems, 1997).

The 1997 assessment painted a dismal picture. Kentucky had abysmal attendance and graduation rates at its high schools and colleges and poor transfer rates from two-year to four-year institutions, and it lacked a nationally ranked research university. The entire higher-education system was financially impoverished, particularly its community colleges and technical colleges. Internecine squabbling among regions and institutions crippled attempts at strategic cooperation to improve colleges or help Kentucky as a whole. (Arnone, 2003, p. A43) NCHEMS's analysis led to the Kentucky General Assembly enacting House Bill 1 in 1997. The Kentucky Council on Postsecondary Education (CPE), in its annual report, The Status of Kentucky Postsecondary Education: Progress Toward Reform 1998, articulated six goals to measure progress toward legislated reform for all five public colleges and universities in the Commonwealth of Kentucky:

1. A seamless, integrated system of postsecondary education strategically planned and adequately funded to enhance economic development and quality of life; 
2. A major comprehensive research institution ranked nationally in the top 20 public universities at the University of Kentucky;

3. A premier, nationally recognized metropolitan research university at the University of Louisville;

4. Regional universities, with at least one nationally recognized program of distinction, working cooperatively with other postsecondary institutions;

5. A comprehensive community and technical college system;

6. An efficient, responsive, and coordinated system of autonomous institutions that delivers educational services to citizens in quantities and of a quality that is comparable to the national average. (Kentucky Council on Postsecondary Education, 1998, p.2)

The CPE, as the coordinating agency for postsecondary education reform in Kentucky, developed five questions to measure the state's progress toward achieving the mandates of postsecondary reform:

1. Are more Kentuckians ready for postsecondary education?

2. Are more students enrolling?

3. Are more students advancing through the system?

4. Are we preparing Kentuckians for life and work?

5. Are Kentucky's communities and economy benefiting? (Kentucky Council on Postsecondary Education, 2003, p.1)

Eighteen months after the passage of the landmark legislation, CPE President, Dr. Gordon K. Davies, succinctly expressed the challenges faced by the Commonwealth and reiterated the importance of the reform efforts: 
As a state, Kentucky lags far behind others in postsecondary education achievement. Our college-going rate is substantially lower than the national average and the percentage of Kentuckians holding a bachelor's degree is just over half the national average. Even more alarming, the low level of aspiration among many Kentuckians indicates that we not only need to improve the services of our colleges and universities but also need to convince many people that advanced education is virtually a prerequisite for families seeking economic selfsufficiency and meaningful lives. (Kentucky Council on Postsecondary Education, 1998, p. 1)

$\mathrm{CPE}$ revised and refined the five accountability questions when it published its "Public Agenda for Postsecondary and Adult Education: 2005-2010." The restated questions were as follows:

1. Are more Kentuckians ready for postsecondary education?

2. Is Kentucky postsecondary education affordable for its citizens?

3. Do more Kentuckians have certificates and degrees?

4. Are college graduates prepared for life and work in Kentucky?

5. Are Kentucky's people, communities, and economy benefiting? (Kentucky Council on Postsecondary Education, 2005, p. 1)

A significant aspect of the far-reaching legislation focused on Kentucky's twoyear colleges and vocational/technical institutes and the creation of a comprehensive system. According to KRS 164.580 of the Kentucky Postsecondary Education Improvement Act of 1997, the Kentucky Community and Technical College System (KCTCS) was created to provide the following: 
1. A general two-year academic curriculum with credits transferable to two-year and four-year colleges and universities;

2. Technical and semiprofessional programs of two years or less;

3. Within a two-year college curriculum, courses in general education, including adult education, not necessarily intended for transfer nor technically oriented; and

4. Services to Kentucky's employers and the general public to provide continuing education and customized training for purposes of improving the knowledge and skills of Kentucky workers and citizens in all regions of the state. (Kentucky Postsecondary Education Improvement Act, 1997)

The Kentucky Community and Technical College System was statutorily mandated according to KRS 164.580 of the Kentucky Postsecondary Education Improvement Act of 1997 (House Bill 1) to be responsive to the needs of students and employers in all regions of the Commonwealth with accessible education and training to support the lifelong learning needs of Kentucky citizens in order to accomplish the following:

1. Increase the basic academic and literacy skills of adults through adult basic education and remedial education services;

2. Increase the technical skills and professional expertise of Kentucky workers through associate and technical degrees, diploma, and certificate programs;

3. Increase the access for students to complete the pre-baccalaureate associate degree in arts or associate degree in science for ease of transfer to four-year institutions; 
4. Enhance the relationship of credentials between secondary and postsecondary programs which permit secondary students to enter programs through early admission, advanced placement, or dual enrollment;

5. Facilitate transfers of credit between certificate, diploma, technical, and associate degree programs;

6. Develop a pool of educated citizens to support the expansion of existing business and industry and the recruitment of new business and industry;

7. Enhance the flexibility and adaptability of Kentucky workers in an everchanging and global economy through continuing education and customized training for business and industry;

8. Promote the cultural and economic well-being of the communities throughout Kentucky; and

9. Improve the quality of life for Kentucky's citizens. (Kentucky Postsecondary Education Improvement Act, 1997)

When the 1997 legislation created the Kentucky Community and Technical College System (KCTCS), a tremendous cultural shift began for the faculty, staff, and students of Kentucky's two-year, postsecondary institutions. After the enactment of House Bill 1, radical changes took place at the KCTCS campuses across the state as community and technical colleges consolidated programs, functions, and services of the state's community colleges and technical schools. From governance structure to administrative procedures to centralization of computing functions, Kentucky's two-year institutions were forever altered. Such monumental postsecondary educational change 
presented tremendous challenges for the newly created system, most notably for the employees of KCTCS.

In 1998, a planning assessment, conducted by The Clements Group, L.C. of Salt Lake City, Utah, measured attitudes of a cross-section of KCTCS personnel. The assessment focused on a variety of issues. The two major challenges most often mentioned included (a) the difference in backgrounds of KCTCS institutions and personnel and (b) the need for stability throughout the transition into a system (The Clements Group, 1998). But the whirlwind of change for the state's two-year institutions continued from momentum begun nearly a decade earlier.

In the late 1990s, the proportion of Kentucky's population with less than a high school diploma was greater than all but one of its sister states. To address the problem, state leaders set out to define a strategic agenda for Kentucky's system of postsecondary education (Kentucky Council on Postsecondary Education, 2000). "The general welfare and material well-being of citizens of the Commonwealth depend in large measure upon the development of a well-educated and highly trained workforce." (Kentucky Postsecondary Education Improvement Act, 1997)

When Governor Paul E. Patton signed the Kentucky Postsecondary Education Improvement Act (House Bill 1) into law in May 1997, the Kentucky Community and Technical College System (KCTCS) was created by legislative mandate. At its formation, KCTCS included 13 community colleges and 25 postsecondary technical schools (Kentucky Postsecondary Education Improvement Act, 1997) [see Appendix A]. KCTCS was established with a vision "to create, by the year 2020 , a comprehensive community 
and technical college system recognized as the nation's best" (Kentucky Community and Technical College System, 2001).

The 13 community colleges, formerly governed by the University of Kentucky, and the 25 postsecondary technical schools of Kentucky Tech, previously administered by the Workforce Development Cabinet of Kentucky State Government, together formed a comprehensive system of public, two-year institutions in the state. Lexington Community College remained a part of the University of Kentucky and continued to be governed by the University of Kentucky Board of Trustees (Kentucky Postsecondary Education Improvement Act, 1997). Soon after House Bill 1 created KCTCS, the original 25 vocational-technical institutes reorganized into 15 technical colleges (Kentucky Community and Technical College System, 1998).

House Bill 1 addressed a recommendation made the previous year by the Commission on the Future of the University of Kentucky Community College System that the Kentucky Executive and Legislative Policymakers "work toward a merged system of Kentucky Tech postsecondary vocational-technical schools and centers and the University of Kentucky Community College System" (Commission on the Future of the University of Kentucky Community College System, 1996, p. 4). Policymakers designed KCTCS to address the need for a "responsive and flexible system of postsecondary education to help Kentucky flourish in the early decades of the twenty-first century" (Kentucky Council on Postsecondary Education, 2000, p. 1). The resulting document, 2020 Vision: A Strategic Agenda for Kentucky's System of Postsecondary Education, championed the elevated status of Kentucky's community and technical colleges and 
KCTCS' clearly-defined role with regard to the state's other postsecondary providers (CPE, 2000).

In April 1999, the KCTCS Board of Regents approved a resolution encouraging colleges "to bring forward for approval by the President and Board of Regents community-driven proposals to consolidate functions, services, and programs to better serve students and citizens of the Commonwealth" (Board of Regents, 1999). On April 2, 2004, Governor Ernie Fletcher signed a joint resolution (HJR214) of the Kentucky General Assembly, transferring governance of Lexington Community College from the University of Kentucky to KCTCS as of July 1, 2004. The move to reunite LCC with the former UKCCS community colleges under the new KCTCS governance structure pointed to KCTCS's growing influence. The legislative attention placed on two-year colleges in Kentucky affirmed state leaders' continuing interest in the state's community and technical colleges.

A single president/CEO was named to oversee both LCC and Central Kentucky Community and Technical College. A process was immediately initiated to consolidate the programs, functions, and services of the two institutions into the sixteenth community and technical college within the Kentucky Community and Technical College System. On June 10, 2005, the KCTCS Board of Regents approved the merger of Lexington Community College and Central Kentucky Technical College into the newly formed Bluegrass Community and Technical College. Today, the sixteen comprehensive community and technical colleges that make up KCTCS include:

Ashland Community and Technical College

Big Sandy Community and Technical College 
Bluegrass Community and Technical College

Bowling Green Technical College

Elizabethtown Community and Technical College

Gateway Community and Technical College

Hazard Community and Technical College

Henderson Community College

Hopkinsville Community College

Jefferson Community and Technical College

Madisonville Community College

Maysville Community and Technical College

Owensboro Community and Technical College

Somerset Community College

Southeast Kentucky Community and Technical College

West Kentucky Community and Technical College

KCTCS consolidation efforts, with the addition of Gateway Community and Technical College in northern Kentucky and Bluegrass Community and Technical College (formerly Lexington Community College), resulted in 16 comprehensive community and technical colleges statewide [see Appendix B]. At the time, the System's merged colleges had secured or were in the process of seeking single accreditation under the Southern Association of Colleges and Schools (Council on Postsecondary Education, 2003). From the formation of KCTCS in 1997 until 2003, enrollment in all credit programs in the System increased more than 50 percent to more than 72,000 students (Kentucky Community and Technical College System, 2004; Kentucky Council on 
Postsecondary Education, 2004). In addition, the KCTCS Board of Regents approved more than 1,000 new programs in an effort to respond to the needs of employers, students, and communities (Kentucky Council on Postsecondary Education, 2003). In 2006, KCTCS maintained an annual budget of $\$ 673$ million and $\$ 228$ million in additional capital projects, 16 colleges with 65 campuses statewide, and reportedly impacting 300,000 citizens annually. The system enrolled 84,931 students $(64.4$ percent enrollment growth since 1998), offered 600 credit program options, and awarded 15,741 credentials (5,723 associate degrees, 2,310 diplomas, 7,708 certificates) - an increase of 6,231 since 2001. Additionally, KCTCS enrolled 32,379 in adult education programs, 29,589 in community education offerings and 77,650 in fire and rescue training and served 2,721 businesses and had 36,921 in workforce development (Kentucky Community and Technical College System, 2006).

One of the biggest controversies during the reform debate involved removing the community colleges from the University of Kentucky's authority and placing them and the two-year technical schools under a single administration, the Kentucky Community and Technical College System. Now, some observers consider KCTCS to be the most successful of the reforms. (Mills, 2005, p. 7) KCTCS represented a new, market-oriented, "entrepreneurial" community college model intended to respond more effectively to constituents. The state-wide, comprehensive community and technical colleges in Kentucky continued to evolve as they were publicly challenged to balance the traditional academic transfer function with the more specialized workforce training mission. The comprehensive, two-year KCTCS colleges provided accessible and affordable education and training through academic and 
technical associate degrees; diplomas and certificate programs in occupational fields; prebaccalaureate education; adult, continuing and developmental education; customized training for business and industry; and distance learning. According to Aims C. McGuinness, Jr, a consultant with the National Center for Higher Education Management System, "Creating this centralized community and technical college management is one of two changes that may have the most long-term effects." (Mills, 2005, p. 10). McGuinness had suggested nearly a decade earlier that balance would be key to a unified system's success:

If the academic model becomes dominant, the institutions may become less responsive to individuals with diverse educational foundations. If the vocational model dominates, quality may suffer. Ideally, however, a merged system would preserve and even expand opportunity for clients or customers with different educational foundations. (Smith-Mello et al., 1996, p. 71)

Although the body of literature is limited regarding faculty and administrator views of the merger of the state's community colleges and vocational/technical institutes, there is substantial research documenting existing faculty and administrator perceptual differences in a number of areas on higher educational change and beyond. A faculty/administrator chasm serves as a potential obstacle to the continued evolution of a successful entrepreneurial college concept in Kentucky. Yes, the numbers detail growth and success. But can the momentum be maintained? Does the numeric growth accurately reflect reality? Are there any internal threats that could potentially slow or derail progress toward reform? How did merger affect academic quality and rigor? The next three subsections will explore how faculty and administrators make sense of their 
environments and may provide insight on how faculty and administrators form their perceptions of the merger of Kentucky's community colleges and vocational/technical institutes: (a) personality and curricular values of faculty and administrators, (b) institutional climate and organizational functioning, and (c) faculty and administrator world views. Together the sections form the basis for a theoretical framework - the faculty/administrator chasm - that provides a foundation for the present study.

Personality Characteristics and Curricular Values of Faculty and Administrators The unique personality characteristics and curricular values of faculty and administrators contribute to their differing world views (Cardot, 1990; Garmon, 1984). Specifically, the literature revealed faculty/administrator differences in determinism (Garmon, 1984), communication predispositions and basic philosophical styles (Cardot 1990), and curricular values (Blimling, 1993; Brewer, 1995; Cross, 1980; DickersonGifford, 1990; Kuh \& Whitt, 1988; Samuelowicz \& Bain, 2001). With regard to curricular values differences, Brewer (1995) more specifically explored views of academic-vocational integration. Cross (1980) studied faculty preferences toward cognitive development and student affairs administrators' leanings toward affective development. Kuh and Whitt (1988), like Cross, compared the faculty subculture with the student affairs subculture. Dickerson-Gifford (1990) explored goal differences between student affairs administrators and academic affairs administrators. Blimling (1993) reviewed faculty and administrator curricular values differences regarding formal curriculum and co-curricular activities. Further, literature on personality and curricular values of faculty and administrators contained substantial evidence of differences with 
regard to academic freedom (Ambrose, 1988; Grubiak, 1996) and tenure (Cooper, 1982; Grubiak, 1996).

Garmon (1984) investigated whether or not faculty and administrators held significantly different world views. Specifically, the researcher examined personality traits and sought to reveal philosophical characteristics of higher education administrators and faculty members. The researcher hypothesized that educational administrators were more deterministic than faculty members.

The methodology utilized was quasi-experimental. The researcher collected data by administering a questionnaire that contained the Likert-type, Personal Report of World View (PRWV) scale (Dodd \& Garmon, 1980) and a section to gather various demographic data. Respondents' total score on the Personal Report of World View was the dependent variable. Various demographic characteristics served as the independent variables.

The authors of the PRWV scale tested an original 26-item PRWV scale in 1980 in two studies to measure reliability of the instrument using Cronbach's alpha. Study One produced a reliability coefficient of .79 for 17 of 26 items. Four factors explained $54.1 \%$ of the variance: (a) the individual's resignation to external control, (b) acceptance of predetermined control from a supreme power, (c) control by other humans, such as ancestors, relatives, and acquaintances, and (d) the possibility of human control of nature. Study Two produced a reliability coefficient of .82 for 17 of 26 items. Three factors explained $48.8 \%$ of the variance. Another independent study produced an alpha of .818 for the same four factors which accounted for $56.9 \%$ of the variance. In all, eight studies were conducted in an attempt to validate the 17 -item scale. Further work resulted in the 
development of a 50-item scale to measure world view. In 1982, the instrument was submitted to a varimax rotation factor analysis. A 28 -item scale resulted with a Cronbach's alpha of .80 .

For the study examining faculty and administrator world views, the researcher utilized the 28-item PRVW scale, based on the original 17-item scale. A test for reliability produced a Cronbach's alpha of 83.8. The researcher used a stratified random sample of $10 \%$ of the 384 institutions accredited by the Southern Association of Colleges and Schools (SACS) offering at least a bachelor's degree, yielding the names of 39 institutions. From the institutions sampled, the researcher selected a purposeful sample of faculty and administrators and mailed a total of 665 questionnaires. Individuals were selected from the highest level of administration and from faculty most removed from administrative roles. Total return rate for the mailed survey was 69 percent and yielded 331 usable surveys $(n=331)$.

The researcher employed both one-way and two-way ANOVAs for data analysis. Analysis of variance revealed significant difference between world views of educational administrators and faculty members in general $(F=4,134, p<.05)$. Faculty members displayed less deterministic world views $(M=67)$ than those of educational administrators $(M=64.2)$.

Salient findings suggested that differences in outlook on the world exist in certain higher educational subcultures. The study revealed that administrators were more deterministic than faculty in that they have less ability to control their futures than the faculty. Conversely, the world view of faculty was one of greater freedom of choice over issues that affect their future. World view influences self-concept, behavior, interpersonal 
relationships, and the person's basic understanding of education. The author suggested that improved faculty and administrator coordination may be accomplished through an increased understanding of existing philosophical differences.

An implication for the present study is that KCTCS faculty and administrators may view the merger of Kentucky's community colleges and vocational/technical institutes differently because of their basic world views. A lack of congruity among faculty and administrator perceptions of the merger may serve as a barrier to success. Another personality difference between faculty and administrators identified in the literature is communication predispositions and basic philosophical styles.

Cardot (1990) examined faculty and administrator communicator social style and world view. The researcher sought to link the constructs of communicator social style and world view by identifying personality differences among the administrators and faculty, namely communication predispositions and basic philosophical styles. The researcher attempted a replicate study on the conceptual framework outlined by Garmon (1984).

The methodology was quasi-experimental. A stratified random sample of $10 \%$ of the 351 SACS institutions granting bachelor's degrees or higher was selected. The procedure yielded a total of 35 institutions. Like Garmon (1984), the author surveyed individuals ( $n=490$ ) from the highest levels of administration and faculty most removed from administrative roles. The researcher administered the Personal Report of World View (PRWV) and the Social Impression Scale survey instruments by mail. Mailings resulted in 301 usable surveys, or a 61.4 percent return. The independent variable was position held, faculty (subdivided into four major groups) or administrator (subdivided 
into three major groups). Two dependent variables were examined, communicator social style and world view.

The researcher employed Chi Squares and ANOVAs for the majority of the statistical data analysis. The dependent and independent variables were analyzed at various levels. A $4 \times 2$ matrix was implemented to examine the relationship between the four categories of communicator social style with the two categories of classification, administrator and faculty. A two-way ANOVA was used to compare world view with four categories of social style and two categories of classification, administrator or faculty. Where appropriate, $t$-tests were used as post hoc analysis to flesh out specific differences.

Analysis of data with a $4 \times 2$ factoral design revealed a significant difference between the communicator social styles of administrators and faculty members in general (Chi Square $=31.3511, \mathrm{df}=3, p<.00001)$. A two-way ANOVA revealed a significant interaction effect between classification (administrator or faculty) with both communicator social style and world view $(F=4.18475, \mathrm{df}=3, p<.0064)$. The findings also indicated a high relationship between classification and world view in that faculty members displayed world views significantly less deterministic than those of administrators $(F=53.05, \mathrm{df}=1, p<.00001)$.

Study findings indicated that administrators and faculty members in postsecondary institutions possess communicator social styles as compared with world views that differ from each other such that personality differences between the two groups are predictable. The study's findings revealed real, predictable differences in assertiveness and responsiveness of administrators and faculty. "The higher one moves 
into administration positions, the more likely he or she is to be highly organized, thorough, systematic, and results or task oriented" (p. 86). The study results revealed contrasting faculty traits in that they "are more likely to be the risk takers, problem solvers, and empathetic catalysts for both colleagues and students" (p. 86).

An additional finding supported the Garmon (1984) work establishing world view differences among administrators and faculty. Carbot (1990) found that faculty perceived greater control over their lives, work, and employment than did administrators. Although faculty perceived a greater exercise of control, they are less tolerant of disagreements and are less willing to recognize differences in the interaction styles of others. By contrast, study results showed that administrators are more willing to adapt to those they are interacting with than are faculty.

Implications germane to the present study are that KCTCS faculty and administrators may view the merger of Kentucky's community colleges and vocational/technical institutes differently as a result of their differing communication predispositions, philosophical styles, and overall world view. A lack of congruity among faculty and administrator perceptions of the merger may serve as a barrier to its successful implementation, and the disconnect may also represent an obstacle to achieving the statewide reform goals that precipitated the merger legislation. Also present in the literature on postsecondary education faculty and administrators are differences in curricular values.

Samuelowicz and Bain (2001) investigated basic underlying assumptions, values, and beliefs about teaching and learning. The purpose of the qualitative study was to examine the belief dimensions associated with different orientations to teaching and 
learning held by university faculty. The researcher observed that although different styles of teaching and assessment depend on the educational belief systems held by faculty, not enough was known about the assumptions, values, and beliefs on which faculty base their teaching approaches.

The researchers collected data through semi-structured interviews. The researchers interviewed academics $(n=39)$ who were employed by Australian universities and represented a wide range of disciplines. Participants described their perspectives on teaching and learning (beliefs about teaching, beliefs about knowledge, beliefs about student learning, and beliefs about the links between teaching and learning). Participants also provided specific teaching situations that exemplified their perspectives. Further probing centered on the examples offered.

A three-phase grounded analysis of the data was conducted to determine the teaching and learning orientations. In the first phase, the constant comparative method was used with the interview transcripts to further establish wide-ranging orientations to teaching and learning. The transcripts were read and re-read to establish emerging categories. Two dominant faculty orientations to teaching emerged from the study, one which was teacher-centered (transmissive) and another which was learner-centered (facilitative). Seven global orientations emerged from the constant comparative analysis and were categorized under the two dominant orientations. Three sub-categories for the teacher-centered orientation were identified: (a) imparting knowledge, (b) transmitting structured knowledge, and (c) providing and facilitating understanding. Four subcategories for the learner-centered orientation were identified: (a) helping students develop expertise, (b) preventing misunderstandings, (c) negotiating understanding, and 
(d) encouraging knowledge creation. The researchers did not indicate inter-rater reliability.

In the second phase, researchers compared categories to establish implicit beliefs within each. Nine belief dimensions emerged (desired learning outcomes, expected use of knowledge, responsibility for organizing or transforming knowledge, nature of knowledge, students' existing conceptions, teacher-students interaction, control of content, professional development, and interest motivation).

Phase three consisted of coding individual transcripts on all belief dimensions to check consistency of global orientations and confirm placement in a particular category through cluster analysis. The three phases resulted in a matrix grid depicting faculty orientations to teaching and learning.

One limitation of the matrix grid summarized in the study was the difficulty in analyzing the results beyond similarities and differences among faculty orientations. To address the limitation, the researcher used two illustrative stories to provide a contextualized sense of individual faculty beliefs and practices. The two stories characterized faculty on each end of the spectrum of orientations, one faculty example represented the teaching-centered orientation and another faculty member example represented the learning-centered orientation.

The interpretive research suggested that differences do exist in underlying curricular values among faculty. According to the study findings, academics conceptualized teaching and learning differently. An implication for the present study is that KCTCS faculty and administrators may hold incongruent views of the merger of Kentucky's community colleges and vocational/technical institutes because of differing 
curricular values and basic conceptualization of teaching and learning. Since department chairs and other key college administrators such as presidents and academic deans most often come from the faculty ranks, their pre-existing differences in basic curricular values may play an important role in their views of merger. Dissimilar perceptions between faculty and administrators on the institutional merger may serve as a barrier to successful integration of the two entities. The conclusions drawn by Samuelowicz and Bain (2001) supported curricular values research of faculty and administrators conducted by Brewer (1995) which confirmed the presences of unique personality characteristics and differing curricular values of the two higher education subcultures.

Brewer (1995) investigated the attitudes and curricular values of administrators, general education faculty, and occupational faculty with respect to the integration of academic and vocational education. Specifically, the researcher studied academic and vocational education in two-year technical colleges in the Wisconsin Technical College System.

The methodology included a nine-section survey developed around eight subthemes identified in the literature: (a) capabilities of a technical college graduate, (b) technical college faculty preparation, (c) meaning of academic-vocational integration, (d) benefits of academic-vocational integration, (e) general education core curriculum, (f) current integration practices, $(\mathrm{g})$ barriers to integration, and $(\mathrm{h})$ indicators of effective integration practices. The independent variable was Job Status (administrator, general education faculty, and occupational faculty). Survey questions were Likert-scale $(1=$ not important; $5=$ essential). Various demographic characteristics served as additional independent variables. The dependent variable was respondents' rating of the questions in 
the various sub-sections. Cronbach's alpha exceeded .70 on seven of the nine sections. The Pearson Product Moment coefficient for the instrument was .70 at the .001 confidence level.

The researcher initiated a survey to 525 faculty and administrators in the Wisconsin Technical College System. The sample yielded 126 administrators, 152 general education faculty, and 225 occupational faculty $(n=503)$. The return rate was $71 \%$.

Descriptive statistics were utilized for calculating means, standard deviations, standard error, and variance by job status and job category. Analysis of variance (ANOVA) was employed to compare mean scores for the eight questions. Post-hoc analysis (Tukey) was used to determine statistically significant differences among the three employee groups: administrators, general education faculty, and occupational faculty. Multiple regression analysis was used to resolve questions relating to capabilities of graduates and the importance of core outcomes.

Researcher findings suggested that all three employee groups (administrators, general education faculty, and occupational faculty) differed significantly in their conceptions of the benefits of academic-vocational integration. Eight of ten items in the section showed a significant difference at the .05 level or higher: (a) integration will benefit all students (general education faculty $M=4.13$, occupational faculty $M=3.98$, administrator $M=4.57, p<.0000$ ), (b) integration will benefit special needs and at-risk students (general education faculty $M=3.80$, occupational faculty $M=3.65$, administrator $M=4.40, p<.0000$ ), (c) integration will better prepare students for the workforce (general education faculty $M=4.41$, occupational faculty $M=4.33$, 
administrator $M=4.72, p<.0001$ ), (d) integration will foster increased collaboration between general education and occupational faculty (general education faculty $M=4.08$, occupational faculty $M=3.85$, administrator $M=4.53, p<.0000$ ), (e) integration will help students understand general education concepts better (general education faculty $M$ $=4.19$, occupational faculty $M=3.96$, administrator $M=4.46, p<.0000$ ), (f) integration will help students understand occupational concepts better (general education faculty $M=$ 3.98, occupational faculty $M=3.81$, administrator $M=4.27, p<.0002$ ), (g) integration will create more coherence in the entire curriculum (general education faculty $M=4.17$, occupational faculty $M=4.08$, administrator $M=4.48, p<.0012$ ), (h) integration will contribute to the modification of teaching methods of general education and occupational faculty (general education faculty $M=3.98$, occupational faculty $M=3.76$, administrator $M=4.20, p<.0021)$. Only mean scores and standard deviations were provided by the researcher in the report.

In all of the cases, administrators rated the benefits of integration higher than did the other two groups. The study results further showed that occupational faculty rated the importance of academic skills lowest of the three employee groups. Administrators identified the benefits of academic/vocational integration highest in importance. Of significance, the groups named several barriers to integration. Faculty cited lack of time for curriculum revision as an obstacle while administrators noted lack of time for collaboration and faculty resistance to change. As a whole, the study revealed that the various groups across the system did not clearly understand the meaning of academicvocational integration. 
An implication germane to the present study is that KCTCS administrators may maintain a more positive view of the merger of Kentucky's community colleges and vocational/technical institutes than KCTCS faculty. The previously described empirical study outlined differing faculty and administrator curricular values, specifically the benefits of academic-vocational integration according to employee groups. The central theme of Kentucky's public, two-year college reforms is the integration of academic and vocational education and, ultimately, organizational merger. A lack of congruity among faculty and administrator perceptions of the academic-vocational merger may serve as a barrier to success. The study provided additional evidence of unique personality characteristics and curricular values of faculty and administrators. Other research attributes the differing personality characteristics and curricular values of faculty and administrators to the presence of subcultures within postsecondary education institutions [Blimling, 1993; Cross, 1980; Dickerson-Gifford, 1990; Kuh \& Whitt, 1988].

Cross (1980) identified the chasm between the two subcultures as a dualism that separates cognitive development from affective development. The author suggested that the faculty maintain responsibility for the cognitive development, while student affairs administrators assume responsibility for affective development. According to Cross (1980), the dualism generates conflict between the two subcultures.

Kuh and Whitt (1988, p. 93) echoed the points outlined by Cross (1980) and described the notion of subcultures at colleges and universities which is important for understanding the campus environment:

The cultures of colleges and universities are subdivided, complicated, and enriched by the development of subcultures around common roles, tasks, and 
problems. Groups of students, faculty, and administrators develop common beliefs, values, solutions, and norms as well as systems of symbols, rituals, and socialization processes to maintain their groups.

"Cultural perspectives can be penetrating lenses for examining and understanding events in an institution and the behavior of faculty, students, and administrators" (p. 109). According to the authors, two significant groups are the faculty subculture and the student affairs subculture. Each maintains a different perspective on the purpose of education and the academic process. Faculty and student administrators receive very different job preparation training, have unique interests and duties, and interact with one another differently which leads to significant perceptual differences. Specifically, differences center on commitments, priorities, values, and assumptions. "Administrators may encounter difficulty in mobilizing faculty and students to pursue goals that conflict with the institution's culture" (p. 99). "The presence of subcultures with sharply contrasting views works against a feeling of community, dilutes the potency of the learning experience for students, and strains structures of campus governance" (p. 98).

Dickerson-Gifford (1990) examined institutional goal differences between student affairs administrators and academic administrators. The purpose of the study was to compare institutional values, practices, and beliefs between the two subcultures within higher education. The researcher hypothesized that academic administrators would regard a campus climate fostering academic freedom, democratic governance, and research. The researcher anticipated that student affairs administrators would conversely value offcampus learning experiences and individual development. 
The population for the study included student affairs administrators and academic affairs administrators at the University of Louisville, Louisville, Kentucky. The researcher selected a quasi-experimental methodology utilizing an existing survey instrument.

For quantitative data collection, the researcher administered the Educational Testing Service (ETS) Institutional Goals Inventory which provided data on 20 different goal areas. The instrument consisted of 90 statements of possible institutional goals, and respondents were asked to rate each statement on a Likert-type 5-point scale. Data analysis involved two-tailed $t$-tests to determine differences in the values of the subcultures.

Research findings indicated that, similar to faculty, multiple subcultures exist within the larger umbrella of administration. The subcultures contained distinct sets of values, actions, and beliefs. Significant differences were identified in the values related to individual personal development, off-campus learning, social egalitarianism, vocational preparation, meeting local needs, humanism/altruism, and providing a broad program of extracurricular activities. As hypothesized, student affairs administrators placed a higher value on off-campus learning experiences than academic administrators. Academic administrators placed a higher value on the university's research emphasis.

Blimling (1993) addressed the context of faculty/administrator conflict in the Academy and conducted an educational dialectic on faculty and student affairs educators. The author suggested that faculty and student affairs administrators see education from quite different perspectives. Most faculty view the formal curriculum as the primary reason that students enroll at a university, and many do not regard co-curricular activities 
as educational. Faculty tend to describe student affairs administrators as "soft on students" and "having ill-defined responsibilities" (p. 6).

Student affairs educators view their role as contributing to the education of students in much the same way that faculty do. They see the co-curriculum as a set of meaningful educational experiences that help students grow and develop psychosocially and cognitively.... Often, student affairs educators view faculty as uncaring and distant from the student experience. They see faculty consumed by narrow research interests and the drive to publish. Stories abound about faculty who do not keep office hours, who are too busy to talk to students, and who are away from campus on consulting jobs or engaged in activities unrelated to student learning. ... Despite the pursuit of academic excellence, student affairs educators often see the relationship between students and faculty as impersonal, cold, and sometimes hostile. (p. 8)

An implication of the research by Cross (1980), Kuh and Whitt (1988), Dickerson-Gifford (1990), and Blimling (1993) for the present study is that the differing cultural perspectives of faculty and administrators subcultures may contribute to the unique personality characteristics and curricular values that they exhibit. Ultimately such differences may impact faculty and administrator views of merger. The two groups may have unique views of Kentucky's postsecondary education reform initiatives and the resulting merger of the state's community colleges and vocational/technical institutes. Such differences between faculty and administrator may present an obstacle to mobilizing the two groups toward common goals and may exacerbate the strain of the "merged" campus governance structure. Differing personality characteristics and 
curricular values of faculty and administrators is also clearly evident with regard to views of academic freedom and tenure.

Grubiak (1996) explored the extent to which administrators and faculty in Washington State community colleges differed in their opinions of academic freedom and tenure. According to the researcher, academic freedom and tenure mean different things to different people. The researcher hypothesized, based on role theory, that faculty and administrators held differing beliefs about academic freedom and tenure.

Role theory provides a useful construct for analyzing differences between groups that exhibit differing roles within an organization (Grubiak, 1996). Role theory suggests that such groups may be expected to behave differently from one another and maintain unique perceptions of their environments. Role theory, which centers on human social expectations, identities, and behaviors, originated in the late 1920s and early 1930s. Over that relatively brief time period, the concept arose coincidentally in a number of academic disciplines. As a result, role theory links social psychology, sociology, and anthropology. Biddle (1986, p. 68) defined role theory the following way:

Role theory concerns one of the most important characteristics of social behavior - the fact that human beings behave in ways that are different and predictable depending on their respective social identities and the situation. As the term role suggests, the theory began life as a theatrical metaphor. If performances in the theater were differentiated and predictable because actors were constrained to perform "parts" for which "scripts" were written, then it seemed reasonable to believe that social behaviors in other contexts were also associated with parts and scripts understood by social actors. 
The methodology selected was a self-administered mail survey of faculty and administrators in community colleges in Washington State to identify attitudes and opinions toward academic freedom and tenure. The questionnaire contained 5-point Likert-type questions $(-2=$ strongly disagree; +2 strongly agree $)$. A pre-test of the instrument was conducted utilizing 22 participants. A confidence interval was set at the $p$ $<.05$ level of significance. The dependent variable was Level of Agreement or Disagreement about Academic Freedom or Tenure. The independent variable was Respondent Status, Faculty or Administrator. A systematic sample with a random start was employed to determine which faculty in the population $(N=2,833)$ and which administrators in the population $(N=480)$ were to be mailed survey instruments. The appropriate sample size was mathematically calculated for faculty $(n=338)$ and for administrators $(n=214)$. A total of 1,224 surveys were mailed. Of the total, 480 were mailed to administrators, and 744 were mailed to faculty. A total of 914 surveys were returning yielding a return rate of $74.7 \%$.

Data analysis included factor analysis and a three-way ANOVA. Means and standard deviations were reported for each factor. The factor analysis identified nine factors related to academic freedom and tenure: (a) Importance and Impact, (b) Understandability, (c) Professional Autonomy, (d) Classroom Autonomy, (e) Dismissal for Wrongful Behavior, (f) General Freedom of Speech, (g) Dismissal for Cause, (h) Student Rights, and (i) Academic Speech. Statistically significant differences between the factor means of administrators and faculty were discovered for four of the nine factors: Importance and Impact $(p=<.001)$; Professional Autonomy $(p=<.001)$; Classroom Autonomy $(p=.001)$; and General Freedom of Speech $(p=.031)$. The results suggested 
that faculty members believe academic freedom and tenure were important principles while administrators did not believe they are. Faculty members believe they have rights that prevent administrators from controlling curriculum, grades, and off-campus teaching and consultative activities while administrators do not believe faculty members possess these rights. Faculty members believe they have rights that prevent administrators from controlling teaching methods and grading policies while administrators do not believe faculty members have these rights. The study confirmed Biddle's (1979) hypothesis that role expectations are unlikely to be held consensually throughout a complex social system and that there may be overlapping fields of consensus along with dissensus or even conflicting role expectation.

An implication for the present study is the high likelihood of differing role expectations of faculty and administrators employed by such a complex social system as KCTCS. In addition, the lack of agreement on such an important issue as academic freedom and tenure may suggest the potential for differing perceptions of institutional merger. Role theory suggests that such groups may be expected to behave differently from one another and maintain unique perceptions of their environments. Thus, it may be hypothesized, that KCTCS faculty and administrators, because they serve unique roles within colleges and universities, will respond differently from one another when surveyed about their perceptions of the merger of Kentucky's community colleges and vocational/technical institutes. Differences of opinion about merger may present a challenge to its successful implementation.

Cooper (1982) studied attitudes toward tenure by administrators and faculty in the two-year and four-year institutions of the state of Georgia. The researcher desired to 
understand more about the controversial concept which historically garnered strong loyalties and intense criticism.

The researcher gathered data using a 31-item questionnaire constructed specifically for the study. The instrument was employed to determine whether respondents were positively or negatively disposed toward tenure. The instrument contained Likert-type questions $(1=$ strongly disagree, $5=$ strongly agree $)$. Ten questionnaire items, all worded positively for tenure, were grouped to obtain a Tenure Attitude Index (TAI). Group means from the analysis were the basis for the TAI scale. Respondents' attitudes toward tenure was the dependent variable. Respondent status academic dean, tenured faculty, or non-tenured faculty - was the independent variable. A pilot study was conducted at Dalton Junior College to enhance the instrument and improve reliability.

The population for the study was the 55 two-year and four-year institutions of higher education in Georgia with the exceptions of the universities. All institutions were accredited by the Southern Association of Colleges and Schools (SACS). Five questionnaires were mailed to the academic deans of each institution for completing and distributing to four faculty members. The overall response rate was $89.1 \%$ (49 of 55 institutions).

The researcher computed response means for each question item and employed Analysis of Variance to detect significant differences between groups at the $(p<.05)$ level of significance. Comparisons were made between (a) deans, tenured faculty, and non-tenured faculty; (b) two-year institutions and four-year institutions; and (c) public and private institutions. The $F$ statistic was used to establish ranges for the level of 
support for tenure: (a) $1-2.50$ strongly disagree, (b) $2.51-3.50$ disagree, (c) $3.51-3.80$ moderately or slightly disagree, (d) $3.81-4.20$ neutral or no opinion, (e) $4.21-4.50$ moderately or slightly agree, (f) $4.51-5.50$ agree, and (g) $5.51-7.00$ strongly agree.

Findings indicated that the best predictor of tenure attitude was institutional role. Deans as administrators were less favorable toward tenure than faculty. The opinion of academic deans was found to be significantly different from faculty based on the Tenure Attitude Index (TAI) $(F=6.41, p<.01)$ : deans $(M=3.99$, neutral), tenured faculty ( $M=$ 4.75 , positive), and non-tenured faculty ( $M=4.42$, positive). Significant differences between faculty and administrators were found with regard to Survey Item $31-$ Overall, the strengths of tenure outweigh the weaknesses $(F=4.72, p<.05)$. Means were calculated for each group: deans ( $M=4.44$, slightly positive), tenured faculty ( $M=5.51$, strongly positive), and non-tenured faculty ( $M=4.86$, positive).

Implications for the present study correspond with earlier mentioned studies on faculty and administration personality and curricular values. The lack of congruity on such a key topic as tenure suggests the potential for differing perceptions of the merger of Kentucky's community colleges and technical/vocational institutes.

Ambrose (1988) examined faculty members' and administrators' attitudes toward, and perceptions of, academic freedom. The author pointed to an abundance of studies and scholarly articles on academic freedom as defined by the courts. However, the researcher noted that little was known about faculty members' and administrators' definitions of, and attitudes toward, the concept of academic freedom.

Using a general taxonomy of court cases in the literature, the study attempted to determine if differences in attitudes and definitions existed between faculty and 
administrators toward academic freedom and its associated concepts. Numerous challenges and conflicts confronted by faculty and administrators involve the related concepts of tenure, due process, employment policies and procedures, teaching and classroom discussions, and the appropriateness of certain research and scholarly activities.

The researcher employed a cross-sectional ex post facto design involving a survey of academic administrators $(N=123)$, department chairs $(N=232)$, and full-time faculty members $(N=2,130)$ in the 15 senior colleges in The University System of Georgia. The research population for the study included all academic administrators and department chairs. Additionally, a simple random sample of one-third of the full-time teaching faculty members $(n=700)$ was used for the study.

A survey questionnaire was developed to assess faculty members' and administrators' definitions of, and attitudes toward, academic freedom. The questionnaire included three sections: (a) demographic and background information, (b) a 12-item semantic differential scale, using a 7-point rating scale for each of the 12 bi-polar adjectives (Snider \& Osgood, 1969) to measure respondents' attitudes toward academic freedom, and (c) 16 short summaries of actual court cases whereby respondents were asked if they thought academic freedom was an issue in each case. For the court cases assessment, respondents responded on a 4-point Likert-type scale $(1=$ clearly not an issue, $4=$ clearly an issue). Also, faculty members specializing in the law and higher education judged the selected cases for the questionnaire to be representative of the five broad areas protected by the courts under the concept of academic freedom. 
Principle component analyses were conducted on both the 12-item semantic differential scale to determine underlying attitudes toward the concept of academic freedom and on the 16 case studies to ascertain if the underlying factors were consistent with the general taxonomy of cases found in the academic freedom literature. Factors with eigenvalues $>1.0$ were subjected to varimax rotation (Kaiser, 1959). An analysis of variance (ANOVA) was performed on the factor scale scores for both the semantic differential and the 16 case study factors. Researchers utilized ANOVA to determine the existence of statistically significant differences among faculty members, department chairs, and administrators concerning their attitudes toward, and definitions of, academic freedom.

The analyses yielded two factors with eigenvalues $>1.0$ : Factor I "Goodness/Merit" and Factor II "Scope/Profundity." The factors measured the merit of the concept of academic freedom and its depth and breadth within contemporary higher education, respectively. One-way analysis of variance (ANOVA) revealed no statistically significant differences among faculty members, department chairs, or administrators in terms of Factor I or Factor II $(p<.05)$.

The factor analysis of the 16 court cases yielded five factors: academic personnel decisions, freedom of expression, rights of instruction, research information disclosure, and unnamed. The analysis of variance indicated statistically significant differences exist among the three groups on three of the five underlying factors at the $(p<.05)$ level: academic personnel decisions $(p<.001)$, freedom of expression $(p<.05)$, and rights of instruction $(p<.01)$. The Scheffé method and Tukey's procedure were used where 
significant overall differences among the groups existed. The post hoc tests determined which specific pairs differed as to the meaning of academic freedom.

In terms of "academic personnel decisions" (decisions related to outside income, faculty transfers, leaves of absence, and collective bargaining), the study results showed that administrators and department chairs defined academic freedom differently $(F=$ $3.01, p<.05$ ). Due to the conservative nature of the Scheffé post hoc test, the direction of the differences among the three groups on "freedom of expression" (use of profanity in the classroom, faculty participation in protest marches, release of scientific data, and the distribution of political materials on campus) could not be determined. A more liberal method, Tukey's procedure, was used to determine that department chairs appear to differ from faculty on case factors dealing with the "freedom of expression" at the $(p<.10)$ level.

Finally, administrators seem to differ with faculty and department chairs on questions dealing with the "rights of instruction" (contents of lecture discussions, faculty's concentration on a particular field of study, and specific pedagogical attitudes) at the $(p<.05)$ level.

Statistical analysis showed that administrators, department chairs, and faculty share a common, elevated opinion of academic freedom. However, differences exist in terms of the scope of academic freedom. The potential for conflict exists on campus due to revealed differences in the personal definitions of academic freedom in the areas of personnel decisions, freedom of expression, and the rights of instruction.

Significant differences exist between what the respondents felt about the concept and how they would apply academic freedom to specific circumstances on 
campus... The differences among faculty members, department chairs, and administrators concerning the range or scope of academic freedom within specific circumstances may be attributed more to role behavior or role responsibilities than to the effects of an academic or administrative culture within their colleges. (Ambrose, 1989, pp. 91-92)

Like earlier-cited studies of academic freedom and tenure, the research suggests that faculty and administrators maintain differing roles and often have contrasting perceptions. An implication for the present study is that KCTCS faculty and administrators may hold dissimilar perceptions of the merger of Kentucky's community colleges and vocational/technical institutes.

Implications of the studies in this section are that faculty and administrators differ significantly in their personality characteristics and curricular values which contribute to their varying world views (Cardot 1990; Garmon, 1984). The literature reveals faculty/administrator differences in determinism (Garmon, 1984), communication predispositions and basic philosophical styles (Cardot 1990), curricular values (Blimling, 1993; Brewer, 1995; Cross, 1980; Dickerson-Gifford, 1990; Kuh \& Whitt, 1988; Samuelowicz \& Bain, 2001) and differences with regard to academic freedom (Ambrose, 1988; Grubiak, 1996) and tenure (Cooper, 1982; Grubiak, 1996). The studies described in this section are germane to the present study of KCTCS faculty and administrator perceptions of the merger of Kentucky's community colleges and vocational/technical institutes. A comprehensive analysis of higher education research on faculty and administrators also revealed that faculty and administrators maintained differing views of 
institutional climate and organizational functioning which may contribute perception differences regarding merger.

Institutional Climate and Organizational Functioning

Organizational climate has served as a significant construct in organizational research for many years (Field \& Abelson, 1982; Joyce \& Slocum, 1979, 1982; Litwin \& Stringer, 1966). Differences in faculty and administrator perceptions of institutional climate and organizational functioning contribute to their differing world views. Specifically, the literature revealed that faculty possess contrasting cognitive models of how their institutions operate (Hartnett \& Centra, 1974; Peterson \& White, 1992), perceptions of the role of department chairpersons and other role dissonance factors (Cohen, Bleha, \& Olswang, 1981), perceptions of institutional/organizational climate (Blackburn, Lawrence and Associates, 1990; Cardozier, 1984; Moran \& Vokwein, 1988; Warburton, 1989), administrative supportiveness (Blackburn et al., 1990), response to job strains and job stress (Blackburn, Horowitz, Edington \& Kloss, 1986), job satisfaction (Davis \& Chamberlin, 1996), administrative supportiveness (Blackburn et al., 1990), perceptions of university goals and which groups held positions of power (Gross \& Grambsch, 1968; Hartnett \& Centra, 1974), academic purpose and teaching-learning performance (Cardozier, 1984), institutional functioning (Hartnett \& Centra, 1974), behaviors and distinct group tasks (Bare, 1986), external collaborative relationships (Campbell \& Slaughter, 1999), and faculty performance evaluation process (McDonnell, 1986).

As the public increasingly demands more effective and responsive postsecondary institutions and rapid institutional change ensues, efforts must be made to assure a 
positive campus climate. The cultural health of an organization significantly impacts institutional effectiveness (Alfred \& Kreider, 1991). Stern (1970) described the interrelationship among the concepts of psychological climate, organizational climate, and climate discrepancy as the following:

There is a point at which this private world (psychological climate) merges with that of others: people who share a common ideology also tend to share common interpretations of the events in which they participate. This suggests a further distinction: between the truly idiosyncratic private beta press (climate discrepancy) and the mutually shared consensual beta press (organizational climate). (p. 6)

Tierney (1988) observed that "a central goal of understanding organizational culture is to minimize the occurrence and consequences of cultural conflict and help foster the development of shared goals" (p. 5). The researcher noted the importance of understanding organizations in order to effectively respond to issues confronting higher education:

Our lack of understanding about the role of organizational culture in improving management and institutional performance inhibits our ability to address the challenges that face higher education. As these challenges mount, our need to understand organizational culture only intensifies. (p. 4)

One tool available to assist in the understanding of human behavior and potential cultural conflict is role theory. Role theory offers a valuable model for exploring anticipated differences between faculty and administration (Grubiak, 1996). Research by Biddle $(1979,1986)$ provides a useful theoretical framework for the present study. Role 
theory states that individuals behave in ways that are predictable according to their respective social identities and the situation.

Tichy (1983) observed that different constituent groups in an organization, in addition to possessing dissimilar views, might hold conceptually different implicit organizational models of how their institutions function. Peterson and White (1992) utilized Tichy's observations as a basis for a study of faculty and administrator perceptual differences. The researchers examined how faculty and administrators differ in their perceptions: (a) whether the perceptual differences are affected by institutional type and (b) to what extent faculty and administrators held differing implicit models of their institutions.

The researchers pointed out that if faculty and administrators held contrasting cognitive models of how their institutions are operating, an assumption might be made that different variables influence important dependent variables. The authors stated, "Their [faculty and administrator] disagreements are not just in the relative perceptions of organizational variables but in what variables are most influential in effecting a key variable" (p. 178).

The authors based their research on a conceptual framework of "faculty and administrative perceptions of the organizational and administrative environment for undergraduate teaching and learning on their campuses" (p. 180). For the study, the researchers selected three community colleges, three private liberal arts colleges, and four comprehensive universities. The study conducted at the National Center for Research to Improve Postsecondary Teaching and Learning (NCRIPTAL), examined the Organizational and Administrative Context for Teaching and Learning. 
An earlier national survey of "Academic Management Practices" sent to 2300 postsecondary institutions yielded 1,053 respondents. From the respondents $(N=1,053)$, the researcher selected institutions that reported diverse academic management practices and college-wide efforts to improve undergraduate education $(n=10)$.

Data utilized in the study were drawn from a survey instrument, the Organizational Climate for Teaching and Learning (OCTL), developed at NCRIPTAL. The survey was administered to faculty and administrators at the 10 institutions. The overall response rate was 50\% yielding 1,123 faculty responses and 381 administrator responses $(n=1,504)$.

The Organizational Climate Survey instrument consisted of 164 items in nine sections. Four indices of Organizational Culture and 14 discrete items measuring Academic Purpose, Academic Governance Style, and Educational Change were used to measure organizational culture. The measurements were based on a conceptual framwork and not on factor analysis. Factor analysis with varimax rotation was used to identify 20 Organizational and Administrative Climate and 4 Faculty Motivational factors for the study. The researcher conducted statistical analyses using SPSS.

The researcher used ipsative measures to quantitatively assess Academic Purpose and Institutional Culture. Study participants distributed 100 points over four or five response items measuring Academic Purpose, Organizational Culture, Academic Governance Style, and Educational Change Orientation. The authors suggested that the ipsative measures provided a better understanding of the degree of strongly held beliefs and personal values than a simple Likert-type scale. 
A 5-point Likert-type scale was, however, used to measure Organizational and Administrative Climate. Respondents reported their perceptions of the "institution's emphasis on policies, practices or processes supporting undergraduate education" (p. 186). Indices $(1=$ None, $5=$ Very Strong $)$ included measures of Academic Management Climate, Academic Innovation, Academic Workplace, Administrative Support, and Resource Availability.

Finally, a Likert-format scale was also used to measure Faculty Motivational Climate. Respondents reported their perceptions of their peers' "satisfaction with and commitment to undergraduate education at their institutions" (p. 188). Four indices measured Personal and Faculty Colleague Satisfaction with Undergraduate Education and Personal and Faculty Colleague Commitment to Undergraduate Education.

The researchers used analysis of variance (ANOVA) to identify patterns of difference in faculty and administrator perceptions and among institutional types for all respondents. Additional analysis compared faculty/administrators within institutional type: community college, liberal arts college, and comprehensive university. The analysis of variance by institutional type revealed substantial diversity in the perceptions of community college, liberal arts college, and comprehensive university respondents on the Academic Purpose and Institutional Culture, Organizational and Administrative Climate, and Faculty Motivational indices. Significant differences at the .05 level occurred on 34 of the 40 indices. The analysis of variance between faculty and administrator respondents revealed significant difference at the .05 level on 28 of the 40 indices. Faculty and administrators differed on only 7 of 18 indices of Academic Purpose and Institutional Culture but on all 20 of the Organizational and Administrative Climate indices. 
A clear theme emerged when the researchers analyzed faculty and administrator differences by institutional type. Community college faculty and administrators disagreed on 28 of the 40 indices. Community college faculty and administrators disagreed on 9 of 18 measures of Academic Purpose and Organizational Culture and on 18 of 20 measures of the Organizational and Administrative Climate. Overall, community college faculty and administrators disagreed more than liberal arts colleges and comprehensive universities both on Academic Purpose and Institutional Culture and on Organizational and Administrative Climate.

In summary, the study yielded significant contrast in faculty and administrator perceptions which may provide insight on potentially differing faculty and administrator perceptions of the merger of Kentucky's community colleges and vocational/technical institutes. The study result led the researchers to conclude that faculty and administrators consistently differed in their perceptions of academic purposes and institutional culture, of the organizational and administrative climate, and of the faculty motivational climate for undergraduate education. The study further revealed significant perceptual differences according to institutional type. Faculty and administrator differences were more evident in the community colleges and comprehensive universities than in the liberal arts colleges. However, no research comparisons were made with postsecondary technical institutions.

Cohen, Bleha, \& Olswang (1981) examined the congruency among administrators, chairmen, and faculty perceptions of the role of an academic unit chairman in the structure and function of governance at a single community college (Green River Community College in the Pacific Northwest). The researchers collected 
data through mailed survey questionnaires. Subjects were surveyed using a modified, 8point, Likert-type continuum rating scale [based on Richardson (1972)] $(1=$ extremely authoritative, $8=$ participative $)$. The subject sample $(n=55)$ consisted of 15 central administrators, 11 division chairpersons, and 29 faculty members, all representing fulltime employees of the college.

The researchers used $t$-tests and ANOVAs to determine if there were any statistically significant differences among the administrator, chairperson, and faculty perceptions of the role of the chairperson in the college's organizational structure. The results were evaluated at the .05 level of significance. The research design also included one-way analysis of variance (ANOVA) and Scheffé tests to determine if length of time in current position [independent variable - length of time in position (0-5 years, 5-10 years, 10-15 years) / dependent variable - perception rating] was related to participants' perceptions of the role of the chairperson in the college's organizational structure.

The $t$-tests were used to examine the existence of dissonance among the administrator, chairperson, and faculty perceptions, provided evidence that perceptual differences do exist at statistically significant levels. The results remained consistent with other studies evidencing perceptual role dissonance among various college personnel. The study confirmed one of the bases for such dissonance, time in position. The fewer the number of years respondents had in the position, the more likely the positive interpretation and perception. Conversely, the more years in position for the respondent, the more skeptical and negative the responses: (a) perception of how well division chairs understand the problems faced by their divisions: Group $1(0-5$ years) $M=6.15, p<.05$; Group 2 (5-10 years) $M=6.29, p<.05$; Group 3 (10-15 years) $M=5.5, p<.05$, (b) 
perception of division chair being involved in decisions related to their work: Group 1 ( 0 5 years) $M=5.73, p<.05$; Group $2(5-10$ years) $M=5.26, p<.05$; Group 3 ( $10-15$ years) $M=4.41, p<.05$, and (c) perception of teamwork: Group $1(0-5$ years) $M=5.42, p<.05$; Group 2 (5-10 years) $M=4.88, p<.05$; Group 3 ( $10-15$ years) $M=4.12, p<.05$.

The study suggested that it is important to determine the existence of perceptual role dissonance and factors causing the dissonance in order to correct misconceptions and improve administrative operations. An implication for the present study is the potential origin of faculty and administrator perceptual role dissonances. The existence of such dissonance is germane to a study comparing faculty and administration perceptions of the merger of Kentucky's community colleges and vocational/technical institutes. Faculty and administrator time in position may serve as a predictor variable for how faculty and administrators view the merger.

Moran and Volkwein (1988) investigated differences in the perception of institutional climate with regard to various subgroups. According to the researchers, major questions remained unresolved concerning organizational climate despite the existence of a considerable body of research. The authors desired to determine whether organizational climate primarily characterized organizations as a whole or small subgroups within organizations. The study compared perceptions of organizations within campuses, looked at campus differences among positive climates and negative climates, and examined the effects of work group, organizational role, and length of service.

The methodology for the study was causal-comparative. The sample included board members, presidents, administrators, faculty, staff, and students. The researchers 
used ANOVA to test differences among variables of organization, role, length of service, and work groups.

The authors utilized existing data obtained from the Higher Education Management Institutes' (HEMI) data bank. HEMI formed as an organizational product of the American Council on Education (ACE). A sample of nine, four-year public postsecondary institutions was drawn from the HEMI database $(n=2,937)$. The database contained results of a University of Michigan survey instrument that had been used to determine attitudes toward and perceptions of a large number of institutions. The HEMI questionnaire section on organizational climate was extracted from the larger questionnaire. The evaluation instrument contained 36 Likert-format items related to organizational climate dimensions.

The study provided a number of insights. First, the researchers determined that faculty tended to perceive the institutional climate more negatively than administrators do. They suggested that perceptual variance may be due, in part, to differing needs and expectations of faculty and administrators. For instance, the researchers pointed out that administrators remain more isolated from routine problems and frustrations and maintain less frequent contact with faculty and students. The result tended to be a more optimistic outlook of the world than faculty. The researchers concluded that role indeed influences organizational climate. Second, the study identified that faculty employed at campuses possessing more positive climates reported greater goal clarity and performance standards. And last, the study results suggested that climate does have relevance in distinguishing campuses from one another. However, subunits accounted for the largest proportion of variance. 
The researchers suggested that further research is needed to determine if administrators' perceptions of climate are more positive than those of faculty under a wide variety of conditions on a diverse number of campuses. The authors did conclude that faculty perceive organizational climate more negatively than administrators, and the perceptions of departmental chairs tended to be more similar to those of administrators.

Warburton (1989) investigated the topic of communication specifically between faculty and administration within the college/university context. The author noted that the literature contained some analysis in the area but commented that the research was less than extensive.

The researcher discovered a "multiplicity of factors related to facultyadministration relations" (p. 5). One such factor revolved around the difficulty of identifying the locus of leadership on campus because "some aspects of leadership would appear to be in the administrative domain, but other aspects are more readily associated with the faculty" (p. 5). The investigator concluded that significant differences existed in faculty and administrator perceptions of organizational climate. Faculty perceive the climate more negatively than administrators. He noted that social interaction tends to be increasingly written and formal as the distance of the communication chain between faculty and administrators lengthens. Consequently, a macro versus micro perspective between the two groups creates an ever-widening gap. He suggests that administrators maintain a more macroscopic view of their institutions and concern themselves most often with the formal structure of the organization. Dissimilarly, faculty do not face the general concerns of the institutions as frequently as do administrators. As a result, they are less concerned with the macroscopic view of the institution and generally maintain a 
micro perspective. The mere existence of the differences does necessarily lead to difficult faculty-administrator relations, but the "presence of ambiguous jurisdictions and unclear mutual expectations may contribute to problems" (p. 7).

Birnbaum (1989, p. 7) pointed out that in today's increasingly complex organizations administrators tend to remain separated from the rest of the organization. Consequently, administrators and faculty form "separated and isolated conclaves in which they are likely to communicate only with people similar to themselves." He further suggested that administrators "come to be seen by the faculty as ever more remote from the central academic concerns that define the institution" while "faculty in turn come to be seen by the administration as self-interested, unconcerned with controlling costs, or unwilling to respond to legitimate requests for accountability" (p.7). It is therefore not surprising that faculty and administrators often hold opposing perceptions of one another.

Blackburn, Lawrence, and Associates (1990) studied faculty and administrator views of institutional organization on several dimensions. Using a representative national survey of faculty and administrators, the researchers identified consistent differences between faculty and administrator views of organizational climate, academic workplace, and administrative supportiveness.

Blackburn, Horowitz, Edington, and Kloss (1986) examined university faculty and administrator responses to job strains. Specifically, the researchers investigated the relationship of job stress, job strain, moderating variables, and quality of life (QOL) indicators. The researchers conducted a quantitative study utilizing descriptive statistics and correlational methodology. 
The researchers based the study on a theoretical model showing the association of job strain (independent variable) and three presumed, associated consequences (dependent variables) defined as quality of life (QOL) indicators (health, job satisfaction, life satisfaction). The model further explored three types of moderating variables (personal, social support, and fitness) that were presumed to serve as a buffer for individuals possessing the moderating characteristics.

A stratified random sample of subjects $(\mathrm{N}=103)$ was selected from the University of Michigan. The sample included 57 non-academic, high-level administrators and 46 faculty from humanities and natural science departments. All subjects were males and the majority were Caucasian (99\%), a potential limitation of the study. The subjects were further stratified by number of years at the university and indirect evidence of physical activity.

Data were obtained from the Lifestyle Analysis Questionnaire (LAQ), treadmill stress test, and underwater weighing. Additionally, the subjects self-reported the total number of sick days taken in the past 3 years. The LAQ, a self-report instrument, was composed of nine difference reliable instruments: Clinical Affect Scale (Cobb, 1970), Self-Esteem Scale (Coopersmith, 1959), Problem Prevention (ISR), Environmental Preference Scale (Haase, 1979), Social Support Scale (LaRocco, House, \& French, 1980), Healthy Health Habits (Breslow \& Enstrom, 1980), Psychophysiological Symptoms (Langner, 1962), Job-Descriptive Index (Locke, Smith, \& Hulin, 1965), and Life Satisfaction Scale (Quinn \& Staines, 1979). However, no specific reliability data for the nine instruments were provided. 
Each variable was measured on, at a minimum, an ordinal scale. Pearson productmoment correlations and regression statistics were used for data analysis. The researchers obtained intercorrelations among the stressors, the moderators, and the QOL indicators. Stepwise multiple regression was performed using the QOL indicators as the dependent variables. Then, the moderating variables were examined for possible buffering effects. The only significant difference between faculty and administrators was for the self-reported measure, absence of psychophysiological symptoms $(p<.05)$. The measure indicated the extent of emotional and physical problems experienced within the previous year. A score of 100 indicated no symptoms. Fewer stress-related problems were reported by administrators (92.2) than faculty (88.6).

For both faculty and administrators, statistically significant Pearson productmoment correlations $(\mathrm{p}<.01)$ were found between job strain and all QOL indicators (job satisfaction, life satisfaction, symptoms) except supervisor satisfaction. Self-reported number of days ill in the previous 3 years was not significantly related to job strain. Unlike administrators, there was no statistically significant relationship between job strain and QOL indicator, supervisor satisfaction, for faculty. The researchers suggested that faculty do not perceive that they have supervisors.

In addition, faculty appear to manifest job strain in the form of poorer life satisfaction, slightly higher stress-related symptomatology, and greater number of days ill. For faculty, work is life, and a low estimation of the professorial life is translated into a low quality of life as well. (p. 37) 
Finally, a number of moderators were found to be effective in mitigating the effects of job strain on the QOL variables. However, the moderators differentially influence job strain-QOL relationships for faculty and administrators.

The suggestion by the researchers that faculty do not perceive that they have supervisors represents a notable implication for the present study. Such a disconnect between faculty and administrator perceptions of their basic working relationship provides a hint that differences of perception may be present regarding such a significant event as the merger of Kentucky's community colleges and vocational/technical institutes.

Davis and Chamberlin (1996) studied the relationship between the level of job satisfaction of faculty and administrators and the budget reduction strategies used at public, comprehensive higher education institutions that had experienced budget reductions. The study also attempted to identify differences in faculty and administrator responses to the strategies employed. Because necessary institutional change typically involves financial issues, the researchers suggested that examining the effects of the fiscal constraints on job satisfaction and the reaction to various budget reduction methods might provide some guidelines for administrators.

Faculty $(n=484)$ and administrators $(n=189)$ at five public comprehensive universities that had experienced annual budget reductions of at least $10 \%$ were surveyed concerning their job satisfaction and reactions to the reduction process. Two institutions achieved budget reductions through planned and systematic approaches establishing program and institutional priorities. Three of the selected institutions achieved budget 
reductions through more opportunistic, unplanned strategies such as deferring maintenance, freezing vacant positions, and across the board reductions.

The researchers employed a non-experimental methodology. A 32-item questionnaire was designed to measure the job satisfaction level of faculty and administrators, and their reactions to the employed budget reduction strategies. Respondents rated their job satisfaction levels on a 4-point Likert-type scale $(4=$ strongly satisfied, $1=$ strongly dissatisfied ). No indication of instrument reliability or validity was included in the study. The researchers, with the assistance of chief academic officers at the five institutions, sent the questionnaire to randomly-selected faculty $(n=484)$ and administrators $(n=189)$ in the winter of 1994. Completed instruments were received from 247 faculty members ( $51 \%$ return rate) and 122 administrators ( $65 \%$ return rate). The total response rate for the questionnaire was $55 \%$.

The researchers used descriptive and inferential statistics to analyze data from two population sets: faculty and administrators and planned and unplanned institutions. Six interactions were analyzed within four population sets: faculty and administrators, planned and unplanned institutions, planned faculty and planned administrators, unplanned faculty and unplanned administrators, planned faculty and unplanned faculty, planned administrators and unplanned administrators. Analysis of variance (ANOVA) was used to determine differences in job satisfaction for each of the six population interactions. Chi Square was used to determined reactions to budget reduction strategies on the same six interactions.

Study findings indicated that both faculty and administrators were more satisfied than dissatisfied with their jobs, but administrators noted more satisfaction than faculty. 
Faculty identified seven items of dissatisfaction, while administrators listed only one primary indicator of dissatisfaction. In addition, administrators were more satisfied with more aspects of their employment than faculty.

A multiple classification analysis of variance conducted on job satisfaction between the planned and unplanned institutions and faculty and administrators yielded no significant differences between the two groups. The report did not list ANOVA statistics. The results indicated that, although administrators revealed more job satisfaction, both administrators and faculty were more satisfied than dissatisfied.

The survey also questioned respondents on the adequacy of communication during the budget reduction process. A Chi Square analysis identified statistically significant differences between nearly all of the subgroups. No Chi Square statistics were listed in the report, however.

Faculty and administrators disagreed on every category about whether communication was adequate concerning the reasons for the budget reductions (faculty $42.9 \%$ agreement, administrators $68.9 \%$ agreement), during the process about the cuts to be made (faculty $26.6 \%$ agreement, administrators $48.7 \%$ agreement), and about the reductions that were made (faculty 30 percent agreement, administrators $57.6 \%$ agreement).

Survey questions probed the success of the budget reductions, the fairness and equity involved, the appropriateness of the eventual reductions, the appropriate use of the faculty governance structure and other members of the campus community, and the level of campus morale during the budget reduction period. According to Chi Square analyses, significant differences existed between faculty and administrators. Again, the report did 
not include Chi Square values. The faculty regarded the budget reductions as unsuccessful, while the administrators regarded the budget reductions as unsuccessful.

Faculty and administrators also generally disagreed about the fair and equitable nature of the budget reduction with administrators maintaining a more positive view of the process. Additionally, faculty were negative and administrators were positive toward the appropriateness of the reductions.

No significant Chi Square differences were identified between faculty and administrators or between planned and unplanned institutions with regard to campus morale. Both groups described campus morale as low. However, significant differences between faculty and administrators existed regarding essential strategies used for the budget reductions. Faculty disagreed significantly with administrators with regard to eliminating programs and the retrenchment of staff and tenured faculty. Administrators, in contrast to faculty, considered the strategies essential to the budget reduction process.

Faculty and administrators agreed that the best approach to budget reductions would be a collaborative model consisting of a review of programs by all campus constituencies for selective restructuring or downsizing.

The presence of faculty/administrator differences in job satisfaction and strategies for dealing with budget crises represents important implications for the present study. The findings imply that differences of opinion exist with regard to campus issues that directly affect administrators and faculty. Such differences suggest the potential for faculty/administrator differences of opinion about merger.

Gross and Grambsch (1968) compared the backgrounds and characteristics of administrators and faculty and their perceptions of what the goals of the university are, 
what they should be, and what persons or groups are in positions of real power. The study included a sample of public and private institutions $(\mathrm{n}=68)$. A non-experimental methodology was selected by the researchers. For data collection, the researchers used a questionnaire designed to provide a perceived and a preferred goal structure for both the overall institutional sample and for each university in the sample. The survey measured faculty and administrator respondents on 47 identified goals in postsecondary education. Data were analyzed quantitatively.

Research findings indicated that faculty and administrators generally shared agreement on 34 of the 47 goals identified in the survey. However, administrators rated 13 goals somewhat higher than faculty: (a) develop the character of students so that they can make sound, correct moral choices; (b) make a good consumer of the student; (c) produce a student who is able to perform his citizenship responsibilities effectively; (d) serve as a center for the preservation of cultural heritage; (e) ensure the confidence and support of those who contribute substantially to the university; (f) satisfy the special needs of the immediate geographical region; $(\mathrm{g})$ retain staff in the face of inducements from other institutions; (h) base rewards on the contribution that the person makes to the institution; (i) insure that the university is run by those best able to attain its goals in the most efficient manner possible; (j) develop faculty loyalty to the university; (k) cultivate pride in the university; (l) maintain top quality in the programs felt to be especially important; (m) increase or maintain the prestige of the university.

Faculty placed higher emphasis than administrators on two goals: (a) insure the will of the faculty prevails on all important issues and (b) make the university a place in 
which faculty have maximum opportunity to pursue their careers in a manner satisfactory to them by their own criteria.

Overall, administrators tended to favor goals emphasizing issues related to students, quality programs, institutional efficiency, and the university's image. In contrast, faculty placed more emphasis on goals related to their own professional interests.

Study findings suggested that significant differences did not seem to exist between faculty and administrators in terms of higher education goals. The findings revealed more agreement than commonly supposed between faculty and administrators. The researchers noted that the differences were "too slight to warrant any inference of deep seated conflict" (p. 105). The researchers suggested that the high degree of congruence between perceived and preferred goals highlights the tendency of U.S. universities to attract and retain faculty and administrators who generally share its goal emphases.

Cardozier (1984) identified substantial variation on academic purpose, institutional culture, organizational climate, and even teaching-learning performance by institutional type.

Hartnett and Centra (1974) noted that little was known about the extent to which higher educational cultural and sub-cultural groups differ. In particular, the authors pointed out that there is not a full understanding of the various group' views and interpretations of institutional functioning and organizational goals. The researchers sought to learn more about situational and institutional perspectives on college 
environments. Additionally, the authors examined possible differences in sub-groups' views of institutional goals and procedures.

The researchers gathered data using the Institutional Functioning Inventory (IFI), an instrument designed to determine faculty members', administrators', and students' views of the academic environment. The instrument consisted of 132 items that yielded scores on 11 scales, each comprised of 12 items. Of the 60 colleges and universities used in developing norms for the IFI, a number of institutions $(n=13)$ provided data on all three groups — faculty, administrators, and students. The authors' study focused on these 13 colleges and universities.

The research findings noted that administrators' perceptions of the academic environment were consistently more favorable than those of the faculty and students. Across the 13 institutions, the administrators' mean perception scores were higher than the mean IFI scores of either faculty or students. The researchers concluded that administrators tended to possess a more optimistic view of institutional emphases and organizational functioning than either students or faculty.

Bare (1986) examined role profiles of academic and non-academic managers within the context of Daft's dual-core model of educational organization. The conceptual framework for the study centered on the contrasting roles of teaching/research positions which are organized by "intellective specialization of professional problem-solvers" and administrators whose work is characterized by "routinization" (p. 129).

The researcher conducted a non-experimental study utilizing a survey instrument for data collection. The population included academic and department chairpersons and nonacademic unit managers across 140 American colleges and universities $(n=6,357)$ 
which participated in the Exxon-funded Higher Education Management Development and Training Program between 1979 and 1981.

The study attempted to answer two research questions:

1. How do the managerial behaviors of academic department chairpersons differ from those of administrative unit managers in colleges and universities.

2. Are the observed differences in managerial role profiles consistent with Daft's dual-core model? (p. 129)

The research was based on questionnaire data provided by the Higher Education Management Institute of the American Council on Education (ACE). The instrument profiled respondents' work group characteristics, their formal leader's behavior, and their personal satisfaction. The survey offered eight response choices for each of 54 questions in a Likert-type format $(1=$ very little, $8=$ very great $)$. With regard to instrument validity, the report referred to a description in Van Wijk (1981) with no further details provided on validity nor reliability.

The study used the responses of 3,048 faculty and 3,309 nonacademic administrators. Response rates from the survey ranged from $99 \%$ to $57 \%$ depending on the question. SPSS Stepwise analysis (Hull \& Nie, 1981) was used to evaluate collected data. Of the 54 variables included in the stepwise analysis, 31 contributed to the discriminant function.

Research findings suggested that the two groups behaved differently in ways consistent with their distinct group tasks. Faculty identified clearer individual work goals and objectives than did administrators. In contrast to administrators who reported more clarity about department goals, faculty focused on personal teaching and research goals. 
Additionally, faculty reported significantly more interaction with their chairpersons than administrators reported with their managers. And faculty viewed budgets as less supportive of institutional priorities than did administrators. Faculty, in contrast to administrators, reported more frequently that institutional decisions that directly affected them were often made outside the formal decision-making structure of the institution. Faculty also reported more open and candid communication with group members than did administrators. The researcher offered that the study validated Daft's dual-core model and suggested the need for situational models of leadership in postsecondary educational institutions.

According to Campbell and Slaughter (1999), as the collaborative relationships have intensified between higher educational institutions and industry, there is potential for tensions to arise between faculty and administrators. Campbell and Slaughter (1999) noted that few studies existed that explored the new entrepreneurial norms being established by administrators, faculty, and business persons. The authors conducted a study that examined the areas of possible tension between faculty and administrators engaged in business-university activity. The research focused on three potential sources of faculty/administrator tension: issues related to potential conflicts of interest, conflict of commitment, and conflict over internal equity.

The study looked at both academics and administrators involved in universityindustry collaboration activity and academics and administrators not involved in university-industry collaboration activity. The researchers wanted to know if faculty and administrators held differing views on such activity. 
A survey instrument comprised of Likert-type questions was mailed to 86 colleges and universities. Respondents included 127 university administrators and 280 faculty members $(n=407)$. Analysis of variance (ANOVA) was used to analyze respondents' views toward the questions.

The analysis of survey responses suggested that faculty/administrator tensions surrounding university-industry activity centered on autonomy, resources, and flexibility to capture financial gain. The study confirmed the hypothesis that faculty and administrators hold different views toward potential conflicts, particularly in terms of control of the industry relationship. The greatest dissimilarity in faculty/administrator views related to the conflict of commitment. Faculty desired to maintain autonomy. In contrast, administrators desired more control over faculty's discretionary time, income from external activity, and institutional ownership of faculty discoveries.

McDowell (1986) examined the differences in how administrators (department heads/chairs) and faculty perceived the faculty performance evaluation process. Due to the lack of previous research on the academic appraisal interview, the researcher conducted an exploratory study designed to discover how administrators (department heads/chairs) perceived faculty members and themselves in the appraisal interview. Quantitative methods were used for data analysis.

Two research questions were established for the study: (a) Are there significant differences between biological sex groups, among academic rank groups, among teaching experiences groups, among age groups, and between academic groups in rating faculty members/administrators on each item of performance appraisal? and (b) Are there significant differences between biological sex groups, among academic rank groups, 
among teaching experience groups, among age groups, and between academic groups in rating faculty member/administrators on dimensions of performance appraisal?

The researcher selected a random sample of faculty $(N=450)$ and administrators $(N=200)$ from a midwestern university to participate in the study. The sample faculty and administrators were mailed an Appraisal Interview Questionnaire. The five-part instrument required respondents to rate administrator performance, content, and methods in interviews; to assess faculty member role during interviews; to rank interview methods; and to assess faculty member performance during the interview.

The instrument was developed by reviewing a number of other performance instruments. However, the report did not indicate reliability or validity data for the instrument utilized in the study. The mailing yielded completed questionnaires from $41 \%$ of faculty $(n=184)$ and $52 \%$ of administrators $(n=104)$.

The researcher computed frequencies and conducted Chi Square analyses between and among groups on each item of the questionnaire. Mann-Whitney $U$ tests were completed for ranked data, and factor analyses were computed on items in two parts of the questionnaire. Oblique factor analyses with the pattern matrix and multiple discriminant function analyses were also completed.

The researcher utilized the following as independent variables in the study: biological sex groups (male and female), academic rank groups (assistant, associate, full professor), teaching experience groups (1-5, 6-10, 11-15, 16-20, 20+ years), age groups (25-30, 31-40, 41-50, 51-60, 60+ years) and academic groups (faculty members and administrators-department heads/chairs). 
The percentages and Chi Square results indicated significant differences between groups on a majority of items. From the factor analyses, three factors emerged: "Methods and Contents" (accounted for 80\% of the variance), "Appraisal Process" (accounted for $80 \%$ of the variance), and "Interviewee Performance" (accounted for $75 \%$ of the variance).

Discriminant function analysis results reinforced the analysis of variance results. The overall multivariate $F$ was significant at the $(\mathrm{p}<.001)$ level for academic groups. The Bartlett Chi Square test yielded significant differences $(p<.01)$ for the first two discriminant functions, "Methods and Content" and "Appraisal Process." The "Methods and Contents" factor $(\mathrm{r}=.77)$ and the "Interviewee Performance" factor $(\mathrm{r}=.31)$ correlated significantly with the discriminant function. The findings suggested that "academic group" was a good discriminating variable. No other significant differences occurred between or among levels of other independent variables in rating questionnaire items. Study results revealed high percentage differences between academic groups.

Study findings suggested that a significant majority (80\%) of administrators were satisfied with the appraisal interview methods utilized in communicating evaluation, stimulating growth, persuading faculty members to improve, encouraging upward communication, discussing major accomplishments, human relation factors, and work environment. In contrast, however, a significant minority (less than $40 \%$ ) of faculty members perceived that such items were addressed and were, as a result, dissatisfied with administrators' methods.

Seventy-eight percent of administrators believed that faculty had an opportunity to release defensive feelings whereas only $19 \%$ of faculty members believed they had the 
opportunity. Additionally, $94 \%$ of administrators believed that they stimulated growth and development. In contrast, however, only $42 \%$ of faculty members believed that administrators stimulated growth and development.

With regard to performance, both administrators and faculty positively rated themselves on their performance during the interview. However, a significant majority (70\%) of faculty members considered evaluations as unreliable and invalid when used as criteria for determining merit pay. Quite the opposite, a significant majority $(90 \%)$ of administrators considered their evaluations of faculty members to be valid and reliable for determining merit pay even though administrators had little formal training in interviewing. Also, findings indicated that administrators rated their role in faculty performance positively. Dissimilarly, faculty members rated administrators' role in faculty performance negatively.

In addition, only $31 \%$ of faculty members perceived that they had much influence on department activities. In contrast, $92 \%$ of administrators believed faculty members maintained significant influence on department activities.

Implications of the higher education literature in this section are that faculty and administrators differ in their perceptions of institutional climate and organizational functioning. Specifically, the literature revealed that faculty possess contrasting cognitive models of how their institutions operate (Hartnett \& Centra, 1974; Peterson \& White, 1992), perceptions of the role of department chairpersons and other role dissonance factors (Cohen, Bleha \& Olswang, 1981), perceptions of institutional/organizational climate (Blackburn, Lawrence and Associates, 1990; Cardozier, 1984; Moran \& Vokwein, 1988; Warburton, 1989), administrative supportiveness (Blackburn et al., 
1990), response to job strains and job stress (Blackburn, Horowitz, Edington, \& Kloss, 1986), job satisfaction (Davis \& Chamberlin, 1996), administrative supportiveness (Blackburn et al., 1990), perceptions of university goals and which groups held positions of power (Gross \& Grambsch, 1968; Hartnett \& Centra, 1974), academic purpose and teaching-learning performance (Cardozier, 1984), institutional functioning (Hartnett \& Centra, 1974), behaviors and distinct group tasks (Bare, 1986), external collaborative relationships (Campbell \& Slaughter, 1999), and faculty performance evaluation process (McDonnell, 1986). Such pre-existing faculty and administrator differences contribute to a theoretical framework for understanding the faculty/administrator chasm. The studies described in this section are germane to the present study comparing faculty and administrators' perceptions of the merger of Kentucky's community colleges and vocational/technical institutes.

\section{Summary}

Two broad categories of pre-existing factors impact faculty and administrator perceptions of merger: (a) personality and curricular values and (b) perceptions of institutional climate and organizational functioning. Such perceptual incongruity may serve as an important clue in the understanding of how faculty and administrators conceptualize state-mandated postsecondary education reforms in Kentucky, how they respond to change, and most importantly, how they view the merger of the community colleges and technical/vocational institutes.

The next subsections will outline five potential variables which may influence faculty and administrators' world views and perceptions of the merger of Kentucky's community colleges and vocational/technical institutes: (a) type of institutional decision- 
making, (b) depth of merger implementation, (c) level of involvement in merger initiatives, (d) internal versus external motivation for reforms that led to merger, and (e) level of support for state postsecondary education reforms that led to merger.

$$
\text { Faculty and Administrator World Views }
$$

A review of higher education literature reveals substantial evidence of differing, and oftentimes conflicting, world views and underlying perceptions held by faculty and administrators. The existence of disparate world views held by faculty and administrators in the postsecondary educational institutions in the U.S. has been clearly documented in the literature and is relevant to the present study. Numerous researchers have identified differences in faculty and administrator perceptions (Blackburn, Lawrence \& Associates, 1989; Campbell \& Slaughter, 1999; Cardot, 1990; Dodd \& Garmon, 1987; Garmon, 1984; Holton \& Phillips, 1995; Kelsey, Jr., Mezack, III, \& Cardot, III, 1992; McMillin, 2002; Peterson \& White, 1992; Petry, 1957; Richard, Blocker \& Bender, 1972; White, 1990; and Zemsky, 1996).

The faculty/administrator divide may be characterized many ways: collegial vs. managerial cultures, disciplinary vs. institutional perspectives, micro vs. macro foci (McMillin, 2002). The faculty/administrator conflict traces its roots to the early 1900 s with the transition of American colleges and universities from simple institutions to complex organizations. The evolution resulted in the rise of specialized administrators with unique duties different from those of the faculty (Rudolph, 1990). Rudolph (1990, p. 434) noted the following:

The growth of administration, the proliferation of administrators, was a response to enrollment increases and the demand for new services. It was a response also 
for the need to free research-minded scholars from the detailed but necessary work that went into the management of an organized institution.

The faculty resented the increased numbers of administrators. According to Veysey (1965, p. 360), "Almost from its beginning, the appearance of administration provoked divisive resentments within the academic population ... the administration represented an alien and illegitimate force which had captured the leadership of the university."

Richard, Blocker, and Bender (1972, p. 70) stated, "It is a well-known fact that administrative values do not always coincide with faculty values." Campbell and Slaughter (1999, p. 310) further noted, "Some tension between faculty and administrators has been accepted as an enduring part of academic life." Bender, Blocker, and Martorana (1975) contended that the academic community generally believes that scholarship and administration are incompatible. Kelsey, Jr., Mezack, III, and Cardot, III (1992, p. 3) noted that day-to-day interaction between administrators and faculty is "commonly characterized by feelings of distrust, frustration, and, sometimes, envy."

Petry (1957, p. 15) summed up from the perspective of a faculty member the nature and sources of the tenuous faculty and administrator relationship:

The significant differences between faculty and academic administration is of course in the nature of their responsibilities. The professor must educate; the academic administrator must keep the academic machine running, must meet deadlines, above all must make decisions, many of which vitally affect the faculty. This difference in responsibility, especially if complicated by failure of communication and a little ineptitude, can be a prolific source of tension. 
A survey conducted by the U.S. Department of Education, Office of Educational Research and Improvement revealed that only $54 \%$ of the full-time faculty surveyed described their relationship with administration as either somewhat or very satisfying (U.S. Department of Education, 1990). The report results suggested a deep divide in the way academicians and administrators interact with one another.

Holton and Phillips (1995, p. 43) noted the long history of faculty and administrator conflict:

Since the dawn of academia, faculty and administrators have worked together and have disagreed. The current catch-phrase "you just don't understand," used to describe miscommunication between men and women (Tannen, 1990), could be applied to faculty and administrators because the occupants of these two worlds often do not understand each other. Faculty bemoan the lack of support by administrators, administrators wonder what faculty actually do. The two often lack sufficient appreciation for the importance of each other's jobs and often view each other as "opposing camps" on campus.

Holton and Phillips (1995, pp. 44-49) further suggested eight possible reasons for faculty and administrator conflict:

1. Being an administrator is not a promotion for a professor, it is a new career path;

2. Professors and administrators answer to different authorities;

3. Policy is always in conflict with local option. The independence of the tenured full professor is often an affront to the administrator; 
4. There are persistent irritations-personality conflict, jealousy, tenure and promotion decisions, hiring decisions, new courses, course assignments, policy, and, of course, parking;

5. Standards of judgment are never clear. Professors do not really understand how they are judged on teaching, service, and scholarship. The roles of student evaluation, peer evaluation, and evaluation by the higher-ups are not always clear;

6. Professors are urgent for input. That means they want their own way. Administrators want to give the illusion of input. That means they will have their own way and act like it was democratically decided;

7. It is rarely clear to either party how much power each has and how each can affect the other. The professor is a potential saboteur or guerrilla. The administrator is an obstacle;

8. There are natural irritations in any boss-employee relationship and despite protestations to the contrary, the administrator is a boss.

Zemsky (1996, p. 9) summed up the dilemma facing higher education institutions regarding the faculty/administrator relationship:

The challenge to administrators and faculty is to build an environment of trust and support, a set of relationships that recognizes the intrinsic values that motivate faculty and acknowledges their accountability to the institution that pays them ... to hold in purposeful juxtaposition the often contrary perspectives of faculty and administration to remain accountable to the public trust while preserving the spirit of inquiry that gives life to the academy's teaching and research. 
A theoretical framework may be useful for understanding faculty and administrator differences and useful for the present study of faculty and administrator perceptions of merger. The previous sections served to lay the foundation for better understanding the faculty/administrator chasm which may influence faculty and administrator perceptions of the merger of Kentucky's community colleges and vocational/technical colleges.

A Theoretical Framework: The Faculty/Administrator Chasm

As previously described in this chapter, the body of research detailing faculty and administrator perceptual differences is extensive. Furthermore, the wide-ranging literature on the topic may be conveniently grouped into three broad categories outlined previously: (a) personality characteristics and curricular values of faculty and administrators, (b) institutional climate and organizational functioning, and (c) faculty and administrator world view.

There was ample evidence in the literature of the presence of a faculty/administrator chasm. The present study attempted to determine if faculty and administrators have different perceptions of the merger of Kentucky's community colleges and vocational/technical institutes and, if so, whether or not perceptions are influenced by five potential control variables which are present in the literature: (a) type of institutional decision making, (b) depth of merger implementation, (c) level of involvement in merger initiatives, (d) internal versus external motivation for reforms that led to merger, and (e) level of support for state postsecondary educational reform initiatives that led to merger. 


\section{Type of Institutional Decision Making}

Institutional decision making is a popular topic of writings and research.

Numerous researchers have described the positive relationship between employee participation in decision-making and employee performance and satisfaction (Deming, 1982; Likert \& Likert, 1967; McGregor, 1960). Dupont (2000) noted that Kentucky Community and Technical College System (KCTCS) faculty believed they had the greatest influence in academic affairs issues with academic rank cited as the primary predictor of a faculty member's influence on decision making. The researcher pointed out that KCTCS faculty felt they had the least influence in the areas of financial affairs, student affairs, and system decision making.

Perceptions of decision making contribute to employee work attitudes and behaviors (Denton \& Zeytinoglu, 1993). Additionally, organizational structures and individual roles within an organization impact perceived participation and influence in decision making (Kanter, 1977). Dupont (2000, p. 3) suggested that "it is reasonable to speculate that individuals who believe they are excluded from decision-making processes in their organization may as a result harbor feelings of anger and resentment, which will consequently have an adverse effect on their work performance."

Collegiality is viewed as the model framework for institutional decision-making (Austin, 1990). Martin and Samels (1994, pp. 232-234) noted collaborative decision making as a key characteristic integral to merging colleges for mutual growth. The terms "shared governance," "collegiality," and "academic community" are used frequently; however, the higher education world is rarely so ideal (Del Favero, 2001, p. 1). Dupont (2000, p. 2) noted that external influences have "created tension with mounting pressure 
to move the locus of decision-making from individuals within the academy to these external constituencies." Gayle, Hakim, Agarwal, and Alfonso (1999, p. 24) stated, "Perceptions of institutional governance often vary widely among faculty, administrators, and trustees."

Administrators are criticized by faculty as having a penchant for unilateral decision making and for failure to consult faculty on matters affecting faculty work and the learning environment. Faculty are labeled by administrators as disinterested, uninvolved, and recalcitrant when it comes to collaborative institutional activity. The reality is that structural fragmentation of administrative and academic work results in disparate worlds with different objectives and realities. (Del Favero, 2002, pp. 1-2)

As mentioned earlier in this chapter, Tillery and Deegan (1985) described a framework of four generations of community colleges as well as an emerging fifth generation. The authors illustrated the increasing complexity of the community college as it moved from generation to generation. Of particular interest concerns the evolution of institutional decision making that took place in Generation 3, "The Community College" generation from 1950 to 1970 :

Governance of community colleges in Generation 3 became more complex: Many districts became multi-unit, faculty made increased demands for formal roles in decision making, and state agencies exerted new influences in legislative and coordination affairs. The political model of governance was, and remains, dominant; and organized constituency groups engaged in vigorous lobbying of legislatures and state agencies. (p.13) 
Baldridge, Curtis, Ecker, and Riley (1978) described three unique decisionmaking models in higher education: bureaucratic, collegial, and political. Birnbaum (1989) further elaborated on the three models of higher educational organizational functioning with a description of a fourth type: the anarchical organization. Collegial institutions share power and values in a community of equals and embrace participation. Bureaucratic institutions are characterized by their organizational charts and the value placed on strict lines of authority and communication. Political institutions compete for power and resources. Anarchical institutions are "organized anarchies" (p. 154) that are characterized by their problematic goals, unclear technology, and fluid participation.

Bing and Dye (1992) centered on what they considered as two extremes: hierarchical and collegial. The authors explained the hierarchical principle as a model taken from business, governmental, and military organizations where a president "listens to constituent groups, yet boldly makes decisions and imposes them on the university community." (p. 16)

Hodgkinson (1974) examined the campus senate and found that administrators supported senates and collegiality. However, the study indicated that faculty members believed campus senates to be much less effective than did administrators. The researcher pointed out that a major shift in campus decision-making occurred during the 1960s. By the early 1970 s, a significant campus senate movement was under way in the U.S. that drew representatives from three influential campus constituencies: faculty, students, and administrators.

Researchers from the Center for Research and Development in Higher Education at the University of California, Berkeley, pointed to a lack of research on the campus 
senate movement and the need for a national survey of all institutions of higher education. Using both quantitative and qualitative research design methods, Hodgkinson (1974) administered a national survey to examine campus senates on behalf of the Center. The Center developed a single, four-page questionnaire, answerable in 5 minutes. The researcher mailed the instrument to colleges and universities nationwide. Although the report did not indicate the total survey sample $(N)$, the Center received replies from 1,863 institutions $(n=1,863)$ to the original questionnaire.

From the responses, the Center developed a more detailed questionnaire that was subsequently sent to all institutions indicating the existence of campus senates $(n=688)$. With the more detailed survey, the researcher sought to ascertain: (a) constituencies represented on senates, (b) how they were selected, and (c) the nature of their responsibilities.

Of the 688 institutions identified in the national survey as having campus senates, 364 responded to the more detailed questionnaire. The mailing produced 310 usable surveys. The more detailed survey instrument sent to the institutions with a campus senate consisted of both forced response questions (the number was not indicated in the report) and six open-ended, evaluative questionnaire items. The researcher sought to identify the origins, structure, and functioning of the 310 representative campus senates.

Finally, the researcher chose four institutions as case studies to typify the problems and processes revealed in the questionnaire analysis, particularly the openended items. Attempts were made to identify themes that emerged from the participant observer data. Additionally, the Institutional Functioning Inventory (IFI) was administered at each of the case study institutions to assess campus climate. The IFA, 
produced by the Educational Testing Service in Princeton, New Jersey, was given to either full or representative samples of students, faculty, and administrators. Unfortunately, the researcher did not mention the instrument's validity or reliability nor were actual surveys included in the report.

Researchers identified a major discrepancy between the questionnaire data (mostly completed by administrators) and the participant observer data (the basis for the case studies that took into account a broader view that included student, faculty, and administrator perspectives). Researchers concluded from the discrepancy findings that administrators were more positive toward campus senates than were students and faculty. Additionally, the researcher noted that the meaning "participation" for administrators was quite different than that interpreted by students and faculty members.

Students and faculty were frequently surprised to discover that they were not going to make actual decisions. Rather, the campus senate representatives provided an advisory role function.

Another theme that emerged from the research was the indication that the possibility of success of the senate increased when the mission of the institution was clear. The researcher anticipated early on that commuter institutions such as community colleges would likely have more difficulty establishing a campus senate. However, research data from the study suggested that campus senates could be useful if goals and functions were made clear. Research results indicated that community college senates showed apparent success.

Reyes and Twombly (1987) examined the mode of governance in community colleges as perceived by community college presidents, deans, chairpersons, and faculty. 
The researchers conducted a non-experimental, exploratory study based on a "Transformational Model" theoretical framework proposed by Reyes and McCarty (1986). The theoretical model, which conceptualizes colleges and universities as organisms adapting to environmental influences, also included a conceptual taxonomy of postsecondary institutions.

According to the taxonomy, three levels of organizations exist: Type I, II, and III. Additionally, the research literature outlined three organizational models: bureaucratic, collegial, and political. The bureaucratic model "includes a hierarchy of authority in which those in top positions would wield much of the organizational power" (p. 5). The collegial model "depicts the college organization as a community of scholars in which leadership, authority, and other institutional governing mechanisms are executed through shared decision-making processes" (p. 5). The political model suggests "the idea of conflict and coalition development within educational organizations . . thereby implying that colleges and universities are socially structured by coalitions" (p. 5). In the political model, "the relationship between administrators and professors, therefore, is perceived to be adversarial to some extent" (p. 5).

Organizations in the Type III category are capable of responding with political, bureaucratic, or collegial behaviors. Type II institutions maintain a more limited range of organizational systems, primarily using political and bureaucratic behaviors. Type I institutions maintain the most limited range of organizational systems relying on primarily the political mode of behaviors.

According to the researchers, community college governance had not been the subject of significant empirical scrutiny. The purpose of the study was to determine and 
analyze the most predominant mode of college governance in community colleges as perceived by community college presidents, deans, chairpersons, and faculty.

The researchers randomly selected 11 community colleges. Four participants were selected a priori from each institution: the president, a dean, an academic chairperson, and one faculty member. The 44 individuals selected yielded 39 usable questionnaires. The participants $(n=39)$ responded to an instrument used to identify the predominant mode of governance at the colleges.

The authors conducted 25 interviews with faculty and administrators of community colleges in the states of Wisconsin and Minnesota. The goal was to develop an instrument capable of measuring the most predominant mode of academic organization in community colleges. The interviews produced 40 questions that were narrowed to 25 for the questionnaire. Five factors emerged when the instrument was factor-analyzed: decision-making, leadership, authority, organizational structure, and internal processes. The factor loadings exceeded .70 for each factor. Correlations among the factors were below .30 suggesting discriminant validity among factors. When the instrument was tested for reliability, the test-retest process yielded a reliability coefficient of .87 .

Data from the questionnaire were coded. The researchers used cluster analysis complete linkage method, a technique for exploratory data analysis. The study findings indicated that community colleges exhibited strong bureaucratic tendencies. Nearly all faculty respondents described their organization as bureaucratic. In contrast, the majority of the chairpersons identified their college governance pattern as either political or collegial. Presidents and deans overwhelming selected the bureaucratic model. Overall, 
the majority of faculty and administrators maintained consistent views of their college governance as bureaucratic and political. The researchers concluded that community colleges tend to organize around the political-bureaucratic model, as perceived by faculty and administration. The researchers also cautioned that the small sample size used in the study limited the generalizability of the study results.

Reiten (1992) examined faculty and administrator beliefs regarding academic decision-making. The researcher attempted to describe, analyze, and understand the differences and similarities between faculty and administrators in their belief systems concerning academic decision making. The investigator desired to ascertain how the belief systems, or sets of values, influenced academic decision making in a research university.

The researcher interviewed faculty and administrators $(n=60)$ utilizing a structured interview technique based on academic governance models theorized by Baldridge, Clark, Mintzberg, Bess, Chamberlain, and others. The study was qualitative and primarily exploratory. Research findings indicated both faculty and administrators value and participate in departmental governance and decision-making. In contrast to administrators who value power as necessary to accomplish their work, faculty maintain mixed feelings regarding the value and role of power in academic decision-making. Faculty and administrators, however, generally maintained agreement in a number of areas: a high value of collegiality, dislike of academic decision-making when perceived to be non-collegial, and harmony of professional goals with the university's goal. The results suggest that although differences exist, the values and belief systems of faculty and administrators are more similar than different. 
Nunez (2003) examined the levels of support for strategic planning activities by faculty and academic administrators of Kentucky's public colleges and universities. The researcher initiated a survey with 5-point, Likert-scale questions ranging from strongly agree to strongly disagree to full-time administrators $(N=164)$ and faculty $(N=5,764)$ in the Commonwealth of Kentucky's eight public institutions of postsecondary education according to the 2003 higher Education Directory. The researcher employed a fourmember panel of experts to review the questions to obtain content validity. The survey items were also correlated and received a Cronbach coefficient alpha over the desired .70 level for all six indices: Support for Strategic Planning index (.8246), Type of DecisionMaking Model index (.7869), Type of Planning Model index (.8968), Level of Involvement index (.8576), Depth of Implementation index (.9049), and Support for State Reform Initiatives index (.8148).

The independent variable was position held, faculty or academic administrator. The dependent variable was attitudes toward support for strategic planning activities. Covariables were: (a) type of institutional decision-making, (b) type of planning model and structure, (c) level of involvement, and (d) depth of implementation.

Analysis methods for the data were descriptive statistics including mean, median, and mode and measures of variability including range, variance, and standard deviation calculated for each survey item and each index. In addition, a one-way multivariate analysis of variance (MANOVA) was performed on one research question. A hierarchical multiple regression was performed for research questions two through six.

Key findings revealed that academic administrators supported strategic planning activities at a significantly higher level than did faculty members $[F(2,707)=22.56, p<$ 
.001]. Results of a hierarchical multiple regression analysis revealed that five predictor variables were significantly related to the level of support for strategic planning and further helped explain the differences between faculty and academic administrators: (a) type of decision-making $[F(1,700)=293.93, p<.01]$ accounting for approximately $30 \%$ of the variance, (b) type of planning model $[F(1,707)=290.06, p<.01]$ accounting for approximately $30 \%$ of the variance, (c) level of involvement $[F(1,703)=113.43, p<.01]$ accounting for approximately $14 \%$ of the variance, (d) depth of implementation $[F(1,697)$ $=303.63, p<.01]$ accounting for approximately $30 \%$ of the variance, and (e) support for state reform $[F(1,615)=130.505, p<.01]$ accounting for approximately $18 \%$ of the variance.

Findings germane to this study include significant differences in support of strategic planning activities by faculty and academic administrators and the identification of predictor variables such as the type of decision-making, level of involvement, depth of implementation, and support for state reform. Implications for the present study are that faculty and administrators maintain significant differences regarding strategic planning. Kentucky's statewide reform initiatives represent an important method of statewide strategic planning. If faculty and administrators maintain basic differing views of strategic planning activities, then faculty and administrators may maintain differing views of the strategic merger of Kentucky's community colleges and vocational/technical institutes. Furthermore, the type of decision-making present at KCTCS, the level of involvement faculty and administrators have had in the merger initiatives, the depth of merger implementation, and faculty and administrator support for state reform efforts 
may serve as predictor variables for how faculty and administrators employed by KCTCS view the merger of the community colleges and vocational/technical institutes.

Weaver (1977) examined faculty and administrator perceptions of governance. The purpose of the study was to ascertain faculty/administrators' perceptions of a college's existing governance characteristics. The researcher stated that: "The effectiveness or ineffectiveness of a college's organizational model must be concerned with the personalized perceptions of those who work within the model and must recognize and attempt to understand the interrelationships involved between these various persons" (p. 12). With the aforementioned statement in mind, the investigator identified perceiver characteristics related to governance at a single institution, Central Florida Community College.

In the study the researcher measured top administrators', other administrators', and faculty attitudes at Central Florida Community College $(n=101)$. The survey results revealed that significantly differing perceptions of what occurs at the college existed among the three groups. Administrator responses revealed consistently high positive perceptions of interaction, decision-making, communication, leadership, motivation, and goals. In distinct contrast, faculty perceptions were more negative in all areas measured.

Drummond and Reitsch (1995) investigated existing faculty and administrator attitudes of shared governance models. According to the authors, a lack of research existed regarding the relationship between faculty and administrator attitudes and the degree of shared governance of higher educational institutions.

In the study, the researchers randomly selected universities $(n=605)$ from a published listing by the Carnegie Foundation for the Advancement of Teaching. 
Following the sampling procedure, the researchers mailed 4,235 surveys. Survey respondents $(n=1,191)$ consisted of 236 presidents, 232 provosts, and 723 faculty. The SPSS CROSSTABS procedure was implemented to evaluate attitudes on nine statements from the survey instrument. Attitudes were compared for faculty, for administrators, and for the two groups together. A total of 27 cross tabulations were tested.

An analysis of the data suggested that differences of perception existed between faculty and administrators concerning decision-making and the degree of shared governance present at the various institutions. A significant finding of the research acknowledged that the perceived level of participation in the shared governance system directly affected participant attitudes about the quality of the institution.

Rawls (1998) investigated administrator/faculty conflict. The purpose of the exploratory study was to identify specific areas causing tension and conflict between faculty members and administrators in higher education. Specific areas of interest included: administrator/faculty interaction, institutional authority and governance, job characteristics/job satisfaction, and time orientation.

The researcher outlined six hypotheses:

1. There will not be significant differences between administrators and faculty members in the position statements.

2. There will not be significant differences between administrators and faculty members in the management statements.

3. There will not be significant differences between administrators and faculty members in general policy statements. 
4. There will not be significant differences between administrators and faculty members in who should hold ultimate authority within a college/university.

5. There will not be significant differences between administrators and faculty members in elements of job satisfaction.

6. There will not be significant differences between administrators and faculty members in time orientation. (p. 77)

The population consisted of faculty and administrators at institutions with Carnegie Classification Doctoral II status $(N=59)$. The population was stratified into two groups, administrators $(N=25,319)$ and faculty $(N=2,071)$. The 2,000 mailed instruments yielded 351 usable surveys from faculty $(n=196)$ and administrators $(n=$ $155)$.

The methodology used in the study was survey research. Survey questioned focused on how tasks were operationalized between the two groups. Additionally, the survey questions probed the internal institutional environment.

Eight questions were used by the researchers to develop a survey framework for the study. The researchers utilized feedback from a pilot study to correct potential problems with the survey questions. The resulting survey instrument required participants to respond to questions on a Likert-type rating scale $(1=$ strongly disagree, $6=$ strongly agree). Questions explored position statements, management issues, rating of faculty and administrator traits, frequency of personal contact with faculty and administrators, general university statements, institutional authority, and level of satisfaction with various job aspects. 
Once collected, the researchers conducted descriptive analysis and inferential analysis on the data. Descriptive statistics (measures of central tendency and frequency distribution statistics) were utilized to organize and summarize sample data. The researchers used $t$-tests, a test of differences between two means, to identify statistical differences at the .05 level of significance. Research findings outlined results of the six research hypotheses.

For Hypothesis 1, 4 out of 10 position statements revealed statistically significant differences with regard to goals. For Hypothesis 2, differences in management goals produced more statistically significant findings than the position goals with 7 out of 10 goals eliciting differences. For Hypothesis 3, 10 of 13 general policy statements elicited a statistically significant difference. For Hypothesis 4 , there were no significant differences found. Findings indicated agreement between the two groups in the perception that administrators have strong authority. The means for both groups were high (faculty, $\underline{\mathrm{M}}$ = 4.86; administration, $\underline{M}=4.67)$. For Hypothesis 5 , significant differences were found in 12 of the 16 job elements. For Hypothesis 6 , no statistically significant differences were found with regard to time orientation.

Study findings echoed the reports of Garmon (1984) and Cardot (1990) that perceptual differences (world views) exist among faculty and administrators. Overall, statistical differences were identified in several of the management and position goals and general policy statements. Study findings suggested that faculty and administrators significantly differ in perceptions, job satisfaction, and the ways in which they operationalize tasks. The researcher noted that a significant perceptual discrepancy 
existed between faculty and administrators related to which group perceived it was in charge of the organization.

The author also concluded, based on critical (but not statistically significant differences) that faculty and administrators maintain different "time orientations" (p. 115). Faculty perceived their jobs as focused on the present while administrators regard their jobs as preparing the organization for the future. Among the research findings was that faculty members put a substantially higher emphasis on the requirement for administrators to have teaching experience. And finally, the study identified that administrators are less likely to favor democratic governance even though the research suggested that both faculty and administrators valued the idea of collaborative decisionmaking. The researcher concluded that the faculty and administrator differences identified in the study created the potential for tension and conflict and indicated variations in climate within the institution.

Implications of the studies in this section are that differences exist regarding faculty and administrator perceptions of institutional decision-making (Drummond \& Reitsch, 1995; Hodgkinson, 1974; Martin \& Samels, 1994; Rawls, 1998; Reiten, 1992; Reyes \& Twombly, 1987; Weaver, 1977). Such differences are germane to the present study of faculty and administration perceptions of the merger of Kentucky's community colleges and vocational/technical institutes. Kelsey, Jr., Mezack, III, \& Cardot, III, (1992 p. 3) suggested that "the ability to understand the philosophical basis for differences between administrators and faculty would help to bridge gaps in institutional decisionmaking" and that "differing perspectives are potentially counterproductive." Faculty and administrator perceived type of institutional decision-making (collegial, political, or 
hierarchical) may serve as a predictor variable for faculty/administrator differences of perception.

\section{Depth of Merger Implementation}

The depth of implementation of postsecondary reform initiatives can influence faculty and administrator views of activities such as institutional effectiveness (Metcalf, 2001; Welsh \& Metcalf, 2003; Welsh, Petrosko \& Metcalf, 2003) and strategic planning (Nunez, 2003; Welsh, Nunez \& Petrosko, 2006). Faculty and administrators who perceive that the merger and reform efforts are limited in scope may maintain more negative perceptions of the merger. In contrast, faculty and administrators who perceive that the merger initiatives were comprehensive and will have significant, far reaching effects toward the institution may indicate more positive perceptions of the merger of Kentucky's community colleges and vocational/technical institutes.

\section{Level of Involvement in Merger Initiatives}

Research suggests that broad participation and involvement of faculty and administrators in educational change and innovation is critical to the success of major reform initiatives (Bennis, 1984; Metcalf, 2001; Nunez 2003; Puyear, 2001). However, faculty and administrators who attribute low importance to reform efforts may do so due to insufficient involvement in the process. Administrators typically report more faculty involvement in governance procedures than do faculty (Drummond \& Reitsch, 1995). Schilling and Schilling (1998) noted that "Higher education contains little, if any, history of successful top-down initiatives, as faculty ownership is a key element of change in institutions of higher education" (p. 64). Puryear (2001) commented that "When change is imposed from the outside the organization, stress increases" (p. 8). 
Klein \& Dunlop (1994) also point to the importance of involvement amidst change: "When change originates with administrators, it is easy for the change process to evolve into an 'us and them' situation where nobody is a winner. Thus it is important for administrators to involve the faculty as early in the change process and in a collaborative manner" (p. 199). Martin and Samels (1994) stressed the importance of three key characteristics integral to merging colleges for mutual growth: (a) campus-wide commitment, (b) shared vision, and (c) collaborative decision making.

Metcalf (2002) examined faculty and administrator perceptions of institutional effectiveness in a non-experimental study. The quantitative methodology included a survey instrument for data collection. The population for the study consisted of full-time faculty and academic administrators in institutions hosting Southern Association of Colleges and Schools (SACS) accreditation site team visits between September 1998 and May $2000(N=179)$. The sample consisted of all faculty members and academic administrators from the selected institutions $(\mathrm{N}=1,245)$. The researcher performed a census of all potential respondents. As a result, no sampling procedures were necessary.

The researcher utilized a 54-item survey instrument containing a Likert-type scale $(1=$ strongly disagree, $5=$ strongly agree $)$. Respondents were asked to indicate their perceptions of variables related to institutional effectiveness at their respective institutions.

Surveys were sent to 704 faculty members and 541 academic administrators. The survey yielded 386 faculty respondents for a return rate of 54.8 percent. The mailing produced 294 academic administrator respondents representing a response rate of 54.3 percent. Cronbach's coefficient alpha scores ranged from a high of .93 to a low of .67. 
The researcher tested the null hypothesis that there would be no statistically significant difference between faculty and academic administrators in their perception of the importance of institutional effectiveness, or in the degree to which the control variables affected the perception of importance. Metcalf (2002) employed two-tailed independent samples $t$-tests for data analysis.

The results of the $t$-tests identified a significant difference between the mean scores for faculty and academic administrators on the Internal Versus External Motivation index $[t(592)=-6.18, p<.001]$. Of nine index questions, seven were statistically significant at the $(p<.01)$ level. One was significant at the $(p<.05)$ level. One was not statistically significant. The $t$-tests revealed that academic administrators are significantly more likely than faculty to perceive institutional effectiveness as important.

After conducting the $t$-test analysis, the researcher employed a hierarchical regression analysis to examine the impact of four control variables on the perception of importance. The regression analysis revealed that control variables operated differently with academic administrators than with faculty.

Although the research findings indicated that statistically significant differences exist in faculty and administrator perceptions of the importance of institutional effectiveness in apparent contrast to the conclusions of Robins (1996), the data indicated that faculty still perceived institutional effectiveness as important. The apparent difference lies in degree of importance. The researcher pointed out that the findings, while statistically significant, are not indicative of a "gaping chasm" (p. 146) between faculty and administrator perceptions of institutional effectiveness importance. 
In addition, four variables were found to be predictors of the perception of importance. Two variables were significant predictors for both faculty and academic administrators (internal motivation, level of involvement). The research indicated that faculty support is likely to increase if members are personally involved in institutional effectiveness activities. One variable was a significant predictor for faculty and not academic administrators (definition of quality). One variable was a significant predictor for academic administrators and not faculty (depth of implementation).

Internal Versus External Motivation for Reform Initiatives that Led to Merger The spread of the quality movement from the business sector to public education has influenced significant change in higher education (Quehl, Bergquist, \& Subbiondo, 1999). External forces such as student demands, public agencies, and industry have a greater influence on higher education than internally motivated initiatives (Banta, 1995). The research literature, however, documents an extensive history of resistance toward change by public colleges. (Benjamin, 1994; Bok, 1986; McConnell, 1992). Puyear (2001, p. 8) described the traumatic nature of structural change, particularly when the change results from outside influences:

Change always causes stress. When the change is imposed from outside the organization, stress increases. Structural change in higher education usually includes the perception of winners and losers and always involves a change in culture and methods of operation. All of these produce fear, anger, a sense of loss and even grief. These feelings, which are natural, can be intense. They need to be addressed honestly and compassionately, but they also must be left behind so that the process can proceed. 
The independent nature of the academy may affect the degree to which faculty and administrators view the importance of the merger of Kentucky's community colleges and vocational/technical institutes. Chambliss (1994) pointed out that faculty members selected their academic careers largely due to the premium they personally placed on autonomy. Faculty value "maximum freedom, and few distracting, mindless, menial required tasks ... faculty generally resent being told what to do" (pp. 2-3).

If campus faculty and administrators perceive merger as simply efforts to please outside stakeholders, they will likely perceive lower levels of importance for the merger and will probably remain less supportive of the endeavors. If they perceive merger as a positive impact on the mission of the college - such as educational access and attainment - they will likely be more supportive of merger and reform initiatives.

Level of Support for State Postsecondary Education Reform Initiatives that Led to Merger

Faculty and Administrators' Support for Innovation/Change

Organizational change literature reveals that employees' attitudes toward change serves as one factor affecting the integration of higher educational institutions (Dee, 1999; Levin, 1998; Solis, 1995; Welhaven, 1996). When experiencing change, faculty and administrators tended to respond according to four distinct modes: activeconstructive, passive-constructive, active-resistant, and passive-resistant (Klein \& Dunlap, 1994).

Dee (1999) examined the relationship between dimensions of organizational climate and support for innovation in community colleges. The researcher conducted a non-experimental study using a survey instrument for data collection. 
The population for the study included faculty members $(\mathrm{N}=184)$ from an urban community college with an international reputation for innovation. The survey questionnaire was designed to measure perceived support for innovation and climaterelated variables.

Research findings indicated no significant variability in respondent perceptions with regard to gender, age, education level, racial identification, tenure in current position, or employment status. However, faculty support for innovation was positively associated with years of professional experience, intent to stay, the existence of open communication, and work autonomy. The two variables, communication openness and work autonomy, accounted for over $50 \%$ of the variance in the support for innovation scores.

Welhaven (1996) studied four Minnesota higher educational institutions to determine employees' attitudes toward change, attitudes toward institutional integration, and their perception of the impact of integration of the four higher educational institutions.

The researcher conducted a non-experimental study using a survey for quantitative data collection. A single research question was investigated: What are the factors affecting the integration of the institutions?

The population consisted of all employees of the four institutions as of October $13,1995(\mathrm{~N}=430)$. The researcher administered a descriptive survey composed of three instruments measuring employees' attitudes toward change, attitudes toward the specific change of integration, and their perceptions related to the impact of the integration. The survey response rate was $74 \%, 68 \%$ of which were usable $(n=294)$ for data analysis. 
Data analysis included descriptive statistics, $t$-tests for paired samples, and analysis of variance which were tested at the .05 level of significance. Independent variables for the study were institutions (Minnesota Riverland Technical CollegeRochester Campus, Winona State University-Rochester Center, Rochester Community College, University of Minnesota-Rochester Center), employee groups (faculty, staff, administration), and demographics (gender, age, service, education, residency, ethnicity). Dependent variables for the study were respondents' ratings of change, integration, and impact.

Study findings revealed statistically significant perceptual and attitudinal differences among the four institutions and three employee groups (faculty, staff, administrators) toward change, integration, and the impact of integration.

Levin (1998) looked at how individuals at community colleges made sense of organizational change. The study sought to examine sense-making with regard to the external and internal forces of change.

A non-experimental research design was used in the study. The researcher conducted an in-depth multiple case study investigation to identify college sense-making and behaviors. The study was based upon interviews with over 200 administrators, faculty, staff, students, and board members at six community colleges in the western U.S. and western Canada during 1996 and 1997.

In-depth interviews and informal conversations with college employees and students were conducted at multiple campus sites. The use of more than one site permitted comparisons, generalizations, and potential theory construction. Two methods of site selection were used: purposeful sampling (community colleges) and site access. 
Additionally the sample pool included different organizational systems, different political jurisdictions, and different sized institutions.

The researcher used a cultural framework that explored sense-making. In the interviews, the researcher questioned how organizational members understand organizational change at their institution and sought to explain the understandings. Topics covered in the interviews focused on institutional change, particularly large, macro, external impacts such as economic, political, and social forces.

Collected data included the following: (a) tape-recorded interviews, (b) interview notes of field researchers, (c) field notes of researchers, and (d) journal of principal investigator comprised of descriptions, observations, and hypotheses recorded during site investigations. Multiple data sources allowed for triangulation. The researcher analyzed themes that emerged from the qualitative data.

The stories and explanations identified in the study suggest that both external and internal environments play a role in organizational change. According to the author, the stories and explanations suggested that: "Organizational change is the interplay between external and internal forces, between the perceptions of internal members of organizational identity and the external environment and between the organizational fit with the external environment and organizational symbols that match environmental needs" (p. 28).

Five observations were made based on the case study interviews:

1. Managers were limited in the objective manipulation of the environment, functioning instead symbolically to manipulate and manage institutional interpretations of events. (p. 27) 
2. A college's organizational context (its particular system identity) was a main influence, with colleges in loosely controlled systems exhibiting greater control than those in tightly managed systems. (p. 28)

3. The more college personnel assumed that a strong system existed, the less control they perceived that their college had over its own actions. (p. 28)

4. Colleges that responded to environmental changes chose strategies that fit their institutional self-perceptions, while those that ignored changes saw them as inconsistent with their identity. (p. 29)

5. Internal influences over organizational change were contained within the organization's existing structures, combining these with institutional history, culture, and symbols as well as the organization's state of development. (p. 29)

Solis (1995) examined attitudinal and perceptual differences among employee groups at a comprehensive, multi-campus community college that had recently experienced a stressful CEO transition. The researcher conducted a non-experimental study using a survey questionnaire for data collection. In the study, three hypotheses were tested at the .05 level of confidence:

Hypothesis 1: There are no significant differences among administrators, faculty, and staff in the measures of 16 perceptual and attitudinal variables of interest in the absence of a permanent CEO. (p. 25)

Hypothesis 2: There are no significant differences among administrators, faculty, and staff in the measures of 16 perceptual and attitudinal variables of interest in the presence of a permanent CEO. (p. 25) 
Hypothesis 3: Within each employee group, there are no significant differences on each of the 16 perceptual and attitudinal variables when compared in two settings, pre- and post-permanent CEO. (p. 26)

The researcher selected all faculty, staff, and administrators at a comprehensive, multi-campus community college $(N=800)$ for participation in the study. A 16-item questionnaire containing attitudinal and perceptual variables was developed. However, no information on the reliability or validity of the survey instrument was provided in the report.

The first part of the questionnaire solicited demographic and position information. The second section, composed of a 6-point Likert scale $(1=l o w, 6=$ high $)$, examined person job-related stress, attitudes about the college, relationships with colleagues, and willingness to take risks. The survey was designed to elicit responses concerning 16 attitudinal and perceptual variables: (a) Concern about job security, (b) Level of personal stress; (c) Degree of job satisfaction; (d) Quality of collegial relationships; (e) Desire to undertake new challenges; (f) Desire to remain at the college; (g) Commitment to career; (h) Interest in personal development; (i) Willingness to take risks; (j) Concern for the future of the college; (k) Feeling of working for a common goal; (1) College meeting community needs; (m) College meeting student needs; (n) Re-accreditation concerns; (o) Community confidence in the college; and (p) Sense of camaraderie.

The researcher distributed the questionnaire through campus mail to all community college employees. Two hundred ninety-six questionnaires $(n=296)$ were returned, yielding a $37 \%$ response rate. 
The first and second research hypotheses were analyzed using multivariate analysis of variance (MANOVA) and Sheffé's test for multiple comparisons. The third research hypothesis was examined using tests of means for paired measures.

Within the dimension "absence of a permanent CEO," analysis of the data identified statistically significant differences among the three employee groups in four variables: Variable 5-desire to undertake new challenges $(\mathrm{F}=5.25, p<.006)$, Variable 11-feelings of working for a common goal $(\mathrm{F}=4.53, p<.012)$, Variable 12-college meeting community needs $(\mathrm{F}=3.95, p<.021)$, and Variable 13 -college meeting student needs $(\mathrm{F}=4.28, p<.015)$. Research Hypothesis I was therefore rejected for Variables 5 , 11,12 , and 13 at the .05 level of confidence.

Within the dimension of "presence of a permanent CEO," analysis of the data identified similar results with the exception of Variable 13 where no statistically significant differences were found among three employee groups. Research Hypothesis II was therefore rejected for Variables 5, 11, and 12 at the .05 level of confidence.

The researcher tested Hypothesis 3 by comparing the differences in scores for each employee classification on all 16 variables. Within-group pre- and post-CEO mean scores differed significantly for all groups, with faculty indicating more differences. Faculty mean scores changed for 13 of 16 variables; administrators' mean scores changed for 9 of 16 variables; and staff mean scores changed for 10 of 16 variables.

Group mean scores suggest that when there is no permanent president, faculty are more reluctant to undertake new challenges, have greater feelings of alienation, and believe less that the college is meeting student needs than do administrators and support staff. (p. 31) 
Research findings indicated that, of the three groups surveyed, faculty members were the most sensitive to the need for stable leadership. Additionally, study results suggested that faculty were less willing to take risks in the absence of leadership. Findings further revealed that faculty maintained different perceptions and attitudes compared to the other employee groups. In particular, evidence suggested that faculty were less optimistic with regard to change outcomes. The use of a single community college, however, limits the generalizability of the results.

Implications of the studies in this section (Dee, 1999; Levin, 1998; Nunez, 2003; Solis, 1995; Welhaven, 1996) are that differences in faculty and administrator support for innovation/change indeed exist. The level of support for state postsecondary education reform initiatives can influence the views of those activities (Nunez, 2003). If faculty and administrators maintain a high level of support for state postsecondary education reform initiatives in general, they will likely maintain more positive views of the merger of Kentucky's community colleges and vocational/technical institutes. Faculty and administrator support for innovation, change, and reform may serve as a predictor variable for how faculty and administrators perceive the merger.

\section{Summary of Literature Review}

This chapter summarized relevant literature on faculty and administrator world views and presented a theoretical framework for understanding the faculty/administrator chasm. The research clearly shows that important perceptual differences do indeed exist between faculty and administrators of America's higher educational institutions. Furthermore, two broad categories of pre-existing factors impact faculty and administrator perceptions are important in the understanding of the faculty/administrator 
chasm: (a) personality and curricular values and (b) perceptions of institutional climate and organizational functioning.

Additionally, the chapter outlined five potential variables which may influence faculty and administrators' perceptions of the merger of Kentucky's community colleges and technical/vocational institutes: (a) type of institutional decision-making, (b) depth of merger implementation, (c) level of involvement in merger, (d) motivation for reform initiatives that led to merger, and (e) level of support for state reform initiatives that led to merger. Faculty/administrator basic differences of perception, evidenced by the variables and related research studies, may serve as an important clue in the understanding of how faculty and administrators conceptualize state-mandated postsecondary education reforms, how they respond to change, and ultimately how they view the community colleges and vocational/technical institutes' mergers.

In reaction to an American public's desire for the development of new "entrepreneurial colleges" that can better respond to the needs of external organizations, a comprehensive community college movement is taking place nationwide. In Kentucky, two-year public colleges have experienced a radical evolution since significant legislative reform was enacted in 1997.

Despite the reform efforts in Kentucky's community and technical colleges, little is known about faculty and administrator perceptions of the merger. A thorough review of the literature revealed the presence of faculty and administrator dissonance and evidence of predictor variables influencing existing perceptual differences. The relevant literature will serve as a useful base on which to begin a study exploring faculty and 
administration perceptions of the merger of Kentucky's community colleges and vocational/technical institutes. This study was intended to explore these perceptions. 


\section{CHAPTER III}

\section{METHODOLOGY}

One of the most nationally-recognized, two-year college legislative reform initiatives in the U.S. began in Kentucky in 1997 with the passage of the Kentucky Postsecondary Education Improvement Act. A key aspect of the legislation resulted in the merger of the state's public community colleges and vocational/technical institutes. Since the merger, Kentucky's two-year college reform efforts and unique governance structure have gained increased attention.

The purpose of this project was to investigate how Kentucky Community and Technical Colleges System (KCTCS) faculty and administrators perceived the impact of the merger legislation, as well as whether differences in perceptions existed between the two groups. This exploratory, cross-sectional, correlational study examined faculty and administrators' perceptions of the merger of two, distinctive organizational cultures.

Nationwide, several two-year college mergers have taken place (Bailey \& Morest, 2004; McGuinness, 2002; Puyear, 2001), and little is known about the outcomes. Much can be learned from the merger of Kentucky's two-year community colleges and vocational/technical institutes that could be utilized by other state systems that are considering institutional mission convergence and centralized community and technical college governance. In particular, other states may benefit from ascertaining the characteristics and conditions necessary for successful two-year college mergers and the challenges that might lead to unsuccessful mergers. 
Perceptual differences in KCTCS faculty and administrators' perceptions of the merger of community colleges and vocational/technical institutes may be influenced by their prevailing world views. It was suspected, because of documented research on college and university faculty/administrator world view dissimilarity in higher education, that KCTCS faculty and administrators might differ significantly in their perceptions of the merger. An existing body of literature supports the research problem.

Essentially, the problem was that if the resulting merger of Kentucky's community colleges and technical/vocational institutes was not deemed successful by key external constituencies, increasingly skeptical of public education in general, the twoyear colleges might lose relevance in the new century. Without strong public support, the merged Kentucky Community and Technical College System (KCTCS) would not be able to take advantage of the many opportunities before it. Little is known about KCTCS faculty and administrators' perceptions of the merger of Kentucky's community colleges and vocational/technical institutes.

Little research exists on KCTCS since House Bill 1 was enacted into law. The potentially differing views held by KCTCS faculty and administrators may serve as an obstacle for the successful implementation of the goals of the statewide reform initiatives. A review of the literature in Chapter 2 provided ample evidence of a pre-existing faculty/administrator chasm which served as a potential source for the differing perceptions of the merger. The research covered faculty/administrator world view differences, higher educational change, and institutional mergers which led to research questions that explored potential differences in faculty and administrators' perceptions of the merger of Kentucky's community colleges and technical/vocational institutes. As 
themes in the literature emerged, suspected relationships between faculty and administrator perceptions of the resulting mergers of Kentucky's community colleges and vocational/technical institutes and other variables formed.

Rosenberg (1964, p. 24) described a conceptual framework for introducing control variables, "The most important systematic way of examining the relationship between two variables is to introduce a third variable, called a test factor, into the analysis." Rosenberg (1964, p. 40), in describing his "elaboration" model, suggested that once a relationship between two variables has been determined additional information can be obtained about the nature of that relationship by introducing control variables. According to Rosenberg $(1964$, p. 36$)$, the control variable has "a positive role to play in interpretation by increasing one's confidence that there is a meaningful and inherent link between the two variables." This study sought to explore the perceptions of KCTCS faculty and administrators about merger, and the two research questions outlined in Chapter 1 framed this study and provided the basis for analysis:

(1) Are there significant differences between faculty and administrators in their perceptions of the merger of Kentucky's community colleges and vocational/technical institutes?

(2) What factors help us understand faculty and administrator perceptions of the merger of Kentucky's community colleges and vocational/technical institutes? The literature review suggested that faculty and administrator views of the merger of Kentucky's community colleges and vocational/technical institutes may be affected by five variables: (a) perceived type of institutional decision-making - collegial, hierarchical, or political, (b) perceived depth of merger implementation, (c) level of 
involvement in the merger initiatives, (d) perception of reform initiatives as internally or externally motivated, and (e) level of support for state postsecondary education reform initiatives that led to merger.

A survey instrument titled Perceptions of the Merger of Kentucky's Community Colleges and Vocational/Technical Institutes (see Appendix C) yielded data relevant to each of the two research questions. According to Creswell (2003), survey methodology was appropriate for the present study. Surveys are the most frequently employed tool for data collection in related studies. This research approach was selected in the interest of time, cost, exploratory nature of the project, and the success of similarly-designed studies such as Metcalf (2001) and Nunez (2003).

The present study adhered to the principle of parsimony since, given observed data, more than one theory is generally possible. According to Maxwell (1976, p. 567), "given any amount of observed evidence, there always exists an infinite number of mutually incompatible theories that explain (entail, or, in cases of statistical explanation, imply statistically) the evidence at hand." As such, every effort was made to conserve assumptions and avoid needless complications throughout the research. Barker (1961, p. 273) acknowledged that the simplest theory is not always true but when presented two competing explanations - both of which are consistent with the observed facts - "that we regard it as right and obligatory to prefer the simpler."

\section{Study Design}

The study design was quantitative with data collected by survey. Data analysis was conducted through the use of descriptive statistics including mean, median, and mode and measures of variability including range, variance, and standard deviation. In 
addition, $t$-tests and ANOVAs and MANOVAs were implemented to draw inferences about population means and variances. Correlation and hierarchical regression analysis techniques were employed to measure and describe relationships between the variables.

\section{Selection of Participants \\ Population}

The available population for this study consisted of all full-time faculty $(N=$ $1,995)$ and all administrators $(N=195)$ employed by the 16 individually-accredited, twoyear colleges that made up the Kentucky Community and Technical College System (KCTCS). Faculty were those full-time community and technical college employees whose primary role was classroom teaching and who were listed under "Faculty" in the official 2007-2008 Kentucky Community and Technical College System Catalog. Administrators were those full-time community and technical college employees who held the position of president, vice president, dean, or a mid-management/supervisory role who were listed under "Administration" in the official 2007-2008 Kentucky Community and Technical College System Catalog. Non-teaching administrators holding faculty status were grouped in the "administrator" category for the purpose of this study. Faculty holding division chair responsibilities or administrative council or Senate duties were grouped in the "faculty" category. Administrators employed in the KCTCS central administration office in Versailles, Kentucky were excluded from the study because the intent of the research was to examine perceptions from employees of the 16 individual KCTCS institutions. Participants in the pilot study were also excluded from the present study as well as the researcher who was employed by one of the colleges studied. Table 1 identifies the available population by status. 
Table 1

Available Population $(N)$ by Kentucky Community and Technical College System (KCTCS) Institution and Status (Source: 2007-2008 KCTCS Catalog)

Institution

Faculty $(N)$

Administrators $(N)$

Ashland Community and Technical College

96

12

Big Sandy Community and Technical College

117

26

Bluegrass Community and Technical College

286

13

Bowling Green Technical College

58

10

Elizabethtown Community and Technical College

125

8

Gateway Community and Technical College

71

26

Hazard Community and Technical College

118

7

Henderson Community College

51

12

Hopkinsville Community College

66

9

Jefferson Community and Technical College

323

16

Madisonville Community College

110

7

Maysville Community and Technical College

83

9

Owensboro Community and Technical College

96

10

Somerset Community College

151

8

Southeast Kentucky Community and Technical College

109

7

West Kentucky Community and Technical College

135

15

Total Available Population

1,995

195

NOTE: Division chairs are included with "faculty" category. 
Participant Selections and Sampling Procedures

Selection Methodology and Sampling Procedures

The population of all administrators, as listed in the 2007-2008 Kentucky

Community and Technical College Catalog for the 16 individual KCTCS institutions, was selected for this research. Therefore, no sampling procedures were required for administrators. A convenience sample of faculty was chosen for ease and accessibility. The sample size for the faculty was determined by conducting a test of statistical power (Cohen \& Cohen, 1983). The researcher acknowledged that the convenience sampling methods selected for this study limits the generalizability of the study results beyond Kentucky community and technical colleges.

According to Cohen and Cohen (1988) power is the probability of finding significance if significance exists. To determine sample size, the following elements are required:

1. Power - Power is the probability of detecting relationships. Power is acquired through a methodological source and is stated as low, medium, or high. When needed, Cohen and Cohen (1983) suggested using .80.

2. Alpha or level of statistical significance - This is the conventional .05 or .01 .

3. Effect size - The significant effect for the study stated as R-squared for multiple regression. This statistic is also acquired from a methodological source or previous literature. Cohen and Cohen (1988) suggested an R-squared of .02 for a small effect, .13 as a medium effect, and .26 as a large effect size.

The population of administrators was $N=195$. The population of faculty in the 16 institutions of KCTCS was $N=1,995$. The results of a power analysis (Cohen \& Cohen, 
1983 ), using a high power criterion of .80 , a stringent alpha of .05 , and a medium to small effect size of .20, suggests that survey responses from at least $n=405$ faculty members was desired.

Faculty were selected by taking a stratified random sample with the strata being the specific KCTCS institution of employment. According to Gay (2000), the steps in selecting a stratified random sample include: (a) identify and define the population KCTCS faculty; (b) determine the desired sample size - 405 faculty; (c) identify the variable and subgroups for which you want to guarantee appropriate, equal representation - faculty from the $16 \mathrm{KCTCS}$ institutions; (d) classify all members of the population as members of one of the identified subgroups; and (e) randomly select (using a table of random numbers or a random number generator) an appropriate number of individuals from each subgroup. A total of $75 \%$ of each faculty subgroup (KCTCS institution) were randomly selected to achieve a total of 1,497. A number generator was utilized to select the 1,497 stratified random sample from the 2007-08 Kentucky Community and Technical College System Catalog list of faculty names entered into an Excel spreadsheet. An expected return rate of $30 \%$ was determined to generate the desired sample of $n=405$ faculty. The stratified random sample figures are outlined below in Table 2. The KCTCS catalog was published in July 2007 and the study took place in September 2007. To improve potential response rates, a KCTCS institution human resources director was utilized to verify current employment of the sample at the time of the study. Replacements were made as necessary to ensure accuracy of the initial mailing. 
Table 2

Stratified Random Sample (n) of Kentucky Community and Technical College System (KCTCS) Institution Faculty (Source: 2007-2008 Kentucky Community and Technical College System Catalog)

Institution

Faculty $(n)$

Ashland Community and Technical College

72

Big Sandy Community and Technical College $\quad 88$

Bluegrass Community and Technical College 215

Bowling Green Technical College $\quad 44$

Elizabethtown Community and Technical College 94

Gateway Community and Technical College $\quad 53$

Hazard Community and Technical College $\quad 89$

$\begin{array}{ll}\text { Henderson Community College } & 38\end{array}$

Hopkinsville Community College $\quad 50$

Jefferson Community and Technical College 242

$\begin{array}{lr}\text { Madisonville Community College } & 82\end{array}$

Maysville Community and Technical College 62

$\begin{array}{ll}\text { Owensboro Community and Technical College } & 72\end{array}$

$\begin{array}{ll}\text { Somerset Community College } & 113\end{array}$

Southeast Kentucky Community and Technical College 82

$\begin{array}{ll}\text { West Kentucky Community and Technical College } & 101\end{array}$

Total Stratified Random Sample $\quad 1,497$ 
Response Rates

A summary of survey response rates is included in Appendix D and Appendix E. A response rate of $50 \%$ is commonly considered adequate for analysis and reporting (Babbie 1990; Nachmias \& Nachmias, 1987). A response rate of $70 \%$ or more is normally considered very good (Babbie, 1990). A more typical response rate for a mail survey in the social sciences is between $20 \%$ and $40 \%$ (Nachmias \& Nachmias, 1987). The response rate goal of this study was 30\%. A 30\% response rate will result in 449 returned faculty surveys, comfortably beyond the number suggested by the power analysis described above. A $30 \%$ response rate will result in 59 administrator surveys.

Various strategies were employed to ensure adequate response rates such as multiple contacts with potential participants and the assistance of colleagues communicating on behalf of the researcher. In addition, the instrument was designed with attention to professional appearance, clearly written instructions, and readability as well as a conventional, vertical booklet format (Dillman, 2000; Fowler, 1988).

Instrumentation

\section{Design of Indices}

The survey instrument included six indices designed to yield information about the seven variables included in the research questions introduced in Chapter 1.

1. Perception of Merger Index

2. Type of Institutional Decision-Making Index

3. Depth of Merger Implementation Index

4. Level of Involvement in Merger Initiatives Index

5. Motivation for Reform Initiatives That Led to Merger Index 


\section{Level of Support for Reform Initiatives That Led to Merger Index}

The first index measured respondents' perceptions of merger. The second index measured the type of institutional decision-making as perceived by the respondents at their institutions. The third index measured the depth of implementation of merger initiatives as perceived by the respondents. The fourth index measured the level of involvement in merger initiatives as perceived by the respondents. The fifth index measured whether respondents perceive the merger as internally or externally motivated. The sixth index measured respondents' level of support for statewide reform initiatives that led to merger. Table 3 details the survey items that were combined to form the six indices.

Table 3

Questions Forming Research Indices

Index Survey Items

Perception of Merger

Items: $1,9,17,23,25,27,28,30$

Type of Institutional Decision Making

Items: 11, 16, 19, 22, 26, 29

Depth of Merger Implementation

Items: $5, \mathbf{6}, 12,13,15,24$

Level of Involvement in Merger Initiatives

Items: $2,3,14,18,21$

Motivation for Reform Initiatives

That Led to Merger

Items: $4,7,8,10,20$

Level of Support for Reform Initiatives

That Led to Merger

Items: $31,32, \mathbf{3 3}, 34,35,36$

Note. Survey items identified in bold print are reverse-coded questions on the survey instrument. 
The indices outlined above were developed specifically for this research. Survey questions categorized in each index were written by the researcher or derived from previous research (Metcalf, 2001; Nunez, 2003; Welsh \& Metcalf, 2003). Each index included from five to eight questions. Some items were reverse coded. The reverse coding technique was employed in order to mix up the direction (positive or negative) of the statements to minimize response biases.

\section{Physical Design of Instrument}

Data collection consisted of a researcher-designed, self-report survey instrument. The survey instrument was fashioned to create a simple, professional, easy-to-follow format for respondents. The Perception of the Merger of Kentucky's Community Colleges and Vocational/Technical Institutes survey utilized an appealing format that maximized the use of white space. A similar layout was used successfully by previous researchers (Metcalf, 2001; Nunez, 2003; Sanders, 2005). Consistently throughout the merger perception scale instrument, a five-point, Likert-type scale designed for participants to denote their responses ( $5=$ strongly agree $; 1=$ strongly disagree) was employed. The 5point, Likert-type scale is widely used in instruments measuring perceptions, beliefs, and attitudes (DeVellis, 1991, p. 70). The merger perception scale included a neutral midpoint of "neither agree nor disagree." As suggested by DeVellis:

Common choices for a midpoint includes neither agree nor disagree and agree and disagree equally. The first [selection] implies apathetic disinterest while the latter suggests strong but equal attraction to both agreement and disagreement. It may very well be that most respondents do not focus very much attention on subtleties 
of language but merely regard any reasonable response option in the center of the range as a midpoint irrespective of its precise wording. (1991)

The closed-ended layout provided respondents with fixed choices which allowed respondents to easily indicate their answers. An open-ended "additional comments" survey instrument insert (see Appendix F) gave respondents an opportunity to provide qualitative responses. To increase accuracy and reduce confusion, a legend was included at the top of every survey page. Respondents could select Don't Know / No Opinion if the question did not apply to the respondent. The instrument was divided into two sections. The first section was designed to measure general perceptions of KCTCS faculty and administrators of the merger of Kentucky's community colleges and technical/vocational institutes. The second section was designed to gather demographic information. Demographic questions were located at the end of the questionnaire to reduce respondent fatigue (Wimmer \& Dominick, 2005).

\section{Demographic Variables}

In addition to the 36 survey items measuring faculty and administrator perceptions of the merger of Kentucky's community colleges and technical/vocational institutes, demographic variables assessing faculty and administrator characteristics were also measured. The demographic variables, selected to add depth and breadth to the study, were as follows (survey question numbers listed):

37. Position at the college (faculty or administrator)

38. Primary academic discipline (if faculty)

39. Years employed in present job

40. Years employed in higher education 
41. Gender

42. Age

43. Faculty rank

44. Tenure (yes or no)

45. Type of institution employed at time of merger (vocational/technical-KY, community college-UK, N.A./other)

A survey insert was included to allow respondents an opportunity to provide additional, open-ended comments.

\section{Instrument Validity and Reliability}

\section{Validity}

Validity represents how well a survey measures what it claims to measure (Litwin, 1995). Survey content validity addresses the degree to which the measure covers the range of meanings included within a concept (Fowler, 1988). Further, content validity is supported when a panel of experts reviews the data collection instrument and the experts determine if the survey questions adequately sample the content domain (Gall, Gall, \& Borg, 2003).

A panel of postsecondary education experts in institutional mergers, educational reform, and survey methodology reviewed the instrument utilized in the present study (see Table 4). Each panel member was mailed a copy of the survey instrument, survey dimensions evaluation, research questions, and definitions of the survey variables. Panel members reviewed the cover letters and each survey item and assessed the degree to which items measured the six indices. Expert panelists were provided a survey dimensions evaluation document (see Appendix G) that utilized a 5-point Likert-type 
scale $(5=$ Excellent, $1=$ Poor $)$ for each question and index. Blank sections were provided for written comments. Feedback from the panel of experts was used to make revisions and enhancements to the survey materials and ensure content validity.

One panelist commented that the research questions were "well-focused, on target, and more than appropriate for the larger research question." Another suggested the addition of a demographic question to identify whether respondents were employed by a community college or technical college prior to merger. The researcher made the addition to the survey instrument. Another panelist suggested the inclusion of an open-ended "additional comments" section, and the researcher incorporated the recommendation into the survey instrument.

Table 4

Expert Panel Members

\begin{tabular}{lll}
\hline \multicolumn{1}{c}{ Name } & Institution/Organization & Position \\
\hline Dr. Jeff Hockaday & $\begin{array}{l}\text { Hockaday-Hunter \& Associates } \\
\text { Executive Search Services }\end{array}$ & $\begin{array}{l}\text { President; Former } \\
\text { Interim President- } \\
\text { Kentucky Community } \\
\text { and Technical } \\
\text { College System } \\
\text { (KCTCS); Former } \\
\text { Chancellor, Virginia } \\
\text { Community College } \\
\text { System }\end{array}$ \\
& & $\begin{array}{l}\text { Senior Associate and } \\
\text { Consultant on }\end{array}$ \\
& & $\begin{array}{l}\text { Kentucky Higher } \\
\text { Education Reforms }\end{array}$ \\
Dr. Aimes C. & National Center for Higher & Education Management \\
McGinness, Jr. & Systems (NCHEMS) & V.P. for Instruction \\
& & and Extended Studies,
\end{tabular}


Former Executive Director of the State Board of Directors for the Community Colleges of Arizona, Past Commissioner to the Education Commission of the States (ECS)

Dr. John E. Roueche

The University of Texas at

Professor and Austin Director, Community College Leadership Program (CCLP); Nationally-recognized community college author

\section{Reliability}

Gay (2000, p. 169) noted that reliability is "the degree to which a test consistently measures whatever it is measuring." Litwin (1995) further commented that reliability measures how reproducible the survey instrument's data are. Internal reliability of the research instrument was enhanced by randomly distributing questions from the seven indices throughout the instrument to nullify the effect of respondent fatigue. Another strategy utilized to reduce respondent fatigue was the placement of demographic questions at the end of the survey.

Reliability was further addressed by the inclusion of both positively and negatively worded questions (Wimmer \& Dominick, 2005). The survey was printed on high quality heavy paper, included a signature on the cover letter, and printed postagepaid return envelopes (internal campus mail or U.S. mail). A booklet format was used to enhance readability and to prevent lost pages (Dillman, 2000; Sudman \& Bradburn, 
1982). The open-ended "additional comments" insert was the only loose paper section of the survey, but the insert was design not to detract from the primary quantitative data collection instrument.

\section{Pilot Study}

Borg and Gall (2003, p. 230) stated that "... it is very desirable to carry out a thorough pretest of your questionnaire before using it in your study." Gay (2000, p. 111) commented that, " $\ldots$ a pilot study can help in refining procedures such as instrument administration, scoring routines, and analysis techniques." A pilot study for the present study was conducted in September 2007 [see Pilot Study Cover Letter in Appendix H and Pilot Study Questionnaire Evaluation Form in Appendix I]. Participants included 20 retired/former Hopkinsville Community College faculty and 10 retired/former HCC administrators. The pilot study for this research generated useful feedback from participants and the data obtained were utilized for making adjustments to the instrument and improving the process. The pilot study offered an opportunity to correct typographical errors, to determine the clarity of the instrument, to learn the length of time required to complete the survey, to identify other problematic issues, and to gather other suggestions.

\section{Data Collection Procedures}

The present study utilized the Dillman (2000) tailored design model as a basic, underlying guide for data collection with some additional methods incorporated such as email correspondences to the survey population by key contacts at each institution and personal emails and letters from the researcher. KCTCS colleagues of the researcher communicated to various groups of faculty and administrators to encourage participation 
in the survey. Dillman (2000) suggested five procedures for gaining optimal survey responses: (1) a respondent-friendly questionnaire, (2) multiple contacts with the questionnaire recipients, (3) inclusion of stamped return envelopes, (4) personalized correspondence, and (5) a token financial incentive that is sent with the survey request.

The approach taken by the researcher in the present study focused primarily on four of the five strategies suggested by Dillman (2000). A token financial incentive was not practical or possible for the present study.

Table 5

Data Collection Correspondence

\begin{tabular}{lll} 
Type of Contact & Number of Contact & Date \\
\hline $\begin{array}{l}\text { Pre-Letter; Advocacy } \\
\begin{array}{l}\text { Email (Sent on Behalf of } \\
\text { Researcher by Various }\end{array}\end{array}$ & First Third Party Contact & Mid-September 2007 \\
$\begin{array}{l}\text { KCTCS Colleagues' } \\
\text { Email Distribution Groups) }\end{array}$ & & \\
$\begin{array}{l}\text { Cover Letter/Informed } \\
\text { Consent }\end{array}$ & Second Contact & Late-September 2007 \\
$\begin{array}{l}\text { Thank You and Follow-Up } \\
\text { Emails }\end{array}$ & Third and Fourth Contacts & $\begin{array}{l}\text { Early October 2007 } \\
\text { Through End of Data } \\
\text { Collection }\end{array}$ \\
\hline
\end{tabular}

A first-contact, advocacy notification was sent via KCTCS email delivery system in September 2007 involving several of the researcher's colleagues who were enlisted to encourage participation in the study (see Appendix J). First, the President/CEO of one KCTCS institution was enlisted to send an email correspondence to the KCTCS Presidents/CEOs electronic distribution list describing the nature of the research study 
and asking colleagues to encourage their leadership team members to complete the survey when it was received. Secondly, the Chief Academic Officer of one KCTCS institution was enlisted to send an email correspondence to the KCTCS Chief Academic Officers electronic distribution list describing the nature of the research study and asking colleagues to encourage their faculty members to complete the survey when it was received. Thirdly, the researcher communicated regularly with the KCTCS Institutional Researchers at each institution to obtain their assistance with survey completion at their institutions. A similar approach was utilized for the Chief Business Affairs Officers, Deans of Workforce and Community Development, Information Technology Directors, and Institutional Advancement/PR Coordinators.

Approximately one week later in September 2007, survey instruments were mailed to KCTCS faculty and administrators via the internal, KCTCS mail delivery system (as approved by the KCTCS central office). Each packet included a cover letter (see Appendix K), including a statement of the institution's human subjects policy/informed consent, a survey instrument, and a pre-addressed, postage-paid envelope designed for convenient return to the researcher. Detailed return instructions were also included. Participants were asked to rate their responses on a Likert-type scale ( 5 = strongly agree $; 1=$ strongly disagree $)$. The researcher sent follow-up emails to nonresponders as a third contact [see Appendix L].

Survey anonymity was assured to survey participants; however, each envelope was coded to allow for the tracking of responses. The code was a random number assigned to each participant and stored in the survey database. Tracking numbers were printed above the participant name on the outbound envelope and above the return 
address on the inbound envelope label. An Excel spreadsheet listed the tracking numbers and corresponding participants and tracked forms of communications/contacts with participants. Additionally, the researcher communicated directly with non-responders via emails and telephone to encourage survey completion.

\section{Data Analysis}

The study was a causal comparative design in which $t$-tests, analysis of variance (ANOVA), correlation, and multiple regression were used to address the six research questions. The investigation utilized two independent variables and a dependent variable. In the multiple regressions there were five control (predictor) variables. The independent variable was respondent status, faculty or administrator. The dependent variable utilized in the study was perception of the merger of Kentucky's community colleges and technical/vocational institutes.

The review of literature pertaining to faculty/administrator world views led to an exploration of educational change and institutional mergers. As themes in the literature emerged, suspected relationships between KCTCS faculty and administrators' perceptions of merger and other major variables (control variables) developed. Five related control (predictor) variables, gleaned from the literature, were introduced to determine whether each served as a predictor of respondents' perception of merger. The five control variables were the following: (a) type of institutional decision-making, (b) depth of merger implementation, (c) level of involvement in merger initiatives, (d) internal versus external motivation for reform initiatives that led to merger, and (e) respondents' level of support for reform initiatives that led to merger. Each control 
variable was examined to determine if it served as a predictor of faculty and administrators perceptions of merger.

\section{Statistical Analysis}

Data entry and analysis were performed using the SPSS, version 16 . A $95 \%$ confidence interval was established for this research. The alpha level of significance was .05. Parametric statistical methods were used for data analysis due to the interval data generated from the 5-point Likert-type response scale. Gay (2000) suggested that educational research on achievement, aptitude, motivation, and attitude are generally treated as interval variables. Descriptive statistics including mean, median, and mode and measures of variability including range, variance, and standard deviation were derived for each survey item and each index. These findings are presented in the results section of Chapter IV. T-tests, ANOVAs, correlation, and hierarchical multiple regression were employed for data analysis and the results are presented in Tables 12-16.

The purpose of the present study was to determine if a significant difference existed between faculty and administrator perceptions of the merger of Kentucky's community colleges and vocational/technical institutes and variables potentially affecting these perceptions. Employing the survey data to answer the research questions necessitated the determination of the existence of significantly different perceptions of faculty and administrators regarding merger. Additionally, information was analyzed according to which variables influenced the perceptions. To explore the impact of each of the control variables on the overall perception of merger held by faculty and administrators, a hierarchical multiple regression analysis was performed. 
Cohen and Cohen (1983) stated that multiple regression should be used whenever a quantitative variable is to be studied as a factor of, or in relationship to any factors of interest. Cohen and Cohen (1983, p. 120) also noted the following:

One of the most powerful tools for extracting information from a data set is hierarchical analysis where the choice of a particular sequence of independent variables is made in advance. A major advantage of hierarchical multiple regression analysis of the data is that once the order of the independent variables has been specified, a unique portioning of the total variance can be accounted for. There are three steps in the hierarchical multiple regression statistical procedure utilized in this study (discussed in greater detail in Chapter 4):

1. Measure the effects of the control variables on the dependent variable (perception of merger).

2. Measure the effect of the independent variable (respondent status, faculty or administrator) on the dependent variable (perception of merger).

3. Test for significant interaction effects between the control variables and the independent variable.

Hierarchical multiple regression analysis allows for investigation of the "multiplicity of influences" impacting the dependent variable (Cohen \& Cohen, 1983, p. 7). Prior to the regression analysis, a correlation matrix is outlined.

The first step measures the effect of the study's control variables upon the dependent variable (perception of merger). The second step is a measure of the effect of the independent variable (status as faculty or administrator) on the dependent variable. The third and final step in the entry order of the hierarchical multiple regression equation 
is the test for interaction effects - significant interactions between the control variables and the independent variable.

\section{Summary}

Survey research offers a quantitative explanation of trends, attitudes, or opinions of a population by studying a sample of that population (Creswell, 2003, p. 157). The present study sought to examine perceptions held by faculty and administrators of the Kentucky Community and Technical College System regarding the merger of Kentucky's community colleges and vocational/technical institutes. Survey methodology was determined as the correct design for the research. The survey instrument was developed based on a comprehensive review of the literature on faculty and administrator world view and the guidance of the best practices outlined by a cross-section of research design texts (Dillman, 2000; Groves, Fowler, Couper, Lepkowski, Singer, \& Tourangeau, 2004; Sudman \& Bradburn, 1982). Validity and reliability were tested utilizing an expert panel and a pilot study of the instrument. Revisions and adjustments to the survey instrument were made incorporating feedback received. The survey was distributed in September 2007. The population for the research was all full-time administrators and a stratified random sample of full-time faculty employed by the 16 public institutions that make up the Kentucky Community and Technical College System in the Commonwealth of Kentucky. Hierarchical multiple regression was the primary statistical procedure employed against the data set. The chapter that follows outlines the results of the study. 


\section{CHAPTER IV}

\section{RESULTS}

As described in Chapter 1, the researcher examined Kentucky Community and Technical College System (KCTCS) faculty and administrators' perceptions of the merger of Kentucky's community colleges and vocational/technical institutes. Chapter 4 is organized around the two research questions that framed this study: (a) whether a significant difference in perceptions of merger was found between KCTCS administrators and faculty, and (b) if differences could be explained through five control variables. These included the following: (a) perceived type of institutional decision-making, (b) perceived depth of merger implementation, (c) level of involvement in the merger initiatives, (d) perception of motivation for reform initiatives, and (e) level of support for state postsecondary education reform initiatives that led to merger.

\section{Participants}

The population of potential study participants consisted of 1,692 KCTCS faculty and administrators. All 195 administrators from the 16 KCTCS institutions were surveyed in addition to a stratified random sample of faculty which equaled 1,497 from a total population of 1,995 . One survey was returned unusable and two other surveys were received after data tabulation.

Various strategies were employed to ensure adequate response rates such as multiple contacts with potential participants and the assistance of KCTCS colleagues 
communicating on behalf of the researcher. In addition, the instrument was designed with attention to professional appearance, clearly written instructions, and readability as well as a conventional, vertical booklet format (Dillman, 2000; Fowler, 1988). The survey was distributed in a 9" X 12" envelope including a self-addressed stamped envelope (SASE) with an introductory letter approved by the Institutional Review Boards of KCTCS, Western Kentucky University, and the University of Louisville. Multiple contacts using varying formats were made with potential participants in an effort to achieve a maximum response rate (Dillman, 2000).

A total of 569 faculty and administrators returned completed, usable surveys and became the sample for the study. Nachmias and Nachmias (1987) reported that a typical response rate for a mail survey in the social sciences was between 20 and 40 percent. The $33.7 \%$ total return rate for this study was consistent within the acceptable range described in the research literature. The response rate for administrators was $48 \%$ (see Appendix D) and the response rate for faculty was $31.8 \%$ (see Appendix E).

Tables 6 through 9 show frequency distributions and descriptive statistics for gender, years in present job, years in higher education, age, position, rank, tenure, and type of institution employed. A frequency table for faculty respondent's academic discipline is listed in Appendix L and a frequency table by institution is listed in Appendix M. As can be seen in Table 6, the majority of respondents (almost 60\%) were female. Respondents had an average of almost 13 years on the job and an average of approximately 18 years' employment in higher education.

Table 7 shows frequency distributions for age and position. The largest portion of cases were in the range of 51 to 60 . The great majority of respondents, about $83 \%$, were 
faculty members and the remainder administrators. As shown in Table 8, the academic rank of respondents was generally Professor or Associate Professor. This response was most relevant to faculty members. Regarding tenure status, about $62 \%$ of respondents reported having tenure. As shown in Table 9 , about half of the respondents had been associated with a community college before merger, and about $19 \%$ with a vocationaltechnical college/institute.

Table 6

Respondents' Gender, Average Years in Present Job, and Average Years in Higher Education

Gender

$\underline{\mathrm{n}} \quad \underline{\%}$

Female

331

58.1

Male

227

39.8

Unreported

12

$\underline{2.1}$

Total

570

100

Years in Present Job

Mean $\quad \underline{S D}$

12.77

7.96

$\underline{N}$

556

Years in Higher Education

17.88

9.07

552 


\section{Table 7}

Age and Position of Respondents

\begin{tabular}{lcc}
\hline Age & $\underline{n}$ & $\underline{\%}$ \\
Over 60 & 93 & 16.3 \\
$51-60$ & 229 & 40.2 \\
$41-50$ & 153 & 26.8 \\
$31-40$ & 71 & 12.5 \\
30 or under & 4 & 0.7 \\
Unreported & 20 & 3.5 \\
\hline Total & - & -100 \\
Position & 570 & $\underline{n}$ \\
Administrator & $\underline{n}$ & 16.5 \\
Faculty & 475 & 83.3 \\
Unreported & 1 & 0.2 \\
\hline Total & -100 \\
\hline
\end{tabular}


Table 8

Respondents' Academic Rank and Tenure Status

Academic Rank

$\underline{n} \quad \underline{\%}$

Professor

211

37.0

Associate Professor

180

31.6

Assistant Professor

56

9.8

Instructor

29

5.1

Unreported

94

16.5

Total

570

100

$\underline{\text { Tenure Status }}$

$\underline{n} \quad \underline{\%}$

Tenure (YES)

352

61.8

Tenure (NO)

159

27.9

Unreported

59

10.4

Total

570

100 
Table 9

Type of Institution Where Respondents Were Employed Prior to Merger

\begin{tabular}{lll}
\hline & $\underline{n}$ & $\underline{\%}$ \\
& 109 & 19.1 \\
Vocational-Technical College/Institute (KY) & 287 & 50.4 \\
Community College (UK) & 160 & 28.1 \\
N.A. - Other & $\underline{14}$ & $\underline{1.5}$ \\
Unreported & 570 & 100 \\
Total & & \\
\hline
\end{tabular}

Reliability of the Scales Used in the Study

Four of the six indices met the .70 Cronbach's coefficient alpha score threshold established for this study. A .70 Cronbach score is generally viewed as acceptable (Litwin, 1995; Nunnally \& Bernstein, 1994). The scores ranged from a high of .91 for the Perception of Merger Index to a low of .54 for the Depth of Merger Implementation Index. The Type of Institutional Decision-Making Index scored a .80 after some necessary modifications were made. Reverse-coded survey questions \#22 and \#26 were perceived similarly to items \#16 and \#19. But it was deemed necessary to eliminate question \#29 [Decision-making at my institution may be classified as political.] from the data analysis; otherwise, it contributed substantially to reliability error. The Depth of Merger Implementation Index score was .54 which was weak, but considered acceptable as described by Nunnally \& Bernstein (1984). During data analysis it was determined that questions \#12 and \#13 should be reverse-coded in the data analysis as respondent 
responses were positively correlated for these items. An Cronbach alpha coefficient could not be calculated for the Motivation for Reform Initiatives That Led To Merger Index due to respondents perceiving the items in a much different manner than expected. For the purpose of data analysis, it was determined to only use question \#4 from the Motivation for Reform Initiatives That Led to Merger Index. A respondent agreeing with this item believed the primary motivation for merger was increasing educational access and attainment. The reliability of this item could not be calculated because at least two items are needed to calculate Cronbach's alpha. Table 10 shows the Cronbach's alpha coefficient for the scales.

Table 10

Cronbach's Coefficient Alpha Scores for Study Indices

$\underline{\text { Scale }}$

Perception of Merger

Type of Institutional Decision-Making*

Depth of Merger Implementation**

Level of Involvement in Merger Initiatives

Motivation for Reform Initiatives

That Led to Merger***

Level of Support for Reform Initiatives

That Led to Merger
Number of Items $\quad$ Coefficient Alpha

8

.913

6

.802

6

.539

5

.871

5

Unable to Calculate

6 .760

*Eliminated question 29 for purposes of data analysis to enhance reliability.

**Reverse-coded questions 12 and 13 during data analysis

*** Determination made to only used question number 4 for purpose of data analysis because 5 -item scale has low reliability 
As stated in Chapter 1, two research questions framed this study that examined KCTCS faculty and administrators' perceptions of the merger of Kentucky's community colleges and vocational/technical institutes. The results for each research question are described below.

\section{Research Question 1}

Are there significant differences between KCTCS faculty and administrators in their perceptions of the merger of Kentucky's community colleges and vocational/technical institutes?

To test the null hypothesis that there was no difference in the perception of merger between KCTCS faculty and administrators, a one-way analysis of variance (ANOVA) was performed with the perception of merger as the dependent variable and independent variable was respondent status, faculty or administrator.

Table 11 shows mean scores and accompanying statistics for each respondent group. A one-way ANOVA revealed a significant difference among means, $F(1,567)=$ $60.91, p<.001$. Statistically significant differences in perception of merger were observed. The mean score of administrators $(M=4.24)$ exceeded the mean of the faculty respondents $(M=3.33)$. The mean score of the administrators was significantly higher than the faculty group at the .001 level of significance.

Cohen (1988) suggested that, for eta squared, .01 represents a small effect size, .06 medium, and .14 a large effect size. The eta squared statistic for the present study was .097 indicating an effect size between medium and large for the effects of the respondent group on the perception of merger. 
Table 11

Descriptive Statistics for Perception of Merger by Respondent Group

\begin{tabular}{|c|c|c|c|c|c|c|}
\hline & \multirow[b]{2}{*}{$\underline{N}$} & \multirow[b]{2}{*}{$\underline{M}$} & \multirow[b]{2}{*}{$\underline{S D}$} & \multirow[b]{2}{*}{$\underline{S E}$} & \multicolumn{2}{|c|}{$\underline{95 \% \text { Confidence Interval for Mean }}$} \\
\hline & & & & & Lower Bound & Upper Bound \\
\hline Administrator & 94 & 4.24 & .81 & .106 & 4.03 & 4.44 \\
\hline Faculty & 475 & 3.33 & 1.06 & .047 & 3.24 & 3.43 \\
\hline Total & 569 & 3.48 & 1.08 & .058 & 3.67 & 3.90 \\
\hline
\end{tabular}


Research Question 2

What factors help us understand faculty and administrator perceptions of the merger of Kentucky's community colleges and vocational/technical institutes?

A multivariate analysis of variance (MANOVA) was performed with the six indices used as dependent variables: (a) perception of merger, (b) perceived type of institutional decision-making - collegial or hierarchical, (c) perceived depth of merger implementation, (d) level of involvement in the merger initiatives, (e) perception of reform initiatives as to increase educational access and attainment, and (f) level of support for state postsecondary education reform initiatives that led to merger. The independent variable was respondent status, faculty or administrator.

The MANOVA was statistically significant, Wilks' lambda $=.843, F(6,562)=$ $17.50, p<.001$. Univariate ANOVA were performed on each dependent variable (with $d f$ for each $F=1,567$ ). The ANOVA revealed significantly higher mean scores were obtained by administrators compared to faculty (see Table 12). Table 13 shows F-ratios, obtained significance values, and partial eta square statistics (an indicator of effect size). As can be seen in the table, largest effect sizes were found for the scales Type of Decision-Making, Perception of Merger, and Level of Support. 
Table 12

Descriptive Statistics for Six Scales Comparing Faculty and Administrators

\begin{tabular}{|c|c|c|c|c|}
\hline Scales & Position & $M$ & $S D$ & $n$ \\
\hline \multirow[t]{3}{*}{ Perception of Merger } & Administrator & 4.24 & .81 & 94 \\
\hline & Faculty & 3.33 & 1.06 & 475 \\
\hline & Total & 3.48 & 1.08 & 569 \\
\hline \multirow[t]{3}{*}{ Type of Institutional Decision-Making } & Administrator & 3.83 & .83 & 94 \\
\hline & Faculty & 2.84 & .92 & 475 \\
\hline & Total & 3.00 & .98 & 569 \\
\hline \multirow[t]{3}{*}{ Depth of Merger Implementation } & Administrator & 4.18 & .60 & 94 \\
\hline & Faculty & 3.92 & .63 & 475 \\
\hline & Total & 3.97 & .63 & 569 \\
\hline \multirow{3}{*}{$\begin{array}{l}\text { Level of Support for State Postsecondary Reform } \\
\text { Initiatives That Led to Merger }\end{array}$} & Administrator & 4.26 & .73 & 94 \\
\hline & Faculty & 3.54 & .85 & 475 \\
\hline & Total & 3.66 & .88 & 569 \\
\hline
\end{tabular}




\begin{tabular}{lllll}
\hline Level of Involvement in Merger Initiatives & Administrator & 3.96 & 1.26 & 94 \\
& Faculty & 3.49 & 1.19 & 475 \\
& Total & 3.57 & 1.21 & 569 \\
\hline $\begin{array}{l}\text { Motivation for Reform Initiatives That Led to Merger } \\
\text { (as increased educational access and attainment) }\end{array}$ & Administrator & 4.08 & 1.12 & 94 \\
& Faculty & 3.06 & 1.45 & 475 \\
& Total & 3.23 & 1.45 & 569
\end{tabular}


Table 13

Results of ANOVA Comparing Administrators and Faculty on Six Indices

\begin{tabular}{|c|c|c|c|c|}
\hline Scale & $\underline{F(1,567)}$ & $\underline{p}$ & $\eta^{2}$ & $\underline{\text { Effect Size }}$ \\
\hline Perception of Merger & 60.91 & $<.001$ & .10 & Moderate to Large \\
\hline Type of Decision-Making & 93.30 & $<.001$ & .14 & Large \\
\hline $\begin{array}{l}\text { Depth of Merger } \\
\text { Implementation }\end{array}$ & 13.41 & $<.001$ & .02 & Small \\
\hline $\begin{array}{l}\text { Level of Support } \\
\text { for State Postsecondary } \\
\text { Reform Initiatives That } \\
\text { Led to Merger }\end{array}$ & 59.55 & $<.001$ & .10 & Moderate to Large \\
\hline $\begin{array}{l}\text { Level of Involvement } \\
\text { In Merger Initiatives }\end{array}$ & 11.98 & $<.001$ & .02 & Small \\
\hline $\begin{array}{l}\text { Motivation for Reform } \\
\text { Initiatives That Led to } \\
\text { Merger }\end{array}$ & 41.38 & $<.001$ & .07 & Moderate \\
\hline \multicolumn{5}{|c|}{$\begin{array}{l}\text { Note. For all scales, the mean scale score of administrators exceeded the mean score of } \\
\text { faculty members. }\end{array}$} \\
\hline \multicolumn{5}{|l|}{ Regression Analysis } \\
\hline \multicolumn{5}{|c|}{ The researcher then conducted a hierarchical multiple regression to determine the } \\
\hline \multicolumn{5}{|c|}{ respondent status (administrator or faculty) after entering the control variables: perceive } \\
\hline \multicolumn{5}{|c|}{ type of decision-making, perceived depth of merger implementation, support for } \\
\hline postsecondary education re & rm initiative & that led to & er, 1 & 1 of involvement in \\
\hline
\end{tabular}


Cohen and Cohen (1983) stated that multiple regression should be used whenever a quantitative variable is to be studied as a factor of, or in relationship to any factors of interest. Cohen and Cohen (1983, p. 120) also noted the following:

One of the most powerful tools for extracting information from a data set is hierarchical analysis where the choice of a particular sequence of independent variables is made in advance. A major advantage of hierarchical multiple regression analysis of the data is that once the order of the independent variables has been specified, a unique portioning of the total variance can be accounted for. There are three steps in the hierarchical multiple regression statistical procedure utilized in this study:

1. Measure the effects of the control variables on the dependent variable (perception of merger).

2. Measure the effect of the independent variable (respondent status, faculty or administrator) on the dependent variable (perception of merger).

3. Test for significant interaction effects between the control variables and independent variable.

Hierarchical multiple regression analysis allows for investigation of the "multiplicity of influences" impacting the dependent variable (Cohen \& Cohen, 1983, p. 7). Prior to the regression analysis, a correlation matrix was calculated.

The first step measures the effect of the study's control variables upon the dependent variable (perception of merger). The second step is a measure of the effect of the independent variable (status as faculty or administrator) on the dependent variable. The third and final step in the entry order of the hierarchical multiple regression equation 
is the test for interaction effects - significant interactions between the control variables and the independent variable.

Table 14 shows means, standard deviations, and correlations among all the variables used in the regression. The strongest correlation for the dependent variable, Perception of Merger, among the control variables was Level of Support for State Postsecondary Education Reform Initiatives That Led to Merger (.83), followed by Motivation for Reform Initiatives That Led to Merger (as increased educational access and attainment) (.70), followed by Type of Institutional Decision-Making (.61), followed by Depth of Merger Implementation (.29), and Level of Involvement in Merger Initiatives (.23). The relationships among the control variables and Respondent Status (Position) were also positive and ranged from .14 to .38 .

In the first step of the hierarchical regression, the five control variables were entered. They were significantly associated with Perception of Merger, the dependent variable $F(5,563)=332.35, p<.001$. In the second step, variable Respondent Status (position) was entered. The latter did not significantly increase the percentage of variance accounted for in the dependent variable, $F(1,562)=0.23, p=.63$. In step 3 , five interaction terms were entered into the regression equation. These were not significant, $F$ $(5,557)=0.50, p=.77$. This meant the homogeneity of regression coefficients assumption of ANCOVA was met. 
Table 14

Means, Standard Deviations and Inter-correlations for Perception of Merger and Six Predictor Variables: Five Scale Variables and Respondent Status $(n=569)$

\begin{tabular}{|c|c|c|c|c|c|c|c|c|}
\hline Variable & $M$ & $S D$ & 1 & 2 & 3 & 4 & 5 & 6 \\
\hline Perception of Merger & 3.48 & 1.08 & .61 & .29 & .23 & .70 & .83 & .31 \\
\hline \multicolumn{9}{|l|}{ Predictor Variable } \\
\hline 1. Type of Institutional Decision-Making & 3.00 & .98 & & .28 & .26 & .49 & .59 & .38 \\
\hline 2. Depth of Merger Implementation & 3.97 & .63 & & $\underline{-}$ & .08 & .18 & .27 & .15 \\
\hline 3. Level of Involvement in Merger Initiatives & 3.57 & 1.21 & & & & .13 & .20 & .14 \\
\hline $\begin{array}{l}\text { 4. Motivation for Reform Initiatives That } \\
\text { Led to Merger }\end{array}$ & 3.23 & 1.45 & & & & 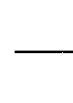 & .67 & .26 \\
\hline $\begin{array}{l}\text { 5. Level of Support for Reform Initiatives That } \\
\text { Led to Merger }\end{array}$ & 3.66 & .88 & & & & & 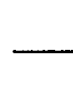 & .31 \\
\hline 6. Respondent Status (Position) & .17 & .37 & & & & & & 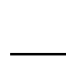 \\
\hline
\end{tabular}

Note. All correlation coefficients are significant at $p<.05$ in one-tailed tests.

For the variable Respondent Status (Position): Faculty $=0$, Administrator $=1$. 
As shown in Table 15 , approximately $74 \%$ of the variance was predicted by the control variables and this did not increase when the respondents' status (position) was added to the equation.

Table 15

R-Squared Statistics and Standard Error of Estimate for Two Regression Models

Model $\quad \underline{R} \quad \underline{R \text { square }} \quad \underline{\text { Adjusted } R \text { Square }} \quad \underline{\text { Std. Error of The Estimate }}$

$\begin{array}{lllll}1 . & .864^{\mathrm{a}} & .747 & .745 & .54485\end{array}$

2.

$.864^{\mathrm{b}} \quad .747 \quad .744$

.54522

a. Predictors: Constant, Support, Involvement, Depth, Type, Motivation b. Predictors: Constant, Support, Involvement, Depth, Type, Motivation (Faculty $=0$, Administrator $=1$ ).

Note: Dependent variable: Perception of Merger

Table 16 shows the regression coefficients in the equations. All five control variables were significant predictors of Perception of Merger. Two variables - Depth of Merger Implementation and Level of Involvement in Merger Initiatives - were significant at the $p<.05$ level. Three variables - Type of Institutional Decision-Making, Perceived Motivation for Reform Initiatives That Led to Merger (as educational access and attainment), and Level of Support for State Postsecondary Education Reform Initiatives That Led to Merger - were significant at the $p<.01$ level. All were positively associated predictors. The higher the value of the predictor variable, the more positive the Perception of Merger rating. 
Table 16

Summary of Statistics on Regression Predictors for Dependent Variable Perception of Merger

$\begin{array}{llll}\underline{\text { Predictor Variable }} & \underline{B} & \underline{S E B} & \underline{\beta} \\ \underline{\text { Step 1 }} & & & \\ \text { Type } & .145 & .030 & .131^{* *} \\ \text { Depth } & .092 & .038 & .054^{*} \\ \text { Involvement } & .043 & .020 & .048^{*} \\ \text { Motivation } & .183 & .022 & .246^{* *} \\ \text { Support } & .694 & .039 & .563^{* *}\end{array}$

Step 2

$.747 \quad .744$

Type

$.142 \quad .031$

$.128 * *$

Depth

$.092 \quad .038$

$.053^{*}$

Involvement

$.042 \quad .020$

$.047^{*}$

Motivation

$.183 \quad .022$

$.245^{* *}$

Support

$.693 \quad .039$

$.562^{* *}$

Position

$.032 \quad .067$

.011

(a) For the variable Respondent Status (Position): Faculty $=0$, Administrator $=1$. $* p<.05$

${ }^{* *} p<.01$ 


\section{Open-Ended Responses}

To add depth and breadth to the study, the researcher included an open-ended questionnaire with the survey instrument. The "additional comments" survey instrument insert (see Appendix F) gave respondents an opportunity to expand on any of their answers and to provide additional feedback on the research topic. The self-reported, qualitative data were analyzed for common themes. Inductive analysis was used for the open-ended responses to identify themes emerging from the data (Creswell, 2003; LeCompte \& Preissle, 1993; Marshall \& Rossman, 1995; Vierra, Pollock, \& Golez, 1998).

Table 17 summarizes the open-ended responses received by faculty and administrator respondents. A total of 35 administrators provided comments (for a total of $37.2 \%$ ) and 194 faculty provided qualitative feedback (for a total of 40.8\%). Overall, 229 of 569 survey respondents provided additional, self-reported feedback (for a total of $40.3 \%)$.

Two thematic constructs or clusters emerged from the data collected from administrators offering open-ended comments: (a) increased educational access and attainment - viewed as a positive result of merger, and (b) growth of the KCTCS System Office and bureaucracy - viewed as a negative result of merger. Overall, 31 positive comments were offered regarding the merger and 42 negative comments were provided.

Two positive thematic constructs or clusters emerged from the data collected from faculty offering open-ended comments: (a) increased educational access and attainment and (b) improved technical training - both viewed as positive results of merger.

Additionally, 15 negative themes emerged: (a) growth of the KCTCS System Office and 
bureaucracy, (b) too many administrators, (c) negative impact on technical colleges, (d) KCTCS President's salary and benefits package, (e) lowered academic standards and declining quality of instruction, (f) negative impact on community colleges, $(\mathrm{g})$ top-down management style, (h) differences of cultures/missions, (i) too much emphasis on enrollment numbers, (j) decline of general education transfer program, (k) rising tuition, (1) lack of local college autonomy, (m) loss of faculty authority and influence in college governance, (n) politically-motivated reforms, and (o) the move from a higher education model to a business model. Overall, 52 positive comments on the merger were received and 308 negative comments.

Table 17

Descriptive Statistics Summary of Qualitative Data Collection from Open-Ended Survey Reponses

\% Offering Additional Comments

Faculty 35

$\underline{\text { Administrators }}$

194

$\underline{40.8}$

Total

229

40.3

Summary

The results of this study were based on a 45-item survey with Perception of Merger as the dependent variable and respondent status (faculty or administrator) as the independent variable. The control variables were (a) perceived type if institutional 
decision-making - collegial or hierarchical, (b) perceived depth of merger implementation, (c) level of involvement in the merger initiatives, (d) perception of motivation for reform initiatives (as increased educational access and attainment), and (e) level of support for state postsecondary education reform initiatives that led to merger.

The population of potential study participants consisted of 1,692 KCTCS faculty and administrators. All 195 administrators from the $16 \mathrm{KCTCS}$ institutions were surveyed in addition to a stratified random sample of faculty which equaled 1,497. A total of 569 faculty and administrators returned the survey between November 2007 and March 2008. The total return rate was $33.7 \%$. The response rate for administrators was $48 \%$ and the response rate for faculty was $31.8 \%$.

Two research questions guided the study. The first sought to determine whether significant differences in perceptions of merger were found between KCTCS administrators and faculty. The second research question explored if there was a difference between the perceptions of the two groups concerning merger, could that difference be explained through the control variables of decision-making type, depth of merger implementation, level of involvement, motivation for reforms, and level of support for reforms that led to merger.

A one-way analysis of variance (ANOVA) was used to test the null hypothesis for the first question that there was no difference in the perceptions of merger, with perception of merger as the dependent variable and respondent status, faculty or administrator, as the independent variables. Administrators had a significantly higher mean score than faculty therefore the null hypothesis was rejected. The eta squared 
statistic - which reveals the degree to which a null hypothesis is false - fell in the medium to large range.

For the second research question, a multivariate analysis of variance (MANOVA) was performed with the six indices of perception, type, depth, support, involvement, and motivation as dependent variables. The MANOVA confirmed that the administrators had significantly higher scale mean scores than faculty.

A regression analysis was conducted to determine the degree of relationship between the dependent variable, Perception of Merger, and the five control variables. The control variable with the strongest correlation for the dependent variable, Perception of Merger, was Level of Support for State Postsecondary Education Reform Initiatives That Led to Merger, followed by Motivation for Reform Initiatives That Led to Merger (as increased educational access and attainment), Type of Institutional Decision-Making, Depth of Merger Implementation, and Level of Involvement in Merger Initiatives. All five of the control variables were significantly and positively associated with the dependent variable, Perception of Merger.

In the second step, the variable Respondent Status (position) was entered. It did not significantly increase the percentage of variance accounted for in the dependent variable. Approximately $74 \%$ of the variance was predicted by the control variables and this did not increase when the respondents' status (position) was considered. Based on the regression analysis, all five control variables were significant predictors of Perception of Merger. 


\section{CHAPTER V \\ DISCUSSION AND SUMMARY}

\section{Problem Statement}

One of the most nationally-recognized, two-year legislative reform initiatives in the U.S. began in Kentucky with the passage of the Kentucky Postsecondary Education Improvement Act of 1997 (HB1). This exploratory, cross-sectional, correlational study was administered at the 10-year anniversary of the HB1-legislated formation of the Kentucky Community and Technical College System (KCTCS), which originally combined 13 community colleges formerly governed by the University of Kentucky and 25 vocational/technical institutes previously governed by the Kentucky Cabinet for Workforce Development.

This study examined how KCTCS faculty and administrators perceived the merger of Kentucky's community colleges and vocational/technical institutes that resulted from HB1. Nationwide, several two-year college mergers have taken place (Bailey \& Morest, 2004; McGuinness, 2002; Puyear, 2001), and little is known about the outcomes. Additionally, a review of the literature identified distinctive world views of higher education faculty and administrators and a number of factors that potentially influenced those world views. It was suspected, because of documented research, KCTCS faculty and administrators would possibly differ significantly in their perceptions of the merger. 
Essentially, the problem was that if the resulting merger of Kentucky's community colleges and technical/vocational institutes was not deemed successful by key external constituencies, increasingly skeptical of public education in general, the twoyear college might lose relevancy in the new century - or at minimum face reduced momentum generated by the state reforms. Incongruent perceptions of merger among faculty and administrators could contribute to unsuccessful outcomes. The examination looked at the conditions necessary for successful organizational mergers and attempted to gain insight, using responses from faculty and administrators, on whether or not such conditions existed for KCTCS. This chapter presents a summary of the major findings, implications, limitations of the study and opportunities for future research.

\section{Methodology Review}

As described in Chapter 3, the methodology for this exploratory, cross-sectional study was survey and correlational research. Two research questions guided the study. The first sought to determine whether significant differences in perceptions of merger were found between Kentucky Community and Technical College System (KCTCS) administrators and faculty. The second research question explored that, if there was a difference between the perceptions of the two groups concerning merger, could that difference be explained through five control variables which were gleaned from the research literature: (a) type of institutional decision-making, (b) depth of merger implementation, (c) level of involvement in merger initiatives, (d) internal versus external motivation for reform initiatives that led to merger, and (e) level of support for state postsecondary education reform initiatives that led to merger. 
A 45-item survey instrument containing five indices was developed and tested to measure KCTCS faculty and administrator perceptions of merger in the context of state postsecondary education reforms. The indices measured variables that were identified as important in studies summarized in the literature review. A panel of higher education and community college experts reviewed and validated the instrument. The survey instruments were mailed to a stratified random sample of faculty $(n=1,497)$ and all administrators $(N=195)$ of the 16 public two-year colleges that form the Kentucky Community and Technical College System (KCTCS). A total of 569 faculty and administrators returned completed, usable surveys and became the sample for the study. The 33.7 percent total return rate for this study was consistent within the acceptable range described in the research literature.

The majority of respondents (almost $60 \%$ ) were female and approximately $40 \%$ male. The academic rank of respondents was generally Professor or Associate Professor with the two categories combining for almost $70 \%$ of respondents. The majority $(61.8 \%)$ of the respondents had tenure. A total of $16.5 \%$ of respondents were administrators and $83.3 \%$ faculty members. The largest group of respondents were in the 51-60 age range. Respondents had an average of almost 13 years on the job and an average of approximately 18 years' employment in higher education. About one-half of the respondents had been associated with a community college before merger and about $19 \%$ with a vocational-technical college/institute.

Data entry and analysis were conducted using SPSS statistical software version 14.0. The statistical analysis produced for this study included (a) frequency distributions of selected groups, (b) Cronbach's coefficient alpha scores for study indices, (c) one-way 
ANOVA with respondent status (administrator or faculty) the independent variable and perception of merger the dependent variable, (d) MANOVA with respondent status the independent variable and six indices from the survey the dependent variable, and (e) correlation and multiple regression with five control variables and respondent status as predictors and the dependent variable rated perception of merger.

\section{Summary of the Results}

The results of the study suggested that administrators maintained a more positive view of the merger than faculty. A one-way analysis of variance (ANOVA) was used to test the null hypothesis for the first question that there was no difference in the perception of merger, with Perception of Merger as the dependent variable and respondent status, faculty or administrator, as the independent variables. Administrators had a significantly higher mean score than faculty therefore the null hypothesis was rejected. The mean score of administrators $(M=4.24)$ exceeded the mean of the faculty respondents $(M=$ 3.33). The mean score of the administrators was significantly higher than the faculty group at the .001 level. Administrators maintained significantly more positive perceptions of the merger compared to faculty.

For the second research question, a multivariate analysis of variance (MANOVA) was performed with the six indices of perception, type, depth, support, involvement, and motivation as dependent variables. The MANOVA confirmed that the administrators had significantly higher scale mean scores than faculty. A regression analysis was conducted to determine the degree of the relationship between the dependent variable, Perception of Merger, and the five control variables. The control variable with the strongest correlation for the dependent variable, Perception of Merger, was Level of Support for State 
Postsecondary Education Reform Initiatives That Led to Merger. All five control variables were significantly and positively associated with the dependent variable, Perception of Merger. Approximately $74 \%$ of the variance was predicted by the control variables.

\section{Discussion of the Results}

Faculty and administrator perceptual differences were evidenced in the literature review in Chapter 2. Additionally, recently-published studies examined faculty and administrator perceptions on a number of variables such as institutional effectiveness (Welsh \& Metcalf, 2001), strategic planning (Welsh \& Metcalf, 2003), and the importance of student outcomes assessment activities (Petrosko \& Daniel, 2008). In all three studies, administrators had more positive ratings of the variables than faculty. The present study confirmed those findings with the variable perception of merger and extends the body of research on faculty and administrator world view differences.

All three studies found that control variables reduced or eliminated facultyadministrator differences. The present study was no different. Differences on the ratings of the perception of merger could be reduced with the introduction of control variables. If a community college stakeholder or state higher education board leader wanted to pursue significant organizational change or merger, he or she would benefit from accounting for the control variables described in this study.

Two thematic constructs or clusters emerged from the data collected from administrators offering open-ended comments: (a) increased educational access and attainment - viewed as a positive result of merger, and (b) growth of the KCTCS System Office and resulting bureaucracy - viewed as a negative result of merger. Overall, 
administrators offered 31 positive comments regarding the merger and 42 negative comments.

Two positive thematic constructs or clusters emerged from the data collected from faculty offering open-ended comments: (a) increased educational access and attainment and (b) improved technical training - both viewed as positive results of merger. Additionally, 15 negative themes emerged: (a) growth of the KCTCS System Office and resulting bureaucracy, (b) too many administrators, (c) negative impact on technical colleges, (d) KCTCS President's salary and benefits package, (e) lowered academic standards and declining quality of instruction, (f) negative impact on community colleges, (g) top-down management style, (h) differences of cultures/missions, (i) too much emphasis on enrollment numbers, (j) decline of general education transfer program, (k) rising tuition, (l) lack of local college autonomy, (m) loss of faculty authority and influence in college governance, $(n)$ politically-motivated reforms, and (o) the move from a higher education model to a business model. Overall, faculty made 52 positive comments on the merger and 308 negative comments.

Nicholson (2007) conducted a qualitative study on the merger of Lexington Community College (LCC) and Central Kentucky Technical College (CKTC). The openended comments gathered in the present study reaffirm a number of the themes presented in the Nicholson (2007) research project. Like the present study, faculty and administrators of LCC and CKTC felt the merger provided easier access and increased educational opportunities for students. And, like this study, respondents indicated concerns over the loss of institutional identity, negative effects on transfer credits, and differences of institutional culture between the two colleges. One difference was that the 
Nicholson (2007) study focused on all personnel employed by the college and also students. Nicholson did not compare faculty and administrator perceptions.

In contrast to the majority of the research studies identified in Chapter 2, qualitative data from the present study revealed faculty and administrator agreement on two important issues - one positive and another negative. Rather than an extreme faculty/administrator chasm, the two KCTCS groups indicated considerable agreement on a positive result of merger - increased educational access and attainment. KCTCS faculty and administrators also typically agreed on a negative aspect of merger - the growth of the KCTCS Central Office and resulting increased bureaucracy.

The fact that both groups acknowledged progress on a key goal of HB1 (increased educational access and attainment) suggests merger success in one important area and extends the conclusions of Nicholson (2007). The findings in this study represent a promising indicator of a successful merger and progress toward legislative goals, particularly since "open access" represents à basic hallmark of community and technical college missions. At KCTCS there appears to be significant agreement that the goal of postsecondary education reform was to enhance educational access and attainment and that both administrators and faculty tend to agree that the merger is succeeding on that front. It appears that KCTCS is successfully responding to the public's desire to extend educational opportunities to more Kentuckians. Habeck, Kröger, and Träm (2000) suggested that important elements in successful mergers are a clearly stated vision of the future with achievable, agreed-upon goals. It is clear that KCTCS faculty and administrators agree on the primary goal to reach more citizens. This study's findings support the work of Gross and Grambsch (1968) who discovered few differences between 
faculty and administrators in terms of broad, higher education goals. According to their research, faculty and administrators tended to differ in the details needed to achieve institutional goals, but the two groups maintained congruent opinions on overall "big picture" goals of the institution.

KCTCS leaders and stakeholders would be well served, however, by noting faculty and administrator warnings concerning the growth of the KCTCS Central Office and resulting increased bureaucracy. Both groups tended to agree on an underlying negative theme of centralization away from the uniqueness of individual colleges. These findings mirrored those identified by Nicholson (2007) regarding respondents' concerns over the loss of institutional identity among the 16 colleges.

Although the qualitative data pointed to some areas of agreement between administrators and faculty, the quantitative data showing statistically significant difference in Perception of Merger cannot be ignored. Without question, KCTCS faculty maintain a more negative view of the merger while KCTCS administrators indicated a significantly more positive outlook. The present study extends the theory of faculty and administrator world view differences as noted by Metcalf (2001), Nunez (2003), and Daniel (2008).

This study builds on role theory outlined by Biddle (1986, p. 68) where he stated that human beings "behave in ways that are different and predictable depending on their respective social identities and the situation." Like the theatrical metaphor posed by Biddle (1986), faculty and administrator responses followed predictable scripts. Like Grubiak (1996), however, the present study confirmed Biddle's (1979) hypothesis that role expectations are unlikely to be held consensually throughout a complex social 
system and there may be overlapping fields of consensus along with dissensus or even conflicting role expectations. KCTCS certainly represents a complex social system.

The present study extends the research of Moran and Volkwein (1988) to community colleges and supports the theory posited by Warburton (1989) that faculty perceive institutional climate more negatively than administrators. Moran and Volkwein (1988) suggested that further research was needed to determine if administrators' perceptions of climate were more positive than those of faculty under a wide variety of conditions on a diverse number of campuses. The authors studied faculty and administrators at four-year, public universities and found that faculty tended to perceive institutional climate more negatively than administrators.

Additionally, this study complements the research of Blackburn, Horowitz, Edington and Kloss (1986) whose work implied that faculty do not perceive that they have supervisors. The researchers noted a disconnect between faculty and administrator perceptions of their basic working relationship. The qualitative data from the present study uncovered numerous KCTCS faculty comments such as too many administrators, top-down management, lack of local autonomy, loss of faculty authority, and diminished influence in college governance. The KCTCS faculty open-ended survey comments reveal a resistance to supervision and a dissatisfaction with what they feel is a loss of control over their own destiny. DuPont (2000) conducted a study on decision-making at KCTCS and noted that faculty felt they had the least amount of influence on a) financial affairs, b) student affairs, and c) system decision-making. The researcher suggested that "it is reasonable to speculate that individuals who believe they are excluded from decision-making processes in their organization may as a result harbor feelings of anger 
and resentment, which will consequently have an adverse effect on their work performance." (p. 25) The researcher also noted a discrepancy between KCTCS faculty and administrators over which group perceived it was in charge of the organization.

The study extends the large body of research showing how American colleges and universities in the 1900s grew from simple organizations to today's complex institutions which led to the rise of specialized administrators. Coupled with the increased influence of legislatures, state agencies, and political models of governance, faculty as a whole tend to be suspicious of change and oversight. Veysey (1965) noted that college and university faculty resented the increasing number of administrators. The present study convincingly confirms the growing number of administrators' and faculty members' perception that they have lost influence in decision-making as a modern-day issue within KCTCS.

Lastly, research in Chapter 2 noted significant faculty and administrator differences regarding curricular values (Carbot, 1990; Garmon, 1984; Samuelowicz \& Bain, 2001). The open-ended responses from KCTCS faculty contained numerous comments such as "lowered academic standards" and "declining quality of instruction." It is telling that not a single KCTCS administrator commented on the status of academic rigor or quality - a clear indication that the present study findings support faculty/administrator curricular differences found in the review of literature.

Recommendation for Postsecondary Education Professionals

The literature review revealed that two-year colleges nationwide are positioned to take on an important role in the future of local communities. Therefore, it is highly likely that KCTCS and its 16 institutions will remain in the forefront of postsecondary education for years to follow. As colleges adapt to meet the ever-changing needs, high 
expectations, and lofty demands of a concerned public, reforms will continue to address and meet new challenges.

Understanding the differences in how college faculty and administrators view the world is key to fostering productive working relationships that ultimately benefit institutions and the citizens of the Commonwealth of Kentucky. The success of KCTCS long-term rests with maximizing the talents and creativity of both faculty and administrators. The two groups must work together in service to local communities in order to meet expectations.

Organizational mergers and radical changes in institutional governance are stressful and messy. The results of this study were consistent with previous research initiatives that revealed significantly different perceptional differences among faculty and administrators. This study suggested that two-year college leaders, administrators, and individual faculty would be well-served to acknowledge the impact of institutional decision-making, depth of merger implementation, individual involvement in the merger initiatives, perceived motivation for reforms, and existing level of support for state reforms. While it may not be practical or even possible to control for all variables analyzed in this study in the day-to-day, real-world environment, a thorough grasp of faculty and administrator world views and influencing factors by KCTCS leadership will likely remain significant to future policy-making and achievement of state reform mandates.

\section{Study Limitations}

The population selected for this study included only faculty and administrators from Kentucky's public, two-year community and technical colleges. The convenience 
sample was selected for ease and accessibility; therefore, generalizations of this study are subject to several limiting factors.

First, political climates, state policy goals, and resources vary among different states. Levels of accountability vary across states and expected outcomes and overall needs are unique from state to state. Second, the study used self-reported information based on personal views and was potentially more subjective than observation of actual behaviors. Third, feedback obtained from the panel of experts was subject to bias that might have existed among the experts consulted. Fourth, different community college and technical college mergers (consolidation of programs, functions, and services) occurred at different times. The KCTCS Board of Regents allowed the processes to move forward as local communities worked through the changes - the Board frequently referred to the consolidations as "community driven" processes. Lexington Community College originally remained under University of Kentucky governance when House Bill 1 was enacted and only joined the system recently. Several KCTCS institutions did not have colleges with which to merge and simply added transfer components (e.g., Bowling Green Technical College) or merely added technical programs to become comprehensive community and technical colleges (for example, Henderson Community College and Hopkinsville Community College). As a result, the various colleges were at different points in the mergers at the time of the survey and experienced the merger differently. A fifth limitation for this study involved the response rate. The $33.7 \%$ total return rate fell within the range of typical studies in the social sciences and comparable to similar studies (Daniel, 2008; Metcalf, 2001; Nunez, 2003). However, a response rate of 50\% was not achieved which would have strengthened the results. Fifth, faculty was defined in the 
simplest form for the purposes of the research. The researcher acknowledged that some faculty had non-teaching, administrative responsibilities. Some similar studies have separated faculty into faculty planners and faculty non-planners. However, the researcher chose not to sub-divide the faculty group for the purpose of this study. Sixth, the survey instrument was developed by the researcher, and more psychometric measurement and repeated uses would provide more confidence in the research results. Lastly, the researcher conducting the present study was employed by a KCTCS college at the time of data collection and continues to be employed by a KCTCS college. The researcher acknowledges that unintended biases may be present - another potential limitation.

\section{Suggestions for Additional Research}

One important educational issue not addressed by the survey instrument utilized in the present study was "quality of instruction." The study could be replicated with an emphasis on the perceived impact of merger on instructional quality by faculty and administrators and overall academic rigor. Little is known about the differences, if any, in the academic rigor of the classes taught by KCTCS institutions compared to the premerger period. Some survey respondents expressed concern that the new system emphasizes enrollment numbers and total credentials at the expense of quality. Additional research could prove useful in determining the validity of the criticism.

Additionally, this examination looked at a 10-year "snapshot" of KCTCS a merged educational system in its relative infancy. A similar study could be repeated in another 5 or 10 years after the retirements of faculty and administrators who were employed at the institutions prior to the merger. It is suspected that as an increasingly higher percentage of KCTCS employees possess no knowledge of the previous 
governance models, views would potentially be less impacted by past experiences and historical biases.

Another opportunity for future research is replication of the study in the other states where technical and academic two-year colleges were merged to form comprehensive community and technical colleges. As described in previous chapters, radical organizational reforms were legislated for two-year colleges in states in addition to Kentucky such as Connecticut, Indiana, Louisiana, Minnesota, and Washington (Bailey \& Morest, 2004; McGuinness, 2002; Puyear, 2001). A cross-study comparison would add to the body of knowledge on two-year colleges and help to identify factors contributing to successful mergers.

The study could be replicated where faculty are sub-divided into two groups, faculty planners and faculty non-planners. One could also compare perceptions of central office personnel in Versailles with the personnel in the 16 individuals KCTCS colleges. Central office personnel were not included in the present study. Future examinations could compare the different colleges and different mergers (some colleges merged more recently than others, while others only added programs to become comprehensive). Collecting more qualitative data and using a more ethnographic approach to future study of KCTCS and two-year college mergers might add depth and breadth to the topic and enrich the findings. Lastly, it is entirely possible that variables not considered in this study may have an impact on the findings and could be investigated in future research.

\section{Conclusion}

This examination provides an exploration of Kentucky Community and Technical College faculty and administrator perceptions of the merger of the state's community 
colleges and vocational/technical institutes since the enactment of the 1997 Kentucky Postsecondary Education Reform Act (House Bill 1). The results of this study indicate that KCTCS administrators maintain a much more "rosy" and positive view of merger than KCTCS faculty. In fact, a significant gap exists between the perceptions of the two groups. Administrators are significantly more likely to perceive that the merger of the state's community colleges and vocational/technical institutes into comprehensive community and technical colleges represented an improvement for the Commonwealth of Kentucky. Many faculty members - like numerous administrators - acknowledged that the merger created more access to postsecondary education for local citizenry, but they negatively perceived the fallout from the resulting combination of comprehensive community and technical colleges using terms such as "lower academic standards," "reduced rigor," and "increased bureaucracy."

All five control variables were significantly predictive of merger perception; therefore, if one could control the five influencing factors and equalize the faculty and administrator groups both would likely be positive about merger and not significantly different in perceptions. In practical terms, it is not possible, however, to control type of institutional decision-making, depth of merger implementation, level of involvement in merger initiatives, perceived motivation for reform initiatives that led to merger, and level of support for reform initiatives that led to merger.

One consistent theme of agreement from the two groups centered on frustration with the growing size of the KCTCS central offices located in Versailles - the "corporate offices" of the statewide system. Both faculty and administrators commented frequently their dissatisfaction with the resources utilized to support central administration that, they 
feel, should be made available to the local institutions "to serve students." Faculty and administrators also both articulated concern with what they consider as a "top-down" management style from the system offices. On a positive note, comments were made that merger has raised the national perception of community and technical colleges in Kentucky, benefited students with increased educational access and more options, and elevated technical education overall. The results indicate the presence of both positive and negative conditions for fostering a successful merger.

This study will be helpful for KCTCS leaders, administrators, faculty, primary stakeholders, state postsecondary education board members, and others who wish for KCTCS to successfully achieve its goals of being the best comprehensive community and technical college system by the year 2020 . KCTCS, without question, will play an integral role in postsecondary education within the state and on the nationwide level for years to come. Continued success will depend heavily on KCTCS faculty and administrators working together with other key stakeholders to meet the challenges faced by the relatively young community and technical college system. 


\section{REFERENCES}

Alfred, R.L., \& Kreider, P. (1991). Creating a culture for institutional effectiveness. Community, Technical, and Junior College Journal, 61, pp. 34-39.

Alfred, R. L., \& Linder, V. (1990, February). Rhetoric to reality: Effectiveness in community colleges. Ann Arbor, Michigan: The University of Michigan, Community College Consortium and the Center for the Study of Higher and Postsecondary Education.

Ambrose, C. M. (1990). A comparison of faculty members' and administrators' definitions of, and attitudes toward, academic freedom (Doctoral dissertation, University of Georgia, 1990). Dissertation Abstracts International, 50, 3162.

Ambrose, C. M. (1988). A comparison of faculty members' and administrators' definitions of, and attitudes toward, academic freedom. St. Louis, MO: Association for the Study of Higher Education. (ERIC Document Reproduction Service No. ED303087).

American Association of Community Colleges. (2008). Community college fast facts. Retrieved on August 31, 2008 from http://www2.aacc.nche.edu/reserach/home.htm.

American Association of Community Colleges. (2006). 2006 AACC facts. Retrieved on November 24, 2006 from http://www.aacc.nche.edu/Content/NavigationMenu/ResourceCenter/AACCPubli cations/AACC Publications.htm.

American Association of Community Colleges. (2001). Community colleges: A century of innovation. Community College Journal, 71, 10-12.

American Psychological Association (2001). Publication manual of the American psychological association ( $5^{\text {th }}$ ed.). Washington, DC: American Psychological Association.

Appelbaum, S.H. (2000). Anatomy of a merger: Behavior of organizational factors and processes throughout the pre- during- and post- stages. Management Decision, 38 , pp. 649-679.

Arnone, M. (2003). Revamping of Kentucky college system faces a 'make-or-break moment'. The Chronicle of Higher Education, 49, A23-A24. 
Austin, A.E. (1990). Faculty cultures, faculty values. In W.G. Tierney (Ed.)., Assessing Academic Climates and Cultures. (pp. 61-68. San Francisco: Jossey-Bass Publishers.

Babbie, E. (1990). Survey research methods ( $2^{\text {nd }}$ ed.). Belmont, CA: Wadsworth.

Bailey, T. R., \& Averianova, I. E. (1998, October). Multiple missions of community colleges: Conflicting or complementary? New York: Community College Research Center, Teachers, College, Columbia University.

Bailey, T. R., \& Morest, V. S. (2004, February). The organizational efficiency of multiple missions for community colleges. New York: Community College Research Center, Teachers, College, Columbia University.

Baldridge, J. V., Curtis, D. V., Ecker, G., and Riley, G. L. (1978). Policy making and effective leadership: A national study of academic management. San Francisco: Jossey-Bass.

Banta, T.W. (1995). Is there hope for TQM in the academy? In Brent D. Ruben (Ed.). Quality in higher education (pp. 209-218). New Brunswick, NJ: Transaction Publishers.

Barker, S. (1961). The role of simplicity in explanation. In H. Feigl \& G. Maxwell (Eds.), Current issues in the philosophy of science: Proceedings of the American Association for Advancement of Science, 1959 (pp. 265-274). New York: Holt, Rinehart, and Winston.

Bare, A. C. (1996). Managerial behavior of college chairpersons and administrators, Research in Higher Education, 24, 128-138.

Benjamin, E. (1994). From accreditation to regulation: The decline of academic autonomy in higher education. Academe, 80(4), 34-36.

Bennis, W. (1984). Transformative power and leadership. In T.S. Sergiovanni \& J.E. Corbally (Eds.), Leadership and organizational culture. Urbana, IL: University of Illinois Press.

Biddle, B. J. (1979). Role theory: Expectations, identities, and behaviors. New York: Academic Press.

Biddle, B. J. (1986). Recent developments in role theory. Annual Review of Sociology, $12,67-92$.

Bing, R., \& Dye, L. (1992). Danger of hierarchical decision-making, Academe, 78, 16-18.

Birnbaum, R. (1989). How colleges work. San Francisco: Jossey-Bass. 
Blackburn, R. T., Horowitz, S. M., Edington, D. W., \& Kloss, D. M. (1986). University faculty and administrator responses to job strains. Research in Higher Education, $25,31-41$.

Blackburn, R. T., Lawrence, J., \& Associates (1990). Same institution, different perceptions. Faculty and administrators report on the work environment. Ann Arbor, MI: The National Center for Research to Improve Postsecondary Teaching and Learning.

Blimling, G.S. (1993). The context of conflict in the academy: An educational dialectic on faculty and student affairs educators. College Student Affairs Journal, 13, 412 .

Blocker, C. E., Bender, L. W., \& Martorana, S. V. (1975). The political terrain of American postsecondary education. Fort Lauderdale, Florida: Nova University Press.

Blocker, C. E., Plummer, W., \& Richardson, R. C. (1965). The two-year college: A social synthesis. Englewood Cliffs, NJ: Prentice-Hall.

Bok, D. (1986). Higher learning. Cambridge, MA: Harvard University Press.

Breakwell, G. M., Hammond, S., \& Fife-Schaw, C. (1995). Research methods in psychology. London: Sage Publications.

Breneman, D. W., \& Nelson, S. C. (1980). The community college mission and patterns of funding. New Directions for Community Colleges, 8(4), 73-81.

Breneman, D. W., \& Nelson, S. C. (1981). Financing community colleges: An economic perspective. Washington, DC: Brookings Institution.

Brewer, D. J. (1999, April). How do community college faculty view institutional mission? An analysis of national survey data. New York: Community College Research Center, Teachers, College, Columbia University.

Brewer, J. A. P. (1995). Integrating academic and vocational education: An investigation of the attitudes and curricular values of administrators and faculty in the Wisconsin Technical College Systems (Doctoral dissertation, University of Minnesota, 1995). Dissertation Abstracts International, 57, 185.

Brint, S., \& Karabel, J. (1989). The diverted dream: Community colleges and the promise of educational opportunity, 1900-1985. New York: Oxford University Press.

Buono, A. R., \& Bowditch, J. L. (1989). The human side of mergers and acquisitions: Managing collisions between people, cultures, and organizations. San Francisco: Jossey-Bass. 
Campbell, T. I. D., \& Slaughter, S. (1999). Faculty and administrator attitudes toward potential conflicts of interest, commitment, and equity in university-industry relationships. The Journal of Higher Education, 70, 309-352.

Cardot, J. J. (1990). A comparison of communicator social style and world view between administrators and faculty members of higher education (Doctoral dissertation, Texas Tech University, 1990). Dissertation Abstracts International, 52, 751.

Cardozier, V. R. (1984). Upper-level colleges yesterday, today, and tomorrow. Educational Record, 65, 30-35.

Carnevale, A., \& Desrochers, D. (2001). The credentialing crunch. Community College Journal, 71, 32-39.

Chamblis, C. (1994), Reigniting the flame: TQM tactics for faculty rejuvenation. Washington, DC: ERIC Clearinghouse on Higher Education. (ERIC Document Reproduction Service No. ED 368276).

The Clements Group, L.C. (1998). Kentucky Community and Technical College System Planning Assessment: Executive Summary.

Clark, B. R. (1960). The open door college: A case study. New York: McGraw-Hill.

Clark, B. R. (1980). The 'cooling out' function revisited. In G. Vaughan (Vol. Ed.), Questioning the community college role: New directions in community colleges: Vol. 32 (pp. 15-32). San Francisco: Jossey-Bass.

Cohen, J. (1988). Statistical power analysis for the behavioral sciences $\left(2^{\text {nd }}\right.$ ed.). Hillsdale, NJ: Lawrence Erlbaum Associates.

Cohen, W. D., Bleha, B., \& Olswang, S. G. (1981). Administrative roles and perceptions of governance in the community college. Community/Junior College Research Quarterly, 5, 303-321.

Cohen, A. M., \& Brawer, F. B. (1996). The American community college ( $3^{\text {rd }}$ ed.). San Francisco: Jossey-Bass.

Cohen, J., \& Cohen, P. (1983). Applied multiple regression/correlation analysis for the behavioral sciences $\left(2^{\text {nd }}\right.$ ed.). Hillsdale, NJ: Lawrence Erlbaum Associates.

Commission on the Future of the UK Community College System (1996, January). Pathway to Kentucky's Future. Lexington, KY: University of Kentucky Community College System. 
Cooper, B. P. (1982). An attitudinal study of tenure in the two-year and four-year institutions of the state of Georgia (Doctoral dissertation, University of Georgia, 1982). Dissertation Abstracts International, 43, 1847.

Cox, M. (1999). Community-technical colleges of Connecticut. Community College Journal of Research \& Practice, 23, 325-335.

Creswell, J.W. (2003). Research design: Qualitative, quantitative, and mixed methods approaches $\left(2^{\text {nd }}\right.$ ed.). Thousand Oaks, CA: Sage Publications, Inc.

Cross, K. P. (1980). Education for personal development. In D. DeCoster \& P. Mable (Eds.), Personal education and community development in college residence halls (pp. 1-30). Cincinnati, Ohio: American College Personnel Association.

Daniel, M. B. (2008). Faculty and academic administrator attitudes concerning the importance of outcomes assessment activities (Doctoral dissertation, University of Louisville, 2008). Dissertation Abstracts International, 69.

Davis, S. L., \& Chamberlin, G. D. (1996, May). The satisfaction level of faculty and administrators following planned and unplanned budget reductions. (ERIC Document Reproduction Service No. ED397728).

Dee, J. R. (1999). Organizational support for innovation: Perspectives of community college faculty (Work Autonomy) (Doctoral Dissertation, University of Iowa, 1999). Dissertation Abstracts International, 60, 1878.

Del Favero, M. (2002, June). Faculty-administrator relationships and responsive decision-making systems: new frameworks for study. Paper presented at the Research Forum on Higher Education Governance, Santa Fe, New Mexico.

Del Favero, M. (2003). Faculty-administrator relationships as integral to high-performing governance systems; new frameworks for study. The American Behavioral Scientist, 46, 902-922.

Deming, W. E. (1982). Out of crisis (pp. 41-51). Cambridge, MA: MIT Center for Advanced Engineering.

Denton, M., \& Zeytinoglu, I. U. (1993 January). Perceived participation in decisionmaking in a university setting: The impact of gender. Industrial and labor relations review, 46(2), 320-331.

DeVellis, R. F. (1991). Scale development: Theory and applications. Thousand Oaks, CA: Sage Publications, Inc.

Dillman, D. A. (2000). Mail and internet survey: The tailored design method $\left(2^{\text {nd }}\right.$ ed.). New York: John Wiley and Sons. 
Dickerson-Gifford, D. (1990). A comparison of values of two subcultures within higher education: Academic administrators and student affairs administrators (Doctoral Dissertation, University of Kentucky, 1990). Dissertation Abstracts International, 52,816 .

Dodd, C. H., \& Garmon, C. W. (1980). Measurement of world view. Paper presented to the Speech Communication Association Intercultural Communication Caucus, New York.

Dodd, C. H., \& Garmon, C. W. (1987, November). The measurement of personal report of world view as a cognitive communication variable. Boston, MA: Speech Communication Association. (ERIC Document Reproduction Service No. ED290188).

Dougherty, K. J. (1994). The contradictory college: The conflicting origins, impacts, and futures of the community college. Albany, NY: State University of New York Press.

Drummond, M. E., \& Reitsch, A. (1995). The relationship between shared governance models and faculty and administrator attitudes. Journal for Higher Education Management, 11, 49-58.

Dupont, J. (2000). Factors contributing to faculty perceptions of participation and influence in decision making in a community college system (Doctoral dissertation, University of Kentucky, 2000). Dissertation Abstracts International, 61,3447 .

Dyer, S. (1999). Louisiana's new college system hands vo-techs an altered role. Community College Week, 11, 11.

Eastman, J., \& Lang, D. (2001). Mergers in high education: Lessons from theory and experience. Toronto: University of Toronto Press.

Field, G. R., \& Abelson, M. A. (1982). Climate: A reconceptualization and proposed model. Human Relations, 35, 181-201.

Fielden, J., \& Markham, L. (1997). Learning lessons from mergers in higher education, CHEMS Paper 17. London: Commonwealth Higher Education Management Service (CHEMS).

Fowler, F.J. (1988). Survey research methods. Newbury Park, CA: SAGE.

Gall, M., Borg, W., \& Gall, J.P. (2003). Educational research: An introduction (7 $7^{\text {th }}$ ed.). NY: Longman Publishers USA. 
Garmon, C. W. (1984). A comparison of world views among faculty and administration in institutions of higher education (Doctoral dissertation, Vanderbilt University, 1984). Dissertation Abstracts International, 45, 1309.

Gay, L.R. (2000). Education research: Competencies for analysis and application $\left(6^{\text {th }}\right.$ ed.). Columbus, $\mathrm{OH}$ : Merrill Prentice Hall.

Gayle, D. J., Hakim, T. M., Agarwal, V. K., and Alfonso, P. J. (1999). Turning culture clash into collaboration. Trusteeship, 7, 24-27.

Gennett, N.D., Johnson, C.W., \& Wilson, M.A. (2001). The shift to workforce development. Community College Journal, 71, 60-63.

Goedegebuure, L. (1992). Mergers in higher education. A comparative perspective. Utrecht: Lemma.

Greenspan, A. (2004, February 20). The critical role of education in the nation's economy. Paper presented at the United States Federal Reserve Board at the Greater Omaha Chamber of Commerce 2004 Annual Meeting, Omaha, Nebraska. Retrieved April 6, 2004, from the United States Federal Reserve Board website: http://www.federalreserve.gov/boarddocs/speeches/2004/200402202/defalt.htm

Gregory, K. L. (1983). Native-view paradigms: Multiple cultures and culture conflicts in organizations. Administrative Science Quarterly, 28, 359.

Gross, E., \& Grambsch, P. V. (1968, January). University goals and academic power. (ERIC Document Reproduction Service No. ED028692).

Groves, R.M., Fowler, Jr., F. L., Couper, M.P., Lepkowski, J.M., Singer, E., Tourangeau, R. (2004). Survey methodology. Hoboken, NJ: John Wiley \& Sons, Inc.

Grubb, W. N. (1996). Working in the middle. San Francisco: Jossey-Bass.

Grubb, W. N., Badway, N., Bell, D., Bragg, D., \& Russman, M. (1997). Workforce, economic, and community development: The changing landscape of the entrepreneurial community colleges. Mission Viejo, CA: League for Innovation in the Community College.

Grubiak, M. J. (1996). A comparison of Washington State Community College faculty and administrators' opinions and beliefs on academic freedom and tenure (Doctoral dissertation, University of Washington, 1996). Dissertation Abstracts International, 57, 5030 .

Habeck, M., Kröger, F., \& Träm, M. (2000). After the merger: Seven rules for successful post-merger integration. Prentice Hall. 
Hagberg Consulting Group (2002). Corporate culture/organizational culture:

Understanding and assessment [online]. [cited 3 July 2004] Available from Internet: URL http://w3.hcgnet.com/mergers.html

Harman, K. (2002). Merging divergent campus cultures into coherent educational communities: Challenges for higher education leaders. Higher Education, 44, 91114.

Harmon, K., \& Meek, V. (2002). Introduction to special issue: Merger revisited: International perspectives on mergers in higher education. Higher Education, 44, $1-4$.

Hartnett, R. T., \& Centra, J. (1974). Faculty views of the academic environment: Situational vs. institutional perspectives. Sociology of Education, 47, 159-169.

Healy, P. (1996). Minnesota tackles the possibility and problems of a public-college merger. The Chronicle of Higher Education, 43, A23-A24.

Hodgkinson, H. L. (1974). The campus senate: Experiment in democracy. Berkeley, CA: Center for Research and Development in Higher Education.

Holton, S. A., \& Phillips, G. (1995). Can't live with them, can't live without them: faculty and administrators in conflict. In New directions for higher education (No. 92, pp. 43-50). San Francisco: Jossey-Bass.

Honeycutt, F. D. (1995). An investigation of tech prep as perceived by community college faculties and administrative staff. (Doctoral dissertation, North Carolina State University, 1995). Dissertation Abstracts International, 56, 2978.

Jansen, J. (2003). Mergers in South African higher education: Theorizing change in transitional contexts. Politikon, 30, 27-50.

Joyce, W. F., \& Slocum, J. (1982). Climate discrepancy: Refining the concepts of psychological and organizational climate, Human Relations, 35, 951-972.

Joyce, W. F., \& Slocum, J. (1979). Climates in organizations. In S. Kerr (Ed.)., Organizational behavior, San Francisco: Grid.

Kalish, R. A. (1970). The psychology of human behavior. Belmont, CA: Brooks/Cole Publishing Co.

Kanter, R. M. (1977). Men and women of the corporation. 1993 Ed. New York: Basic Books. 
Kelsey, Jr., C. E., Mezack, III, M., \& Cardot, III, J. (1992). Are higher education's administrators and faculty really different? Washington, DC: ERIC Clearinghouse on Higher Education. (ERIC Document Reproduction Service No. ED352886).

Kentucky Community and Technical College System (2007). 2007-2008 Kentucky Community and Technical College System Catalog.

Kentucky Community and Technical College System (2006). Retrieved November 19, 2006 from http://www.kctcs.edu/organization/mccall.htm.

Kentucky Community and Technical College System (April 27, 2006). KCTCS president Michael B. McCall chairs American Association of Community Colleges Convention in Long Beach, Calif. Retrieved November 19, 2006, from http://www.kctes.edu/newspublications/newsreleases.cfm?nr_id=304.

Kentucky Community and Technical College System (2006). System Profile 2006.

Kentucky Community and Technical College System (2005). Retrieved July 29, 2005, from the Kentucky Community and Technical College System website http://www.kctcs.edu.

Kentucky Community and Technical College System (2004). System Profile 2004.

Kentucky Community and Technical College System (June 14, 2004). KCTCS president elected chair-elect of $A A C C$ board. Retrieved November 19, 2006 from http://www.kctcs.edu/newspublications/2004/2004_06_14.html.

Kentucky Community and Technical College System (2003). Annual Report 2002-2003.

Kentucky Community and Technical College System (2002). Annual Report 2001-2002.

Kentucky Community and Technical College System (2001). System Profile 2000-2001.

Kentucky Community and Technical College System (2000). Annual Report 1999-2000

Kentucky Community and Technical College System (1998). Annual Report 1997-1998.

Kentucky Community and Technical College System-Board of Regents (1999), Resolution on the consolidation of services.

Kentucky Council on Postscondary Education (2006). 2004-05 Kentucky postsecondary education accountability report, January 2006. Retrieved November 24, 2006 from http://www.cpe.ky.gov/planning/statusreports. 
Kentucky Council on Postsecondary Education (2005). Five questions - one mission, Better lives for Kentucky's people: A public agenda for postsecondary and adult education 2005-2010. Retrieved November 24, 2006 from http://www.cpe.ky.gov/planning/strategic/default.htm.

Kentucky Council on Postscondary Education (2004). 2003-04 Kentucky postsecondary education accountability report, December 2004. Retrieved November 24, 2006 from http://www.cpe.ky.gov/planning/statusreports.

Kentucky Council on Postsecondary Education (2003). Kentucky's system of postsecondary education: Progress toward reform.

Kentucky Council on Postsecondary Education (2000). 2020 vision: A strategic agenda for Kentucky's system of postsecondary education.

Kentucky Council on Postsecondary Education (1998). Kentucky's system of postsecondary education: Progress toward reform.

Kentucky Education Reform Act-KERA (1990). KRS Chapters 154.029-160.345.

Kentucky General Assembly (2004). HJR 214.

Kentucky Postsecondary Education Improvement Act. (1997). KRS Chapters 164.575164.600 .

Kingry, L., \& Cole, L. (1986). The role of Oregon community colleges in economic development. Community College Review, 13, 10-16.

Klein, A., \& Dunlap, W. P. (1994). Change: Faculty/administration perspectives. College Student Journal, 28, 199-204.

Kuh, G. D., \& Whitt, E. J. (1988). The invisible tapestry: Culture in American colleges and universities. (ERIC Document Reproduction Service No. ED299934).

LeCompte, M., \& Preissle, J. (1993). Ethnography and qualitative design in educational research. $\left(2^{\text {nd }}\right.$ ed.). San Diego, CA: Academic Press.

Legislative Record (1960). Kentucky General Assembly, SB-102.

Legislative Record (1962). Kentucky General Assembly, HB-234.

Levin, J. S. (1998). Sense-making in the community college: the meanings of organizational change. (ERIC Document Reproduction Service No. ED417777).

Lewis, T. (1991). The global economy and education for work in the United States. Journal of Vocational Education Research, 16, 1-32. 
Likert, R., \& Likert, J.G. (1967). New ways of managing conflict (pp. 71-106). New York: McGraw-Hill.

Litwin, G. H., \& Stringer, R. (1966). The influences of organizational climate. Boston: Harvard University Press.

Litwin, M.S. (1995). How to measure survey reliability and validity. Thousand Oaks, CA: SAGE Publications.

Lords, E. (2000). With a New Community-College System, Indiana Hopes for More Skilled Workers, Chronicle of Higher Education, 46, A27.

MacNeil, W. (2000). Pulling it all together. Community College Week, 12(18), 6-7.

Marshall, C., \& Rossman, G. (1995). Designing qualitative research. ( $2^{\text {nd }}$ ed.). Thousand Oaks, CA: SAGE Publications.

Martin, J., \& Samels, J. E. (1994). Conclusions: The mutual-growth process - myths and realities. In J. Martin, J.E. Samels \& Associates (Eds.), Merging colleges for mutual growth: A new strategy for academic mergers (pp. 232-234). Baltimore: Johns Hopkins University Press.

Maxwell, G. (1976). Some current trends in philosophy of science: With special attention to confirmation, theoretical entities, and mind body. In R.S. Cohen, C.A. Hooker, A.C. Michalos, \& J.W.V. Erva (Eds.) Proceedings of the biennial meeting of the Philosophy of Science Association, 1974 (Boston studies of the philosophy of science, Vol. 32, pp. 564-584). Boston: D. Reidel Publishing Company.

McCall, M.B. (2008). The creative community college: Leading change through innovation. In J. Rouche, M. Richardson, P. Neal, \& S. Rouche (Eds.), Kentucky Community and Technical College System: Building a new system (pp. 189-211). Washington, DC: American Association of Community Colleges.

McConnell, T.R. (1992). Accountability and autonomy. Journal of Higher Education, 42, 445-451.

McDowell, E. E. (1986). Administrators' and faculty members' perceptions of the performance appraisal interview. (ERIC Document Reproduction Service No. ED281247).

McGregor, D. M. (1960). The human side of enterprise (pp. 33-48). New York: McGrawHill.

McGuinness, A. C. (2002). An assessment of postsecondary education reform in Kentucky. Boulder, CO: National Center for Higher Education Management Systems. 
McMillin, L. (2002, Summer). Compacts and collaboration across the faculty/administrator divide. Retrieved on April 14, 2004 from the Association of American Colleges and Universities (AACU) Website: www.aacu-

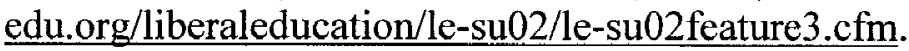

Metcalf, J. K. (2001). Faculty and academic administrator perceptions concerning institutional effectiveness importance in selected colleges and universities accredited by the Southern Association of Colleges and Schools (Doctoral dissertation, University of Louisville, 2001). Dissertation Abstracts International, $62,1663$.

Millet, J.D. (1976). Mergers in higher education: An analysis of ten case studies. Washington: The American Council of Education.

Mills, K. (2005). Kentucky's rocky road: Recent reform legislation produces results, but faces tough challenges. National Crosstalk, 13(4), 6-10.

Minnesota Commission on Post-Secondary Education. (1992, January). At the crossroads: Higher education in Minnesota. St. Paul, MN: Minnesota Planning.

Moe, R., Minnesota State Senator. (1994, November 9). Why merger. In Managing the Merger Conference document. Paper presented at the conference of the Leadership Academy, University of Minnesota (Minneapolis). New York: Delta Consulting Group, Inc.

Moran, E. T. \& Volkwein, J. F. (1988). Examining organizational climate in institutions of higher education. Research in Higher Education, 28, 367-382.

Mulvey, T. (1993). An analysis of the mergers of American institutions of higher education. Ann Arbor: University of Massachussetts.

Nachmias, D., \& Nachmias, C.F. (1987). Research methods in the social sciences. New York: Worth Publishers.

National Center for Higher Education Management Systems (1997, March). An Assessment of postsecondary education in Kentucky: A report to the task force on postsecondary education. Boulder, CO: Author.

National Center for Public Policy and Higher Education, Measuring up 2006: The state report card on higher education, Kentucky (2006).

National Commission on Excellence in Education. (1983). A nation at risk: The imperative for educational reform. Washington, DC: U.S. Government Printing. 
Nicholson, B. G. (2007). Leadership during consolidation of a community and technical college: A descriptive analysis (Doctoral dissertation, University of Kentucky, 2007). Dissertation Abstracts International, 68.

Nunez, W. J. (2003). Faculty and academic administrator support for strategic planning in the context of postsecondary reform (Doctoral dissertation, University of Louisville, 2003). Dissertation Abstracts International, 62, 39.

Nunnally, J.C., \& Bernstein, P. (1984). Psychometric theory (2 ${ }^{\text {nd }}$ ed.). New York: McGraw-Hill.

Osborne, D. \& Gaebler, T. (1992). Reinventing government: How the entrepreneurial spirit is transforming the public sector. Reading, MA: Addison-Wesley.

Pellino, G. R., Blackburn, R. T., \& Boberg, A. L. (1984). The dimensions of academic scholarship: Faculty and administrator views. Research in Higher Education, 20, 103-115.

Peterson, M. W. \& White, T. H. (1992). Faculty and administrator perceptions of their environments: Different views or different models of organization? Research in Higher Education, 33, 177-204.

Petry, L. C. (1957). A faculty view. Faculty-administrative relationships: Report of a work conference. Washington DC: American Council on Education.

Phillippe, K. A., \& Sullivan. G. (2005). National profile of community colleges: Trends and statistics ( $4^{\text {th }}$ ed.). Washington, DC: American Association of Community Colleges.

President's Commission on Higher Education. (1947). Higher education for American Democracy (Vols. 1-6). New York: Harper.

Puyear, D. E. (2001). Community college and technical institute mission convergence study. Denver, CO: Center for Community College Policy, Education Commission of the States.

Quehl, G. H. Bergquist, W. H. \& Subbiondo, J. L. (1999). Fifty years of innovations in higher education: Change and stasis in the pursuit of quality. New Agenda Series, 1(4) (published by USAGroup Foundation, Indianapolis, IN).

Rawls, J. L. (1998). Faculty-administrative conflict: Bridging the gap for collaborative leadership in higher education (Doctoral dissertation, Georgia State University, 1998). Dissertation Abstracts International, 59, 3754.

Reitano, J.R. (1998). The community college mission: Access or anarchy? Community Review, 16, 119-127. 
Reiten, G. N. (1992). A study of differences and similarities in beliefs between faculty and administration regarding academic decision making (Doctoral dissertation, Indiana University, 1992). Dissertation Abstracts International, 54, 2486.

Reyes, P., \& Twombly, S. B. (1987). Perceptions of contemporary governance in community colleges: An empirical study. Community College Review, 14, 4-12.

Richardson, R. C., Blocker, C. E., \& Bender, L. W. (1972). Governance for the two-year college. Englewood Hills, NJ: Prentice-Hall, Inc.

Roueche, J.E., \& Jones, B.R. (2005). The entrepreneurial community college. Washington, DC: American Association of Community Colleges.

Rose v. Council for Better Education, Inc. Ky. 790 S.W.2d 186 (1989).

Rosenberg, M. (1968). The logic of survey analysis. New York: Basic Books, Inc.

Rudolph, F. (1990). The American college and university: A history. Athens, GA: University of Georgia Press.

Salant, P., \& Dillman, D. A. (1994). How to conduct your own survey. New York: John Wiley and Sons, Inc.

Samuelowicz, K., \& Bain, J. D. (2001). Revisiting academics' beliefs about teaching and learning. Higher Education, 41, 299-325.

Sanders, A. R. (2005). Perceptions of efficacy of minority and non-minority school-based decision-making council members in Kentucky's region 1 and region 2 school systems (Doctoral dissertation, University of Louisville, 2005). Dissertation Abstracts International, 66, 1235.

Schilling, K. M., Schilling, K. L. (1998). Proclaiming and sustaining excellence: Assessment as a faculty role. (ERIC Document Reproduction Service No. ED420245).

Selingo, J. (1999). Technical colleges at a crossroads. The Chronicle of Higher Education, 45, A28.

Seymour, D. (1993). On Q. causing quality in higher education. New York: ACE MacMillian.

Seymour, D. (1995). Once upon a campus: Lessons for improving quality and productivity in higher education. Phoenix, AZ: ORYX Press.

Skodvin, O. (1999). Mergers in higher education - success or failure? Tertiary Education and Management, 5, 65-80. 
Smith-Mello, M., Blankenship, S., Hamm, Jr., E., \& Strohmaier, J. (1996, April). Choosing prosperity: Maximizing returns on public investment in workforce development (pp. 69-80). Frankfort, KY: The Kentucky Long-Term Policy Research Center.

Solis, E. (1995). Attitudinal and perceptual differences among community college employee groups during a time of CEO transition. Community College Journal of Research and Practice, 19, 23-32.

Stern, G. G. (1970). People in context: Measuring person-environment congruence in education and industry. New York: Wiley.

Stevens, J. (1996). Applied multivariate statistics for the social sciences. New Jersey: Lawrence Earlbaum Associates.

Sudman, S., \& Bradburn, N. (1982). Asking questions: A practical guide to questionnaire design. San Francisco: Jossey-Bass Publishers.

Swanepoel, A. (2003, June). Library mergers in higher education institutions: Different theories, beliefs and practices. Proceedings of the 2003 International Association of Technological Libraries (IATUL), Ankara, Turkey. Retrieved July 3, 2004 from http://www.iatul.org/conference/proceedings/vol13/.

Tang, T. L., \& Chamberlain, M. (1997). Attitudes toward research and teaching: Differences between administrators and faculty members. Journal of Higher Education, 68, 212-227.

Tichy, N. (1983). Managing strategic change: Technical, political, and cultural dynamics. New York: Wiley.

Tierney, W. G. (1988). Organizational culture in higher education: Defining the essentials. Journal of Higher Education, 59, 2-21.

Tillery, D., \& Deegan, W.L. (1985). The evolution of two-year colleges through four generations. In Deegan, W.L. (Ed.), Renewing the American community college (pp. 3-33). San Francisco: Jossey-Bass, Inc.

University of Kentucky Community College System Fact Book. (1998). Selected Data and Characteristics. Lexington, KY: Office of Institutional Research.

U.S. Department of Education, National Center for Education Statistics, Projections of Education Statistics: 2011 (2001). 
U.S. Department of Education, Office of Educational Research and Improvement, National Center for Educational Statistics, Survey Report, March 1990, 1988 National Survey of Postsecondary Faculty, Faculty in Higher Education Institutions, 1988, 54.

Vaughn, G. B. (1983). President Truman endorsed community college manifesto. Community and Junior College Journal, 53, 21-24.

Vaughan, G. B. (2000). The community college story. Washington, DC: Community College Press.

Veysey, L. R. (1965). The emergence of the American university. Chicago: The University of Chicago Press.

Vierra, A., Pollock, J., \& Golez, F. (1998). Reading educational research ( $3^{\text {rd }}$ ed.). New Jersey: Prentice Hall.

Vogt, W.P. (1999). Dictionary of statistics and methodology: A nontechnical guide for the social sciences $\left(2^{\text {nd }}\right.$ ed.). Thousand Oaks, CA: Sage Publications.

Walker, J.W., \& Price, K.F. (2000, May 13). Why do mergers go right? Retrieved July 3, 2004 from http://www.walkergroup.com/docs/mergers.doc.

Warburton, T. L. (1989, November). Can we talk? Suggestions for clearing the way for communication between faculty and administration. Paper presented to the national convention of the Speech Communication Association, San Francisco, California.

Weaver, T. L. (1977). A profile of faculty and administrator perceptions of a college's governance characteristics. Unpublished doctoral practicum, Nova University.

Welhaven, M. J. (1996). Faculty, staff, and administrative attitudes toward change and integration: Minnesota Riverland Technical College-Rochester Campus, Rochester Community College, University of Minnesota Rochester Center, Winona State University-Rochester Center (Doctoral dissertation, University of Minnesota, 1996). Dissertation Abstracts International, 57, 4672.

Welsh, J. F., Nunez, W. J., \& Petrosko, J. (2006). Assessing and cultivating support for strategic planning: searching for best practices in a reform environment. Assessment and Evaluation in Higher Education, 31(6), 693-708.

Welsh, J. F., \& Metcalf, J. (2003). Faculty and administrative support for institutional effectiveness activities. Journal of Higher Education, 74, 445-468. 
Welsh, J. F., Petrosko, J. M., \& Metcalf, J. (2003). Institutional effectiveness activities: faculty and administrator support at two-year institutions. Community College Journal of Research and Practice, 27, 75-94.

White, T. H. (1990). Differences in faculty and administrator perceptions of their institutions: Implication for institutional performance. Unpublished doctoral preliminary examination. Ann Arbor, MI: University of Michigan.

Wimmer, R.D., \& Dominick, J.R. (2005). Mass media research: An introduction. Belmont, CA: Wadsworth Publishing Company.

Wingspread Group on Higher Education. (1993). An American imperative: Higher expectations for higher education. Racine, WI: Johnson Foundation, Inc. (ERIC Document Reproduction Service No. ED364144.

Yarrington, R. (1980). Employee training for productivity: A report of a 1980 assembly on industry-education cooperation. Wisconsin: AACJC and the Johnson Foundation.

Zekan, D. L. (1994). The implications of a public institutional merger. In J. Martin, J.E. Samels \& Associates (Eds.), Merging colleges for mutual growth: A new strategy for academic mergers (pp. 117-131). Baltimore: Johns Hopkins University Press.

Zemsky, R. (1996, April). Shared purposes. Washington, DC: American Council on Education. (ERIC Document Reproduction Service No. ED395558). 


\section{APPENDIX A: KENTUCKY'S COMMUNITY COLLEGES AND TECHNICAL COLLEGES AT THE TIME KCTCS WAS CREATED BY THE KENTUCKY POSTSECONDARY EDUCATION IMPROVEMENT ACT OF 1997 (HOUSE BILL 1)}

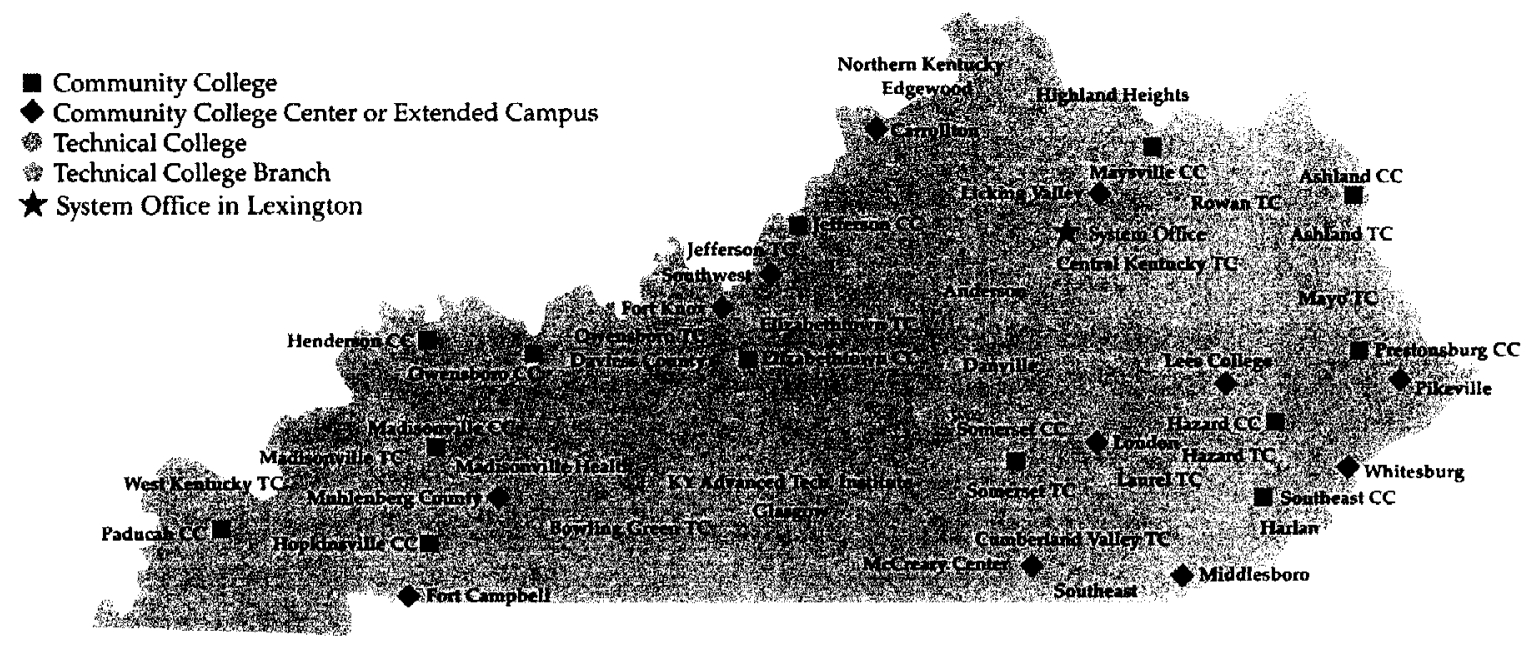

Source: Kentucky Community and Technical College System (KCTCS) 
APPENDIX B: THE KENTUCKY COMMUNITY AND TECHNICAL COLLEGE SYSTEM IN 2008

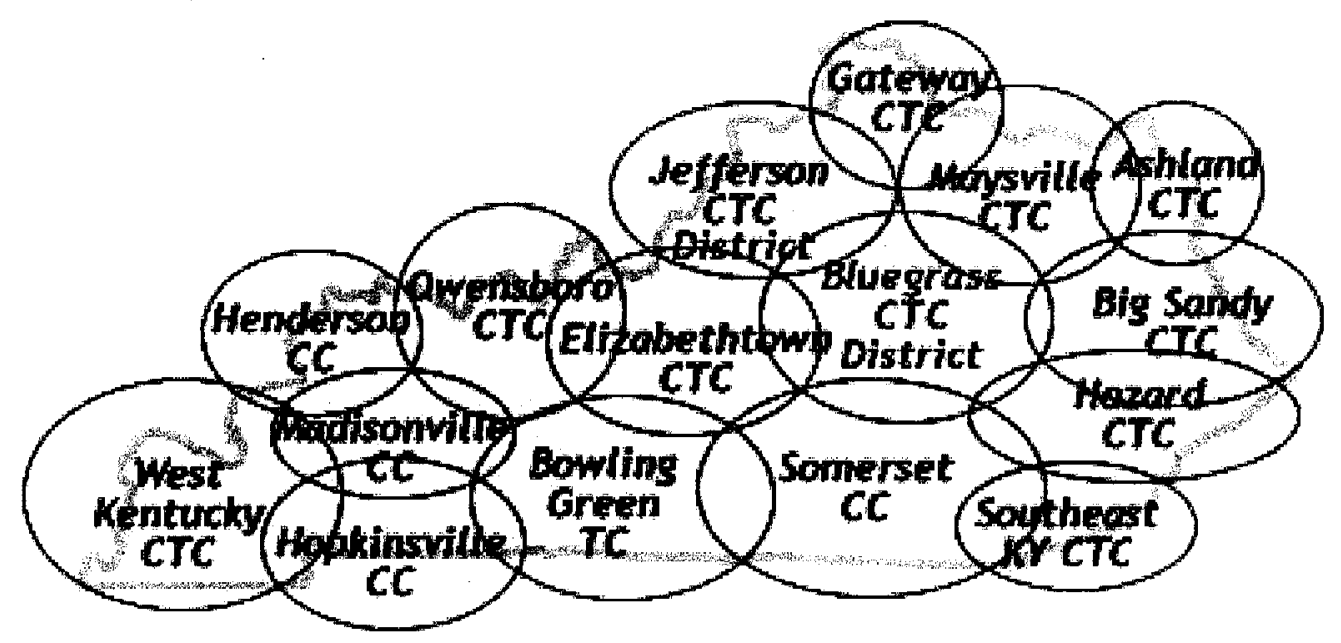

Source: Kentucky Community and Technical College System (KCTCS) 


\section{APPENDIX C: SURVEY INSTRUMENT}

Perception Survey. The merger of Kentucky's community colleges and vocational/technical institutes.

Directions: Please review the questions below and mark the response in the most appropriate box. Place a check $(\checkmark)$ or $X$ in the box using the scale at the top of each section. Please provide only one response per question. Thank you for your time and assistance in this research!

\begin{tabular}{|c|c|c|c|c|c|c|}
\hline & 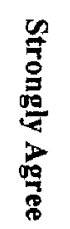 & 尊 & 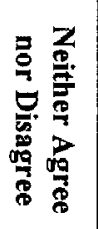 & 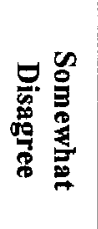 & 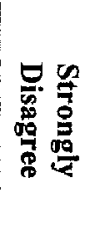 & 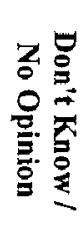 \\
\hline $\begin{array}{l}\text { 1. The creation of KCTCS and the merger of Kentucky's } \\
\text { community colleges and vocational/technical institutes } \\
\text { have enhanced educational opportunities for local citizens. }\end{array}$ & $\overline{0}$ & $\square$ & $\overline{0}$ & $\square$ & $\overline{0}$ & $\square$ \\
\hline $\begin{array}{l}\text { 2. At my institution, I have actively participated in activities } \\
\text { related to the merger of Kentucky's community colleges } \\
\text { and vocational/technical institutes. }\end{array}$ & $\square$ & $\square$ & $\square$ & $\square$ & $\square$ & $\square$ \\
\hline $\begin{array}{l}\text { I have participated in defining specific goals and/or policy } \\
\text { development for my department/division related to the } \\
\text { merger of Kentucky's community colleges and } \\
\text { vocational/technical institutes. }\end{array}$ & $\square$ & $\square$ & $\square$ & $\square$ & $\square$ & $\square$ \\
\hline $\begin{array}{l}\text { 4. Increasing educational access and educational attainment } \\
\text { levels of Kentucky's citizens was the primary motivation } \\
\text { for the creation of KCTCS and the merger of Kentucky's } \\
\text { community colleges and vocational/technical institutes. }\end{array}$ & $\square$ & 0 & $\square$ & $\square$ & D & 0 \\
\hline $\begin{array}{l}\text { 5pecific changes at my institution have occurred as a result } \\
\text { of the creation of KCTCS and the merger of Kentucky's } \\
\text { community colleges and vocational/technical institutes. }\end{array}$ & $\square$ & $\square$ & $\square$ & $\bar{\square}$ & 0 & $\square$ \\
\hline $\begin{array}{l}\text { 6. There have been no changes at my institution related to the } \\
\text { creation of KCTCS and the merger of Kentucky's } \\
\text { community colleges and vocational/techical institutes. }\end{array}$ & $\square$ & D & $\square$ & $\square$ & $\square$ & $\overline{0}$ \\
\hline $\begin{array}{l}\text { The merger of Kentucky's community colleges and } \\
\text { vocational/technical institutes resulted primarily from the } \\
\text { influence of external stakeholders such as policymakers, } \\
\text { community leaders, and businesses/industries. }\end{array}$ & 口 & $\square$ & $\square$ & $\square$ & $\square$ & $\square$ \\
\hline $\begin{array}{l}\text { 8. Community and technical colleges should develop their } \\
\text { programs and services without the involvement of } \\
\text { community leaders, businesses/industries, etc. }\end{array}$ & 口 & D & D & $\square$ & $\square$ & $\square$ \\
\hline $\begin{array}{l}\text { 9. The creation of KCTCS and the merger of Kentucky's } \\
\text { community colleges and vocational/technical institutes } \\
\text { have improved the ways my college supports local } \\
\text { economic/workforce development. }\end{array}$ & $\square$ & $\square$ & $\square$ & $\square$ & 0 & $\square$ \\
\hline $\begin{array}{l}\text { My institution is internally-motivated to improve college } \\
\text { programs and services regardless of external mandates. }\end{array}$ & $\square$ & $\bar{\square}$ & 吕 & $\square$ & $\square$ & $\square$ \\
\hline $\begin{array}{l}\text { Individual administrators at my institution can influence } \\
\text { institutional decisions frequently. }\end{array}$ & $\square$ & $\square$ & $\square$ & $\square$ & 口 & 口 \\
\hline $\begin{array}{l}\text { 12. Community college and vocational/technical institute } \\
\text { merger activities have concluded at my institution. }\end{array}$ & $\square$ & ם & $\bar{\square}$ & 0 & $\square$ & a \\
\hline $\begin{array}{l}\text { 13. Implementation plans related to the merger of Kentucky's } \\
\text { community colleges and vocational/technical institutes will } \\
\text { continue at my institution for the foreseeable future. }\end{array}$ & $\square$ & $\square$ & $\square$ & $\square$ & $\square$ & 口 \\
\hline
\end{tabular}




\begin{tabular}{|c|c|c|c|c|c|c|}
\hline & 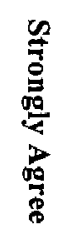 & 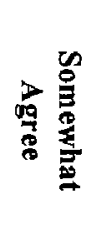 & 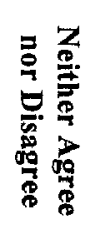 & 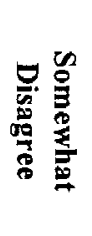 & 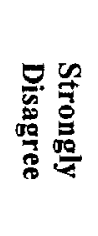 & 2. \\
\hline $\begin{array}{l}\text { 14. I have served on a planning committee or task force } \\
\text { related to the merger of Kentucky's community } \\
\text { colleges and vocational/technical institutes. }\end{array}$ & $\square$ & $\square$ & $\square$ & $\square$ & $\overline{0}$ & $\square$ \\
\hline $\begin{array}{l}\text { 15. At my institution, resources have been dedicated to } \\
\text { implement the merger of Kentucky's community } \\
\text { colleges and vocational/technical institutes. }\end{array}$ & $\square$ & $\square$ & 口 & $\square$ & $\square$ & $\square$ \\
\hline $\begin{array}{l}\text { 16. Individual faculty members at my institution can } \\
\text { influence institutional decisions frequently. }\end{array}$ & $\square$ & $\square$ & $\square$ & $\square$ & $\square$ & 口 \\
\hline $\begin{array}{l}\text { 17. Resources dedicated to the creation of KCTCS and } \\
\text { the merger of Kentucky's community colleges and } \\
\text { vocational/technical institutes represent a valuable } \\
\text { investment in the long-term future of the } \\
\text { Commonwealth of Kentucky. }\end{array}$ & $\square$ & 口 & $\square$ & $\square$ & $\bar{\square}$ & $\square$ \\
\hline $\begin{array}{l}\text { 18. At my institution, I have evaluated and offered advice } \\
\text { related to the merger of Kentucky's community } \\
\text { colleges and vocational/technical institutes. }\end{array}$ & 0 & $\square$ & $\square$ & 0 & 0 & 口 \\
\hline $\begin{array}{l}\text { Decision-making at my institution may be classified } \\
\text { as collegial/participative. }\end{array}$ & $\square$ & 0 & $\square$ & $\square$ & $\square$ & D \\
\hline $\begin{array}{l}\text { If there were no outside requirements or legislative } \\
\text { mandates, the quality of college programs and } \\
\text { services at my institution would probably diminish. }\end{array}$ & 0 & $\square$ & $\square$ & 口 & $\square$ & $\square$ \\
\hline $\begin{array}{l}\text { I have had no involvement at my institution with any } \\
\text { community college and vocational/technical institute } \\
\text { merger activities. }\end{array}$ & 0 & D & $\square$ & $\square$ & $\overline{0}$ & $\overline{0}$ \\
\hline $\begin{array}{l}\text { 22. Decision-making at my institution may be classified } \\
\text { as hierarchical (opinions of various constituent groups } \\
\text { are "listened to" and considered, yet decisions are } \\
\text { boldly made and imposed on the college community). }\end{array}$ & $\square$ & D & $\square$ & $\square$ & $\square$ & $\square$ \\
\hline $\begin{array}{l}\text { 23. The creation of KCTCS and the merger of Kentucky's } \\
\text { community colleges and vocational/technical } \\
\text { institutes have led to increased educational access and } \\
\text { have raised the educational attainment level of } \\
\text { Kentucky's citizens. }\end{array}$ & $\square$ & $\square$ & 0 & $\square$ & 0 & 0 \\
\hline $\begin{array}{l}\text { My institution has had a systemic process for } \\
\text { implementing the merger of Kentucky's community } \\
\text { colleges and vocational/technical institutes. }\end{array}$ & $\square$ & $\square$ & 口 & 口 & $\square$ & 0 \\
\hline $\begin{array}{l}\text { 25. The creation of KCTCS and the merger of Kentucky's } \\
\text { community colleges and vocational/technical } \\
\text { institutes have created efficiencies (reduced } \\
\text { duplication, cost containment, economies of scale). }\end{array}$ & $\square$ & $\square$ & 0 & $\square$ & $\square$ & 0 \\
\hline $\begin{array}{l}\text { 26. Decision-making authority at my institution is } \\
\text { concentrated at the top of the organization. }\end{array}$ & $\bar{a}$ & $\square$ & 0 & $\square$ & $\square$ & $\square$ \\
\hline $\begin{array}{l}\text { 27. I understand the purpose for the creation of KCTCS } \\
\text { and the merger of Kentucky's community colleges } \\
\text { and vocational/technical institutes. }\end{array}$ & $\square$ & 0 & $\square$ & $\square$ & $\square$ & $\square$ \\
\hline $\begin{array}{l}\text { 28. I have a favorable perception of the creation of } \\
\text { KCTCS and the merger of Kentucky's community } \\
\text { colleges and vocational/technical institutes. }\end{array}$ & 口 & 口 & $\square$ & $\square$ & $\square$ & $\square$ \\
\hline
\end{tabular}




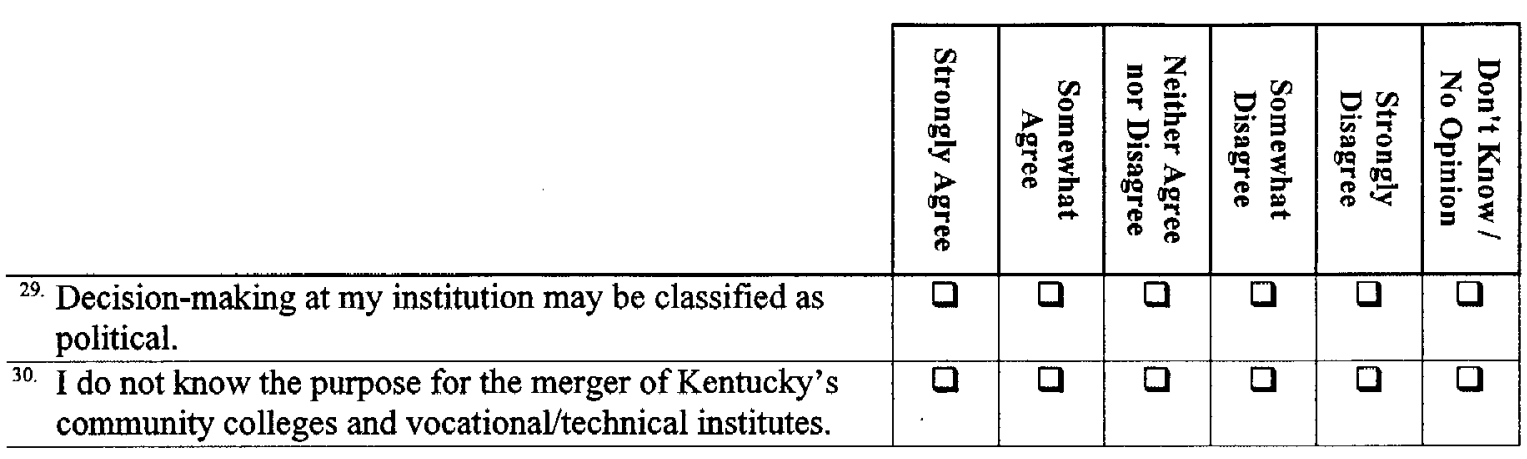

Questions 31 - 36 relate to the Kentucky's Postsecondary Education Reform legislation

\begin{tabular}{|c|c|c|c|c|c|c|}
\hline $\begin{array}{l}\text { 31. The postsecondary education reform legislation enacted in } \\
1997 \text { that created KCTCS and led to the merger of } \\
\text { Kentucky's community colleges and vocational/technical } \\
\text { institutes is beneficial to Kentucky's citizenry. }\end{array}$ & $\square$ & $\square$ & $\square$ & $\square$ & $\square$ & $\square$ \\
\hline $\begin{array}{l}\text { 32. As a public institution, we have an obligation to ensure our } \\
\text { strategic activities are congruent with state initiatives. }\end{array}$ & $\square$ & $\square$ & $\square$ & $\square$ & $\square$ & $\square$ \\
\hline $\begin{array}{l}\text { 33. Community and technical colleges should be governed } \\
\text { separately from KCTCS. }\end{array}$ & $\square$ & $\square$ & $\square$ & $\square$ & 0 & $\square$ \\
\hline $\begin{array}{l}\text { 34. State legislators and governing boards have an obligation } \\
\text { to hold institutions accountable for their use of state } \\
\text { resources. }\end{array}$ & $\square$ & $\square$ & $\square$ & $\square$ & $\square$ & $\square$ \\
\hline $\begin{array}{l}\text { 35. The state should have a role in developing strategic } \\
\text { planning initiatives for my institution. }\end{array}$ & $\square$ & $\square$ & $\square$ & $\square$ & $\square$ & $\square$ \\
\hline $\begin{array}{l}\text { 36. I hold a favorable perception of the postsecondary } \\
\text { education reform initiatives that created KCTCS and led to } \\
\text { the merger of Kentucky's community colleges and } \\
\text { vocational/technical institutes. }\end{array}$ & $\square$ & $\square$ & $\square$ & $\square$ & $\square$ & $\square$ \\
\hline
\end{tabular}

NOTE TO THE RESPONDENT: The demographic information requested below is necessary for the research process. Please be assured that this information and all of your responses on this instrument will be kept strictly confidential. Data will be reported in such a way that individuals will not be identified.

\section{INDIVIDUAL DATA:}

37. What is your position at the college?

$\begin{array}{llll}\square & \text { Administrator } \quad \square \quad \text { Faculty }\end{array}$

38. If you are faculty, what is your primary academic discipline?

39. How many years have you worked in your present job? years

40. How many years have you worked in higher education? years

\begin{tabular}{|c|c|c|c|c|}
\hline 41. What is your gender? & $\square$ & Female & $\square$ & Male \\
\hline 42. What is your age? & $\begin{array}{l}\square \\
\square \\
\square\end{array}$ & $\begin{array}{l}30 \text { or under } \\
31-40 \\
41-50\end{array}$ & $\begin{array}{l}\square \\
\square\end{array}$ & $\begin{array}{l}51-60 \\
\text { Over } 60\end{array}$ \\
\hline 43. If you are faculty, what is your faculty rank? & $\begin{array}{l}\square \\
\square \\
\square\end{array}$ & $\begin{array}{l}\text { Professor } \\
\text { Assoc. Prof. } \\
\text { Assistant Professor }\end{array}$ & $\begin{array}{l}\square \\
\square\end{array}$ & $\begin{array}{l}\text { Instructor } \\
\text { Other }\end{array}$ \\
\hline 44. Do you have tenure? & $\square$ & Yes & 0 & No \\
\hline
\end{tabular}
Thank you for your participation! 


\section{APPENDIX D: RESPONSE RATES BY ADMINISTRATORS}

$\begin{array}{crrr}\text { Institution } & \begin{array}{r}\boldsymbol{N} \\ \text { Mailed }\end{array} & \begin{array}{r}\boldsymbol{N} \\ \text { Returned }\end{array} & \begin{array}{r}\text { Response } \\ \mathbf{\%}\end{array} \\ \text { Ashland CTC } & 12 & 8 & 66.7 \% \\ \text { Big Sandy CTC } & 20 & 7 & 35.0 \% \\ \text { Bluegrass CTC } & 13 & 5 & 38.5 \% \\ \text { Bowling Green TC } & 12 & 6 & 50.0 \% \\ \text { Elizabethtown CTC } & 10 & 5 & 50.0 \% \\ \text { Gateway CTC } & 16 & 5 & 31.3 \% \\ \text { Hazard CTC } & 10 & 7 & 70.0 \% \\ \text { Henderson CC } & 10 & 7 & 70.0 \% \\ \text { Hopkinsville CC } & 10 & 7 & 70.0 \% \\ \text { Jefferson CTC } & 18 & 8 & 44.4 \% \\ \text { Madisonville CC } & 10 & 3 & 30.0 \% \\ \text { Maysville CTC } & 12 & 5 & 41.7 \% \\ \text { Owensboro CTC } & 8 & 3 & 37.5 \% \\ \text { Somerset CTC } & 11 & 5 & 45.5 \% \\ \text { Southeast CTC } & 10 & 5 & 50.0 \% \\ \text { West KY CTC } & 14 & 8 & 57.1 \% \\ \text { TOTAL } & & & \\ & \mathbf{1 9 6} & \mathbf{9 4} & \mathbf{4 8 . 0 \%}\end{array}$


APPENDIX E: RESPONSE RATES BY FACULTY

\author{
Institution \\ Ashland CTC \\ Big Sandy CTC \\ Bluegrass CTC \\ Bowling Green TC \\ Elizabethtown CTC \\ Gateway CTC \\ Hazard CTC \\ Henderson CC \\ Hopkinsville CC \\ Jefferson CTC \\ Madisonville CC \\ Maysville CTC \\ Owensboro CTC \\ Somerset CTC \\ Southeast CTC \\ West KY CTC \\ Untrackable/Usable \\ Untrackable/Unusable
}

TOTAL

$\boldsymbol{n}$
Mailed
72
88
215
44
94
53
89
38
50
242
82
62
72
113
82
101

N/A
N/A

1,497

N/A

$\boldsymbol{n}$
Returned
16
18
73
14
32

18

21

9

32

62

33

23

16

29

21

52

7

1 (not included in

total)

476
Response

$\%$
$22.2 \%$

$20.5 \%$

$34.0 \%$

$31.8 \%$

$34.0 \%$

$34.0 \%$

$23.6 \%$

$23.7 \%$

$64.0 \%$

$25.6 \%$

$40.2 \%$

$37.1 \%$

$22.2 \%$

$25.7 \%$

$25.6 \%$

$51.5 \%$

)

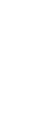

$31.8 \%$ 


\section{APPENDIX F: SURVEY INSTRUMENT INSERT}

Perception Survey. The merger of Kentucky's community colleges and vocational/technical institutes.

Directions: In the spaces provided below, please expand upon any of your survey responses and/or add any additional comments. Thank you for your time and assistance in this research!

\section{ADDITIONAL COMMENTS}




\section{APPENDIX G}

\section{Expert Panel Evaluation Form}

Please review the enclosed survey materials and provide your comments, suggestions, and overall evaluation. Your feedback regarding the dimension questions and their appropriateness as measures is a vital component to the content validity of this study.

Survey Component: Opening Letter / Introduction

Please provide any comments or suggestions in the space provided below: 
Survey Component: Section I - Perception of the merger of Kentucky's community colleges and vocational/technical institutes

Evaluation / Appropriateness Scale: $5=$ Excellent, $4=$ Good, $3=$ Average, $2=$ Below Average, 1 $=$ Poor

Rating of Question Appropriateness

Dimension / Survey Question

PERCEPTION OF THE MERGER OF KENTUCKY'S COMMUNITY

\section{$\begin{array}{lllllll}Q & 5 & 4 & 3 & 2 & 1 & \text { COLLEGES AND VOCATIONAL/TECHNICAL INSTITUTES }\end{array}$}

1. $\square \square \square \square \square$ The merger of Kentucky's community colleges and vocational/technical institutes has played a positive role in improving my institution.

2. $\square \square \square \square \square$ The merger of Kentucky's community colleges and vocational/technical institutes has enhanced educational opportunities for local citizens.

3. $\square \square \square \square \square$ Resources dedicated to the merger of Kentucky's community colleges and vocational/technical institutes represent a valuable investment in the long-term future of my institution.

4. $\square \square \square \square \square$ The merger of Kentucky's community colleges and vocational/technical institutes has clarified the mission of my institution.

5. $\square \square \square \square \square$ The merger of Kentucky's community colleges and vocational/technical institutes has created efficiencies (reduced duplication, cost containment, economies of scale).

6. $\square \square \square \square \square$ I understand the purpose for the merger of Kentucky's community colleges and vocational/technical institutes.

7. $\square \square \square \square \square$ I have a favorable perception of the merger of Kentucky's community colleges and vocational/technical institutes.

8. $\square \square \square \square \square$ I do not know the purpose for the merger of Kentucky's community colleges and vocational/technical institutes. 
Please rate the overall adequacy of the index: Perception of the merqer of Kentucky's community colleges and vocational/technical institutes

Evaluation / Appropriateness Scale: 5 = Excellent, $4=$ Good, $3=$ Average, $2=$ Below Average, 1 $=$ Poor

\section{$\begin{array}{llllll}5 & 4 & 3 & 2 & 1 & \text { Overall Rating }\end{array}$}

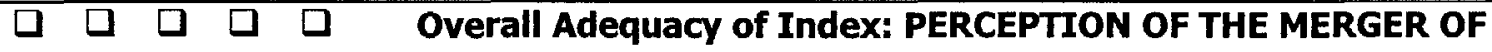
KENTUCKY'S COMMUNITY COLLEGES AND VOCATIONAL/TECHNICAL INSTITUTES

Please provide any comments or suggestions in the space provided below: 
Evaluation / Appropriateness Scale: $5=$ Excellent, $4=$ Good, $3=$ Average, $2=$ Below Average, 1 $=$ Poor

Rating of Question

Dimension / Survey Question Appropriateness

\section{$\begin{array}{lllllll}Q & 5 & 4 & 3 & 2 & 1 & \text { TYPE OF INSTITUTIONAL DECISION-MAKING }\end{array}$}

1. $\square \square \square \square \square$ Individual administrators at my institution can influence institutional decisions frequently.

2. $\quad \square \quad \square \quad \square \quad \square$ Individual faculty members at my institution can influence institutional decisions frequently.

3. $\square \square \square \square \square$ Decision-making at my institution may be classified as collegial/participative.

4. $\square \square \square \square \square$ Decision-making at my institution may be classified as hierarchical (perceptions of various constituent groups are "listened to" and considered, yet decisions are boldly made and imposed on the college community).

5. $\square \square \square \square \square$ Decision-making authority at my institution is concentrated at the top of the organization.

6. $\quad \square \square \square \square$ Decision-making at my institution may be classified as political. 
Please rate the overall adequacy of the index: Type of Institutional Decision Making

Evaluation / Appropriateness Scale: $5=$ Excellent, $4=$ Good, $3=$ Average, $2=$ Below Average, 1 $=$ Poor

\section{$\begin{array}{llllll}5 & 4 & 3 & 2 & 1 & \text { Overall Rating }\end{array}$}

$\square \quad \square \quad \square \quad \square \quad \square$ Overall Adequacy Of Index: TYPE OF INSTITUTIONAL DECISIONMAKING

Please provide any comments or suggestions in the space provided below: 
Evaluation / Appropriateness Scale: $5=$ Excellent, $4=$ Good, $3=$ Average, $2=$ Below Average, 1

$=$ Poor

Rating of Question Appropriateness

\section{Dimension / Survey Question}

\section{$\begin{array}{llllllll}Q & 5 & 4 & 3 & 2 & 1 & \text { DEPTH OF MERGER IMPLEMENTATION }\end{array}$}

1. $\quad \square \quad \square \quad \square \quad \square$ Specific changes at my institution have occurred as a result of the merger of Kentucky's community colleges and vocational/technical institutes.

2. $\square \square \square \quad$ There have been no changes at my institution related to the merger of Kentucky's community colleges and vocational/technical institutes.

3. $\quad$ 口 $\quad$ 口 Activities related to the merger of Kentucky's community colleges and vocational/technical institutes have concluded at my institution.

4. $\quad \square \quad \square \quad$ Implementation plans related to the merger of Kentucky's community colleges and vocational/technical institutes will continue at my institution for the foreseeable future.

5. $\square \square \square$ At my institution, resources have been dedicated to implement the merger of Kentucky's community colleges and vocational/technical institutes.

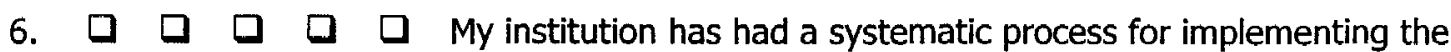
merger of Kentucky's community colleges and vocational/technical institutes. 
Please rate the overall adequacy of the index: Depth of Implementation

Evaluation / Appropriateness Scale: $5=$ Excellent, $4=$ Good, $3=$ Average, $2=$ Below Average, 1 $=$ Poor

\section{$\begin{array}{lllll}5 & 4 & 3 & 2 & 1\end{array}$ \\ Overall Rating}

$\square \square \square \square \square$

\section{Overall Adequacy of Index: DEPTH OF MERGER} IMPLEMENTATION

Please provide any comments or suggestions in the space provided below: 
Evaluation / Appropriateness Scale: $5=$ Excellent, $4=$ Good, $3=$ Average, $2=$ Below Average, 1 $=$ Poor

Rating of Question Appropriateness
Dimension / Survey Question

LEVEL OF INVOLVEMENT IN MERGER INITIATIVES

\section{$\begin{array}{llllll}Q & 5 & 4 & 3 & 2 & 1\end{array}$}

1. $\quad \square \quad \square \quad \square \quad \square$ At my institution, I have actively participated in activities related to the merger of Kentucky's community colleges and vocational/technical institutes.

2. $\square \square \square \square$ I have participated in defining specific goals and/or policy development for my department/division related to the merger of Kentucky's community colleges and vocational/technical institutes.

3. $\quad \square \square \square \square$ I have served on a planning committee or task force related to the merger of Kentucky's community colleges and vocational/technical institutes.

4. $\square \square \square \square \square$ At my institution, I have evaluated and offered advice related to the merger of Kentucky's community colleges and vocational/technical institutes.

5. $\square \square \square \square \square$ I have had no involvement at my institution with any activities related to the merger of Kentucky's community colleges and vocational/technical institutes. 
Please rate the overall adequacy of the index: Level of Involvement in Merger Initiatives

Evaluation / Appropriateness Scale: $5=$ Excellent, $4=$ Good, $3=$ Average, $2=$ Below Average, 1 $=$ Poor

$\begin{array}{llllll}5 & 4 & 3 & 2 & 1 & \text { Overall Rating }\end{array}$

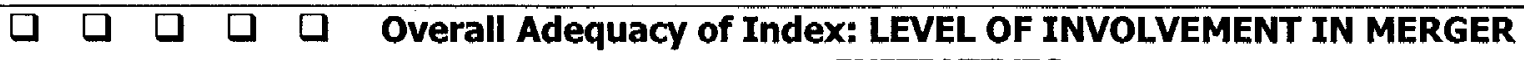
INITIATIVES

Please provide any comments or suggestions in the space provided below: 
Evaluation / Appropriateness Scale: 5 = Excellent, $4=$ Good, $3=$ Average, $2=$ Below Average, 1 $=$ Poor

Rating of Question

Dimension / Survey Question

Appropriateness

\section{$\begin{array}{llllll}Q & 5 & 4 & 3 & 2 & 1\end{array}$}

MOTIVATION FOR REFORM INITIATIVES THAT LED TO

MERGER

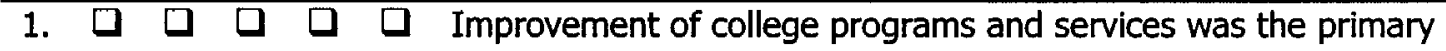
motivation for the merger of Kentucky's community colleges and vocational/technical institutes.

2. $\square \square \square \square \square$ The merger of Kentucky's community colleges and vocational/technical institutes resulted primarily from the influence of external stakeholders such as politicians, community leaders, and businesses/industries.

3. $\square \square \square \square \square$ The merger of Kentucky's community colleges and vocational/technical institutes seems to be more important to outside stakeholders than to my internal campus community.

4. $\square \square \square \square$ My institution is internally-motivated to improve college programs and services regardless of external mandates.

5. $\square \square \square \square \square$ If there were no outside requirements or legislative mandates, the quality of college programs and services at my institution would probably diminish. 
Please rate the overall adequacy of the index: Motivation for Reform Initiatives That Led to Merger

Evaluation / Appropriateness Scale: $5=$ Excellent, $4=$ Good, $3=$ Average, $2=$ Below Average, 1 $=$ Poor

\section{$\begin{array}{llllll}5 & 4 & 3 & 2 & 1 & \text { Overall Rating }\end{array}$}

\begin{tabular}{llllll}
\hline & $\square$ & $\square$ & $\square$ & $\square$ & Overall Adequacy Of Index: INTERNAL VERSUS EXTERNAL
\end{tabular} MOTIVATION FOR REFORM INITIATIVES THAT LED TO MERGER

Please provide any comments or suggestions in the space provided below: 
Evaluation / Appropriateness Scale: $5=$ Excellent, $4=$ Good, $3=$ Average, $2=$ Below Average, 1 $=$ Poor

Rating of Question Appropriateness

Dimension / Survey Question

LEVEL OF SUPPORT FOR STATE REFORM INITIATIVES THAT

$\begin{array}{llllll}Q & 5 & 4 & 3 & 2 & 1\end{array}$ LED TO MERGER

1. $\square \square \square \square \square$ House Bill 1 or the Postsecondary Education Reform legislation enacted in 1997 is beneficial to Kentucky's public colleges and universities.

2. $\square \square \square \square \square$ As a public institution, we have an obligation to ensure our strategic activities are congruent with state initiatives.

3. $\square \square \square \square \square$ Governance authority should reside at the institutional level, not the state or its appointed governing board.

4. $\square \square \quad \square \quad \square \quad \square$ State legislators and governing boards have an obligation to hold institutions accountable for their use of state resources.

5. $\square \square \square \square \square$ The state should have a role in developing strategic planning initiatives for my institution.

6. $\square \square \square \square$ I support the Commonwealth of Kentucky's postsecondary education reform initiatives. 
Please rate the overall adequacy of the index: Level of Support for State Reform Initiatives That Led to Merger

Evaluation / Appropriateness Scale: $5=$ Excellent, $4=$ Good, $3=$ Average, $2=$ Below Average, 1 $=$ Poor

\section{$\begin{array}{llllll}5 & 4 & 3 & 2 & 1 & \text { Overall Rating }\end{array}$}

\begin{tabular}{llllll}
\hline & $\square$ & $\square$ & $\square$ & Overall Adequacy of Index: LEVEL OF SUPPORT FOR STATE
\end{tabular} REFORM INITIATIVES THAT LED TO MERGER

Please provide any comments or suggestions in the space provided below: 
Survey Component: Section II. Demographic Information

Please provide any comments or suggestions in the space provided below: 


\section{APPENDIX H: PILOT STUDY COVER LETTER}

September_, 2007

$<<$ Participant name $>>$

$<<$ Participant address $>>$

$<$ <ity $>>,<<$ state $>>><<$ ZIP $>>$

Dear Colleague:

I am a doctoral candidate in the Department of Leadership, Foundations, and Human Resource Education at the University of Louisville. I am conducting dissertation research on faculty and administrator perceptions of the merger of Kentucky's community colleges and vocational/technical institutes. Your name was selected randomly from a list of faculty and administrators formerly employed by Hopkinsville Community College.

I ask for your assistance in sharing your views of community and technical college reform efforts on your campus and statewide. I would greatly appreciate your assistance in helping me validate my survey instrument by indicating on the body of the enclosed questionnaire any suggestions or thoughts you may have regarding the content, clarity and completeness of individual items. After reviewing the instrument, would you also complete the enclosed Pilot Questionnaire Evaluation Form?

The Kentucky Community and Technical College System (KCTCS) is receiving much attention nationwide. This dissertation research explores the effect of several variables on the perceptions of the merger of Kentucky's community colleges and vocational/technical institutes and compares the responses of two critical stakeholders in Kentucky's community and technical colleges: faculty and administrators.

I have enclosed a postage-paid return envelope for your convenience. Please note that the return envelopes are coded in order to conduct a follow-up mailing to non-responders. However, the codes will be destroyed upon receipt and responses will never be linked to individuals.

Thank you in advance for your assistance and participation in this research effort. If you have questions, please do not hesitate to contact me at (270) 821-0855 or

j_pwarren@bellsouth.net or my advisor, Dr. Joseph M. Petrosko, at (502) 852-0638.

Sincerely,

Jason D. Warren

Doctoral (Ph.D.) Student 


\section{APPENDIX I: PILOT QUESTIONNAIRE EVALUATION FORM Perception of Merger Survey}

1. Approximately how long did it take you to complete the questionnaire? minutes

2. Were any of the directions unclear or difficult to understand?

YES or NO (If yes, please circle [on the questionnaire] all parts of the directions which were unclear or difficult to understand.)

3. Were any of the questions difficult to understand?

YES or NO (If yes, please circle the number of each of these questions on your questionnaire.)

4. Were there any problems or issues not addressed in the questionnaire which you feel should be noted?

YES or NO (If yes, please list here.)

5. If you have any additional comments regarding the questionnaire, please use this space and the back of this page for that purpose.

THANK YOU very much for your cooperation in this effort. 


\section{Pre-Letter - Sample email on behalf of researcher and the study sent by the researcher's colleagues: First Contact}

September_, 2007

Dear Colleagues,

[SAMPLE KCTCS SYSTEM GROUP EMAIL LISTS: Faculty, Business Deans, Chief Academic Officers, Chief Student Affairs Officers, Student Affairs Deans, Academic Deans, Institutional Research and Effectiveness Deans, Community Workforce and Economic Development Deans, Institutional Advancement Officers, Public Relations Coordinators, Presidents/CEOs, Information Technology Directors]

A few days from now you may be selected as part of a research sample. If selected, you will receive in the mail a request from Jason Warren to fill out a questionnaire for an important research project. He is conducting a study as a graduate student in the School of Education and Human Development at the University of Louisville.

The study concerns the perceptions of KCTCS faculty and administrators and the merger of Kentucky's community colleges and vocational/technical institutes.

If you are selected for the study via the statistical sampling process, I encourage you to participate. I have known Jason for a long time, and I support his research endeavor in pursuit of his $\mathrm{Ph}$.D. It will add to the limited body of research on two-year colleges and, specifically, KCTCS.

Thank you in advance for your participation.

Sincerely,

SIGNATURE

[Faculty Member, Business Dean, Chief Academic Officer, Chief Student Affairs Officer, Student Affairs Dean, Academic Dean, Institutional Research and Effectiveness Dean, Community Workforce and Economic Development Dean, Institutional Advancement Officer, Public Relations Coordinator, Presidents/CEO, Information Technology Director] 


\title{
APPENDIX K: INFORMED CONSENT DOCUMENT (UL/WKU) \\ Cover Letter: Second Contact
}

\author{
A COMPARISON OF FACULTY AND ADMINISTRATOR PERCEPTIONS OF THE MERGER OF \\ KENTUCKY'S COMMUNITY COLLEGES AND VOCATIONAL/TECHNICAL INSTITUTES
}

September_, 2007

Dear Colleague:

You are being invited to participate in a research study by answering the attached questionnaire. The study is being conducted by Jason D. Warren and Dr. Joseph M. Petrosko and is sponsored by the University of Louisville's Department of Leadership, Foundations, and Human Resource Education and the Western Kentucky University's Department of Educational Administration, Leadership, and Research. The purpose of the study is to ascertain faculty and administrator perceptions of the merger of Kentucky's community colleges and vocational/technical institutes. There are no foreseeable risks or penalties for your participation in this research study. Your completed questionnaire will be stored at the researcher's locked home file. The questionnaire will take approximately 20 minutes to complete.

Individuals from the University of Louisville's Department of Leadership, Foundations, and Human Resource Education, the Human Studies Protection Program Office and Institutional Review Board, and the Western Kentucky University's Department of Educational Administration, Leadership, and Research and Office of Sponsored Programs, Human Subjects Research may inspect these records. In all other respects, however, the data will be held in confidence to the extent permitted by law. Should the data be published, your identity will not be disclosed. Because identifying information is asked on the questionnaire, it is important that you protect the privacy and confidentiality of your responses until they are returned to the researcher via the pre-addressed, return envelope provided.

Please remember that your participation in this study is voluntary. By completing and returning the attached questionnaire, you are voluntarily agreeing to participate. You are free to decline to answer any particular question that may make you uncomfortable or which may render you prosecutable under law. There may be unforeseeable risks. You may refuse to participate or discontinue participation at any time without incurring penalty or losing any benefits to which you are otherwise entitled.

You acknowledge that all your present questions have been answered in language you can understand and all future questions will be treated in the same manner. If you have questions about the study, please contact Jason D. Warren at (270) 821-0855 or Dr. Joseph M. Petrosko at (502) 852-0638.

If you have any questions about your rights as a research subject, you may call the UofL Human Studies Committee office at (502) 852-5188 or the WKU Human Subjects Committee at (270) 745-2129. You will be given the opportunity to discuss any questions about your rights as a research subject, in confidence, with a member of the committees. These are independent committees composed of members of the University community, staff of the institutions, as well as lay members of the community not connected with these institutions. The Committees reviewed this study.

If you have concerns or complaints about the research or research staff and you do not wish to give your name, you may call 1-877-852-1167. This is a 24-hour hot-line answered by people who do not work at the University of Louisville or Western Kentucky University.

Sincerely,

Jason D. Warren

Doctoral Student 


\section{APPENDIX L}

\section{Follow-up email: Third Contact}

October_, 2007

Last month a questionnaire seeking your responses on a Perception of the Merger of Kentucky's Community and Technical Colleges and Vocational/Technical Institutes Survey was mailed to you.

If you have already completed and returned the questionnaires to me, please accept my sincere thanks. If not, please do so today. I am especially grateful for your help because it is only by asking people like you can we add to the body of research on two-year colleges.

If you did not receive a questionnaire, or if it was misplaced, please call me toll-free at 1-866-534-2224, via my campus extension x63801, via my home number (270) 8210855 , or e-mail me at i pwarren@ bellsouth.net or Jason.Warren@kctcs.edu and I will get another one in the mail to you today.

SIGNATURE

Jason D. Warren

Doctoral candidate, University of Louisville, College of Education and Human Development, Department of Leadership, Foundations and Human Resource Education. Dean of Student Affairs, Hopkinsville Community College 
Academic Discipline

Academic Support

Accounting

Adult Education

Agriculture

Air Conditioning Tech

Allied Health

Anatomy \& Physiology

Anthropology

Auto Diesel

Automotive Technology

Behavioral Sciences

Biological Sciences

Biology

Biomedical Tech

Business

Chemistry

Communication

Computer-Aided Drafting

Construction

Counseling

Criminal Justice

Culinary Arts

Dental Hygiene

Developmental Reading

Developmental Studies

Developmental Writing

Diesel Mechanics

Early Childhood Education

Economics

Education

Electrical Technology

Engineering

Engineering Technology

English

Geography

Health

Health Sciences

History

Horticulture

Human Services

Humanities
Frequency

$\underline{\text { Percent }}$

1

1

4

2

1

19

2

1

1

1

1

1

21

1

30

4

9

2

2

3

5

\section{1}

1

\section{3}

4

1

1

3

\section{2}

1

\section{2}

.2

.7

.4

.2

3.3

.4

.2

.2

.2

.2

.2

3.7 
HVAC Tech

Industrial Tech

Information Technology

Liberal Arts

Library

Machine Tool Technology

Maintenance

Manufacturing

Manufacturing Technology

Math

Natural Science

Nuclear Medicine Tech

Nursing

Office Systems

Philosophy

Physical Sciences

Physical Therapist Assistant

1.6

Physical Therapy

Physics

Political Science

Psychology

Reading

Respiratory Care

Science

Social Sciences

Sociology

Sonography

Spanish

Technical

Technology

Trade and Industrial

Welding

Writing

TOTAL

570

100.0 


\section{APPENDIX N: FREQUENCY TABLE BY RESPONDENTS' INSTITUTION}

\section{$\underline{\text { KCTCS Institution }}$}

Ashland CTC

Big Sandy CTC

Bluegrass CTC

Bowling Green TC

Elizabethtown CTC

Gateway CTC

Hazard CTC

Henderson CC

Hopkinsville CC

Jefferson CTC

Madisonville CC

Maysville CTC

Owensboro CTC

Somerset CC

Southeast KY CTC

West KY CTC

Sub-Total

Unreported / Missing
Frequency

24

25

78

20

37

23

28

16

39

70

36

28

19

34

26

60

563

7 $\underline{\text { Percent }}$

4.2

4.4

13.7

3.5

6.5

4.0

4.9

2.8

6.8

12.3

6.3

4.9

3.3

6.0

4.6

10.5

98.8

1.2

TOTAL

570

100.0 
APPENDIX O: OPEN-ENDED RESPONSES

\section{Administrator Open-Ended Responses}

35 of 94 survey respondents provided additional comments $\rightarrow 37.2 \%$

Positive Themes

Miscellaneous Positives (12)

Increased Educational Access (10)

Increased Financial Resources (3)

Business and Industry

Relationships (3)

Single Vision and Mission (2)

Leadership (1)
Negative Themes

Growth of KCTCS Central Office (20)

Miscellaneous Negatives (11)

Mission Expansion (4)

Bureaucracy / Cumbersome Structure (3)

Loss of Resources (2)

Decreased Educational Access (1)

Decreased Enrollment in Tech Programs (1) 


\section{Faculty Open-Ended Responses}

194 of 475 survey respondents provided additional comments $\rightarrow 40.8 \%$

Positive Themes

Miscellaneous Positives (25)

Increased Educational Access (14)

Improved Technical Training (6)

Cost Efficiencies (3)

Increased Academic Offerings (2)

Improved Technology (1)

Independent Governance and

Legislative Advocacy (1)
Negative Themes

Increased Bureaucracy, Growth of KCTCS Central Offices (41)

Too Many Administrators (28)

Negative Impact on Technical Colleges (26)

KCTCS Presidents's Salary (24)

Lowered Academic Standards and Declining Quality of Instruction (24)

Negative Impact on Community Colleges (20)

Top-Down Management (18)

Miscellaneous Negatives (17)

Differences of Cultures / Different Missions (16)

Too Much Emphasis on Enrollment Numbers (15)

Decline of General Education Transfer

Program (14)

Rising Tuition (11)

Lack of Local Autonomy (10)

Loss of Faculty Authority/Influence in College Governance (10)

Politically-Motivated Reform (10)

Move from Higher Education Model to Business Model (6)

Low Morale (4)

Lack of Funding (4)

Loss of Flexibility (3)

Too Many Programs / Expanded Mission (2)

Stronger Leadership Needed (1)

Inequities in Workload (1)

Move from Full-Time Faculty to Part-Time

Faculty (1)

Erosion of Tenure (1)

Accreditation Issues (1)

\section{Total Open-Ended Responses (administrator and faculty combined)}

229 of 569 survey respondents provided additional comments $\rightarrow 40.3 \%$ 


\section{APPENDIX P: THEMES OF ADMINISTRATOR OPEN-ENDED RESPONSES}

\section{Positive Themes}

Educational Access (cited by 10 respondents)

- One of the most significant acts by the Kentucky legislature in the $20^{\text {th }}$ century (even greater than KERA); nearly doubled the number of students participating in postsecondary education

- Increased number of Kentucky citizens with at least "some college" which is still too low

- Enrollment increases

- Best thing to happen (I thought it would be one of the worst things to be separated from UK)

- Increased access to college by local citizens

- More program opportunities

- More access and some success in increasing the educational level of Kentucky's citizens but not to the extent that is being reported

- Has increased our awareness of the need for vocational training; we are offering more vocational classes than before

- Outcomes of the merger have been positive and have provided better opportunities for Kentuckians.

Financial Resources (cited by 3 respondents)

- Greater resources and support than previous organizational structure

- Increased funding

Vision and Mission (cited by 2 respondents)

- Single vision and mission of all colleges is beneficial

- Unified identity

Business and Industry Relationships (cited by 3 respondents)

- As the primary provider of workforce training in Kentucky, KCTCS has an obligation to pay attention to the needs of businesses and industries and that is why KCTCS was formed

- KCTCS is more responsive to businesses and industries and can be more flexible than in the previous organizational arrangement

- Kentucky is now recognized as having one of the best industry training programs in the U.S.

Leadership (cited by 1 respondent)

- Excellent leadership provided by Dr. McCall and his senior team 
Miscellaneous (cited by 12 respondents)

- Exciting growth potential, progress, and excellence

- KCTCS is largely a good thing with some challenges

- I believe that the current KCTCS organization has created a stronger educational system than previously existed and this is good for the citizens of Kentucky (I was strongly opposed to being separated from UK)

- As long as the community colleges were associated with UK they would remain as stepchildren; KCTCS is vital to the economic development of the Commonwealth

- The formation of KCTCS has been positive for the state and allows UK to focus on its mission

- Our community college did not have to merge with another technical institute which made our transition much easier

- Allows UK to focus on top 20 research university status, removed technical schools from an inefficient and centralized bureaucracy that was part of state government, raises up the status of vocational education, and creates a seamless system dedicated to workforce training and educational access

- Consolidation has been positive for our service area, region, and state.

- The formation of this system has poised our state to meet the challenges of this next millennium.

- The merger of the community colleges with the technical colleges created a system that is diverse, flexible, and working and expanding.

- No one could objectively say Kentucky has not benefited from consolidation of the two systems; it is time to put the issue to bed and move on to serve students.

- Merger was a milestone and we have moved on 


\section{Negative Themes}

KCTCS Central Office in Versailles (cited by 20 respondents)

- Too much of the state appropriation goes to the System Office

- Increased KCTCS central administration costs have more than off-set any cost savings and/or efficiencies created by the merger

- System Office takes away crucial funds needed by the local colleges to serve students

- Versailles is bloated

- Too many resources are diverted from the local colleges to the System Office

- Too much duplication at the System Office

- Some processes should be decentralized

- System Office employs more people than some of the local colleges but does not provide a singe service directly to students

- System Office should serve the local colleges and the emphasis should be on the local colleges, not the other way around; local colleges should be paramount since they serve students

- KCTCS is too controlled by the central office; local boards have limited input

- Too much of the resources have been dedicated to creating the bureaucracy at KCTCS in Versailles and not enough to improve the colleges

- Too much emphasis on KCTCS and not on the individual colleges

- There should be more "local" branding of colleges apart from the System to give the communities more ownership over their colleges

- The System needs to recognize that the local colleges are the institutions of higher learning, not the System itself

- The excessive control by the System Office in Versailles breaks the human spirit and discourages both creativity and out-of-the-box thinking

- The System is facing the "top heavy" problems of the UK days; individual college initiatives are stifled by the "system" priorities and demands; Ivory Tower decision-making threatens experiment and innovation on the local level; too many resources are siphoned away at the System level

- The System Office created by the merger is the perfect example of an organization out of control. We don't get the local resources because one of the 300 System workers needs a flat screen TV.

- We have created a monster; the System Office keeps employing new people and spends a lot of money on highly-paid administrators while the local colleges suffer...no wonder tuition keeps going up

- The huge bureaucracy being created at the System level is concerning

- A great deal of the resources are taken up supporting the central office; if the money was distributed to the colleges tuition would not need to go up so high. 
Bureaucracy / Cumbersome Structure (cited by 3 respondents)

- Slow and cumbersome structure

- Lots of bureaucracy and red tape still with unfunded mandates

- Purchasing rules go against helping local businesses

Mission Expansion (cited by 4 respondents)

- KCTCS is spreading itself too thin

- Too much emphasis on areas outside the reform mandates

- Trying to become "all things to all people" without resources to support

- Seems to me a mismatch of apples and oranges; the community colleges and technical colleges really have different missions - transfer versus workforce skills; I believe both missions have suffered

Resources (cited by 2 respondents)

- Technical faculty and staff think they were better off before the merger with more resources and feel like their input is not valued by the community college faculty

- The resources that have been thus far provided by the Commonwealth are not sufficient to carry on the objectives set forth by the legislature; additional funding is imperative.

Educational Access (cited by 1 respondent)

- Educational opportunities and access have been limited by the doubling and near tripling of tuition since KCTCS was formed

Enrollment (cited by 1 respondent)

- Too much emphasis on headcount numbers and the students being counted are not taking college-level classes nor are they pursuing degrees

Miscellaneous (cited by 11 respondents)

- Many people still think we are with UK

- Should have stayed the way it was

- Fear of technical schools that they would lose students who aren't seeking degrees and only need occupational skills leading to a job; old "technical" programs losing students

- Reason for merger was financial. Community colleges wanted more Perkins funds

- Vocational faculty won't change their ways...7.5 hours per day; causing students to have to take numerous credit hours not covered by financial aid

- Creation of KCTCS was punitive and political with regard to UK and Dr. Wethington 
- The community college faculty do not find the technical college faculty as credible

- Consolidation was the term we were told to use because it sounded more positive; I am surprised to see the increase in the word merger.

- Merger had long been advocated locally by policymakers and businesses/industries prior to formation of KCTCS

- Technical colleges were hurt more than the community colleges.

- Faculty from both sides had no voice in the merger. 


\section{APPENDIX Q: THEMES OF FACULTY OPEN-ENDED RESPONSES}

\section{Positive Themes}

Increased Educational Access (cited by 14 respondents)

- Our enrollment has doubled in the last six years

- Increasing the number of educated citizens is a good thing.

- On some levels education has opened up for Kentuckians at the grassroots level.

- The merger, though rocky from the start, benefits students and access.

- The creation of KCTCS has slightly enhanced the educational opportunities for citizens.

- The merger has been a wonderful boon for my college. Enrollment is up and the school has expanded.

- I was skeptical at first but I embraced it after gaining insight into the opportunities for students, faculty, and the community.

- Technical students have ability to receive credit for their training and apply towards a degree.

- The merger has been great for student access, especially for health care students.

- I think KCTCS has greatly increased education attainment in the Commonwealth.

- Personally, I have seen the good the merger has done for some of the students in offering more educational options.

Miscellaneous (cited by 25 respondents)

- The advent of KCTCS and subsequent merger in our district has resulted in many positive changes

- We must get over our nostalgia for the beloved "academy" prior to merger

- Combining the vo-tech and community colleges has made some positive changes to the overall operation of our college

- I was enthusiastic about the merger because it seemed crazy to have separate systems instead of a single comprehensive one

- More democratic/participatory situation for technical faculty and broader, more realistic perspective for college faculty.

- I think the merger was a good thing.

- I believe the merger has been beneficial to education for the citizens of Kentucky IF the citizens will take advantage of it.

- I believe that the merger was a plus for our students

- I feel very positive about KCTCS and its vital role in the educational, social, and economic development of the Commonwealth of Kentucky.

- The idea to join the two systems was a great one.

- We have raised our requirements (which is a good thing), yet we still accept any skill-set the chance to come here and fail or succeed.

- In the end, the move to merge has resulted in a net gain for Kentucky in spite of the original, politically-motivated reasoning. 
- Overall I think the merger went smoothly although KCTCS did not get enough money to run it.

- The personal integrity and professionalism of faculty and staff on both sides of the house have enabled the rank-and-file to make lemonade out of lemons.

- I am a strong supporter of KCTCS and its mission. Our system is forwardthinking, quality-driven, and student-centered.

- I was initially opposed to the merger, but over time I have come to realize the wisdom of the decision. Not everyone wants an advanced degree and hands-on training is good for the workforce.

- Overall positive for the state but still a lot of politics at play.

- The community colleges should have been removed from UK.

- The merger has served some good.

- I fully support the concept of the merger. KCTCS is better off independent from UK.

- The merger of the community colleges and the technical colleges is the best thing that could have happened for our college.

- I think the merger has been good for the state and for the institutions.

- We are a stronger institution having gone through merger.

- I believe the merger has been overwhelmingly positive for Kentucky.

- Having one "footprint" in the community instead of two competing schools is a benefit.

- We are better off because of the merger. It is time we all got on with educating students. In a business people would be on board or would have to find another job.

- Our colleges blended very nicely.

Improved Technical Training (cited by 6 respondents)

- The merger has greatly improved technical training within the state.

- The technical colleges have increased their stature.

- More resources for technical programs.

- Helping to make technical courses such as electrical, plumbing, automotive, etc. more appealing to potential students.

- I believe the merger had benefited the vocational schools - they have been elevated academically.

- Workforce development projects have greatly increased since the merger as well as the flexibility to react to business and the community (not able to do this under $\mathrm{UK})$

Improved Technology (cited by 1 respondent)

- I believe that there have been vast improvements in technology within my program. 
Increased Academic Offerings (cited by 2 respondents)

- More academic classes are available and encouraged for technical students and more career choices.

- Technical education has improved.

Cost Efficiencies (cited by 3 respondents)

- The merger has led to elimination of duplicative programs.

- The merger of the schools is a positive because it brought together two excellent institutions that now share such services as marketing, services, and buildings.

- The duplication of services of two separate institutions was a waste of money. The merger has improved that area.

Independent Governance / Legislative Advocacy (cited by 1 respondent)

- KCTCS is now a legislative advocate for money and resources; UK did not advocate for the community colleges.

\section{Negative Themes}

Increased Bureaucracy / Growth of KCTCS Central Office (cited by 41 respondents)

- I am particularly sensitive to the increasing requirements for forms and new regulations in the new system and exasperating interference from nonteaching personnel.

- Inefficiencies resulting from increased levels of bureaucracy hurt the system.

- There is more red tape involved in simple decisions and the amount of meetings has tripled, but the meetings are non-productive.

- KCTCS has been disastrous; we have a bureaucracy that's impossible to navigate.

- More cumbersome bureaucracy and more expensive operation.

- KCTCS is a large bureaucracy that is far removed from students and frequently takes actions that are not in the best interest of students; this bureaucracy uses a tremendous amount of funds that could be more effectively used to meet student needs.

- No organizational chart exists for the bloated KCTCS central administration bureaucracy; it is not published

- Overhead has been doubled.

- The merger has sapped our resources.

- The creation of KCTCS provided a new layer of bureaucracy and added to the extraordinary cost of administrative buildings and additional maintenance.

- The KCTCS central administration is huge - way larger than the UKCCS office was. 
- Resources are taken off the top with little remaining for the local colleges.

- The additional red tape has increased costs. The merger was supposed to have increased efficiencies but it has had the opposite effect.

- The promise of cost efficiencies was a false promise - a lie.

- KCTCS has led to a huge, expensive bureaucracy. The system office has hundreds of administrators with huge salaries. These people never see a student.

- Local colleges have dirty, unkept buildings, while KCTCS administrators have designer offices.

- KCTCS is an administrative behemoth.

- A lot of huge salaries and power are concentrated in Versailles and the local colleges are left to beg for the table scraps.

- It is the faculty doing the real work, not the droves at Chateau de Versailles.

- KCTCS does not sit on a working campus which is a disadvantage.

Negative Impact on Community Colleges (cited by 20 respondents)

- The community colleges have lost credibility.

- There has been a loss in the collegiate environment; now we are more of a "secondary education" institution.

- Diminished stature of our institutions has reduced the community college applicant pool of instructors.

- Many accelerated science students are by-passing community colleges because of the limited science offerings.

- The vocational schools have dragged the community colleges down instead of the reverse. We are more like high school than ever.

- Our institution had more clout when we were with UK.

- Student outcomes have not improved since merger.

- We have moved from a mostly academic institution to a mostly technical or trade institution.

- Adding the technical colleges to the community college was a mistake. Test scores indicate students are not prepared for college level classes; we have become welfare for the lower middle class (with all the financial aid available); students aren't trying to improve their status, they just want the aid money.

- We were hurt financially by the merger.

- Two year transfer programs have been weakened to the advantage of technical program.

- The academic transfer component of the community colleges has definitely been hurt.

- The atmosphere is now more like assembly lines and manufacturing and less collegial. 
- We have been strapped with re-educating high school students, baby-sitting refugees, salvaging grade point averages and conducting workforce training for businesses who should be paying for it themselves. If we train workers for a business and it leaves the area, we have wasted taxpayer dollars. Funds should be spent on academic education.

- Some programs are not "college" programs. A merged school makes it unclear to students who think they are getting a college education when they are not.

- There is a misperception in our region that we are now only a trade school.

- The merger may have benefited industry and even the Chamber of Commerce, but it has been a disaster for liberal arts education; community colleges should serve the people not industry; the public views us as a trade school.

- We are now a "job" factory.

Negative Impact on Technical Colleges (cited by 26 respondents)

- The technical colleges have lost significant funding.

- The merger is slowly destroying the technical programs in Kentucky; local industry advisory committees are not taken seriously and have no say in the direction of the technical programs. We know what our students need to enter the workforce.

- The professional academics have forced the tech people to reduce their hours of instruction/lab time and made their students take "regular" college courses like English and history. I believe that if you want to learn car repair, you should be able to do so.

- Not everybody needs to be gifted in sociology, math, or English to be a good mechanic or cosmetologist. Let's not make it too difficult for people to acquire a degree and skill for employment.

- My main concern is the overshadowing of the technical colleges' goals by the community college culture; students going the vocational education route are now taking more general education courses that do not apply to their choice of vocation and that prevents nontraditional students from getting back to the workforce quickly.

- Real industry and business professionals know their customers' needs and quality standards. Can personnel with little or no practical experience supply real world standards? Funds for technical programs have been siphoned off for the general fund.

- New administrators don't have any experience outside of academics so our technical programs are suffering from a lack of understanding; "hands on" technical laboratory hours have been reduced to make room for unnecessary academic requirements.

- Those desiring vocational training at a slow pace are no longer being served since merger.

- Technical programs have been neglected and program enrollment is down.

- There is too much emphasis on academics. There is dignity in all levels.

- Technical faculty were told that credential justification would allow them to keep teaching. Now that were are a SACS college, those faculty are not 
allowed to teach. Meanwhile, faculty with poor student feedback continue to teach.

- Many contact hours were lost as a result of the merger and technical programs were hurt as a result. Also, the cost for technical students has increased dramatically.

- Our program was weakened when requirements were removed.

- Community college curriculum is antiquated and irrelevant to many students. You can leave a community college with an associate's degree and not be trained to do anything! Technical training is much more cost-effective.

- It seemed more like a takeover than a merger and it appears that technical programs are being phased out.

- It seems more emphasis is being placed on gen-ed courses and degrees, while most employers I deal with still want someone who can perform skills, not just talk about them.

- I am troubled by advisors' lack of knowledge about the technical programs.

- Academics were so involved in themselves that they failed to recognize the need for technical skills and "watered down" and weakened a lot of technical programs.

- Vo-Tech got the short end of the stick.

- The Byzantine rules of the community college curriculum structure have dragged the technical colleges down into the same morass that the community colleges were mired in, prior to the formation of KCTCS; technical education has been severely harmed.

- Contact hours have been reduced causing students to be less prepared to enter the world of work.

Top-Down Management (cited by 18 respondents)

- Decisions made at the System Office seem to be made entirely from the top down. We are simply told what to do and must do it. It now feels more like working in a factory than an institution of higher learning.

- Presidents of individual colleges are sanctioned for speaking out and there is no voice allowed in policies or curriculum.

- Authoritarian and disingenuous management style from System Office; heavyhandedness has hurt morale.

- KCTCS has been a disaster. Its top-down management style, dictatorial leadership, and its one-size-fits-all has damaged both community and technical colleges.

- The rigid, doctrinal approach to running all of KCTCS has greatly hindered the inventive and unique position of my institution.

- Changes have been chaotic and shoved down our throats; there is no compassion for the faculty and staff on the front lines.

- The KCTCS President is dictatorial.

- Decision-making, which was formerly participative, is now centralized at the top.

- The speed of the merger was too fast and pushed down our throats too quickly. 
- Sometimes the decisions that are made at the System level regarding curriculum and course content make our job harder than it needs to be - and that is not always the best thing for students in either the transfer or technical programs.

- Heavy-handedness regarding HR/benefits decisions has left many of us distrustful.

- Authoritarian, top-down administration. Too many arbitrary decisions.

- KCTCS is ruled like a dictatorship.

- If you cross the KCTCS President, you are gone and your institution will fall out of favor.

KCTCS President's Salary (cited by 24 respondents)

- The KCTCS President's Salary: Is he worth it?

- I really enjoy teaching and I took an $\$ 11,000$ cut to come here, but I am overwhelmed that we are asked to work for so little in light of the salaries of the KCTCS President and Systems Office administrators.

- The KCTCS President's salary is looking worse and worse during a time of state budget cuts and tuition increases and overall budget tightening.

- The salary of the CEO of KCTCS is ridiculous and unreasonable accommodations (housing allowance).

- We have an overpaid CEO who has no visibility in the colleges themselves.

- Everything is done to make the KCTCS President look good and for him to receive large bonuses.

- What do we get for the KCTCS President being the highest paid "president" in the nation?

- The KCTCS President is paid way too much for me to trust the system.

- The KCTCS President's salary package is a significant issue amidst the financial struggles of the colleges. KCTCS does not allocate funds fairly.

- The KCTCS President's compensation package is barely short of criminal.

- As one of the highest paid leaders of two-year colleges in the nation, you would think that our system would be more accountable for resources. KCTCS probably uses half a million dollars to pay for administrator cell phones, Try to obtain one of those numbers. It will not enhance the students' educations.

- The pay system rewards the CEO unfairly relative to faculty and staff.

- Salary is outrageous.

- The KCTCS President's obscene salary is just one indication of where all the money goes.

- I think the KCTCS President is overpaid by a tremendous amount at $\$ 650,000+$

- The KCTCS President's compensation is higher than the President of the United States - by $\$ 200,000$ !

- Can you believe how much he makes?

Differences of Cultures / Different Missions (cited by 16 respondents)

- I think in time the merger will prove the undoing of KCTCS. Technical schools try to keep every student; community colleges see how many students they can get rid of.

- We have vastly different student bodies but we lack autonomy. 
- We have different cultures, different goals, perhaps even different values...did not blend well... like peanut butter and pickles. We were put together for political reasons.

- There is a great deal of friction between technical and academic faculty.

- The system has come a long way, but the community folks and the technical folks still may not know that much about each other. There are still issues and at times the technical issues are not considered as important as the academic issues.

- The vocational school and the college are fundamentally different and I think this difference matters.

- KCTCS should consider the differences between the technical and academic sides - they are very different.

- Academic and technical programs should not be forced together. They are different. Tech needs smaller classes with more hands on. Can work together in the same building but there must be separate curriculum.

- The inequality between the employees of the two systems exists today at every level.

- Some faculty at community colleges do not understand, nor value, the academic contributions of technical faculty.

- At times I still hear tech faculty say that "community college faculty think they are better than us".

- Faculty with Master's Degrees should be paid more than tech faculty with two-year degrees.

- There is a difference between education and training.

- The technical schools and community colleges serve two purposes which are very distinct. We should not have mixed those purposes together.

- Two different species that do need to be treated exactly the same. Apples and oranges.

Too Many Administrators (cited by 28 respondents)

- KCTCS is too top heavy with administrators.

- Too many administrators since merger

- We have way too many administrators.

- Many faculty resent the involvement of administrators in faculty issues.

- We have twice as many high paid administrators as a result of the merger.

- High priced administrators and bureaucracy is pricing KCTCS out of the postsecondary education market in Kentucky; we should be ashamed.

- We seem to keep adding deans and other administrators.

- Administrative costs are ridiculous.

- The system has only been responsive to the financial needs, wants, and desires of the KCTCS administrators.

- The layers of KCTCS administrators often work against us rather than with us.

- The KCTCS administrators seem to focus on their own programs when they should be supporting the colleges. I don't think the system office supports the local colleges adequately. 
- Many system administrator positions are duplicative.

- Administrators have been added at the expense of faculty positions.

Lack of Local Autonomy (cited by 10 respondents)

- I am disappointed in the lack of autonomy "allowed" to each college to develop the curricula and classes deemed necessary to serve the individual needs of that college. The System wants a "cookie-cutter" curriculum.

- We have less autonomy than when we were with UK

- My institution is internally motivated but that motivation is stifled by KCTCS. Morale is very low.

- Colleges have lost autonomy and have been forced to adhere to the policies of KCTCS.

- What has been lost is the unique positions and role of each college within its community. One size does not fit all.

- The schools should have more autonomy.

- Gov. Patton promised more autonomy under KCTCS, but I have found the opposite to be true.

Loss of Faculty Authority/Influence in College Governance (cited by 10 respondents)

- Faculty perceive a loss of authority and influence in college governance

- Faculty are fearful of offering opinions in the new system...may lose their jobs if suggestions are made that differ from System directives

- Faculty input is largely ignored by the administration.

- Faculty governance has been hurt.

- Faculty are treated like laborers and are no longer considered professionals.

- Teachers and students need to be more involved in and consulted on changes.

- Faculty have a minor voice on inconsequential issues only.

- Faculty have no input.

- Many committees, but when push comes to shove faculty input is ignored and they do whatever they want to do.

Decline of General Education/Transfer Programs (cited by 14 respondents)

- The merger has led to a decline in the general education/transfer programs.

- Resources are being directed away from the transfer programs and into mostly dead-end technical programs; this education does not prepare people to question authority on the social/economic/political structure of our society.

- We are turning out "worker bees" and not truly educated citizens.

- Oftentimes, students resent taking classes that are not "for their career" but are beneficial; the merger exacerbates and further confuses this situation. 
- The merger has decreased the quality of true education that enhances critical thinking skills and that helps to make individuals more well-rounded, thinking, discerning, and cultural and accepting of others' differences; basic training keeps people in low-income, stagnant jobs and lack of broad education hurts potential for advancement. In the long run, it keeps Kentuckians ignorant with low-paying wages so they'll vote for certain politicians.

- Technical programs have taken away money from the transfer programs.

- Transfer students are transferring sooner and fewer university students are taking summer courses

- People don't even know what KCTCS and we're not connected to any wellknown, established, respected entity. This hurts transfer. If not connected to UK, we should at least be connected to a regional university.

- I fear our society is becoming less educated in the arts and letters, in history, political science, and more trained in practical skills.

- Merger has resulted in the decreased transferability of courses to universities.

Lowered Academic Standards and Declining Quality of Instruction (cited by 24 respondents)

- My concern is to strengthen and raise the academic standards. We are accepting students who are not really at college level. There has been too much focus on enrollment numbers. There needs to be a focus on quality.

- The merger has led to a significant decrease in academic rigor and resulting decrease in the worth of a community college degree.

- The quality of our institution has suffered; we are turning into the public schools.

- The merger is tied to the "dumbing down" of education for people who are relatively poor.

- Degree requirements are being watered down. The emphasis is on quantity, not quality...training, not education.

- The quality of students attending our community college is not as high as before the merger.

- The number of students who are academically challenged and not ready for college is increasing. The general education studies and the quality of our students' academic abilities has definitely declined.

- Standards have been weakened due to dumbing down of our curriculum.

- I have noticed a marked decline in the quality of students since KCTCS.

- Without the UK connection, the quality of students has declined significantly.

- Some online classes are merely "selling" credits and our academic standards are so low that we are graduating some students who are functionally illiterate.

- We need to re-evaluate how we test incoming technical students in foundational skills.

- 20 week semesters down to 15 weeks 
- We have created the illusion of higher education. What could have been a great benefit has been made into an academic laughing-stock.

- These are no longer colleges; they are supermarkets of greatly lowered quality offering a vast array of garbage; access has been improved at the expense of academic integrity.

Loss of Flexibility (cited by 3 respondents)

- I am somewhat concerned that the vocational/technical schools have lost some of the flexibility they formerly had to benefit some sectors of the community.

- The college model does not allow students to only complete some parts of training which hurts students who cannot complete the entire course; this kept some off the welfare roles in the past; there is a population that we are no longer serving

- Loss of flexibility at the local level.

Erosion of Tenure (cited by 1 respondent)

- The erosion of tenure, the switch to employment at will, is a serious issue (termination at 30 days notice with no reason needed).

Accreditation Issues (cited by 1 respondent)

- SACS is interested in governance issues - each institution with more localized independent governance including curriculum.

Low Morale (cited by 4 respondents)

- Budgetary shortfalls, loss of autonomy, greater bureaucracy, and the political motivation for the creation of KCTCS contribute to low morale.

- I can't ever remember morale being this low.

Miscellaneous (cited by 17 respondents)

- The real reason for the merger was due to personality clashes among UK, LCC and state government officials.

- KCTCS is totally unnecessary.

- The purpose of KCTCS was to reduce UK's statewide influence. Perhaps the new structure has the potential to be beneficial, but the resulting system remains under-funded, poorly-managed, and disrespected by the people it should serve.

- The concept of KCTCS is sound, but arrogance and the lack of trying to understand the tech side made the merger process difficult and the two sides are still at odds.

- Only certain faculty can influence decisions. 
- There continues to be an "us" versus "them" between community college faculty and vo-tech faculty.

- I believe technical programs and academic programs should operate separately; they have different areas of emphasis.

- The KCTCS Board of Regents is out of touch.

- The reason for the merger was strictly political.

- Separation from UK was probably one of the worst decisions ever made.

- Academic and technical faculty should be treated the same.

- The differences between college education and technical education have not been explained to the public.

- There needs to be more consistency among all the colleges regarding academic calendars, staffing, curriculum, and other policies.

- There is little resource support by KCTCS colleges undergoing SACS accreditation required as a result of the merger.

- The merger was the biggest mistake ever in Kentucky higher education. Community colleges need to do their job of transfer education and VoTechs need to be allowed to do their job of educating the workforce. Also, there is much more "talking" and less "action" now.

- The system is too fragmented.

- The worst thing to ever happen in higher education was taking community colleges away from UK.

- Former UK faculty were unfairly denied salary increases.

- The merger did not go far enough. All two-year colleges should be under KCTCS.

- KCTCS Board of Regents is a rubber-stamp for the KCTCS President.

- Personally, I was much happier under UK.

Move from Higher Education Model to Business Model (cited by 6 respondents)

- It feels like KCTCS is more about "big business" than education.

- The merger continues to encourage the "business model" approach which is detrimental to higher education.

- The Board of Regents is dominated by a "corporate mentality" and "bean counters" which is hostile and detrimental to faculty.

- The academic model has been replaced by a business model with the emphasis on productivity over quality of education.

- The business model is fine for a store, but not a college. Administrators have business titles. Are faculty now "customer service representatives"?

Move from Full-Time Faculty to More Part-Time Faculty (cited by 1 respondent)

- There are moves to increase part-time faculty and decrease full-time faculty.

Too Many Programs / Expanded Mission (cited by 2 respondents)

- Too many programs since merger. 
- The mission of the colleges keeps expanding like WalMart. The community college mission is too broad to be realistic.

Lack of Funding (cited by 4 respondents)

- Funding levels have not kept pace with expectations of HB1

- Accountability must come with an obligation to provide the necessary resources.

Politically Motivated Reform (cited by 10 respondents)

- The change was pure politics from start to finish.

- Governor Patton used his power to "cut UK down to size" do to ill-feelings.

- Politicians wanted to wrest some of the power and money away from UK.

- The regional universities have wanted the two-year colleges for years. UK faculty wanted to rid themselves of the community colleges for their own enhancement.

- A good and much needed idea has devolved into a political morass.

Too Much Emphasis on Enrollment Numbers (cited by 15 respondents)

- We have become more interested in numbers than educational quality.

- We have increased real numbers only modestly; most of the increases have come from changes in the way students are counted... and some duplications are not removed.

- I think the enrollment numbers are skewed and deceptive and there is too much push for 100,000 by 2010 .

- There is way too much emphasis on numbers with KCTCS and lip-service being played to quality. Headcounts are inflated by industrial training BIT offerings. There are unrealistic goals.

- KCTCS has made us a numbers game and has had a negative effect on our student base.

- There is a race to enroll anyone who is alive and getting them some sort of credential (however miniscule) to build numbers up. We're even looking to divide up classes into online partial credit within a class even though pass rates for online classes are very poor.

- The constant emphasis on numbers and "creative statistics" has dumbed down standards.

- Curriculum has been watered down so online classes can show more numbers of people.

- I feel like we are all about numbers now.

- Enrollment numbers do not represent the truth but do help the KCTCS President impress legislators.

- We are numbers-driven and unethical in our representation of the number of students we are serving. We brag about the number of credentials we award, but many of the credentials have little value. 
Rising Tuition (cited by 11 respondents)

- Tuition increased dramatically after merger; students need a quality education at a reasonable cost.

- Lack of fiscal responsibility in administration leads to rising tuition.

- It used to be a lot of education for a little money. Now it is a little education for a lot of money.

- We're experiencing budget cuts and rising tuition, but I don't see administration suffering.

- Nothing limits educational access as surely as climbing tuition.

Stronger Leadership Needed (cited by 1 respondent)

- Need stronger leadership. Need a leader with a business background rather than an educational background.

Inequities in Workload (cited by 1 respondent)

- Technical program faculty teach 30 hours per week and general education faculty teach 15 , and this contributes to inequity and hard feelings. 


\section{APPENDIX R: PERMISSION LETTER TO CONDUCT RESEARCH (KCTCS PRESIDENT/CEO)}

November, 2006

Dear Dr. McCall,

I am working on a research study which involves surveying full-time faculty and administrators who are currently employed by the Kentucky Community and Technical College System (KCTCS). The study is being conducted for the purpose of ascertaining faculty and administrator perceptions of the merger of Kentucky's community colleges and vocational/technical institutes. A description of the project is attached.

Permission from the President/CEO of KCTCS must be obtained in order to conduct this research. All faculty and administrators in sampled KCTCS colleges will be surveyed for the purpose of this study.

The collection of this data will be reported in such a way that the identity of the colleges, faculty members, and administrators will be anonymous.

Your cooperation is asked in this endeavor. You are invited to contact Dr. John F. Welsh at the University of Louisville (502) 852-6411, Dr. at Western Kentucky University (270) 745-XXXX, or the Human Subjects Committees at the University of Louisville (502) 852-5188, Western Kentucky University and the Kentucky Community and Technical College System (KCTCS) if you have any questions or concerns regarding this study.

Sincerely,

Jason D. Warren

773 Glencrest Drive

Madisonville, Kentucky 42431

(270) 821-0855

j pwarren@bellsouth.net

If you consent to allow the System's colleges to participate in this study, please sign below. You may have a copy of this form for your records. Date: 


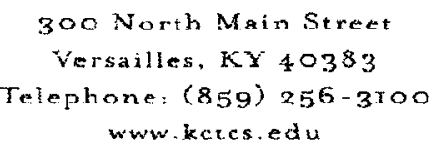

December 7, 2006

Jason Warren

Hopkinsville College

P.O. Box 2100

Hopkinsville, KY 42241-2100

Dear Mr. Warren:

After careful consideration of your application to the KCTCS Human Subjects Review Board, I have determined that you are eligible for a certificate of exemption from federal regulations regarding the protection of human subjects based on your research using a procedure that meets the exemption criteria regulation of Section 7 (1).

Thank you for your cooperation in meeting the Federal requirements for conducting research that utilizes human subjects. We understand that you are also seeking approval from the University of Louisville's and Western Kentucky University's Human Subjects Review Boards. We appreciate your notification to this board and we will keep your information on file.

Sincerely,

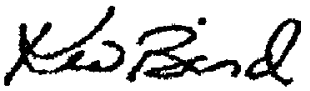

Keith W. Bird, Ph.D.

Chancellor

Chair, KCTCS Human Subjects Review Board

cc: Christina E. Whitfield. Ph.D.

Director of Research and Policy Analysis

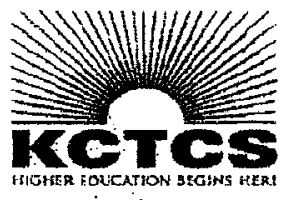

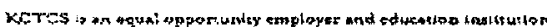




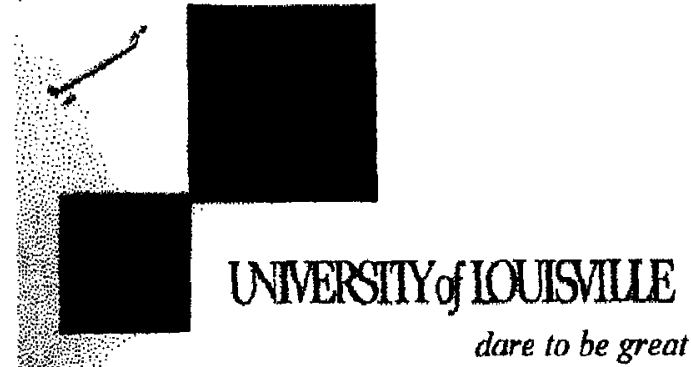

August 10,2007

Joseph Petrosko, Ph.D.

Leadership, Foundations \&

Human Resource Education

CEHD-Belknap Campus

University of Louisville

Louisville, KY 40292
HUMAN SUBJECTS PROTECTION PROGRAM OFFCE

Uriversity of Loulsvilte

MedCerter One, Stite 200

501 E. Broadway

Louisville, Kentucky 40202-1798

Office: $\quad 502-852-5188$

Fax: $\quad 502-852-2164$

RE: $\quad 365.07 /$ A Comparison of Faculty and Administrator Perceptions of the Merger of Kentucky's Community Colleges and Vocational/Technical institutes

Dear Dr. Petrosko:

The above study has been received by the Human Subjects Protection Program Office. It has been detomined by the chair of the Institutional Review Board that the study is exempt according to 45 OFR 46.101(b) 2 since the research involves the use of educational tests (cognitive, diagnostic, opthute, achiovement), survey procedures, interview procedures or observation of public behavior, unles: (i) information obtained is recorded in such a manner that human subjects can be identified, directly or through identifiers linked to the subjects; and (ii) any disclosure of the human subjects' responses outside the research could reasonably place the subjects at risk of criminal or civil liability or be damaging to the subjects' financial standing, employability, or reputation. The study is exempt only if information that could identify subjects is not recorded.

This study was also approved through 45 CFR 46.117 (c), which means that an IRB may waive the requirement for the investigator to obtain a signed informed consent form for some or all subjects if it finds either:

- That the only record linking the subject and the research would be the consent document and the principal risk would be potential harm resulting from a breach of confidentiality. Each subject will be asked whether the subject wants documentation linking the subject with the research, and the subject's wishes will govern; or

- That the research presents no more than minimal risk of harm to subjects and involves no procedures for which written consent is normally required outside of the research context.

The purpose of this study is to determine whether faculty and administrators employed by the Kentucky Community and Technical College System (KCTCS) exhibit significantly different perceptions of the merger of Kentucky's community colleges and vocational/technical institutes. 
Since this study has been found to be exempt, no additional reporting, such as submission of Progress Reports for continuation reviews, is needed. Best wishes for a successful study. Please send all inquires and electronic revised/requested items to our office emall address at

Sincerely,

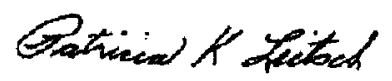

Patricia K. Leitsch, Ph.D., Chair,

Social/Behavioral/Educational Institutional Review Board

PKL/crn 
Human Subjects Review Board Office of Sponsored Prograuns Office: $270-745-4652$

Fax: $270-745-4211$

sean rubinothwa.edu

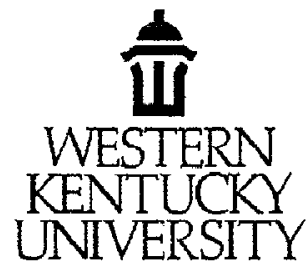

Western Kentucky University 1906 College Heights Blvd. 111026 Bowling Green, KX 42101-1026

The Spirit Makes the Master

In future cortespondence please refer to HS08-030, October 1, 2007

Jason Warren

Graduate Student

WKU/UL Cooperative Program

Dear Jason:

Your revision to your research project, "A Comparison of Faculty and Administrator Perceptions of the Merger of Kentucky's Community Colleges and Vocational/Technical Institutes," was reviewed by the HSRB and it has been determined that risks to subjects are: (1) minimized and reasonable; and that (2) research procedures are consistent with a sound research design and do not expose the subjects to unnecessary risk. Reviewers determined that: (1) benefits to subjects are considered along with the importance of the topic and that outcomes are reasonable; (2) selection of subjects is equitable; and (3) the purposes of the research and the research setting is annemable to subjects' welfare and producing desired outcomes; that indications of coercion or prejudice are absent, and that participation is clearly voluntary.

1. In addition, the IRB found that you need to orient participants as follows: (1) signed informed consent is not required as participation will imply consent; (2) Provision is made for collecting, using and storing data in a manner that protects the safety and privacy of the subjects and the confidentiality of the data. (3) Appropriate safeguards are included to protect the rights and welfare of the subjects.

\section{This project is therefore approved at the Exempt Review Level}

2. Please note that the institution is not responsible for any actions regarding this protocol before approval. If you expand the project at a later date to use other instruments please re-apply. Copies of your request for human subjects review, your application, and this approval, are maintained in the Office of Sponsored Programs at the above address. Please report any changes to this approved protocol to this office.

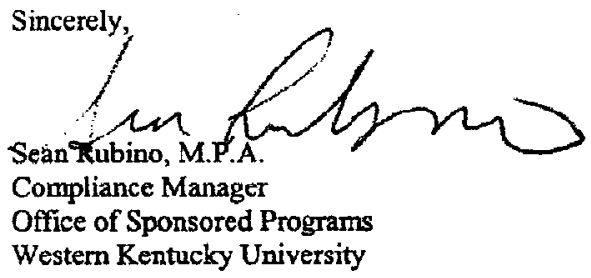

cc: HS file number Warren HS08-030 


\section{CURRICULUM VITAE \\ Jason Douglas Warren \\ 740 Oakwood Lane \\ Madisonville, KY 42431 \\ i_pwarren $(\boldsymbol{a}$, bellsouth.net}

\section{EDUCATION}

Doctor of Philosophy (Ph.D.), Education Leadership and Organizational Development University of Louisville (2008)

Master of Arts (M.A.), Higher Education (with honors)

University of Louisville (1995)

Bachelor of Science (B.S.), Guidance \& Counseling (cum laude)

University of Louisville (1993)

\section{EMPLOYMENT HISTORY}

Chief Student Affairs Officer (Dean of Student Affairs)

Hopkinsville Community College, Hopkinsville, Kentucky (2006 - Present)

Interim Chief Student Affairs Officer (Dean of Student Affairs)

Hopkinsville Community College, Hopkinsville, Kentucky (2005 - 2006)

Chief Institutional Advancement Officer

Executive Director, Hopkinsville Community College Foundation, Inc.

Hopkinsville Community College, Hopkinsville, Kentucky (1997 - 2005)

Upward Bound Director (Federal TRIO Grant)

Hopkinsville Community College, Hopkinsville, Kentucky (1996 - 1997)

Adjunct Instructor

Hopkinsville Community College, Hopkinsville, Kentucky (1999 - Present)

Public Services Library Associate

Kornhauser Health Sciences Library

University of Louisville, Louisville, Kentucky (1995 - 1996) 
Departmental Business Manager

William F. Ekstrom Library

University of Louisville, Louisville, Kentucky (1993 - 1995)

Document Delivery Supervisor

William F. Ekstrom Library

University of Louisville, Louisville, Kentucky (1991 - 1993)

\section{PROFESSIONAL DEVELOPMENT}

"Valencia's Learning Conversations Conference," Valencia Community College, Orlando, Florida, September 2005

College Business Management Institute-CBMI, Southern Association of College and University Business Officers (SACUBO), University of Kentucky, 1998-2000

\section{INTERNSHIPS/ADDITIONAL EDUCATIONAL EXPERIENCES}

Career Services Center, Western Kentucky University, 2006-07

Internship: Conducted organizational SWOT analysis after Center's relocation, assisted with career fair, and provided career exploration services to students

ACCESS (Adult Commuter Center/Evening Student Services), Univ. of Louisville, 1995 Internship: Coordinated "Celebrating the Non-Traditional Student Week," and served as member of the Adult Learner Scholarship Selection Committee.

Office of Alumni and Development, University of Louisville, 1994

Internship: Conducted prospect research for Bicentennial Campaign.

Academic Services for Athletics, University of Louisville, 1992

Internship: Assisted with student-athlete advising.

\section{INTERESTS}

Civil War History

Landscaping/Gardening

Fishing/Camping

Trumpet/Flugelhorn

Genealogy

\section{HONORS \& RECOGNITIONS}

Phi Theta Kappa (PTK)[honorary] - National Two-Year College Honor Society, 2006

Outstanding Mid-Management Award, Hopkinsville Community College, 2001

Outstanding Performance Award for Classified Staff, University of Louisville, 1994 